

Digitized by the Internet Archive in 2010 with funding from

Research Library, The Getty Research Institute 

F R A G M E N T

$\mathrm{ON}$

THE THEORY AND PRACTICE
or

ILandscape Gardenting. 



\title{
FRAGMENTS
}

\author{
ox \\ THE THEORY AND PRACTICE
}

OF

\section{Lamdstape fordoening.}

I N C LU D I NG

S O M E REMARKS

ON

\section{GRECIAN AND GOTHIC ARCHITECTURE,}

\author{
COLLECTED FROM \\ VARIOUS MANUSCRIPTS, \\ IN THE POSSESSION OF \\ THE DIFFERENT NOBLEMEN AND GENTLEMEN, \\ FOR WHOSE USE THEY WERE ORIGINALLY WRITTEN;
}

THE WHOLE TENDING TO ESTABLISH FIXED PRINCIPLES IN THE RESPECTIV ARTS.

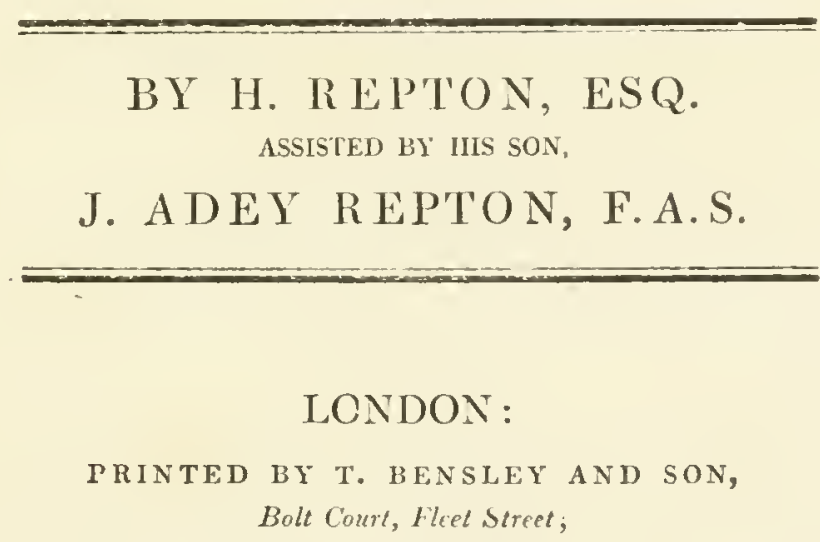

FOR J. TAYLOR, AT THE ARCHITECTURAL LIBRARY, HIGH HOLBORN. 1816. 



\title{
THE PRINCE REGENT, WITII
}

\author{
HIS ROYAL HIGHNESS'S
}

MOS'T GRACIOUS PERMISSION,

\section{THIS VOLUME}

IS H U M L Y I N C R I B D B Y

\section{HIS ROYAL HIGHNESS'S}

MOS'T FAITHE U L, O B E D I N'T,

A N D HUMBLE SERVANTS,

H. AND J. A. REPTON.

Hare-street, near Romford,

July 1816. 



\section{P R E F A C E.}

MaNy years have elapsed since the production of a former Work, under the title of Observations on the Theory and Practice of Landscape Gardening; during which, the Author's attention has been called to such varicty of subjects, such interesting Sccnery, and such novelty of expedients, that a second volume under the former title might have been expected; (the whole of two editions of that Work are entirely sold, and the volume is become very scarce). The contents of the present Tolume, which appears under a new title, will be found neither to be a continuation nor a contradiction of the former Observations; but, from the subject's being elucidated by new and more beantiful eximples, the Author's former principles in the Theory and Practicc of Landscape Gardening will be confirmed.

The following Fragments having been selected from more than four hundred different Reports in MS. an occasional repetition of the same remark will unavoidably, though not frequently, occur; and for this it is hoped, that the varicty and beaty of the subjects may compensate, by giving new and more striking examples and elucidations.

The Art of Landscape Gardening (which more peculiarly belongs to this country) is the only Art which every one professes to understand, and even to practise, without having sudied its Rudinents. No man supposes he can paint a Landscape, or play on an instrument, without sone knowledge of Painting and Music; but every onc llinks himself competent to lay out grounds, and sometimes to plan a House for himself, or to criticise on what 


\section{viii}

others propose, without having bestowed a thought on the first principles of Landscape Gardening or Architecture.

That these two Sister Arts are, and must be inseparable, is obvious from the following consideration. The most beautiful scenes in Nature may surprizc at first sight, or delight for a time, but they camnot long be interesting, unless made habitable; therefore, the whole Art of Landscape Gardening may properly be defined, The pleasing combination of Art and Nature adapted to the use of Man.

During the last ten years, the Art of Landscape Gardening, in common with all other Arts which depend on Peace and Patronage, has felt the inHuence of War and War Taxes, which operate both on the means and the inclination to cultivate the Arts of Peace; these have languished under the imporerishment of the Country, while the sudden acquirement of Riches by individuals has diverted Wealth into new channels; men are solicitous to increase property rather than to enjoy it; they endeavour to improve the Value rather than the Beauty of their newly purchased Estates. The Country Gentleman, in the last century, took more delight in the sports of the field, than in the profits of the Farm; his pleasure was to enjoy in peace the venerable home of his ancestors; but the necessity of living in Camps, and the habit of living in Lodgings or Watering-places, have of late totally changed his character and pursuits; and at the same time, perhaps, tended to alienate half the ancient Landed Property of the Country.

It is not therefore to be wondered at, that the Art of Landscape Grardening should have slowly and gradually declined. Whether the influence of returning Peace may revive its energies, or whether it is hereafter to be classed anong the "Artes pordita," the Author hopes its memory may be preserved a little longer in the following pages. 


\section{TABLE OF CONTENTS.}

FRAGMENT

I. Rural Architecture - - - - - - - - - - - - - - - 1

Exemplified in Gothic and Grecian-adapted to Scenery.

II. Symmetry

Exemplified in Central Entrance into Houses.

III. Fences near the House - - - - - - - - - - - - 7

Exemplified in Terraces-Ballustrades-Gothic Parapers.

IV. Cobham Hall - . - . . - . - . . - . . . 10

Exemplified in Garden surrounding the House-Park seen over it.

V. Dates of Buildings - - - . - - . - . - - - 13

Exemplified in Gothic Cottage and Garden near Woburn-Details in Gothic should be attended to.

VI. Castles .. - . . . - . . . . . . . . 19

Exemplified in Irregularity of Outline-A Castle proposed.

VII. Unity of Character - - . - . - - - - . - - 21

Exemplified in Harlestone Park, Northamptonshire-Remarkable effeet of Wind.

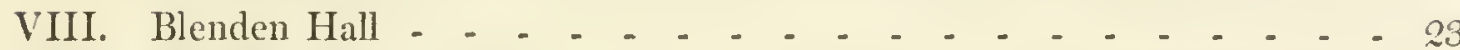

Exemplified in general treatment of a Villa-Effect of removing tall TreesA Garlen more profitable than a Farm.

IX. Windows - - - - . - - . - - - - . - 29

Exemplified in Barningham-hall-Elizabethan Window.

X. Gothic Outline - - . - . - . - . - . - 33

Exemplified in a place near Ludlow-abstraeted from a Report, under the heads of Character, House, and ground abont the House-alt executed, but not by name.

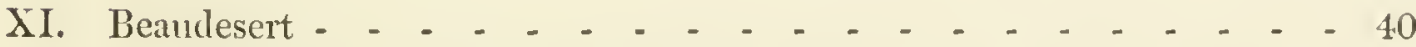

Extracted from the Report under heads of Character and Situation-TreesWater-The Interior-Old Garden restored. 
XII. Of Colours - - . - . - - . - - - - - - 49

Experinents with a prism-Neutral tints-Practical Remarks on Colouring Landscape.

Xill. Of Interiors - . - . - . - . . - . - 52

Example of Conservatories-Mirrors-Houses in Town or Country-Effects of light in rooms-Contrast of the Ancient Cedar Parlour and Modern Living Room.

XIV. Wingerworth - - - - - - - - - - - - - - 59

Extract under heads of Character and Situation-View from the House-The Water - Approaches, sic.

XV. Planting single Trees - . . . . - . . - . 65

Exemplifying effect of different Trees in the foreground.

XVI. Of Villas - - . - - - - - . - . - . 70

Extract from a Report of Streatham-Earl Corentry's recommending a Garden rather than a Farm.

Extract from a Report of a Villa near a Common - - - - - - - 74

Extract from a Villa in Epping Forest - - - - - - - - 77

Extract from Ealing Park-of breaking Brown's Belts - - - - - - 80

Exemplified in Richmond Park-Garden to Lord Sidmouth's House - - - 83

XVII. Garden in Portugal - - - - - - - - - - - -86

Exemplifying the manner of altering the Surface, with its mechanical process.

XVIII. Uppark - - - - - - - - - - - - - - 91

Extract from the Report concerning the Entrance, Sc.

XIX. Of Combinations - - - - - - - - - - - - 94

Exemplified in buildings of different Characters-Darish Church-_ Cemeteries, \&c.

XX. Contrasts - - - - - - - - - - - - - - - 97

Exemplified in Style of Growth-Opacity and Transparency-Repose of Colour-Texture-Size-Cloud and Sunshine.

IXI. Frome House - - - - - - - . - - . - - - 101

Exemplified in Manor House-Charactcristic Situation.

XXII. Aspects and Prospects - . . - . . . . . - 106

Exemplified in Walwood House in Essex. 
XXIII. Variety - . - - . - . - . . - . - 112

Example of much done to little purpose.

XXIV. Longleate - - . - . - - . - . - . - - 115

Extract-Character and Situation-The Water sunk-The House raisedThe Park not locked up.

XXV, A Plan explained - . . . . . . . . . . . . 124

Example of Magnificent Interior-Vinery, \&c.

XIVI. A Villa near the Capital - - - - - - - - - - 129

Example of Geometric Garden compared with the Modern Style-Le Nôtre and Browne

XXVII. Gardens of Ashridge - - - - - - . - - . - 137

Adapted to the Style of Architecture-Fifteen different kinds of GardenWater Fences miscalled, invisible.

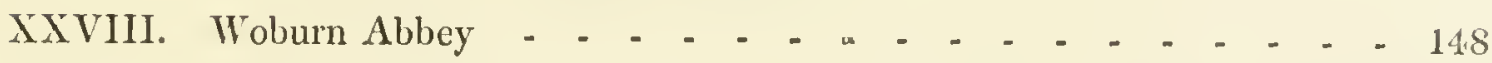

Extract from the Report-Character and Situation-Shape of GroundView from the House-The Water-Bridges and Via-ducts-Origin of Grecian and Gothic-Principles of Pressure-Approaches-Pleasureground-Evergreen Drive-Gardens-The Park-Belts and modes of planting.

XXIX. Luxuries of a Garden - - - - - - - - - . - 177

Adapted to age and infirmity-Strawberry and other raised beds- Care in gathering fruit, \&c.

XXX. Lodges and Cottages - . . . . . . . . . 184

And some Remarks on Gates and Gateways.

XXXI. Water Fences - - . . - . - - . . . . . 188

Example from Sir Thomas Neave's-Reflections in Water.

XXXII. Inprovements - - - - - - - - - - - - 191

Exemplified in new enclosed Land-Value preferred to Beanty-Effects of Modern Riches

XXXIII. Sherringham Bower - - - - . - - . - - . 195

Situation-The Sea-The Woods-Plantations - Site of the HouseVarious considerations-The Village-Walks, Drives, and StationsInterior. 
xii

XXXIV. Endsleigh - . - . . . . . . . . . . 213

Excmplified in Cottage on the Tamar-The River-The Bridge-Of the

Picturesque-The Weir-The Style of Building-Pleasure GroundTerrace Garden-Children's Cottage.

XXXV. House of Industry

Extract of Plan proposcd-Comforts for the Poor-Economy the leading object-Example of a Gothic School-house.

XXXVI. Hare Street - - . - - - - - - - - - 232

Example from the Author's home-View of Mankind-Eflcet of Landscape Gardening in soothing the Mind, confirmed by the testimony of the good and wise. 


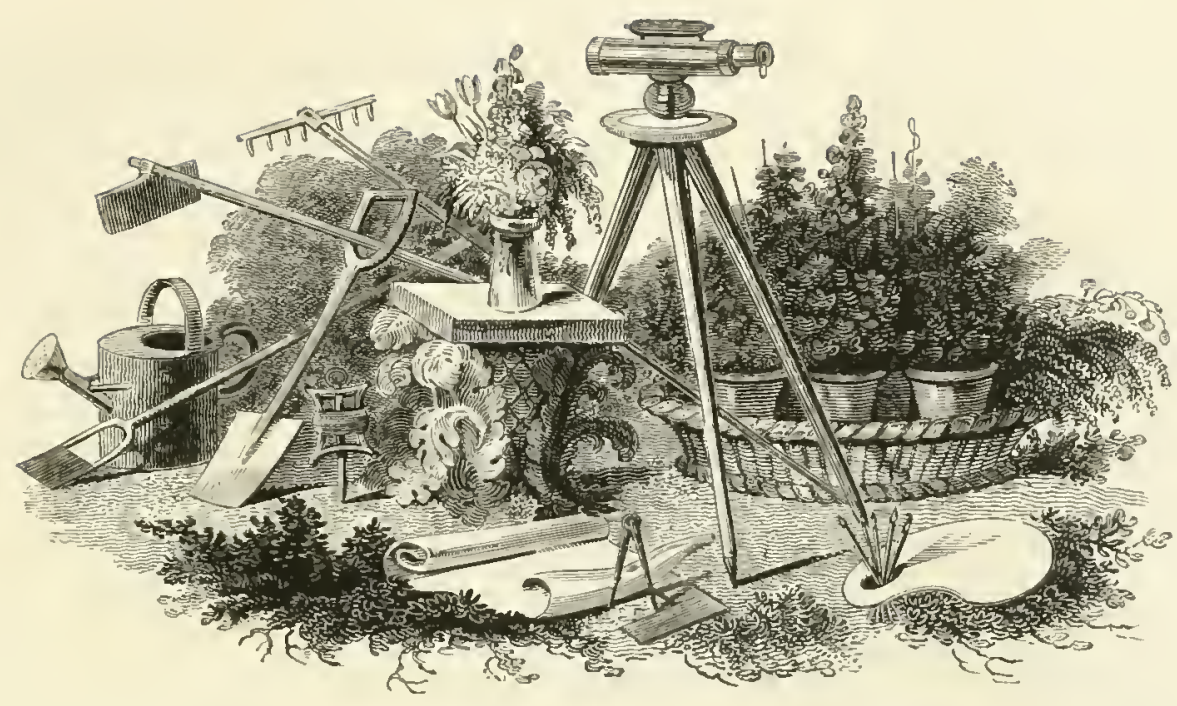

FRAGMENT I.

ON

\section{RURAL ARCHITECTURE.}

Notwithstanding the numerous volumes on Grecian Architecture from the days of Vitruvius to the present time, to which may be added all that have appeared within the last century on the subject of Gothic Antiquities: little or no notice has been taken of the relative effects of the two styles, compared with each other; nor even of those leading principles by which they are to be distinguished, characterised, and appropriated to the scenery of nature. It would seem as if the whole science of Grecian Arehitecture consisted in the five orders of columns, and that of Gothic in pointed arches and notehed battlements.

To explain this subject more clearly, and bring it before the eye more distinctly, I will refer to the following Plate, 
containing three different characters of Elevations, supposing each made applicable to a house of moderate size, not exceeding a front of sixty feet, consisting of three stories, with five windows in a line. This is first represented quite plain, as at A, and afterwards with the surface broken by horizontal lines, as at $B$, and by vertical or perpendicular lines, as at $C$. We may observe, that without introducing any order of columns, or any pointed arches, the eyc seems at once to class the former with the Grecian, and the latter with the Gothic character; and this is the consequence merely of the contrasted horizontal and perpendicular lines.

Let us now proceed one step farther: we must suppose the same building to be taken from the hands of the mere joiner and house carpenter, and committed to the architect to be finished, either in the Grecian or the Gothic style.

For the former, recourse is had to the best specimens and proportions of columms, pilasters, entablatures, pediments, \&c. represented in books of architecture, or copied from remains of ancient fragments in Greece or Ttaly: but, unfortunately, these all relate to temples or public edifices, and consequently, to make the dwelling habitable in this climate, modern sish windows must be added to these sacred forms of remote antiquity. Thus some Grecian or Roman temple is surprised to find itself transported from the banks of the Ilissus or the Tiber, to the shores of the Thames, or to the tame margin of a modem stag. nant sheet of water.

If the Gothic character be preferred, the architect must 

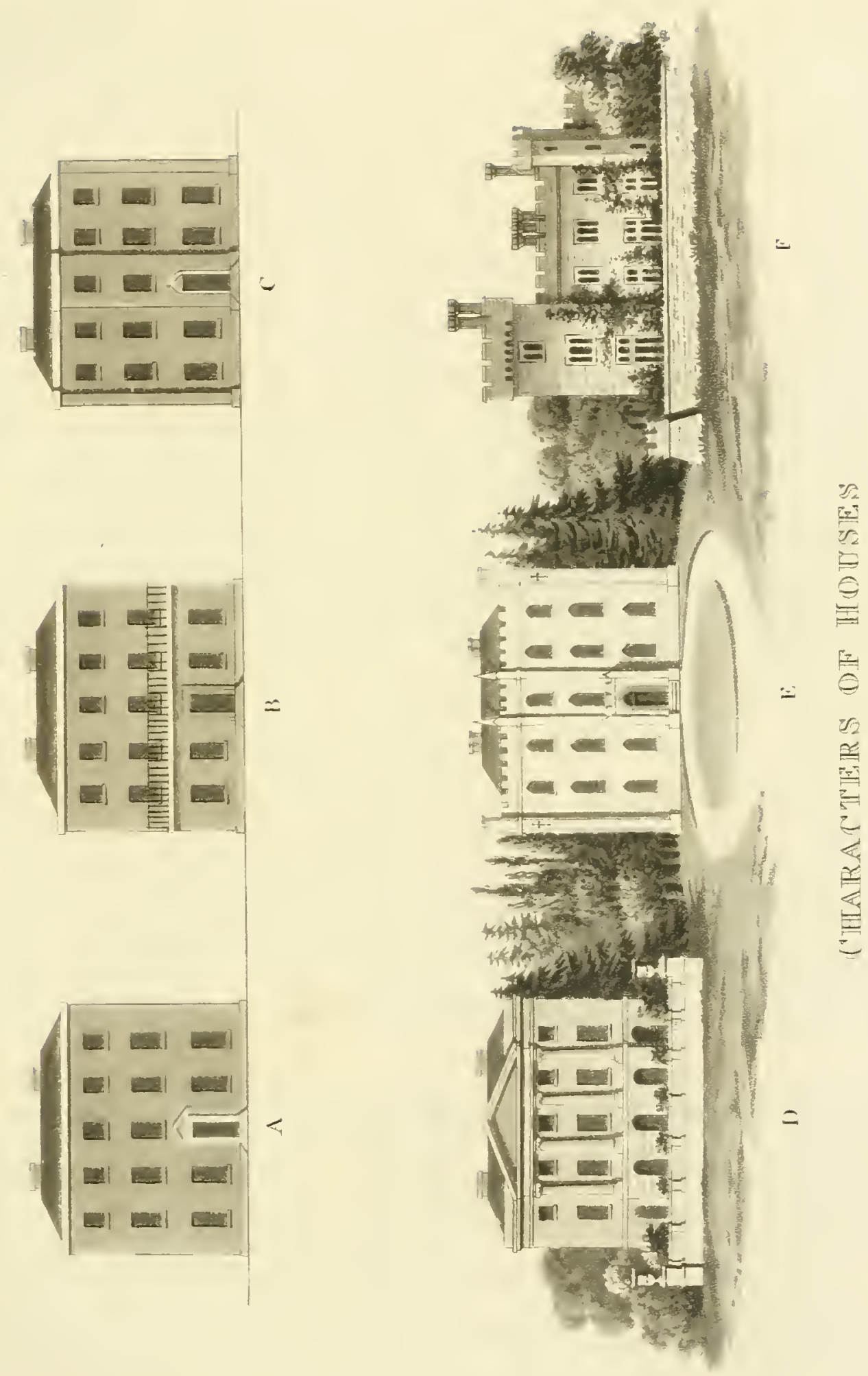

seek for his models among the fragments of his own country: but again, unfortunately, instead of houses, he can only have recourse to castles, eathedrals, abbies, and colleges; many of which have been so mutilated and disfigured by modern repairs, by converting eastles into palaces, and changing convents into dwelling houses, that pointed arches and battements have become the leading features of modern Gothic buildings. The detail of parts is studied, but the character of the whole is overlooked. No altention is given to that bold and irregular outline, which constitutes the real basis and beauty of the Gothic eharacter; where, instead of one uniform line of roof and front, sone parts project, and others recede: but wherever the roof is visible over the battlements, it seems as if it rose to proditim the trimmph of art over science, or carpentry over architecture. The elevation D represents one of these spruce villas, surrounded by spruce firs, atlended by Lombardy poplars, profusely scattered over the face of the country. That at $F$ may be supposed the fragment of some ancient eastle or manor-honse, repaired and restored, to make it habitable; and that at $\mathrm{E}$ is something betwixt the two, which will be further noticed.

The remaining part of this subject more peculiarly belongs to the Landscape Gardener, whose province it is to consider the effect of Nature and Art combined: let us examine the two different styles in the two Landscapes in the next Plate.

In the quiet, calm and beantiful scenery of a tame country, the elegant forms of Grecian art are surely more grateful and 
appropriate than a ruder and severer style; but, on the contrary, there are some wild and romantic sitnations, whose rocks and dashing mountain-streams, or deep umbrageous dells, would seem to harmonize with the prond Baronial Tower or Mitred Abbey, "embosom'd high in tufted trees," as tending to associate the eharacter of the building with that of its native accompaniment.

The outline of a building is never so well seen as when in shadow, and opposed to a brilliant sky; or when it is reflected on the surface of a pool: then the great difference betwixt the Grecian and Gothic charaeter is more peculiarly striking. 


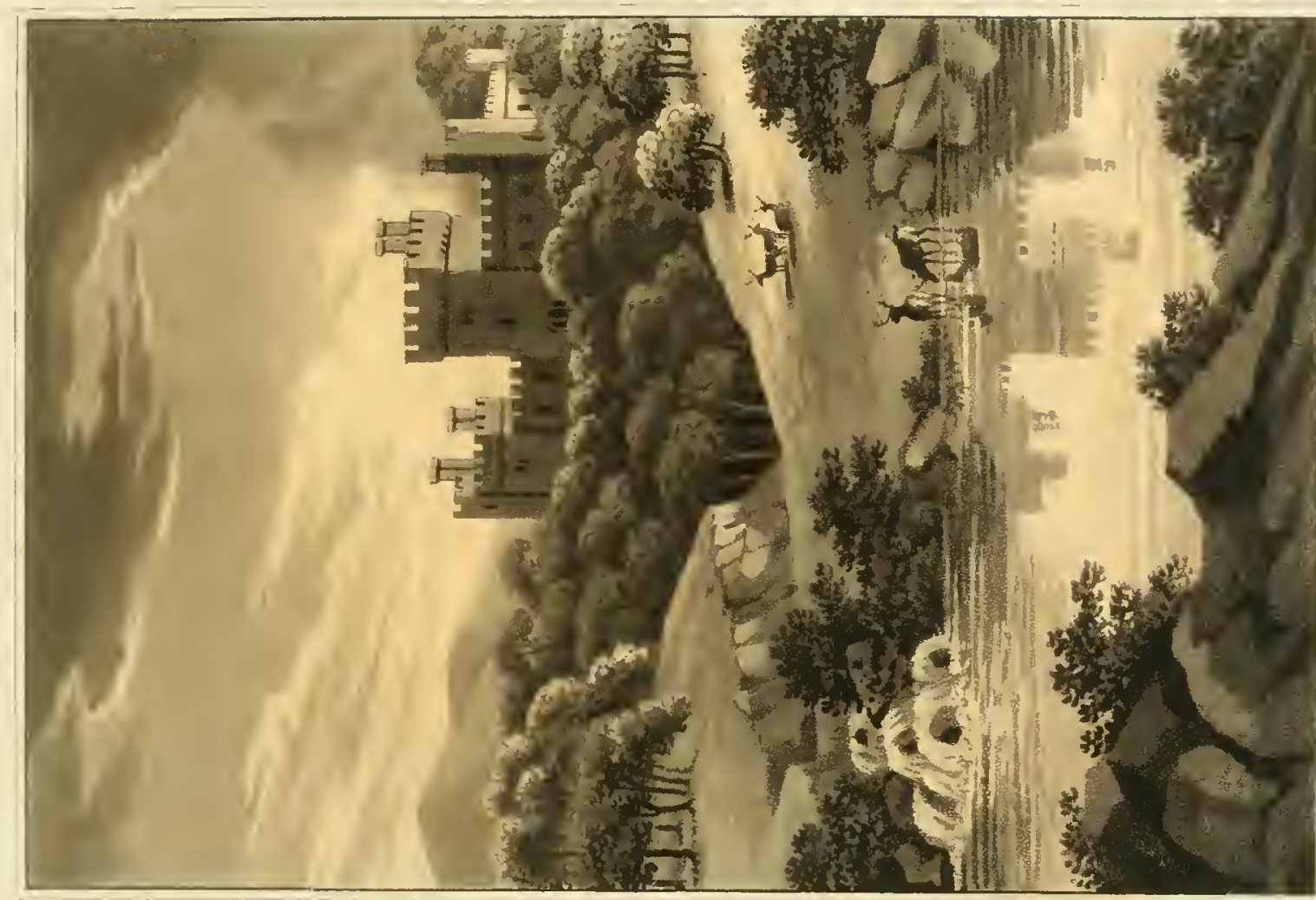

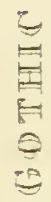

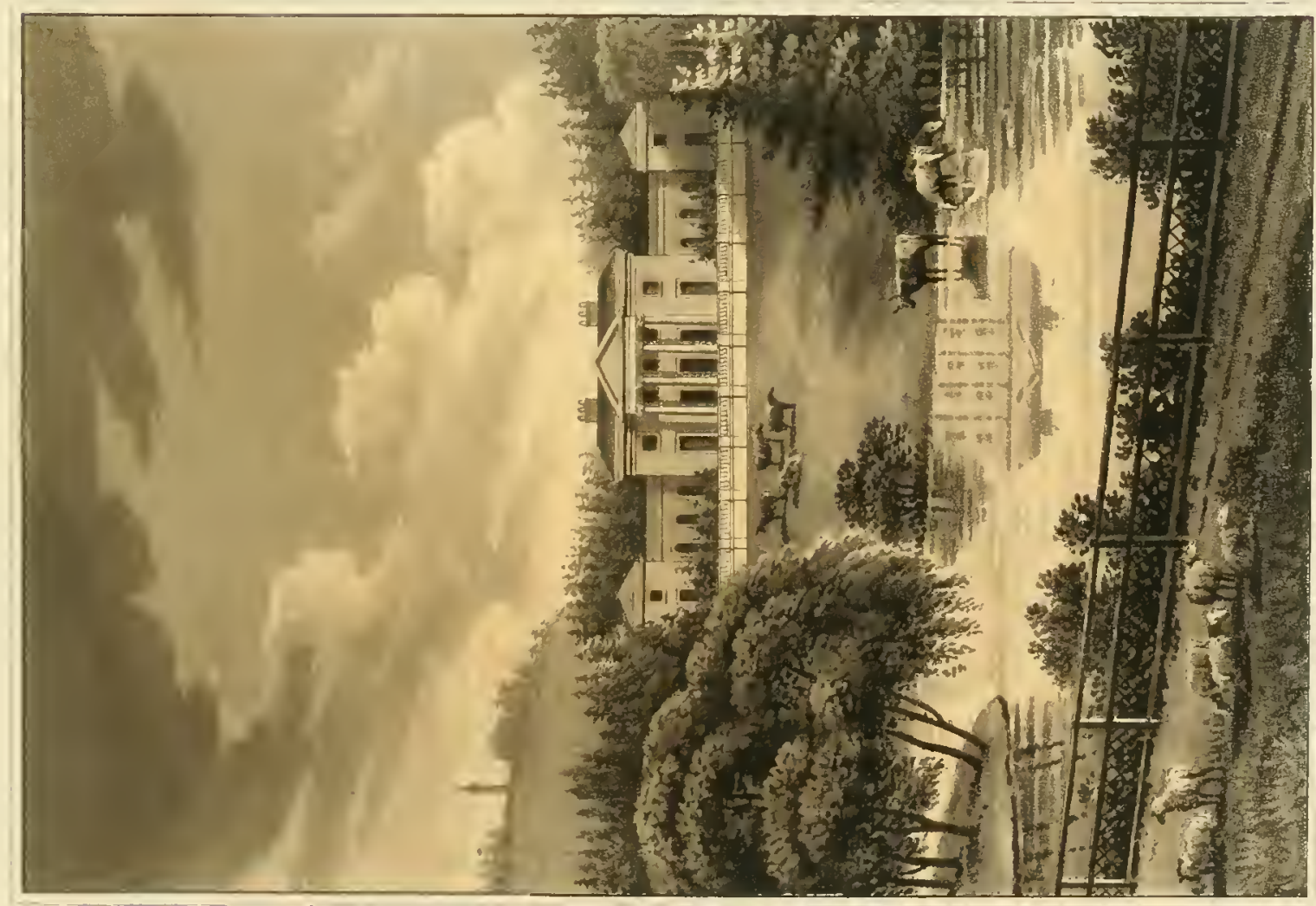

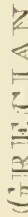





\section{FRAGMENT II.}

\section{RELATING TO SYMMETRY.}

The elevations in the first Plate will serve to elucidate some remarks on Architecture, not to be expected in treatises which relate merely to the five orders, and their symmetrical arrangement. Such works give a very inadequate idea of that art which teaches to adapt the habitation of man to rural scenery, uniting convenience with beauty, and utility with ornament. The houses $A, B$, and $C$, represent that sort of plain front which may be extended to any length, even till it reaches the dimensions of a barrack or an hospital. But in all such fronts, a certain degree of symmetry is deemed essential; and therefore we expect to see the door in the centre of the building. This arrangement, in small houses, tends to destroy interior comfort, by dividing from each other those principal rooms which a family is now supposed to oceupy.

If the principal rooms command a south-east aspect (which is donbtless the most desirable), the entrance in the centre, with a hall or vestibule, destroys that uniformity of temperament, so obviously useful to the comfort of an English dwelling; and therefore, in at least one half of the houses submitted to my opinion, I have found it necessary to change the hall into a saloon, or the vestibule into an anti-room; making the entrance 
either in the side, or at the back of the house, and converting the lawn to the south into pleasure ground or flower garden, or a broad terrace dressed with flowers. This of course makes a total change in the arrangement of all those appendages, in which the comfort of houses in the comntry differs so much from those in at town: in the latter, the oflices of every description are under ground; and the various court-yards, \&c. for which there is no space (as in the country), must be provided for in areas and cellars under the street.

If the centre of a building be marked by a portico, or such a visible entrance as invites the stranger to approach it, some impediment or obstruction becomes necessary to counteract the habitual respect for symmetry, and prevent our inclination to drive up to a door, which is no longer the principal entrance; and this requires a fence, to indicate that it is the garden front, and not the entrance front.

As this is a subject which will be explained farther, I shall for the present only mention, that the hint at D and $\mathrm{F}$ describes the different styles of Fences requisite for Grecian and Gothic Mansions. 


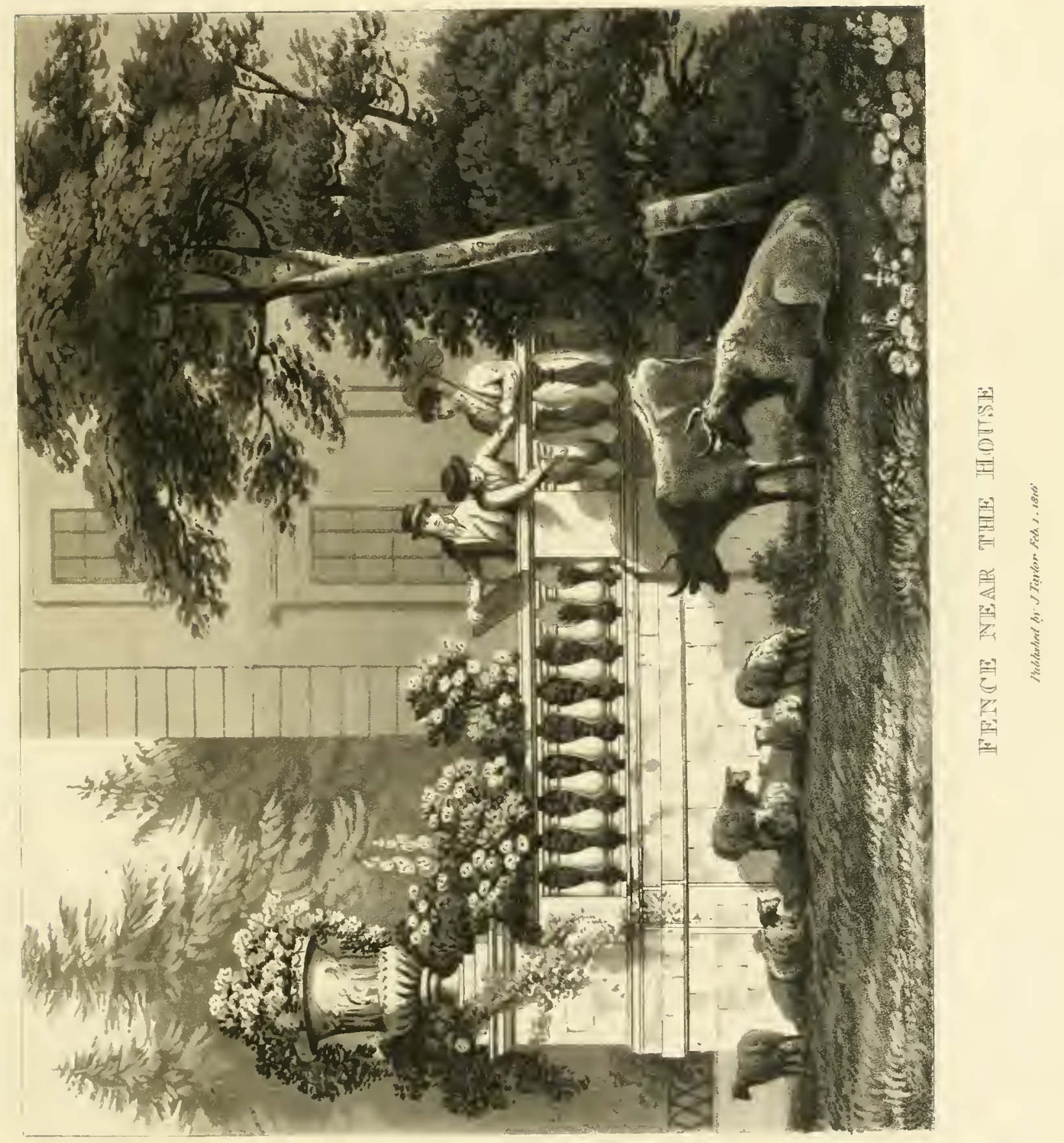





\section{FRAGMENT III.}

\section{ON \\ FENCES NEAR THE HOUSE.}

If there be any part of my practice liable to the accusation of often advising the same thing at different places, it will be true in all that relates to my partiality for a Terrace as a fence near the house. 'Twenty years have, at length, by degrees accomplished that line of demarkation betwixt art and nature, which I have found so much difficulty in establishing, viz. a visible and decided fence betwixt the mown pleasure-ground and the pastured lawn; betwixt the garden and the park; betwixt the ground allotted to the pleasure of man, and that to the use of cattle. So many different modes of producing the same effect may be suggested, that I shall hope to be useful in describing some of them.

First, where the ground falls from the house in an inclined plane, the distance of the fence can only be ascertained by actual experiment on the spot, and of course, the steeper the deseent the nearer or the lower must be the terrace wall.

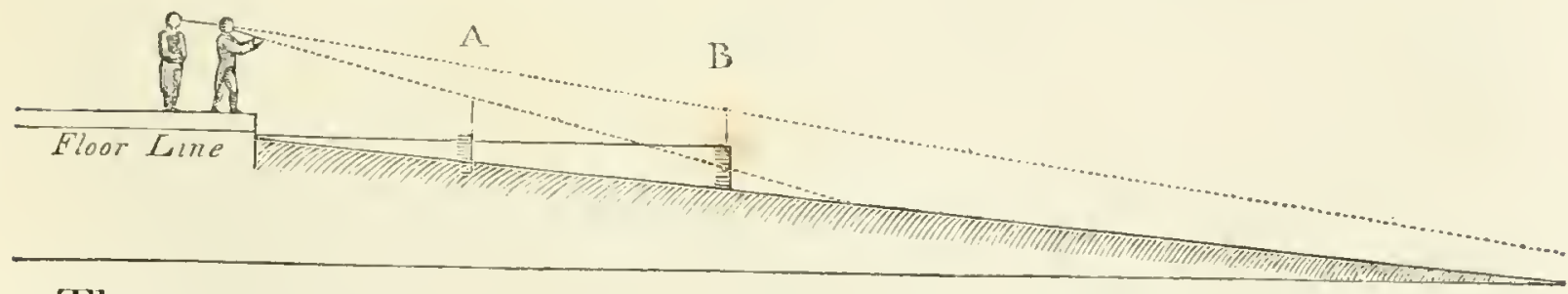

The eye sees the ground over the fence at $A$, but if carried to $B$, all view of the ground will be lost. 
If the ground be flat, as at $\mathrm{C}$, or rises from the house, as at $\mathrm{D}$,

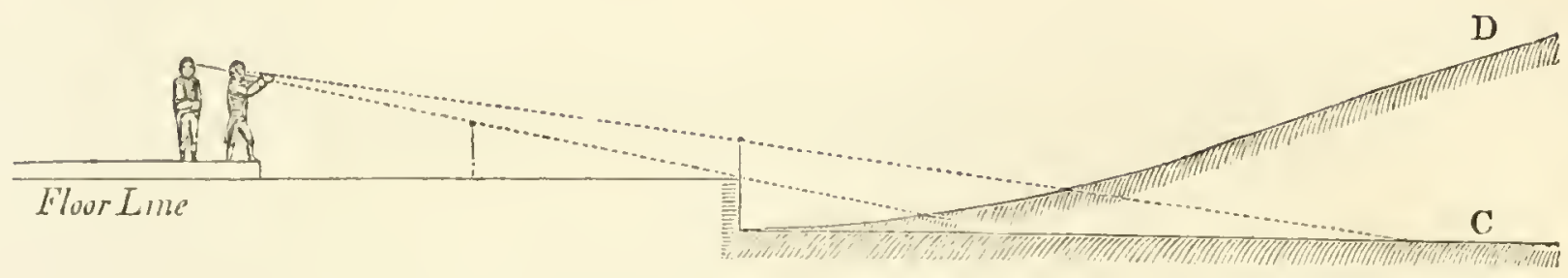

the fence will admit of being placed much farther from the house, without olstructing the view of the lawn.* The necessity of a fence to protect the house from cattle seems to have been doubted by the followers of Brown, who generally used the Ha! Ha! supposing that the fence ought to be invisible. On the contrary, it cannot surely be disputed, that some fence should actually exist between a garden and a pasture; for if it is invisible, we must either suppose cattle to be arlmitted into a garden, or flowers planted in a field; both equally absurd.

There is no fence more garden-like than that with an open trellis. But if the house be architecturally Grecian, and the terrace at no great distance, there is no fence so beautiful and proper as an open ballustrade (like that at Lord Foley's at Villey Court, Woreestershire). And even if the house be Gothic, an open ballustrade may be suited to it; of which an instance will be subjoined under the Fragment concerning Cohham.

* In some cases the ground may be sunk near the wall, which should be two or three feet high, with an open fence of two or three feet, or more, if it be a fence against deer. But in Gothic buildings the wall maty be nuch ligher, and the fence on the top may be wholly onitted. 
In speaking of Ballustrades, I cannot omit some remarks on the use to be made of them in different situations; such as a defence for a platform, or the parapet of a roof: the latter should be of stone, but the former may, in many cases, be an iron-railing; and in the parapets of bridges, the dimensions ought to relate to those of man, rather than to that of the building: *

A magnificent Palace ought not (like many that might be mentioned) to stand in a grass field, exposed to cattle, which are apt to take shelter near the building, and even to enter if, where there is no fence to prevent them; but a terrace or ballustrade marks the line of separation. The inside of the inclosure may be decorated with flowers; and we feel a degree of security for them and for ourselves, by knowing that there is a suflicient fence to protect both. This, which I consider a very important part of my own practice, with regard to the fence near a house, will be found elucidated by many of the sketches relating to other matter, in the course of these Fragments.

* It has often oecurred to me, in walking along Westminster Bridge, that this has not been sufficiently attended to. The large lofty Ballustrade is so managed, that the swelling of eacl heavy balluster exactly ranges with the eye of a foot passenger; and from a carriage, the top of the ballustrade almost entirely obstructs the view of the river. Thus one of the finest rivers in Europe is hid, for the sake of preserving some imaginary proportion in Architecture, relating to its form or entablature, but not applicable to its uses as a defence for safety, without impeding the view. If it be urged that we should judge of it from the water, we should consider that this bridge is seen by an hundred persons firom the land to one from the water. By the aid of an open upright iron fence, the most interesting view of the river might be obtained, with equal safety to the spectator. I have sometimes seen a drive or walk brought to the edge of a precipice, without any adequate fence; but good taste, as well as good sense, requires to be satisfied that there is no danger in the beauties we behold. We do not caress the speckled snake or spotted panther, however we may admire them. 
FRAGMENT IV.

\section{CONCERNING COBHAM.}

Whether we consider its extent, its magnificence, or its comfort, there are few places which can vie with Cobham, in Kent, the seat of the Earl of Darnley; and none which I can mention, where so much has been done, both to the house and grounds, under my direction, for so long a series of years: yet, as the general principles in the improvements originated in the good taste of its noble Proprietor, they may be referred to without incurring the imputation of vanity.

It is now twenty-five years since I first visited Cobham, where a large and splendid Palace, of the date of Queen Elizabeth, formed the three sides of a quadrangle, the fourth side being open to the west. The centre building had been altered by Inigo Jones, who had added four pilastres, without any attention to the original style, and without extending his improvements to the two long sides of the quadrangle.

The interior of this mansion, like that of most old honses, however adapted to the customs and manners of the times in which they were built, was cold and comfortless, compared with modern houses. A large hall, anciently used as the diningroom, occupied more than half the centre; and the rest belonged 
to the buttery and offices, in the manner still preserved in old colleges. The two wings contained rooms inaccessible, but by passing through one to the other; and the two opposite sides were so disjoined by the central hall, that each was entered by a separate porch.

The great hall at Cobham has been converted into a musicroom of fifty feet by thirty-six, and thirty feet high; and is one of the most splendid and costly in the kingdom. The rest of the central building forms the library, or general living room; which, instead of looking into an entrance-court, as formerly; now looks into a flower garden, enriched with marble statues and a fountain, forming an appropriate frame or foreground to the landscape of the park. The entrance has been removed to the north front, under an archway, or Porte Cochere, over which a walk from the level of the picture gallery (which is up stairs) crosses the road, in the manner described by the annexed sketch, representing the north front, as it has been restored to its original character. In this view is also the bastion, by which the terrace-walk terminates with a view into the park. But no drawing can describe the change made in the comfort of the place, since the improvements were first planned, and which, by the help of the map, may be rendered more intelligible.

This renerable pile is situated in a valley in the middle of a large park, and was formerly exposed to the cattle on every side, except towards the east, where a large walled garden intervened. The operations were begun by enveloping the whole of the premises in plantations, shrubberies, or gardens; 
and these, after the growth of twenty-five years, have totally clianged the character of the place. The house is no longer a huge pile, standing naked on a vast grazing ground: its walls are enriched with roses and jasmines; its apartments are perfumed with odours from flowers surrounding it on every side: and the animals which enliven the landscape are not admitted as an annoyance. All around is neatness, elegance, and comfort; while the views of the park are improved by the rich foreground, over which they are seen from the terraces in the garden, or the elevated simation of the apartments.

On the whole, Cobham furnishes a striking example of artificial arrangement for convenience in the grounds, immediately adjoining the house, contributing to the natural advantages of its situation and scenery, and enriched by the most luxuriant foliage and verdure. The home views give a perfect idea of what a park ought to be, without affecting to be a forest; for although its extent of domain might warrant such character, there is a natural amenity in the face of the country, that is more beautiful than romantic, more habitable than wild; and though in the valleys the view is not enlivened by water, which in a chalk soil is not to be expected, yet from the elevated points of the park the two most important rivers of England, the Thames and Medway, form part of the distant prospect. 


\title{
GARDENS OF COBHAM HALL, KENT,
}

\author{
A SEAT OF TIIE EARL OF DARNLEY.
}

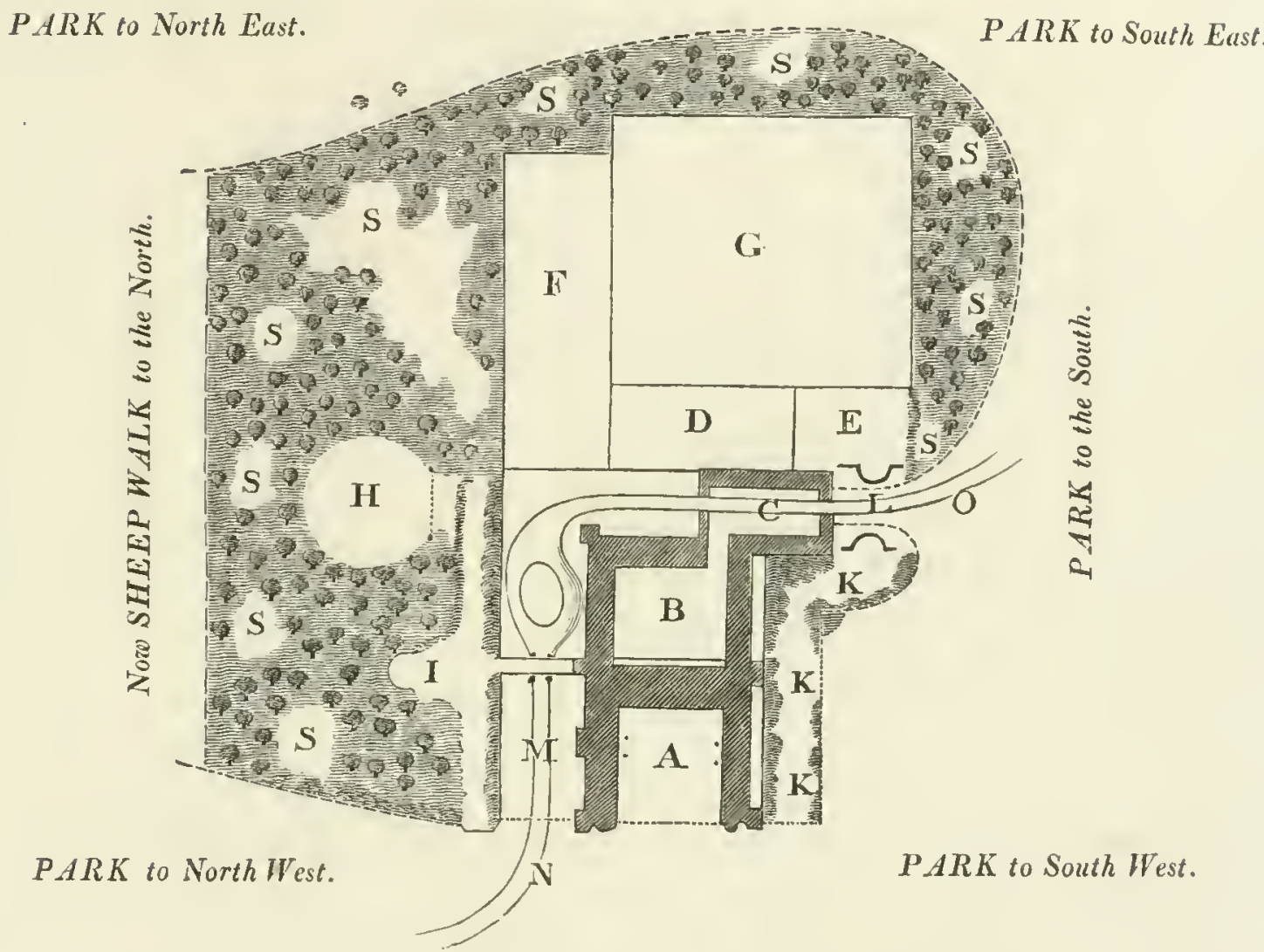

A the Entrance Court, now a Flower Garden, over which the Park is seen from the Music Room, Library, Dining-rooms, Hall, \&c. By two wings a quadrangle is formed about 200 feet on each side; that to the Sonth contains the Family and Private Apartments; that to the North, the Dining-room, Chapel, and State Bed below stairs, and over them the Picture Gallery on the level of the Terrace Garden.-B the Court of Offices.-C Stables.-D Melon and Forcing Garden-E Trellis Garden.-F Irregular Modern Flower Garden.-G Fruit and Kitchen Garden.-H Menagerie.-I Regular Antique Terrace Garden.-K Private Garden, over which the Park is seen from the Private Apartments raised on a Terrace. $-L$ Soutterein $W$ alk passing under the back road. M the present Entrance by an arched Porte Cochere, over which the Walk passes to the Terrace Garden. $-\mathrm{N}$ the Direction of principal Approach from whence the View is taken. $O$ the direction of the back road crossing the Soutterein.-S S Shrubbery and Plantations surrounding the whole, and placing it in a Garden. 



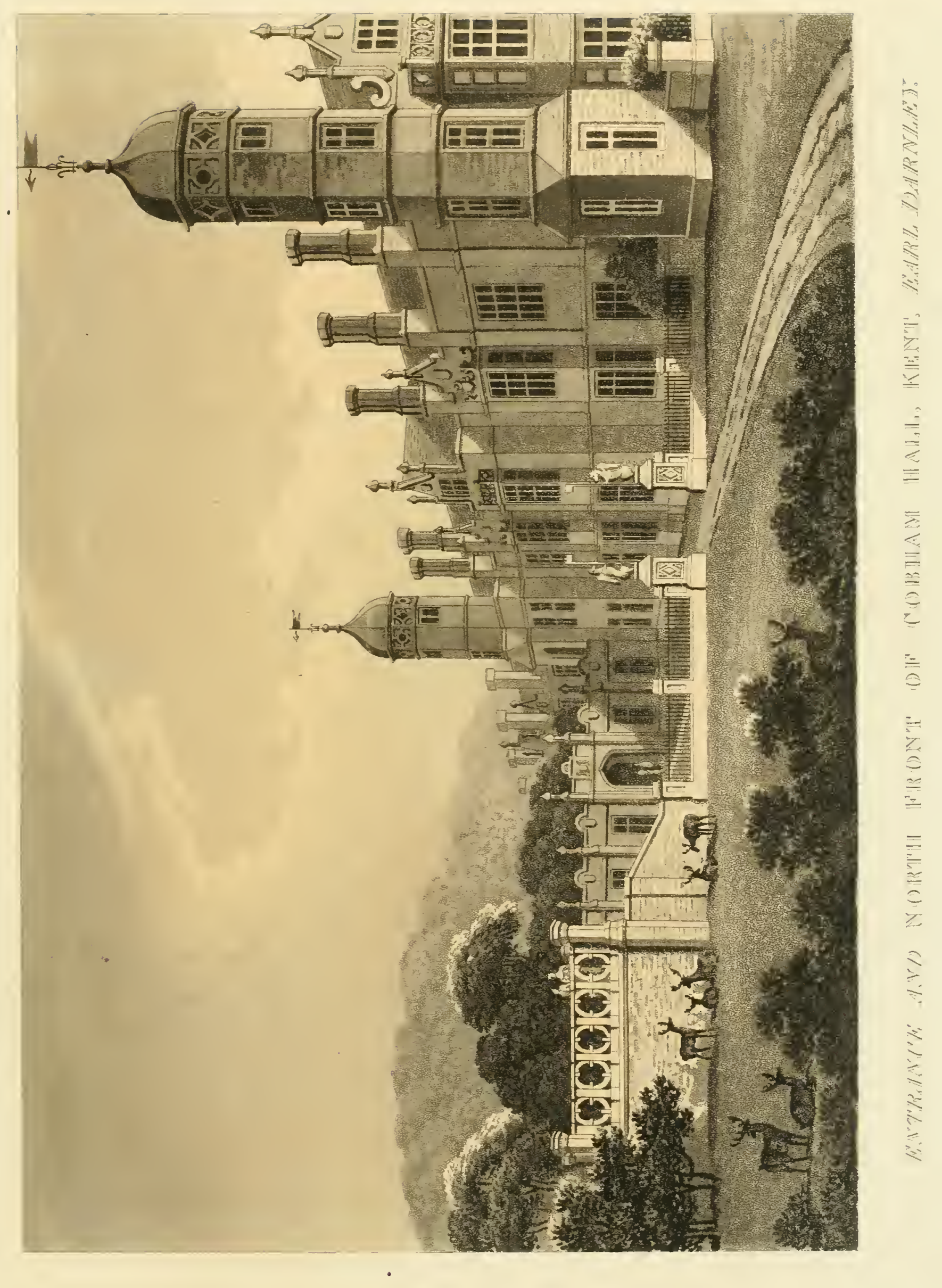



FRAGMENT V.

ON

\section{DATES OF BUILDINGS.}

A cottage or Keeper's House was deemed necessary at Aspley Wood, about three miles from Woburn Abbey. The Duke of Bedford (to whom I am indebted for numerous opportmities of displaying his good Taste) one day observed, that out of the numerous Cottages called Gothie, which every where present themselves near the high roads, he had never seen one which did not betray its modern character and recent date. At the same time his Grace expressed a desire to have a Cottage of the style and date of buildings prior to the reign of Henry VIII, of which only some imperfect fragments now remain.

Adjoining to this building, an attempt has been made to assimilate a garden to the same character, and the annexed Plate will furnish an example of both.

A communication of some curious specimens of Timberhouses was made to the Society of Antiquaries in 1810, which was ordered to be engraved and printed for the Arehæologia. But this building does more than any drawing, to exemplify many of the parts which have been thus rescued from the effects of time.

To admirers of genuine Gothic forms, the following Note 


\section{may prove acceptable, as shewing the authorities for all the detail of this Cottage.*}

* Note by J.A.R. This Cottage serves as a specimen of the Timber houses which prevailed in England from about the year 1450 to 1550 ; that is, from the reign of Henry VI to that of Henry VIII. As few buildings of this date remain entire, and every year reduces their number, the general plan of this Cottage is not copied from any individual specimen, but the parts are taken from the most perfect fragments of the kind, some of which have since been destroyed. The hint of the lower story, being of stone, is taken from a building near Eltham Palace; except that the windows are here executed in oak instcad of stone. In some buildings, both of brick and of stone, it is not uncommon to see oak windows used, as at Wolterton Minor House, East Barslam, Norfolk, and at Carhow Priory near Norwich. Stone and brick corbels, supporting beams, may be found at Lymn Regis and at Ely. The brick-nogging between the timbers is copied from a curions Timber-house in Lynn Regis, built by Walter Conys in the reign of Henry VI or Edward IV. 'The hint of the upright timbers being ornamented witl small arches (over the centre building), was taken from a timber-house near Kelvedon, Essex, which has since been destroyed. The gable-board is copied from a house at St. Edmondsbury, and is not uncommon. The form of the pinnacles (of which few specinens now remain, being the parts most exposed to the weather) is taken from some in brick or stone: the only one I lave ever found carved in oak is at Shrewslury. The square flag is copied from one at Homchurch, Essex. The projecting bow is taken from a window in Norwich, but the tracery of it is not uncommon; a specimen in oak is still to be found at Knowle, in Kent. The tracery of the lower window is taken from a timber-house in Coventry, but this also is not uncommon. The windows are all taken from an earlier date than the end of the reign of Henry VIII; that is, before they were divided by a cross-bar, which did not prevail in wood till the reign of Edward VI, Elizabeth, and the early part of the seventeenth century. The design of the porch is a lint from various specimens of open porches, and particularly the cloisters of old alms-houses, or short galleries leading to dwelling-houses, as at Clapton, near Lea-bridge, since destroyed, \&c. The design for the door of the Cottage is taken from one remaining at Sudbury, in Suffolk. The chimmeys are copied from those at Wolterton Manor House, at Barsham, Norfolk, published in the fourth volume of the 


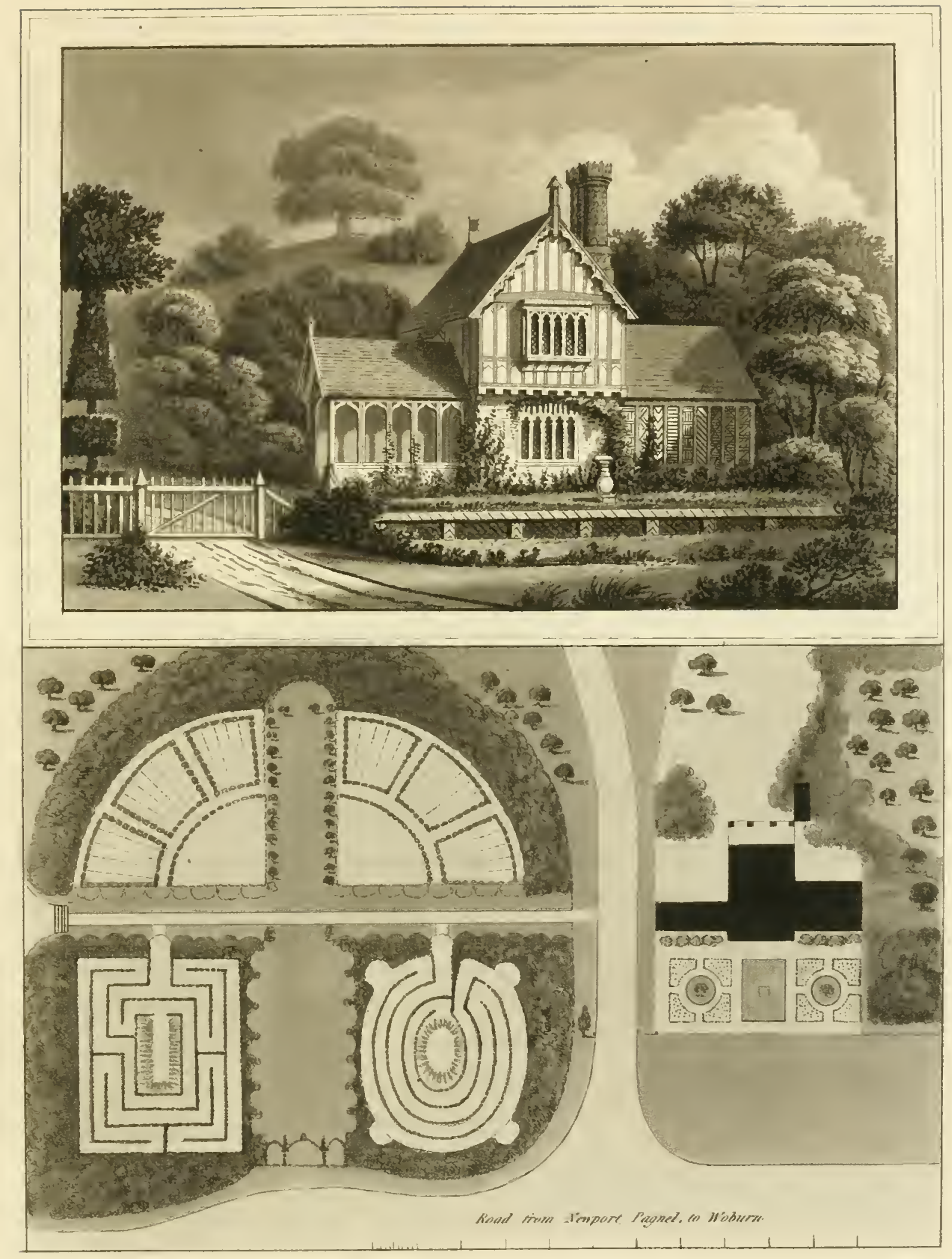

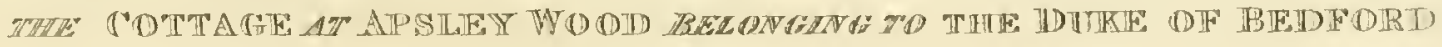



The hints for this Garden have been suggested by various paintings and engravings of the date of King Henry VIII and Elizabeth: and even the selection of flowers has been taken from those represented in the nosegays of old portraits of the same period, preserved in the Picture Gallery of Woburn. 'This attention to strict congruity may appear trifling to such as have never considered, that good taste delights in the harmony of the minutest parts to the whole; and this Coltage, however small, compared with modern mansions, is a tolerably fair specimen of the style and size of private houses three hundred years ago: for although the castles and collegiate buildings were large, some of the dwelling-houses of respectable persons did not much exceed this Cottage in dimensions or comfort, when one living room was often deemed sufficient for all the family.

The change in customs during three or four centuries makes it very diflieult to build such dwelling-houses, as shall contain all the conveniences which modern life requires, and at the same time preserve the ancient forms we admire as picturesque; yet the prevailing taste for the Gothic style must often be complied with; and after all, there is not more absurdity in making; a house look like a castle or convent, than like the portico of a Grecian temple, applied to a square mass, which Mr. Price has not unaptly compared to a clamp of bricks: and so great is the

Vetusta Monumenta. The ornaments painted on the posts and rails are taken from the picture of King Henry VIII and Family, now in the possession of the Society of Antipuaries. 
difference of opinion betwixt the admirers of Grecian and those of Gothic Architecture, that an Artist must adopt either, according to the wishes of the individual by whom he is consulted; happy if he can avoid the mixture of both in the same building; since there are few who possess sufficient taste to distinguish what is perfectly correct, and what is spurious in the two different styles; while those who have most power to indulge their taste, have generally had least leisure to study such minutix. To this may perhaps be attributed the decline of good taste in a country, with the increase of its wealth from commercial speculation.

By the recent works of professed Antiquaries, a spirit of inquiry has been excited respecting the dates of every specimen that remains of ancient beauty or grandeur; and the strictest attention to their dates may be highly proper, in repairs or additions to old houses: but in erecting new buildings, it may reasonably be doubted, whether modern comfort onght to be greatly sacrificed to external correctness in detail; and whether a style may not be tolerated, which gives the most commodious interior, and only adopts the general outline and the picturesque effect of old Gothic buildings.

Among the works professedly written on Architecture, there is none more effective and useful than that by Sir William Chambers: and it were much to be wished that a similar work on the Gothic Style could be referred to; but it has been deemed necessary for Artists to study the Remains of Greece and Rome in those countries, from whence they generally bring 
back the greatest contempt for the style they call Gothic. The late much lamented James Wyatt was the only Architect with whom I was acquainted who had studied on the Continent, yet preferred the Gothic forms to the Grecian. As the reason for this preference, he told me, about twenty years ago, that he conceived the climate of England required the weather mouldings, or labels over doors and windows of the Gothic character, rather than the bolder projections of the Grecian cornices, which he often found it necessary to make more flat than the models from which they were taken, lest the materials should not bear the change of weather to which they were exposed in this country: and this accounts for the occasional want of boldness imputed to him in his Grecian designs. In his Gothic buildings, to unite modern comfort with antiquated forms, he introduced a style which is neither Grecian nor Gothic, but which is now become so prevalent, that it may be considered as a distinct species, and must be called Modern Gothic. The details are often correctly Gothic, but the outline is Grecian, being just the reverse of the houses in the reign of Queen Elizabeth and King James, in which the details are often Grecian, while the general ontline is Gothic. In buildings of that date we observe towers rising boldly above the roof, and long bower windows breaking boldly from the surface; but in the modern Gothic all is flat, and the small octagon turrets, which mark the corners, are neither large enough to contain a screw staircase, nor small enough for chimneys: yet this style has its admirers, and therefore $I$ have inserted a specimen, although I conceive it to 
be in a bad taste, and have placed it betwixt the Grecian and Gothic fronts of D and F, not knowing to which it more properly belongs. If a door or window, or even a battlement or turret, of the true Gothic form, be partially discovered, mixed with foliage, it stamps on the scene the character of picturesqueness; of which the subsequent Vignette may serve as an example; and thus the smallest fragment of genuine Gothic often reconciles to the painter its admission into the landscape; even although the great mass of the building may offend the eye of the antiquary, or man of correct laste, by its occasional departure from the true Gothic style.

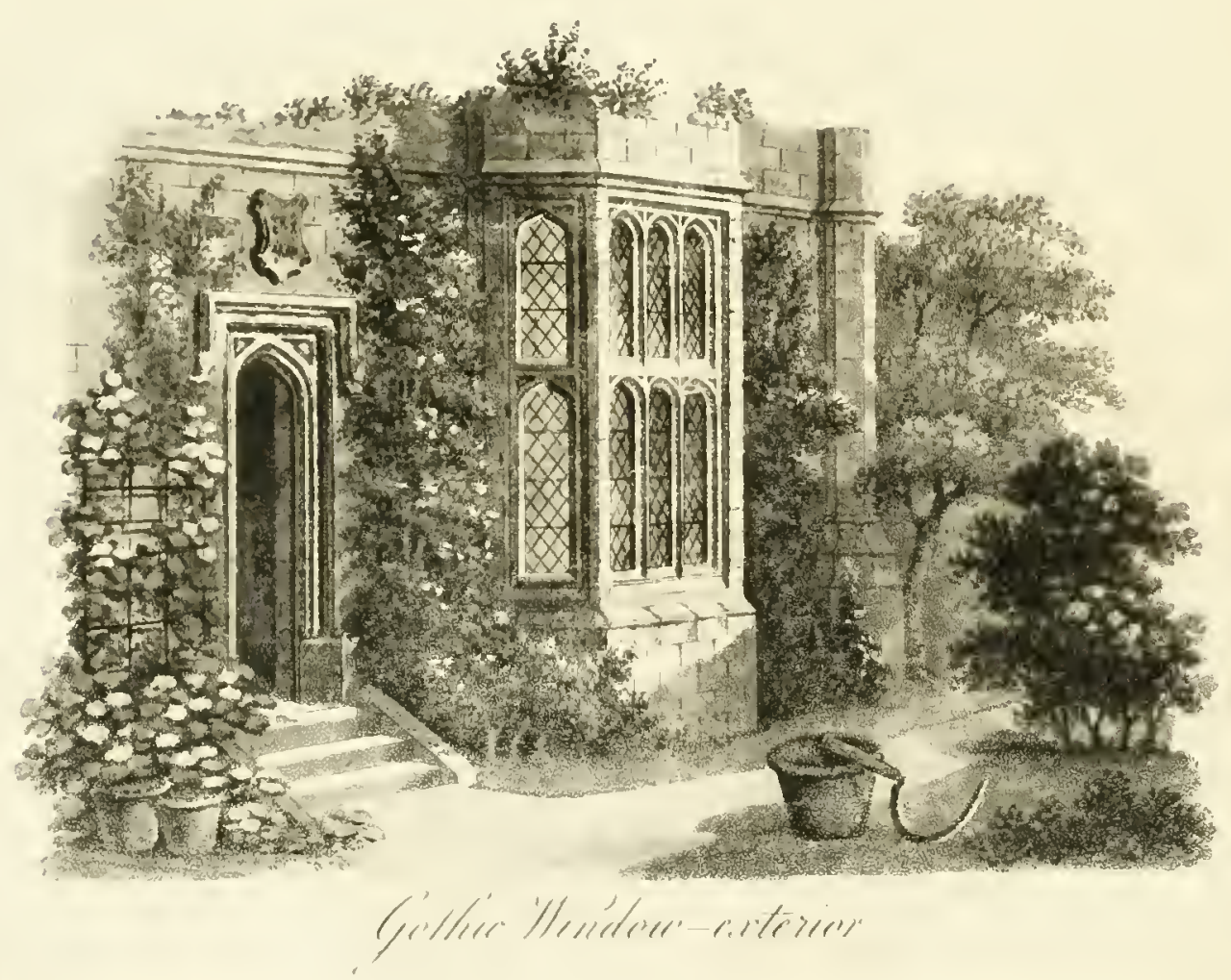




\section{FRAGMENT VI.}

\section{ON CASTLES.}

IT has been frequently observed, that an Artist's fame must depend on what he has written or designed, rather than on the imperfect manner in which his works have been executed. The annexed sketch is a picturesque attempt to add a House and Garden to a romantic situation, near the head of a spring, which spreads its waters through the whole course of a narrow but richly clothed valley. 'The old Mansion was so decply placed in the bottom, that the sun conld never cheer it during the winter months; I proposed, therefore, that a part of this old building should remain as offices, and a new suite of rooms be built on a higher level: and although it was deemed more expedient to add to the old house, this airy castle rose in my imagination; I will therefore avail myself of this imaginary specimen to explain certain leading principles, for all of which combined I can refer to no irregular Gothic buildings, except such as are in ruins; for although many attempts have recently been made to produce modern Gothic Castles, yet the great principle on which the picturesque effect of all Gothic edifices must depend, has too generally been overlooked: viz. irregularity of outline; first, at the top by towers, and pinnacles or chimneys; secondly, in the outline of the faces or elevations, by projections and recesses; thirdly, in the ontline of the apertures, by breaking the horizontal lines with windows of different 
forms and heights; and lastly, in the outline of the base, by the building being placed on ground of different levels. To all these must be added, detached buildings, which tend to spread the locality, and extend the importance of the principal pile, in which some one feature ought to rise boldly above the rest of the irregular mass, while the whole should be broken, but not too much frittered into parts by smaller towers, or clusters of lofty chimneys. After all, no building can appear truly picturesque, unless in its outline the design be enriched by vegetation (such as ivy, or other creeping plants); and the colouring, by those weather stains, which time alone can throw over the works of Art, to blend them with the works of Nature, and bring the united composition into pleasing harmony.

The usual manner in which books of Architecture have represented the elevations of buildings has been either geometrically, without perspective to denote the projecting and receding parts, or else perspectively as a bird's eye view supposed to be taken from an imaginary spot in the air. However intelligible these may be to professed Architects, they are as little comprehended by general observers, as the ground plan of a building by those who are not ashamed to acknowledge they do not understand a plan.*

* 'The antiquities of this country, and the beauties of Gothic outline, have been of late more forcibly elucidated by various picturesque works; of which, that by Hearne and Byrne took the lead; and $I$ cannot omit a tribute to the beantiful combination of correct Gothic Remains and Landscape Scenery displayed in the Antiquities of England published by Mr. Britton. These works have already been followed by many other ingenious productions, tending to increase the knowledge of English Antiquities, and the study of picturesque effect. 


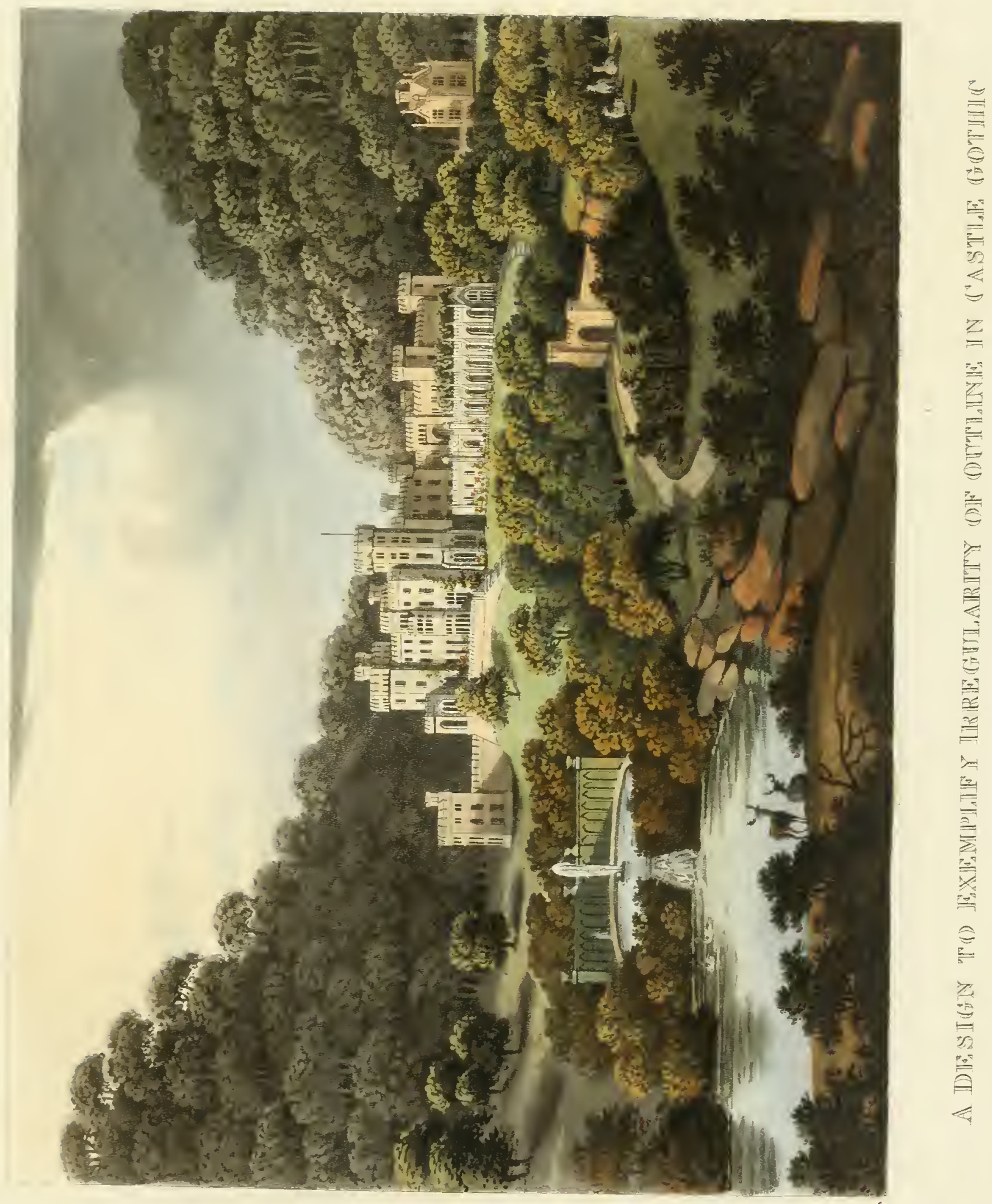





\section{FRAGMENT VII.}

\section{ON \\ UNITY OF CHARACTER.}

Is a House entirely new, Character is at the option of the Artist or Proprietor: it may be Gothic or Grecian, whichever best accords with the face of the country: but where great part of the original structure is to remain, the additions should donbtless partake of the existing character. This we have attempted at Harlestone Park, the seat of Robert Andrew, Esq. near Northampton: and as few places have undergone so much alteration, both in the House and Grounds, it may serve as a specimen of the combined arts of Landscape Gardening and Architecture, in adapting the improvement to the original Character of the Place.

The House was formerly approached and entered in the south front, which was encumbered by stables and farm yards: the road came through the village, and there was a large pool in front: this pool has been changed to an apparent river, and the stables have been removed. An ample Garden has been placed behind the house; the centre of the south front has becn taken down, and a bow added with pilasters in the style of the house: the entrance is changed from the south to the 
north side, and some new rooms to the west have been added. Of the useful and modern appendages to this House, the drawing can give little idea: the more essential part of Landscape Gardening is apt to be overlooked in the general attention to the picturesrue, which has often little aflinity with the more important objects of comfort, convenience, and accommodation.*

* In speaking of Harlestone Park, 1 cannot omit mentioning a remarkable fact connected with its improvement. This Park abounded in large Oaks, irregularly scattered over its uneven surfice, but amongst them were every where intermixed many very tall Elms, not all planted in avenues, but some in single rows, casting their long shadows over the lawn, oppressing the venerable Oaks by their more lofty growth, and spreading shade and gloom over the surface of the Park. I could not help observing, that the greatest improvement of which the place seemed capable might be deemed too bold for me to advise, as it was no less than the removal of almost all the Elms to shew the Oaks, and diffuse sumshine over the lawn. A few days after having delivered this opinion, on the 10th of November, 1810, a furious storm of wind tore up by the roots eighty-seven of the largest Elms, and only one Oak; producing exactly the effect of improvement which I had anticipated, but had not dared to recommend. This occurrence is recorded on a tablet inscribed-GENIO LOCl. 


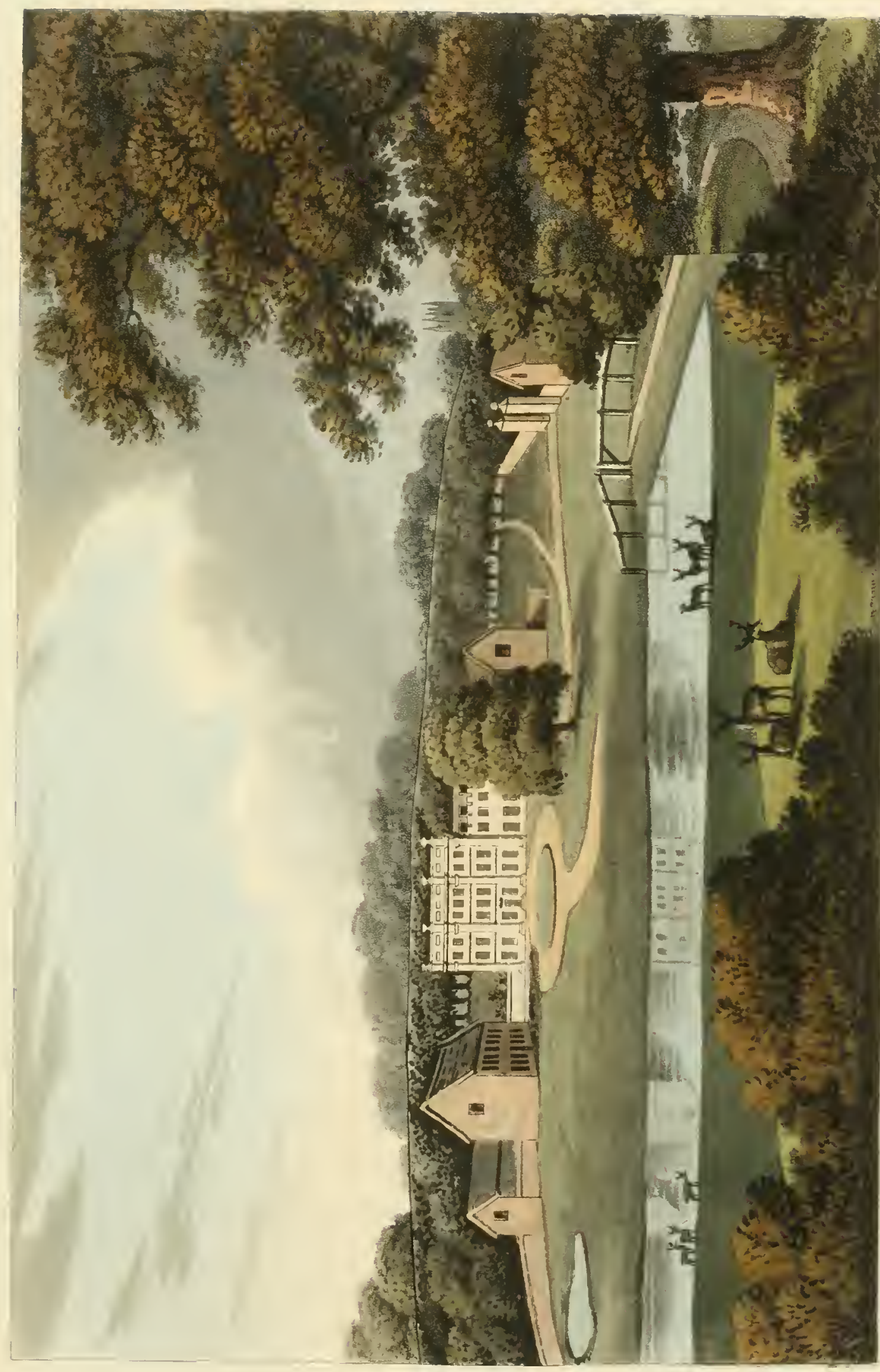

年 



\section{FRAGMENT VIII.}

\section{ON BLENDEN HALL, KENT,}

A VILLA BELONGING 'TO JOHN SMITH, ESQ. M. P.

From the relative situation of this place with respect to the capital, it must be treated as a Villa, rather than a constant residence. This distinction is necessary to explain the principle of its improvement, because in the art of Landscape Gardening two things are often confounded, which require to be kept perfectly distinct, viz. the Landscape, and the Garden. To the former belong the Lawns, the Woods, the Water, and the Prospect; these may be improved by imitating Nature, but a Garden, as I have often repeated, is a Work of Art. At Blenden Hall the Lawn is beautiful in shape, and its surface enriched with venerable trees, which are sufficiently numerous, without the aid of firs and Lombardy poplars; and the boundaries are generally well concealed, or blended with distant woods.

The Water at present consists of two distinct pools; these may be united in appearance, without altering the levels, which would sacrifice too many good trees, if the lower water were raised, and make the banks too steep, if the upper water were sunk. A bridge however may be so constructed, as to give continuity to the water, making it resemble a river: and this idea would also be assisted by extending the water to the east, as 
marked on the ground. With such alterations the water will become a very important feature in the scenery, which, without it, would require some more distant views beyond the place; but a river is always sufficient in itself to form the leading feature of a natural landscape; and with such interesting objects of lawn, wood, and water, in the home scenery, the distant prospect may be dispensed with.

It lias been suggested, that the approach from Eltham ought to be removed to the corner of the premises, in conformity with a commonly received practice in Landscape Gardening: but I prefer the present entrance for the following reasons: I seldom advise entering at the corner of the premises, and in this case the house would present itself ahmost immediately; a road would cut up the lawn, and oblige us to continue the water, as a river, along the whole valley, which is not otherwise advisable, because there are no rooms in this front of the house to require such waste of lawn and expenditure. Perhaps the fence ought to be kept very low at the corner, to give the public a view into the lawn, which would increase the importance of the place more than by leading a road through it. And lastly, the Cottage is well placed to act as a Lodge, and may easily be ornamented for that purpose.

The entrance may serve as an example for a general remark, which will frequently be applicable to other places. The Gate at present being in the continued line of the paling, there is hardly room left to enter commodiously. If the Gate be set back a ferv yards, the trees, thrown out into the road, will give that 
degree of importance to the place, which we may suppose belongs to the manerial right; while a pale, enclosing every tree and bush near the road, counteracts this impression. One other general remark may be useful, however trifling, viz. although the interior fences (to be less visible) may be dark green, yet the entrance-gate and its immediately attached fence, should be white, a little subdued, to avoid the offensive glare of paper whiteness, yet sufficiently white to prevent accidents, which an invisible gate is apt to occasion after sun-set.

THE HOUSE.

The House having adopted a new character, from its late alterations, I have subjoined a sketch of its south and east fronts, combined in perspective, which may serve to explain the effect of removing some tall trees, by which it is now oppressed, and deprived of that consequence which its Gothic character has assumed. This sort of comparative influence of trees on a building deserves attention; and the sketch presents a favourable specimen of that species of Architecture, which has already been mentioned as Wyatt's Gothic, because introduced by that ingenious Architect; although not strictly in conformity with the Abbey, Castle, or Collegiate characters, or even with that of the old Manor-honse; but since it evidently belongs rather to the Gothic than the Grecian style, it will be advisable to adopt such expedients as best assimilate with buildings of the date of 
Queen Elizabeth, all which relate to the appendages; especially as they add not only to the comfort, but to the picturesque effect of the mansion: anong these may be reckoned the forecourt, which extends a degree of neatness a little farther into the lawn, and this being fenced by a dwarf-wall, should be entered by a gate in the centre.

There is an old building at the south west corner of the house, which may form the back wall of a conservatory; and a similar wall may serve to form a correspondent wing at the north west corner; but if these were laid open, it would rob the house of its importance, the pleasure-ground of its privacy, and the character of the place would take no benefit from the Gothic style; because such walls add greatly to the shelter in winter; and there are many plants, such as jasmine, and creepers requiring the support of a wall, which, so clothed, forms a luxuriant decoration to a garden in summer; and by ivy and other evergreens may partly be extended through the year. This naturally leads to the consideration of the Gardens, and their improvement.

Under this head must be included every part of the grounds, in which Art rather than Nature is to please the eye, the smell, and the taste. Each part will require fences, and perhaps of various kinds.

First, near the house, a walled Terrace, to keep cattle from the windows, and protect a border of flowering plants near the eye. Secondly, an iron Fence may be sufficient to exclude cattle from the pleasure ground; but in that part which contains 
fruit, a more substantial guard against man must be provided, and brick walls are the best security.

I will here make some remarks on the occupation of land belonging to a Villa. It is surprising how tenacious every gentleman is of grass land, and with what reluctance he increases his garden, or contracts his farm; as if land were only given to produce hay, or to fatten cattle. He forgets the difference in value betwixt an acre of pasture and an acre of fruit garden; or the quantity of surface required to grow a load of hay or a load of currants, cauliflowers, or asparagus, with the prodigious difference in the value of each. For this reason, the Gardens of a Villa should be the principal object of attention; and at Blenden Hall, the ground betwixt the fruit trees in the orchard, which produces hay, small in quantity and bad in quality, might be turned to more advantage by planting currant bushes, or sowing garden crops; which even if sent to market, will yield five times the value of the feed for cattle. There is a clipt quickset-hedge, which forms the south boundary of the garden; this is as secure as a wall, and therefore worth preserving. I must also advise retaining the lofty wall to the west, as the greatest protection against the west winds: but a skreen of trees, or rather filberts and fruit trees, should be planted, to hide the wall from the approach, and to secure a slip on the outside, and make both sides of this lofty wall productive. If more walls be required, they may be added as described on the map, so as to shelter each other from blights; for it is not necessary that the garden should be a square area within four 


\section{walls. A fruit garden may be so blended with flowers and vegetables, as to be interesting in all seasons; and the delight of a garden highly cultivated, and neatly kept, is amongst the purest pleasures which man can enjoy on earth.*}

* The Pleasures of a Garden have of late been very much neglected. About the middle of the last century, the introduction of Landscape operated to the exelusion of the old Gardens of England, and all straight Gravel Walks. Glades of grass and clipped hedges were condemned as formal and old fashioned; not considering that where the style of the house preserved its ancient character, the Gardens might with propriety partake of the same. After this, a taste, or almost a rage for farming, superseded the delights of a Garden; in many cases for the mercenary reason, that a sack of potatoes would sell for more than a basket of roses or lavender. It is with peculiar satisfaction that I have occasionally observed some few venerable Gardens belonging to parsonage or old manor houses, where still may be traced the former grass walks and box-edged borders, with thick and lofty hedges of holley, quickset, or other topiary plants, which, like the yew or ivy, seem to display a peculiar satisfaction in yielding a fence at once secure, and neat, and opakcly trim. 


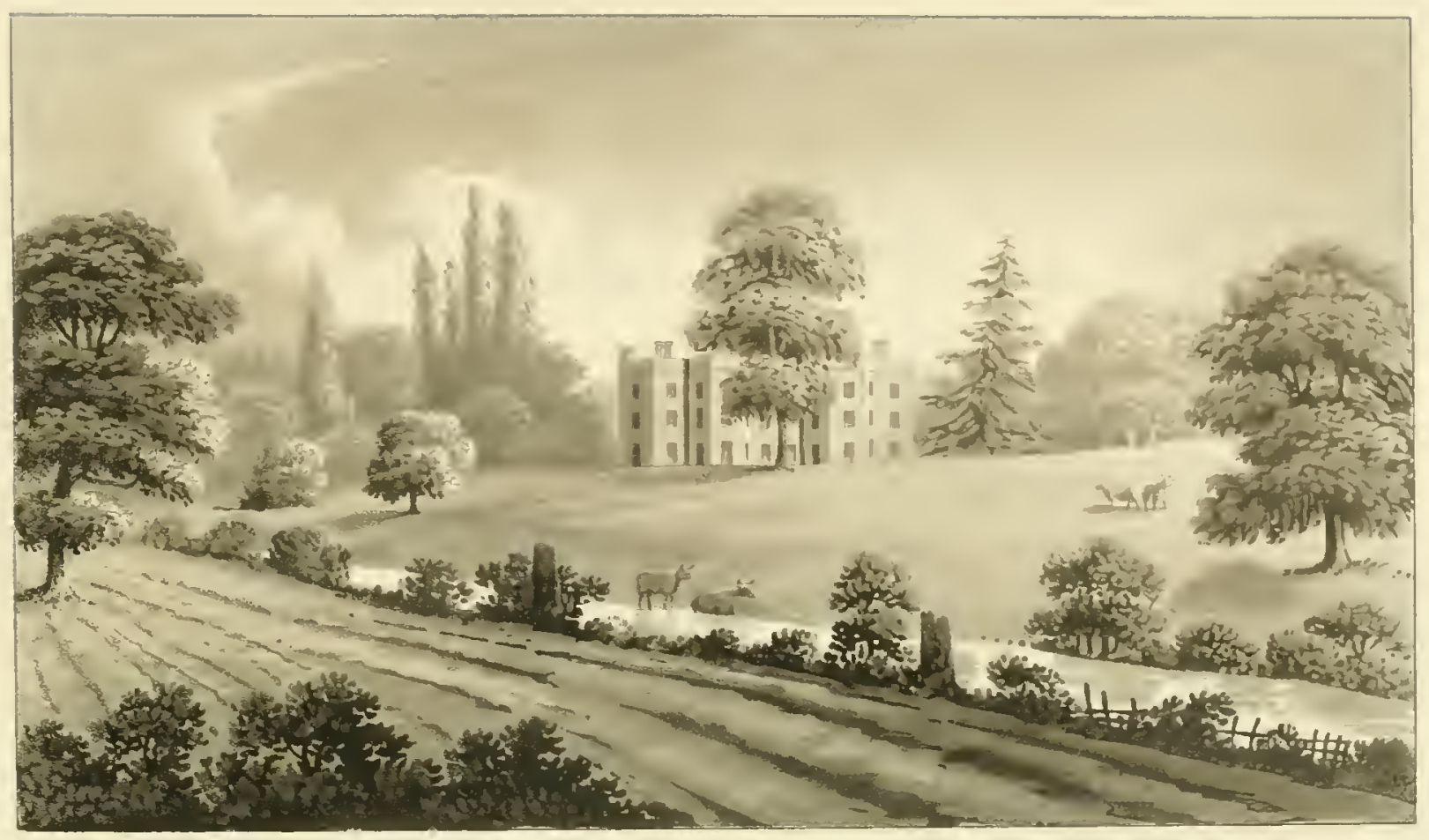

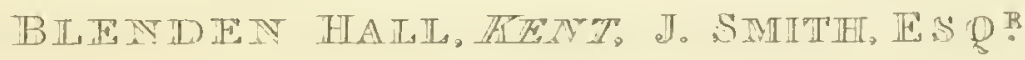

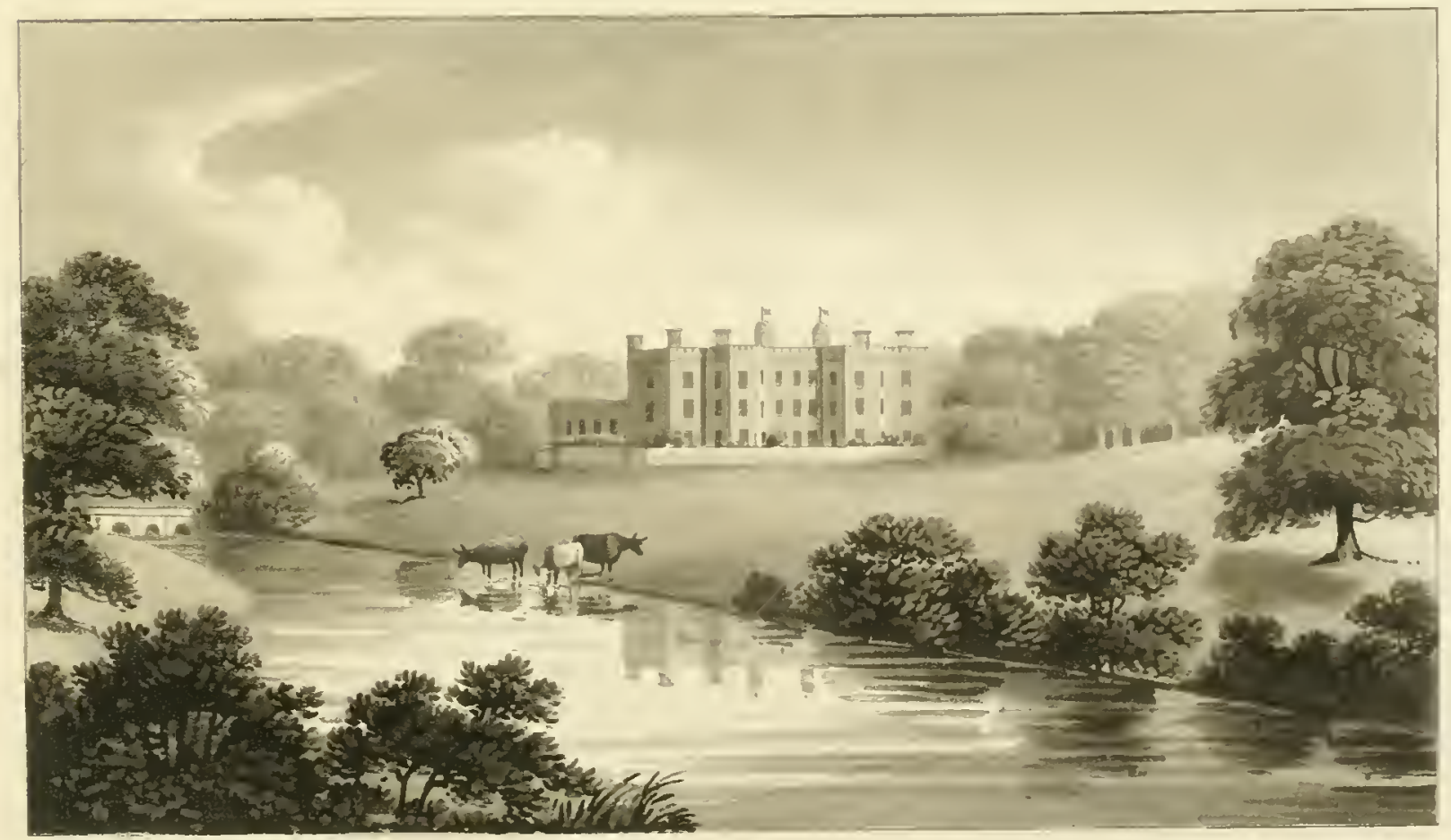





\section{FRAGMENT IX.}

\section{CONCERNING WINDOWS.}

There is no subject connected with Landscape Gardening of more importance, or less attended to, than the Window, through which the landscape is seen. In some ancient houses the windows were glazed in small lozenges, containing the family arms or crest: to this Shakespear alludes in King Richard II. "From mine own Windows torn my household coat:" of course the light was so obscured, that no view could be expected; and indeed in some old mansions the windows are so placed, that it is difficult to make the rooms comfortable in the interior, while the exterior character is preserved. The style of the early Gothic of Elizabeth, when not disfigured by an unseemly mixture of bad Grecian, seems better adapted to habitation than the castle, abbey, or collegiate Gothic. But houses of that date generally consist of a large hall, like that of a college, and one or more long narrow galleries, with a number of small parlours, badly disposed, and ill connected. Yet there is something so venerable and picturesque in many houses of this date, that I have always endeavoured to preserve as much of them as could be adapted to modern uses; and even in some cases advised new houses in that style of architecture. The example selected for 
reference in the present Fragment is Barningham Hall, in Norfolk, the seat of J. T. Mott, Esq. where the east front has been preserved most scrupulously; not a window has been altered, except in the glazing; the improvements and additions have all been made in a new front towards the south, as shewn in the sketch. This house, though it appeared large, did not contain one room that was comfortable, or of a size adapted to our morlern style of living. It consisted of two parlours, in each of which two modern sashes had been introduced about sixty years ago. The slide of the annexed sketch represents the house as it was in 1805, and the drawing shews the additions since made, according to the plan annexed of the ground floor; to which a library or living room is added over the entrance, and extending forty-five feet by eighteen feet wide. The original simple style of Gothic has been preserved and restored in the vestibule and staircase, which are shewn with the plan.

The greatest improvement in this old Mansion has been effected by adopting in the sonth and east fronts a style of Window of the same date, though of a different form from those of the west front. The latter were too small in the apertures to be comfortable, while those, added to the south front, glazed with plate glass, are more cheerful within, and more characteristic on the outside, than any modern bow with three sash windows could have been made.*

* There is a circumstance relative to Windows which is seldom attended to, and which has never been mentioned in books of Architecture, viz. the situation of the bar, which is too apt to cross the eye, and injure the view or landscape. This bar ought never 


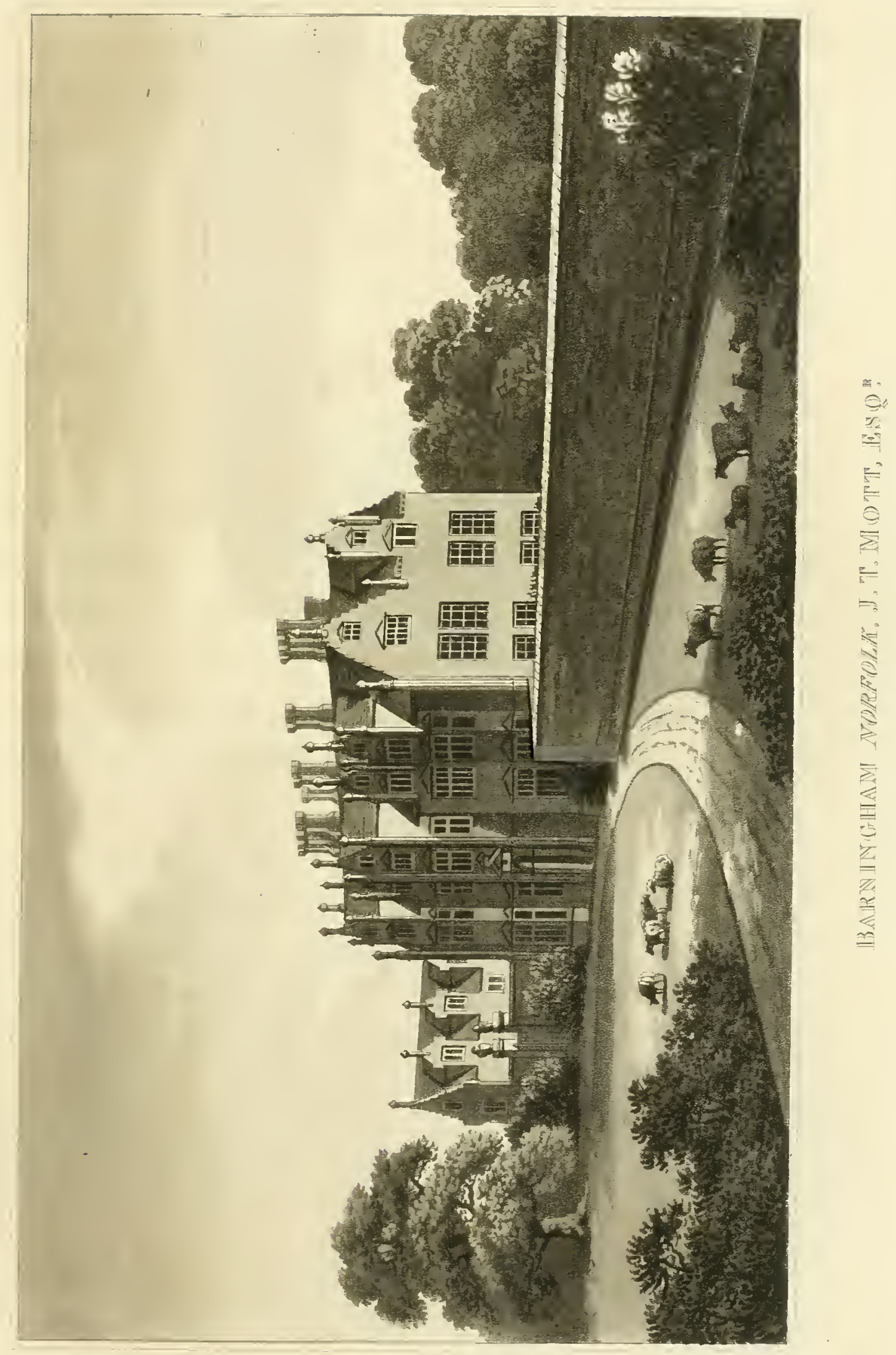



In treating the subject of Windows, some notice may be taken of the modern improvement, borrowed from the French, of folding Glass-doors opening into a garden; by which the effect in a room is like that of a tent or marquée, and in summer delightful.* But as these doors are seldom so construeted as to exclude the cold winds in winter, where they are much exposed, it is found expedient to build up a brick-wall breast high, which may be taken away during the summer months.

In making choice of Gothic Bow Windows for additions to an old house, and at the same time to preserve the correct proportion of the whole, the apertures of the glass ought not to be too large, nor the munions too slender. We should select the best specimens of such remains as may be found in our old manor-houses, without copying defects.

The Plate annexed serves to shew the difference betwixt the same Window munions, \&c. of an ancient Bow Window,

to be more than four feet nine inclies, nor less than four feet six inches from the floor; so that a person in the middle of the room may be able to see under the bar when sitting, and over it when standing; otherwise this bar will form an unpleasing line crossing the sight in the exact range of the horizon, and obliging the spectator to raise or stoop his head. If it can be entirely omitted, the scenery will be improved; but if the bar be preferred, the best position of it may be calculated at four feet six from the floor, and the glass may be continued to any depth below, not more than two feet and a half from the floor; otherwise persons sitting will not have sufficient sight of the ground, and the view will consist, as in many old honses, of sky and the tops of trees.

* This, although more applicable to Grecian than Gothic Houses, may be adapted to the latter, by making the munion in the centre to open. 
and a modern one, as adopted at Barningham Hall. . $N^{\circ} 1$ shews an original Window, supposed to be erected in the reign of Queen Elizabeth, with all its faults, in respect to modern comfort, such as the glazing in lozenges, heavy iron casements, and upright iron bars; also the great inconvenience of the sill being too high above the floor; and lastly, the lofty panels which tend to depress the height of the room.

$\mathrm{N}^{\circ} \mathcal{Q}$ shews a modern Window of the same dimensions and proportions, without copying the defects: instead of the lozenge shape, large panes of plate or crown glass are inserted. The sills of the windows, being lower, admit the landscape. The lofty panels are omitted, and the inside of the room fitted up as best adapted to modern comfort, preserving the character of Gothic Architecture externally. There is no impropriety in supposing that the whole Bow-window has been preserved, and that the inside only has been altered to suit the taste of the present times. 

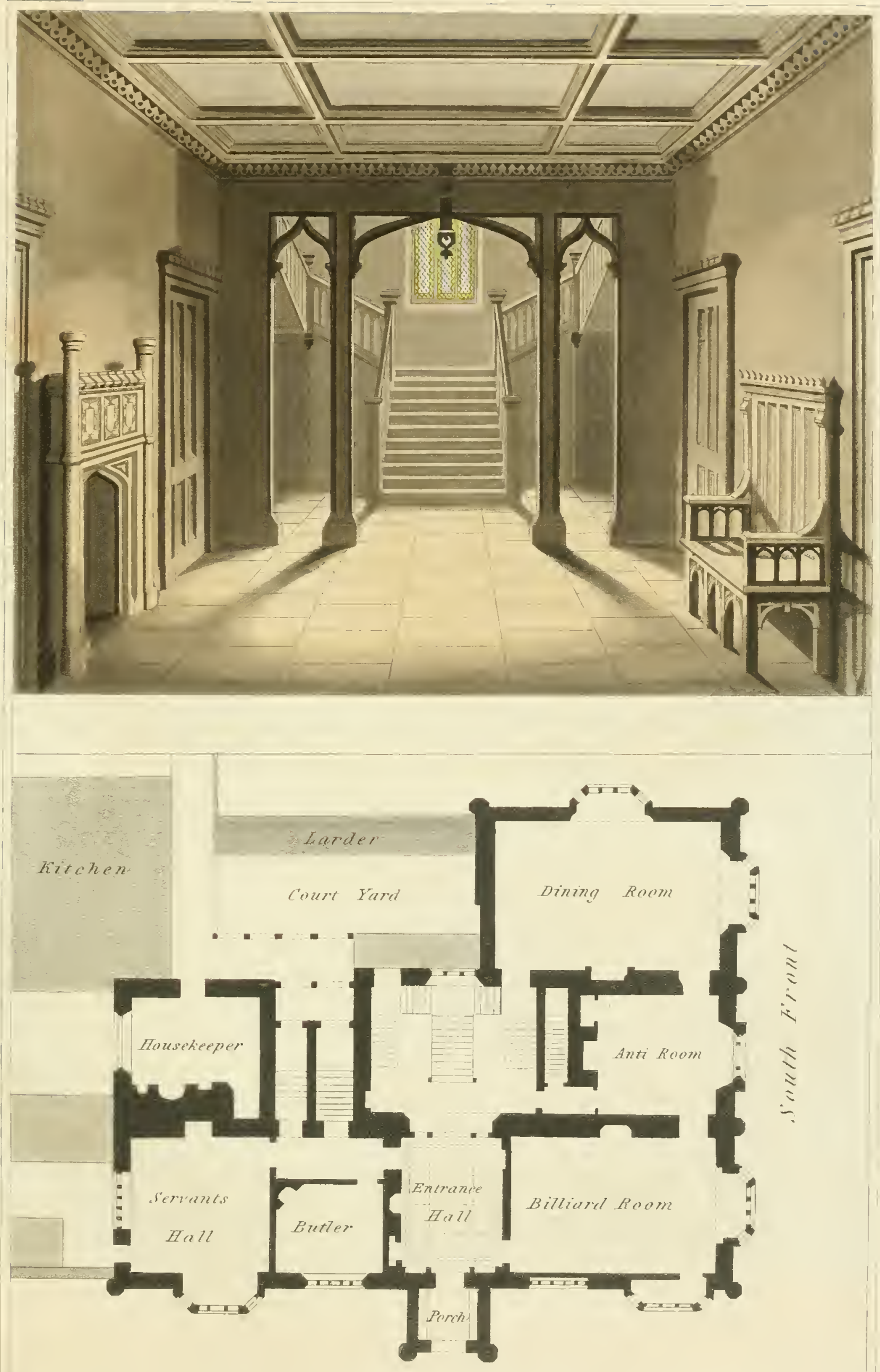



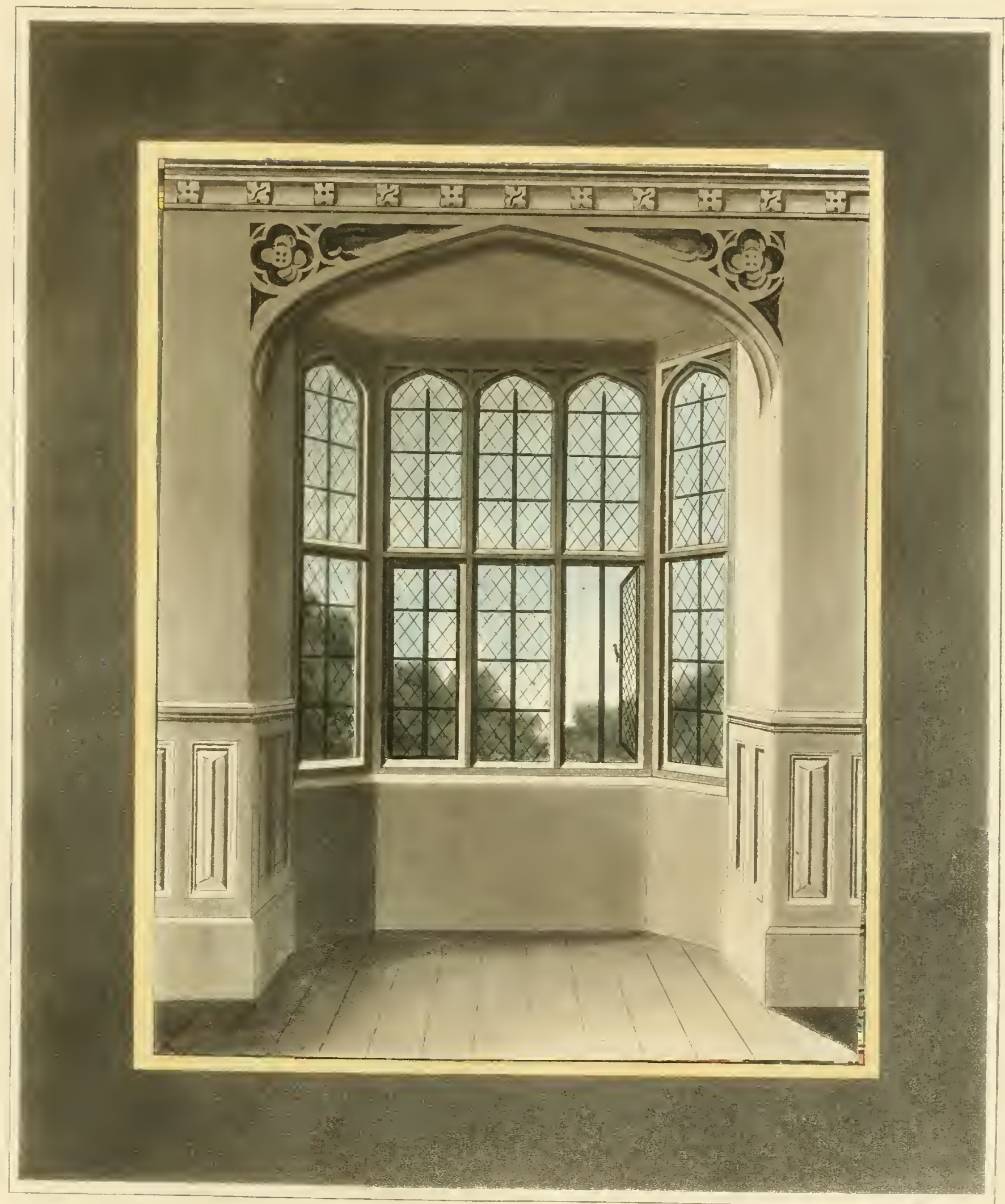

WINT, OW AT BARNINGEAMT 




\section{FRAGMEN'T $\mathrm{X}$.}

\section{oN \\ GOTHIC OUTLINE.}

EXTRACTED FROM THE RED BOOK OF STANAGE PARK.

SITUATION.

BEFore I speak of the character of Stauage Park, it will be proper to consider its situation with respect to the neighbouring scenery; especially as the opposite opinions of two gentlemen* in its vicinity have produced that controversy, in which I have endeavoured to become a Moderator.

When I compare the picturesque scenery of Downton Vale with the meagre efforts of art, which are attributed to the school of Brown, I cannot wonder at the enthusiastic abhorrence which the author of The Landscape expresses for modern Gardening: especially as few parts of the kingdom present more specimens of bad taste than the road from Ludlow to Worcester, in passing over which I wrote the contents of this small volume. And while I was writing, surrounded by plan-

* So many years have now elapsed since the controversy betwixt Mr. Knight and Mr. Price on the subject of Landscape Gardening, that it may not be improper to mention, that the former gentleman published, in quarto, a Poem called The Landscape, and the latter a work in octavo on The Picturesque as distinct from the Sublime and Beautiful. 
tations of firs and larches and Lombardy poplars, I saw new red houses, with all the fanciful apertures of Venetian and pseudo-Gothic windows, which disgust the traveller, who looks in vain for the picturesque shapes and harmonious tints of former times.

In the wild scenery of Stanage Park, how discordant would appear the three Window-Bows of these modern scarlet sins against good taste; or how sprucely would glitter the whitewashed Villa from the neighbourhood of the capital! Yet some house must be erected, or the park becomes a forest, no longer adapted to the purposes of human habitation. This leads me to the consideration of the Character which it ought to assume.

\section{CHARACTER.}

The antiquity, the extent, and the beauty of this Park, together with the command of surrounding property, would justify very great expenditure in preserving the Character of the place: but it is the duty of the Professor to confine his plans within the limits prescribed by the person who consults him; and being in the present inslance restricted to one tenth of that expenditure, which a luxuriant fancy might suggest, I shall not indulge myself in describing what might be done; but rather propose such plans as, I trust, may be accomplished, within the bounds of good taste, restrained by prudence. I must therefore begin by inquiring what Character of House is best adapted to the scenery, since it cannot be a palace. It ought not to be a Villa; it ought not to be a Cottage; and for 
a Shooting Box for a single gentleman, the present rooms in the old house are sufficient; but it must be the residence of a family; and as it is at some distance from society, we must not only provide for the accommodation of its own family, in its various branches, but for the entertainment of other families in the neighbourhood, and for the reception of friends and visitors, who may come from the capital, or other distant parts. All this cannot be expected in a very small mansion. 'The most judicious mode of combating the difficulty, which prudence opposes to magnificence, will be to follow the example set at Downton, where the inside was first considered, and the outside afterwards made to conform to that, under the idea of a picturesque outline: but as the character of a Castle must depend on its dimensions, I dare not recommend that character, lest it be compared with the massive fragments of the ruins of Ludlow.

THE HOUSE.

After the literary controversy between Mr. Knight and me, I should be sorry to be misunderstood as casting any reflection on the Castle Character of Downton; for although perhaps some may think that its outline was directed by the eye of a Painter, rather than that of an Antiquary, yet its general effect must gratify the good taste of both: and I should have been happy to have shewn my assent to that style, in adopting the Castle Character for the House at Stanage; but this would exceed my prescribed limitation; and since we 
cannot imitate the ancient Baronial Castle, let us endeavour to restore that sort of importance, which formerly belonged to the old Manor House; where the proprietor resided among his tenants, not only to collect the rents, but to share the produce of his estate with his humble dependants; and where plenteous hospitality was not sacrificed to ostentatious refinements of luxury.

I do not mean to condemn the improvements in comfort and convenience enjoyed in modern society; nor to leave unprovided for, every accommodation suited to the present habits of life, but to furnish the means of enjoying them at Stanage, without departing from its original character; and this I propose doing by restoring, as far as possible, the same kind of Mansion, on the same identical site, taking for my model the character of the Grange, or old Manor Farm; which I trust will not be deemed incongruous with the surrounding scenery. But before I shew the present state of the site and the effect, I shall describe the internal arrangements of the additions proposed. The three following principles, however they may be at variance with each other, have all been considered in the plan here suggested, viz. 1st. Economy, 2d. Convenience, and 3d. a certain degree of Magnificence.* These are placed according to the respective weight each bears in my mind.

* I mean a certain degree of magnificence, when compared with a common Furm House. I could in this case have used the word licturesqueness; but that bears no relation to its importance, because the meanest objects may sometimes be deemed picturesque; but the extcrnal magnificence of a building will often depend on parts in- 

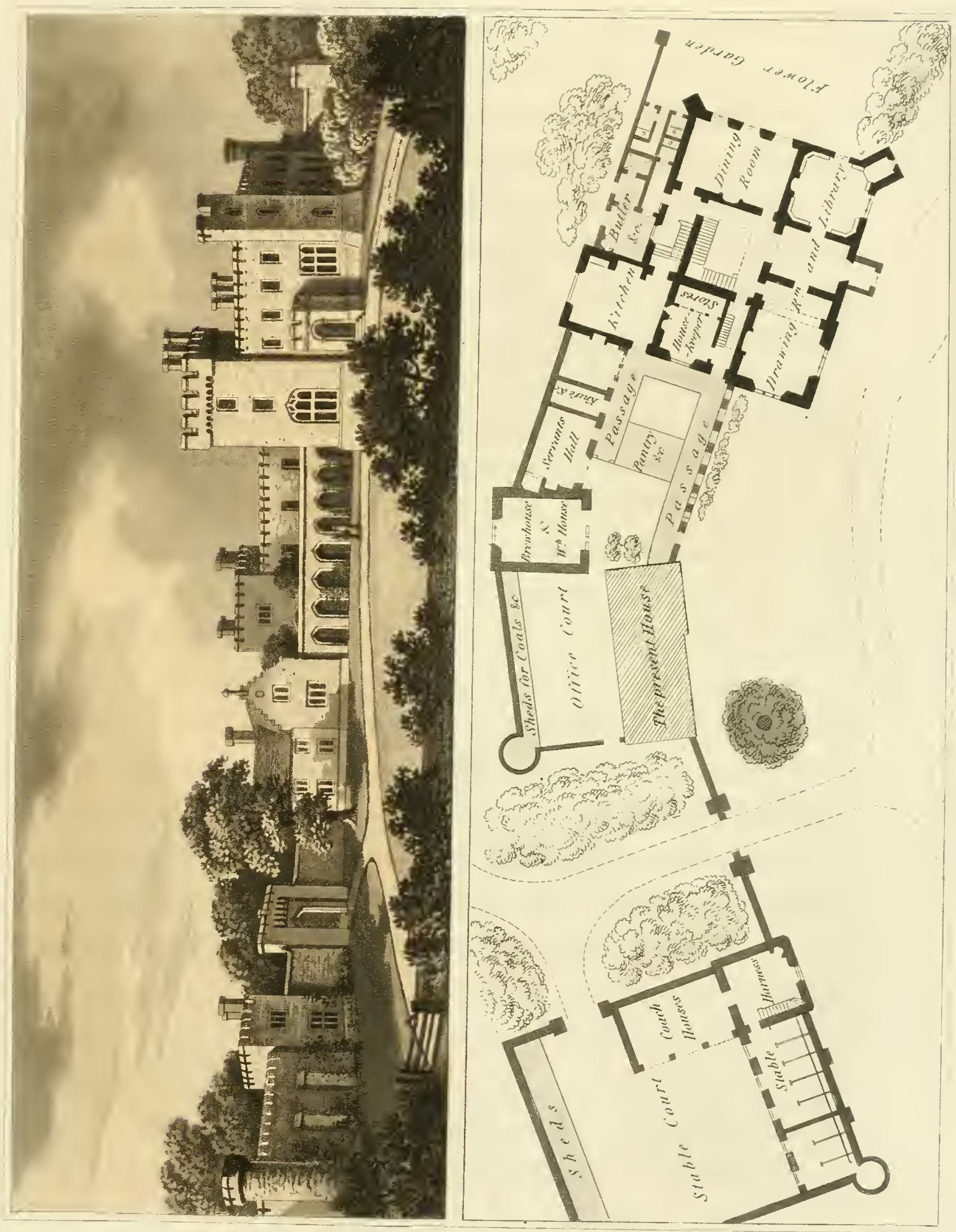

1st. Economy dictates, compressing within a compact and small extent, and preserving every thing which can be retained without alteration, however little it may be worth preserving: but as I prefer the old site of the house to any other in the Park, I see no occasion to take down for the sake of rebuilding.

gd. Convenience requires a certain number of rooms, of certain dimensions; and it will be found that those proposed are ample in size, varied in form, and connected without waste or redundance. The dining-room is detached from the drawing-room, which does away the objection of two immediately adjoining rooms, where conversation in either may be overheard. The drawing-room, which in a house of this date was called the parlour, may be fitted up with books, musical instruments, and card tables, to render it the general living room for the family, according to the modern habits of life, which explode the old absurd fashion of shutting up a large comfortless room, to starve the occasional visitors by damp sophas and bright steel grates. These two rooms, and the study, may be fifteen feet high: the approach to them by the passages and staircase will be sufficiently ample, without the extravagance of a large and lofty hall, to which much was sacrificed in old houses, because it was used as the dining-room on great occasions. *

tended rather for ormament than use, such as lofty Towers in Gothic, and Columns in Grecian Architecture.

* After this house was built, an alteration was made, in conformity to my original wishes; that the entrance Lobby should be changed to an Anti-room; and the real entrance made in the cloisters or passage connecting the old and new buildings. 
In the chamber plan, provision is made for bed-rooms of various sizes, with closets, but not very large dressing-rooms; and the number of bed-rooms, including those in the present old building, and some in the roof over the new part, will be sufficient for all the purposes of convenience or magnificence, as far as the first leading prineiple of economy will allow. But should it hereafter be deemed advisable to extend the plan, a provision may be made in the wall to the north (by changing the position of the butler's pantry, \&c.) to communicate with a billiard-room, library, or any other rooms which may be required.

The offices contain every thing necessary to a house of this kind, connected with each other by passages of communication, with sufficient cellars, \&c.

\section{GROUND ABOUT TIIE HOUSE.}

It may perhaps be observed by the trim imitators of Brown's defects, that the stables, barns, gardens, and other appendages, ought to be removed to a distance. I have, in my former volume, endeavoured to shew the folly of expecting importance in buildings without extent of appendages; and the absurdity of banishing to a distance those objects which are necessary to the comfort of a country residence. There is one point on which I believe iny opinion may differ from the theory of the ingenious Author of The Landscape; at least so far as I have been told he has endeavoured to reduce it to practice near the house at Downton. I fully agree with him in condemning that 
bald and insipid custom, introduced by Brown, of surrounding a house by a naked grass field: but to remedy this by slovenly neglect, or by studied and affected rudeness, seems to be an opposite extreme not less offensive. A house is an artificial object, and the ground immediately contiguous may partake of the same artificial character. In this place, therefore, straight lines of garden walls and walks are advisable, together with such management, as may form the greatest possible contrast with that rude character, which should every where else prevail at Stanage; for when we cannot assimilate, we must produce effects by contrast, still preserving that character which we attempt to restore: and while I thus draw the bold straight line between Art and Nature, in defiance of the scoff of ignorance, and the vanity of fashion, I may respect the errors of prejudice, or the excess of enthusiasm. 


\section{FRAGMENT XI.}

\section{B E A U D E S R T.}

\section{FX'TRAC'T FROM 'IIIE RED BOOK OF BEAUDESERT'.}

CHARACIER AXD SITUATION.

To lay down a rational plan for the improvement of any place, we must begin by considering its Character and Situation.

The very name of this place should have some influence on the mode of treating it. Great command of territory would of itself suggest, that a Character of Greatness, insomuch as relates to Art, should accord with that degree of vastness, which is the prerogative of Nature only: at the same time there is no error so common as the mistaking greatness of dimensions for greatness of character: and this is no where better exemplified than in the Pictures of the date of Louis XIV, when a great General was represented in a great wig, with a great pair of jack boots: the truth is, that great and small are only so by comparison. This fact it is the more necessary to establish, because it has been asserted, that every thing at Beaudesert must be on a large scale, to correspond with the large scale of its domain; while I contend, that every thing should be rather great than large.

A large massive pile, worthy of the rank and antiquity of its possessors, has been placed on the verge of the forest, a royal 
demesne and free warren, with paramount rights over the surrounding country: but, though built in a forest, it is evident, from its name and style, that it was not meant to be situated in a desert, the haunt only of wild beasts: on the contrary, it was to be a desert beautified-un-becu-desert; rendered habitable, with all the elegance, magnificence, and comfort, of which it was capable. We must therefore look back to the reign of Henry VIII, when this mansion was presented to the family. It was at that time surrounded, not only by the wild scenery of the forest, but by the animals which then made forests terrible; such as stags, boars, and wild cattle: to which might perhaps be added the uncivilized human beings, against whom some decided line of defence was absolutely necessary. This was the origin of those court-yards and lofty terrace-walls observable in old pictures of places of this date: so few of these now actually remain in our modern days, that I rejoice to find it the wish of the noble Proprietor of this noble pile to restore its pristine character; and if we are to retain any part of the grandeur of the Mansion, we must not surrender its outworks. Although the same motive for defence no longer exists, yet the semblance must be preserved, to mark the limits betwixt the gardens or pleasure grounds, which belong to man; and the forest or desert, which belongs to the wild denizens of the chace.*

* In the architectural arrangement of such parts of the following plan, as require a knowledge of ancient forms, I am happy to have the advantage and assistance of my ingenious friend, John Shaw, Esq. 
THE SITUATION.

It may perhaps appear presumptuous in me to assert, that the natural beauties of the situation of Beaudesert are very little known, even to those who are best acquainted with the spot: yet I will venture to assert, that those beauties which are at present hidden, and almost totally lost, far exceed those which are obvious to every eye. The materials by which Nature produces the chief beauties of Landscape are four in number, viz. Inequality of Ground, Rocks, Water, and Wood: yet at Beaudesert it is only the latter which abounds, and to which the other three have all been sacrificed. Inequality of ground is apt to be obliterated by trees, which grow taller in the valleys than on the hills; and consequently the surface of a wood, and the surface of the ground on which it grows, are often very different; but at Beaudesert this levelling principle of vegetable growth has actually almost effaced the ravines, where tall ashes in the bottom rise above the oaks on the steep acelivities.

Surface of Wood.

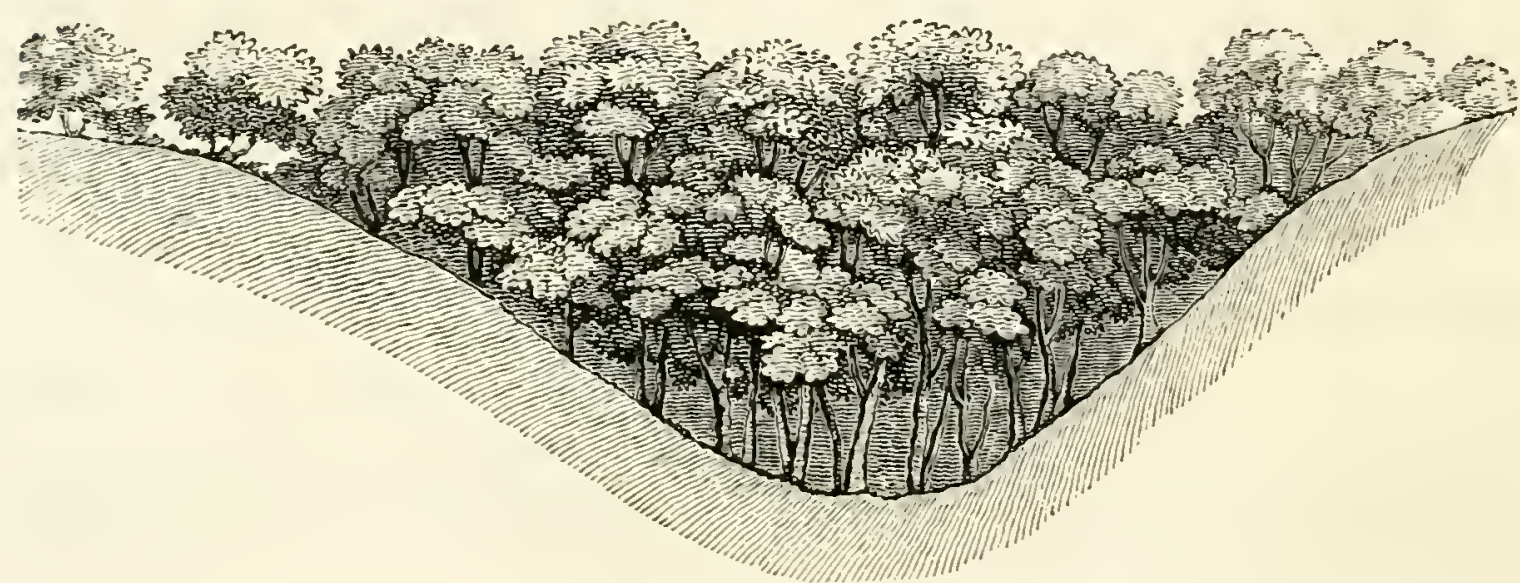

Surface of Ground. 
Wherever a natural glen or ravine exists, we shall generally find rock or water, or both, under the surface; and we know that they abound in the deep dell immediately in front of the house, although at present they are hardly visible, being buried under the surface.

The following sketch will serve to display the capabilities of this place, and discover the true situation of Beaudesert in such a manner, as may induce those, who only view the present visible state, to say, "Quam multa vident pictores in umbris et " in eminentiis quæ nos non videmus." To bring these hidden beauties into notice, the process is very simple: remove the tall trees in the bottom, prevent the water from burying itself in the ground, by stopping the current of the different streamlets with ledges of large stones, wherever the natural channel is narrowest, make every drop of water visible on a hard surface, and yet let the whole appear the work of Nature, and not of Art.

CONCERNING THE TREES, VIEW TO THE NORTH.

As much of the improvement of Beaudesert will depend on the judicious removal of certain large trees, which have outgrown their relative situations, I will defend myself from that clamour which he must expect who dares presume to advise the felling of large trees. After forty years acquaintance with the subject, I now an frequently told, as if unconscious of such truisms, that "a large tree has been a long time growing," and also " that, when cut down, it cannot be put up again:" but there 
are situations, and very many of them at Beaudesert, where one tree conceals a wood, and where the removal of half a dozen will shew a thousand others. In winter we may see through their branches objects totally invisible in summer, when a single tree becomes a skreen as impenetrable as a wall. I therefore availed myself of this semitransparent state of Beaudesert, to shew some effects by sketches, which were taken when the trees were leafless, although I have supposed them in their full foliage: [these sketches have not been engraved.]

THE WATER.

It has been said of Beaudesert, that it is on so vast a scale, that nothing less than an arm of the sea can be adequate to the greatness of the place. This remark, however ingenious, is not sufficiently precise; because, as before observed, greatness of dimension does not confer greatness of character; and if a reach of the "smug and silver Trent" were visible in the grounds of Beaudesert, we should not object to it, because it was not equal to the Straits of Menai.*

There can be no doubt, that any glitter of water visible in the bottom would be the most desirable feature that could be suggested, to increase the beauty of the scenery: and it fortunately happens, that a number of streamlets all unite near the

* On the banks of these straits, in the Isle of Anglesea, stands Plas Newyd, another seat belonging to the noble proprictor of Beaudesert, and therefore often compared with it, although their characters are quite opposite. 
water-meadow, which by a dam would form a lake of such shape, that it would appear quite large enough for its situation; because its size would be indefinite, the natural shape of the ground favouring the concealment of its terminations. This river-like pool or meer would be a cheerful object from every point of view, and an appropriate boundary to the park towards the east; since water is always supposed to be the most natural line of separation betwixt the lawn and arable land. On the banks of this water, a spot might be found for such a garden as would accord with the character of the house; and by its situation with respect to the house and the water, the most delightful walks of communication might be made, to increase the comfort of the place, while they displayed its interesting features to advantage.

The following sketch shews the manner in which the house has been opened by the removal of tall trees in that rocky dell, through which two streams of water now flow invisibly, because buried in a deep channel amongst the brushwood. This water may easily be brought into sight, and the meadow may be converted into a lake, from whence this sketch is supposed to be taken. It also represents a part of that new kitchen garden and fruit garden already mentioned.

Having been permitted to make these extracts from my report of Beaudesert, I will add two fragments from the same MS. one respecting Planting, and the other relating to ancient Interiors and Uniformity of Character. 
Some additional planting may be advisable at Beaudesert; although I will confess that I have never seen a place in which it is less absolutely necessary. In the vast range of chace and forest attached to the place, a wood of fifty acres would appear a clump, if the whole of its outline could be discerned from any elevated station: and to fringe the summit of the hill with that meagre deformity called a belt, would disgrace the character of this wild scenery, especially if such belt were composed of spiral spruce firs and larches, according to the modern fashion of making plantations. It has always appeared to me, that the miserable consideration of trade has introduced these quick growing trees, to make a speedy return of profit: but if the improvement of such places as Beaudesert is to be computed by the rule of pounds, shillings, and pence, it would certainly be better to cut down all the trees, kill the deer, and plough up the park. Very different is my notion of the principle of improvement; and therefore, instead of the conic shaped trees, which so ill accord with an English forest, and belong rather to Norway or the Highlands of Scotland, let the staple of our plantations be oak and Spanish chesnut; let the copse be hornbeam and hazel, and let the trees used as nurses be birch: but, above all, let there be at least five or six thorns and hollies for every tree that is planted; these will grow up with the trees, perhaps choke and destroy 
some, but they will rear many, and in a few years will become an impenetrable thicket, as a cover for game, and a harbour for deer, when the temporary fences will be no longer necessary.

'The internal arrangement of houses has undergone great change since this mansion was first erected. Formerly the great hall at Beaudesert was always used as a dining-room; and there cannot be a better room for that purpose : indeed it would be a violation of all archæological good taste to dine in any other. I would therefore consider the new room to the east as a music or drawing-room, to be used en suite with that venerable gallery of magnificence and comfort, now transformed into the library; and the great hall will then be the rendezvous for breakfasts and dinners, having immediate access to the pleasure ground on the same level; and as it will be advisable to exclude all view to the south by means of stained glass, it is more necessary to attend to the improvement of the view towards the west: this has already been begun, by cutting down some very tall trees, which not only prevented the eye from looking up the rocky ravine or dell, but also excluded the light of the sky, which now sheds its cheerfulness on many valuable Portraits of those Worthies, who in remote times graced the banquets of this room with their presence, and now add dignity to their noble descendants, by still holding a place in the mansion of an ancient family. 
This view is confined to the private front of the mansion, and is appropriated to the family apartments.

'To those who despise every thing they call old fashioned, and who, supposing the perfection of Gardening to consist in waving lines, are apt to shrink from every thing straight or formal, this part of the plan for Beaudesert may give offence; but the renerable dignity of this place is not to be measured by the scale of a villa, or the spruce modern seat of sudden affluence, be-belted and be-clumped in the newest style of the modern taste of Landseape Gardening-No-rather let us go back to former times, when the lofty terraces of the prioy garden gave protection and seclusion to the noble persons, who with

" retired leisure,

"In trim gardens took their pleasure."

To this may be added, the modern luxury of hot-houses and conservatories, with all the agrèmens, which excite interest in the cultivation of every species of flower that can delight the eye by its colours, or gratify the smell by its perfumes: and it is no small satisfaction to have discovered from old labourers on the premises, that in the line of the terrace, and other parts of this artificial and architectural Garden, we are restoring the place to what they remember it in the beginning of the last century. 


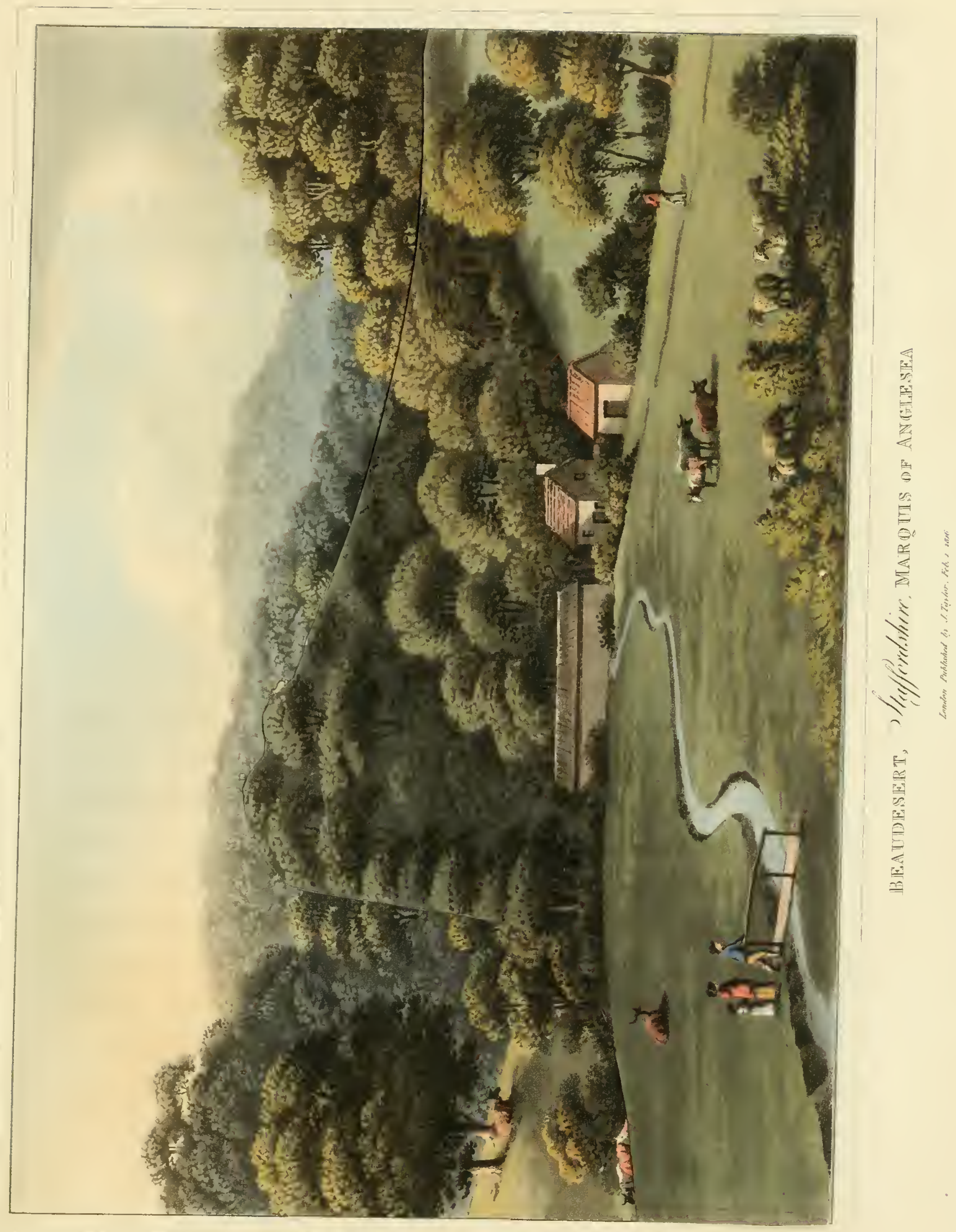





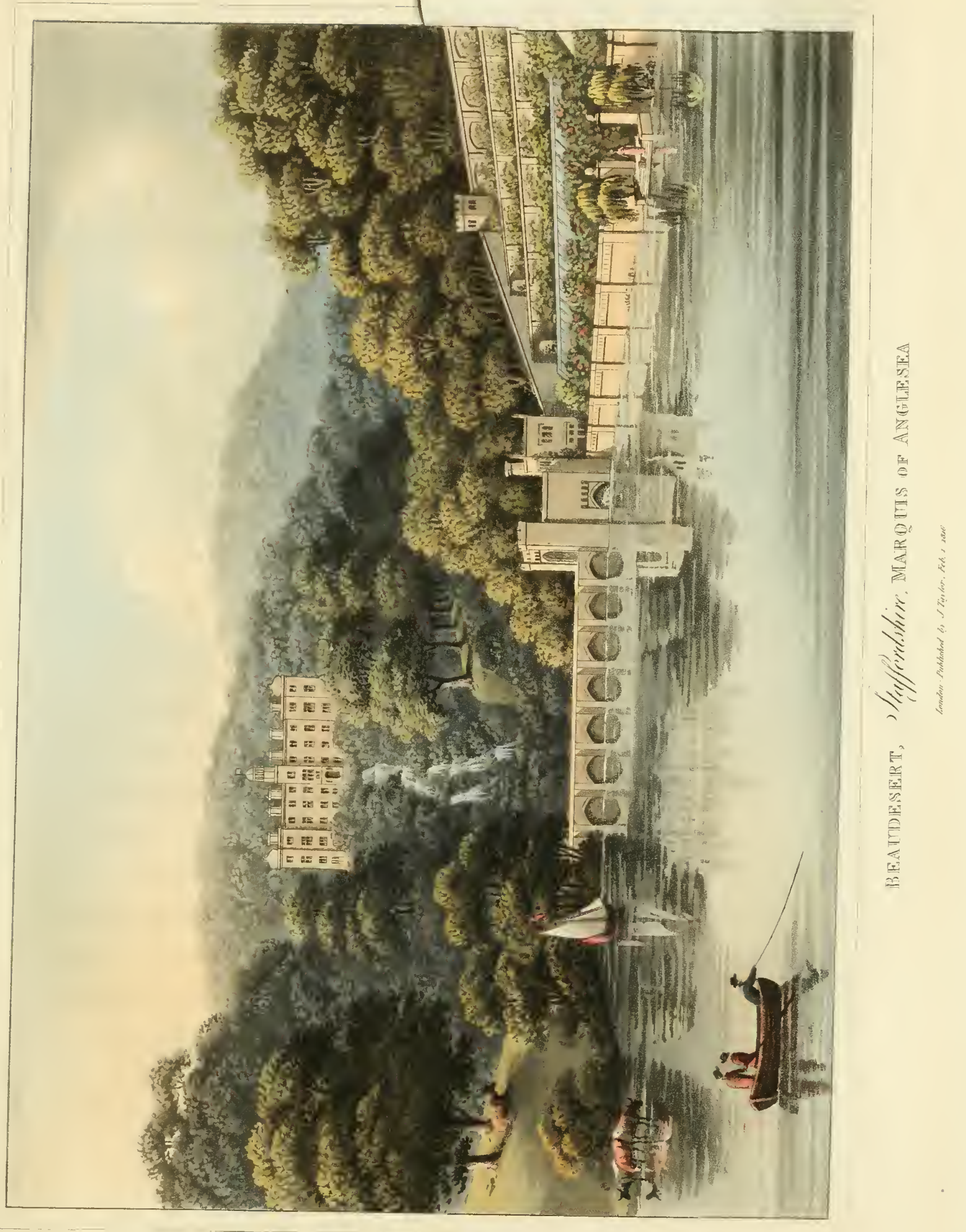





\section{FRAGMENT XII.}

\section{CONCERNING COLOURS.}

ADDRESSED TO WTLLIAM WILBERFORCE, ESQ. M.P.

SIR,

MAny years have elàpsed since you first called my attention to that Theory of Colours, which your learned friend, Dr. Milner, permitted me to publish in his own words in 1803. During this interval frequent opportunities have occurred to confirm the truth of his remarks.

Dr. Milner properly observes, that there are only three primary colours, red, blue, and yellow; although Sir Isaac Newton also mentions orange, green, indigo, and violet: but these are compounds of the other three; and whether in the rainbow, or the prism, they appear to melt gradually into each other; and I have always failed in every experiment to fix the precise limits of each tint; but in the course of some late investigations, I have accidentally discovered certain appearances, from which I have derived some facility in colouring Landscape.

Having placed a piece of dark cloth on a wall opposite to the light, I fastened a sheet of white paper in the middle of it; this I looked at through a prism held across my eyes a little above 
them, when I observed the paper look the curvature of a rainbow: from the upper edge proceeded shades of red-brown, terminating in yellow, and from the lower edge shades of grey, terminating in blue, as I have shewn at (C) in the annexed sketch. 'This I observed under various lights, and remarked, that before sun-rise no red appeared in the brown, and no violet in the grey shades; but they were exactly the same tints which 1 use in shading and finishing my sketches. I always use for my foregrounds a warm brown, and for my distances a cold grey, or neutral tint, and afterwards glaze over the whole with colour; and these two tints exactly coincide with those shewn at (C), where a broad mass of white appeared betwixt them. By gently turning the prism, I found that $I$ could contract this white space, as shewn at (B), and as the sun began to illumine the horizon, I perceived red in the upper edge, and violet in the lower, but no green appeared, till by gently turning the prism a little more, I brought the blue and yellow into contact, when the rainbow was completed in all its colours, as represented at (A). I then considered how I could avail myself of this discovery to facilitate the mechanical process of printing and colouring many thousand plates, to make a fac-simile of my sketches: this I shall endeavour to explain by the annexed two Landscapes, which are supposed to represent the same scene before and after sun-rise; that is, before and after the natural process of colouring takes place. The twilight scene is finished with the two neutral tints, and a harmonizing wash thrown over the whole; the other is also 

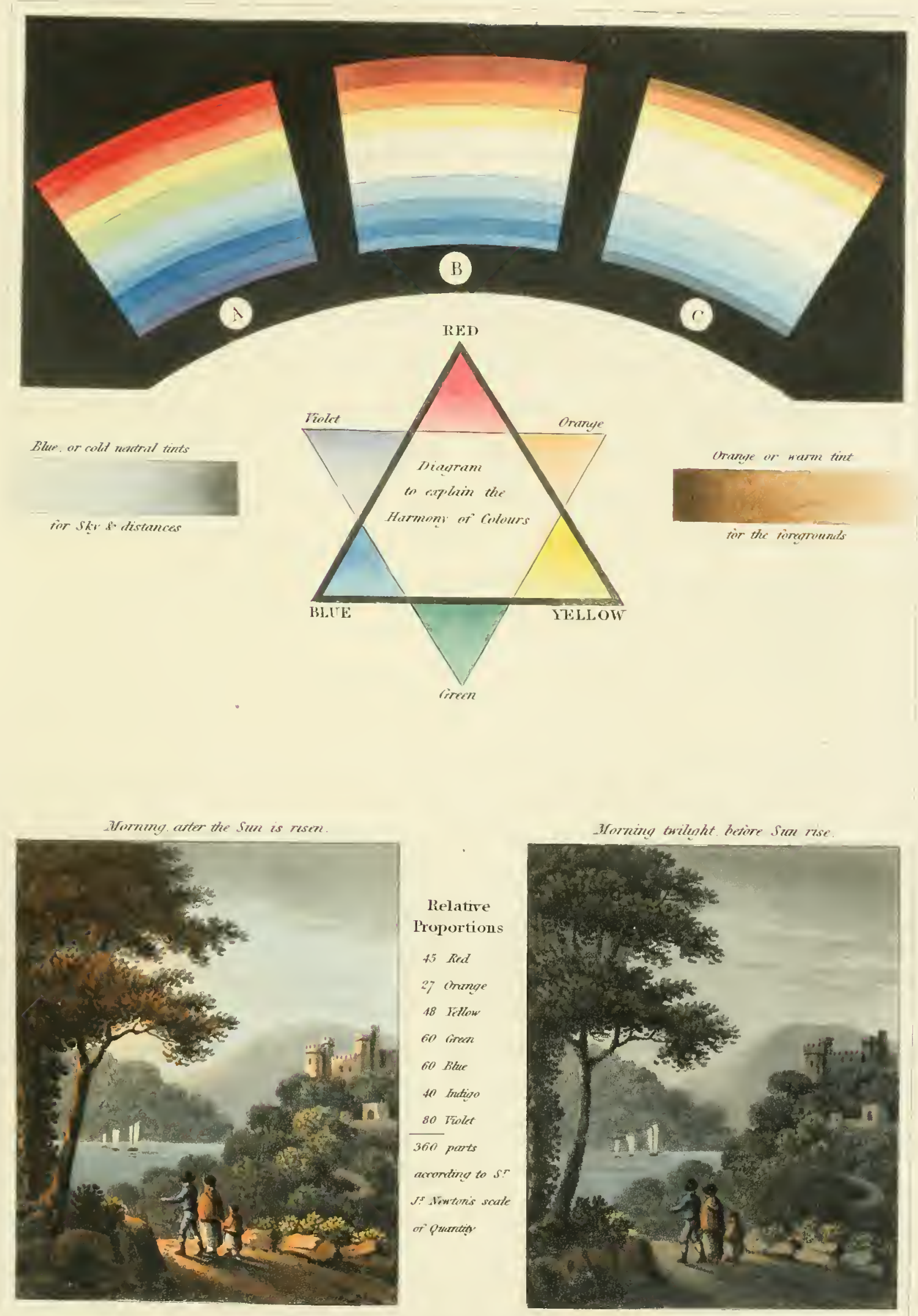

finished with the same two neutral tints, and afterwards washed or glazed over with the colours, in the order described in the diagram, beginning with red, then orange and yellow, in the foreground, with blue and violet for the sky and distances. By this process, in the middle of the picture green will prevail, partaking more of yellow near to, and more of blue as it recedes from the eye; still bearing in mind that all objects will partake of their natural colour: thus a red cloak must be red, and a green tree must be green, till its distance, or the intervening mass of vapour (called aerial perspective) takes away colour, and blends it with the neutral tint.

As the Plates in my former work employed a great number of women and children in colouring them, I expect to render the process much more easy in this present work, by the following instructions given to the printer and colourer.

"The Plates to be printed in a bluish-grey ink (this is the " neutral tint for the light and shade of the Landscape); the "colourer to wash in the sky with blue or violet, \&c. accord" ing to each sketch; also going over the distances with the same " colour; then wash the foregrounds and middle distances with "red, orange, or yellow, copying the drawings; and when dry, "wash over with blue, to produce the greens in the middle dis"tances: this being done as a dead colouring, a few touches " with the hand of the master, and a harmonizing tint to soften " the whole, will produce all the effect expected from a co"loured print." 


\section{FRAGMENT XIII.}

\section{CONCERNING INTERIORS.}

Whatever the style of the exterior may be, the interior of a house should be adapted to the uses of the inhabitants; and whether the house be Grecian or Gothic, large or small, it will require nearly the same rooms for the present habits of life, viz. a dining-room, and two others, one of which may be called a drawing-room, and the other the book-room, if small, or the library, if large: to these is sometimes added a breakfast-room, but of late, especially since the central hall, or vestibule, has been in some degree given up, these rooms have been opened into each other, en suite, by large folding doors; and the effect of this enfilade, or visto, through a moderu house, is occasionally increased by a conservatory at one end, and repeated by a large mirror at the opposite end.*

* Where there are two or more rooms, with an anti-room, it is always better not to let the dining-room open en suite. These rooms may be called libraries, saloons, music-rooms, or breakfast-rooms: but in fict they form one large space, when laid together, which is more properly denominated the living-room, since the useless drawing-room is no longer retained, except by those who venerate the cedar parlour of former days. 
The position of looking glasses, with respect to the light and cheerfulness of rooms, was not well understood in England during the last century, although on the Continent the effect of large mirrors had long been studied in certain palaces: great advantage was in some cases taken by placing them obliquely, and in others by placing them opposite: thus new scenes and unexpected effects were often introduced.

A circumstance occurring by accident has led me to avail myself in many cases of a similar expedient. Having directed a Conservatory to be built along a south wall, in a house near Bristol, I was surprized to find that its whole length appeared from the end of the passage in a very different position to that I had proposed: but on examination I found that a large looking glass, intended for the salon (which was not quite finished to receive it) had been accidentally placed in the green-house, at an angle of forty-five degrees, shewing the conservatory in this manner: and I have since made occasional use of mirrors so placed to introduce views of scenery which could not otherwise be visible from a particular point of view. But of all the improvements in modern luxury, whether belonging to the Architect's or Landscape Gardener's department, none is more delightful than the connection of living-rooms with a green-house or conservatory; although they should always be separated by a small lobby, to prevent the damp and smell of earth; and when a continned covered way extends from the house to objects at some distance, like that at Woburn, it produces a degree of comfort, delight, and beauty, which in every garden ought, more or less, to be 
provided: since there are many days in the year when a walk covered over head, and open on the side to the shrubbery, may be considered as one of the greatest improvements in modern gardens.

It would be endless to describe the varions methods of attaching such covered passages to a house; and without a plan, as well as drawings, it would be impossible to render the subject intelligible.

To make a house in the country perfect, we must consider in what it principally differs from a honse in London: and it is to the inconsistency, I might almost say the folly and vanity, of transplanting cily costumes and fashions into the retirement of rural life, that much bad taste may be ascribed. Some remarks on this subject may not be misplaced, where the comfort, convenience, and elegance of habitation, are to be considered.

First, In magnificent town houses we expect a suite of rooms, opening by folding doors, for the reception of those large parties for assemblies, when the proprietors are driven out of house and home, to make room for more visitors than their rooms can contain. A provision in the country for such an overflow of society can seldom be required; and except for an occasional ball, the relative dimensions of the rooms should bear some proportion to the size of the dining-room, and the number of spare bed-rooms. The most recent modern costume is, to use the library as the general living-room; and that sort of state-room, formerly called the best parlour, and of late years the drawingroom, is now generally found a melancholy apartment, when 
entirely shut up, and only opened to give the visitors a formal cold reception: but if such a room opens into one adjoining, and the two are fitted up with the same carpet, curtains, Sc. they then become in some degree one room; and the comfort of that which has books, or musical instruments, is extended in its space to that which has only sophas, chairs, and cardtables; and thus the living-room is increased in dimensions, when required, with a power of keeping a certain portion detached, and not always used for common purposes.

Secondly, In town houses, the principal rooms for company are generally on the furst floor, and consequently the staircase leading to them requires a correspondent degree of importance; but in the comntry it is generally more desirable to have the principal rooms on the ground floor, and consequently the staircase leading only to the bed-rooms does not require to be displayed with the same degree of importance as that of a town house.

Thirdly, We often hear objections to a Cross-light in a room, from those who take up their opinion on hearsay, without thinking for themselves, or from having observed in a town house, at the corner of a street, the troublesome effect from noise and from the thorough light, rendering the room too public to the street and to the opposite houses. This, hovever, in the country, is totally different, where an additional window gives new landscapes and new aspects. If the room be lighted from the end by two windows, it will leave the opposite end of the room dark and dull; while a window or glazed aperture (at $A$ ) 
opening into a verandah or green-house will give cheerfulness, unattended by the objections mentioned in a town house, and consequently due advantages should be taken of it.

Fourthly, The position of the windows and doors very much contribute to the comfort and cheerfulness of a room, and require very different management in town and country.
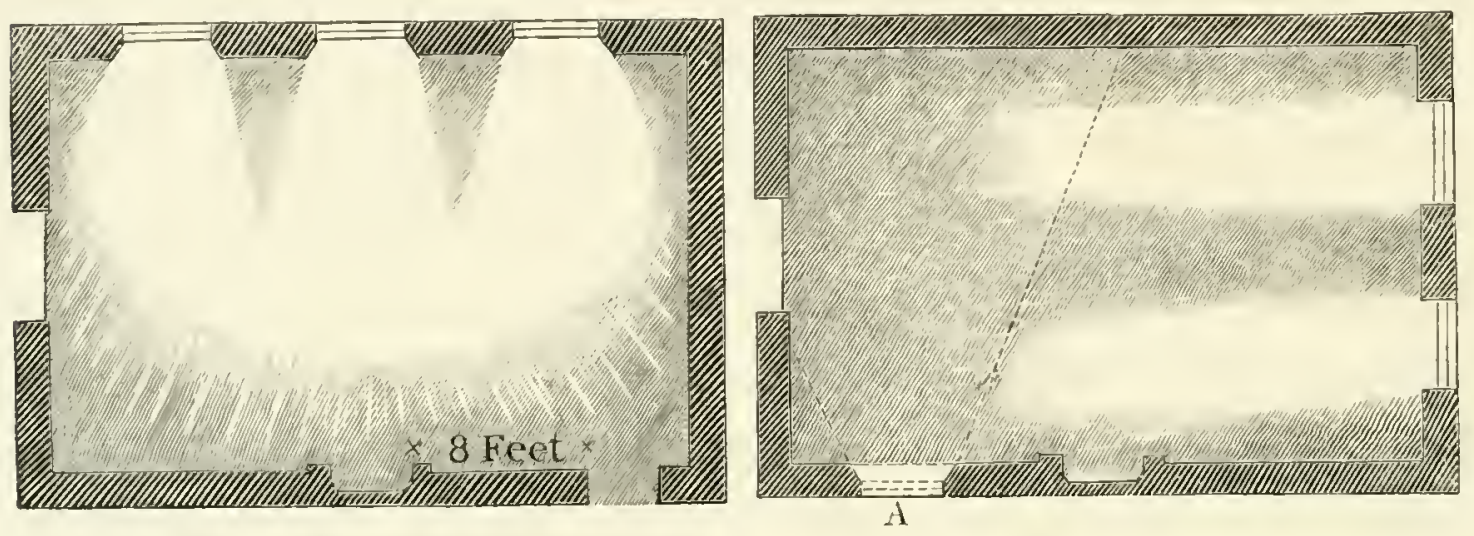

A room longer than it is wide will be best lighted by three sashes in the long side opposite to the fire-place, becanse the light is more generally spread over the whole area, and a looking-glass over the chimney will increase the light, and double the landscape in the country; but in a town-house, where such rooms are more frequently used by candle light, the lookinggliss may be placed betwixt the piers, as the light from the lustres and girandoles will be increased by mirrors so placed; and if the windows be at the end of a long room, which is often necessary in town-houses, the light of candles will be more central, by being reflected from a mirror betwixt wo such windows; but in the country, the daylight is to be studied, and this will be found very defective in a tong room lighted by 
two windows at the farther end; because the central pier will extend its increasing shadow till it casts a gloom over the dark end of the room. In such cases the cross-light will be found a most enlivening remedy to the dulness of a room, or, I might rather say, to one so darkened by a central pier, which, if it contains a looking-glass, will increase the gloom, by reflecting the dark end of the room.

Fifthly, The favourite proportion for a room is asserted to be, the breadth to the length as two to three, or nearly in that proportion: hence a room twenty feet wide is to be thirty feet long; and twenty-four wide to be thirty-six long; and so in proportion, till it reaches any width and length. But when the dimensions are contracted, we must recollect that a certain space betwixt the door and the fire-place ought to be preserved; and therefore $I$ have found it expedient, in small houses, to give more space, by placing the chimney at a proper distance, and forming a new centre to the room, as explained in this diagram.
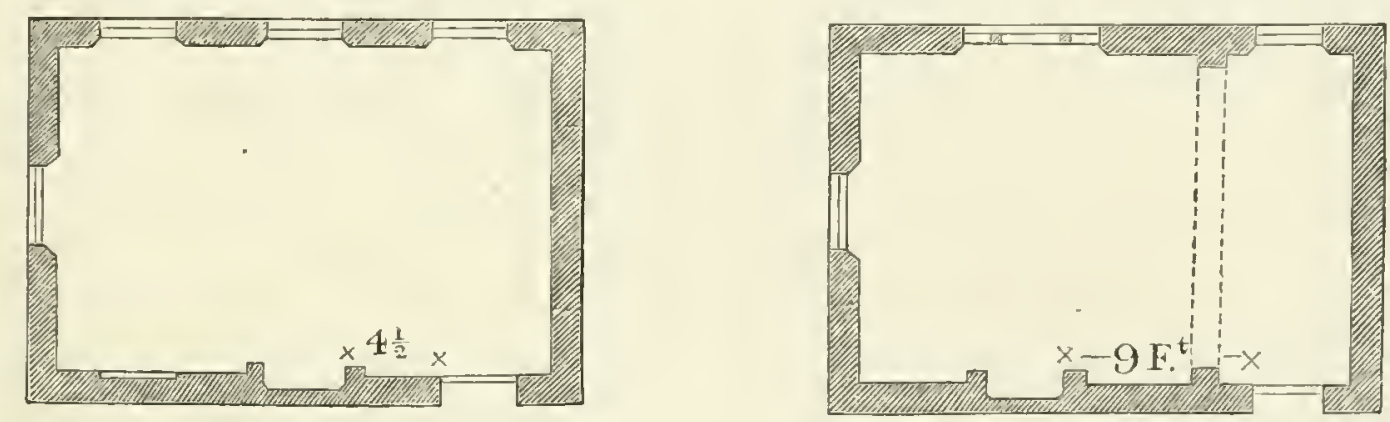

Since the chief object of this collection of Fragments is to bring before the eye those changes or improvements, which words alone will not sufliciently explain, two sketches are introduced, to shew the contrast betwixt the ancicnt cedar parlour 
and the modern living room: but as no drawing can describe those comforts enjoyed in the latter, or the silent gloom of the former, perhaps the annexed lines may be allowed to come in aid of the attempt to delineate both.

\section{A MODERN LIVING-ROOM.}

No more the Cedar Parlour's formal gloom

With dulness chills, 'tis now the Living Room;

Where Guests, to whim, or taste, or fancy true,

Scatter'd in groups, their different plans pursue.

Here Politicians eagerly relate

The last day's news, or the last night's debate,

And there a Lover's conquer'd by Check-mate.

Here books of poetry and books of prints

Furnish aspiring Artists with new hints;

Flow'rs, landscapes, figures, cram'd in one portfolio,

There blend discordant tints to form an olio.

While discords twanging from the half-tun'd harp,

Make dulness cheerful, changing flat to sharp.

Here, 'midst exotic plants, the curious maid

Of Greek and Latin seems no more afraid.

There lounging Beaux and Belles enjoy their folly,

Nor less enjoying learned melancholy.

Silent midst crowds the Doctor here looks big,

Wrap'd in his own importance and his wig. 


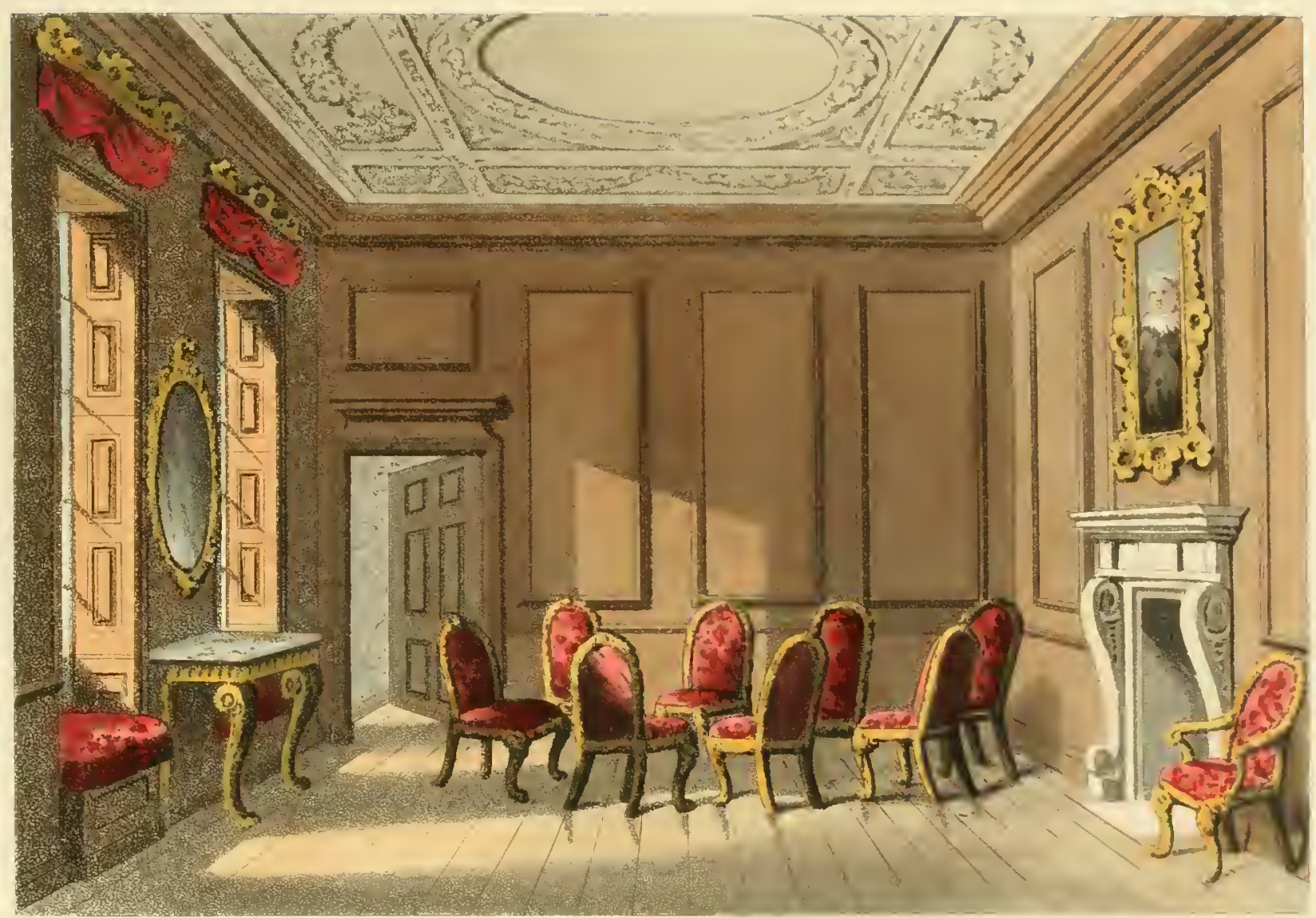

II $\mathbb{N} \mathbb{T} I \mathbb{R} S$

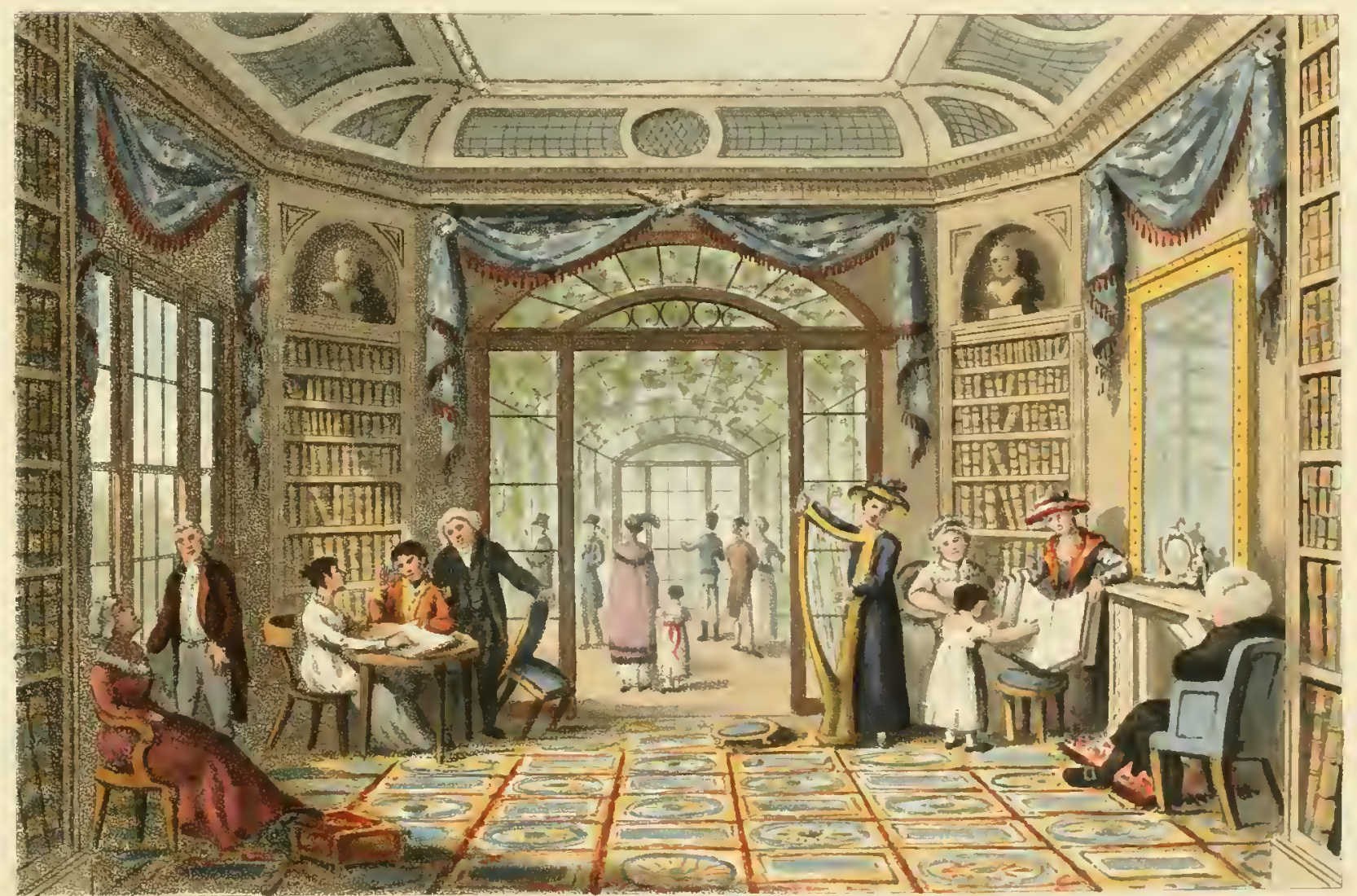





\section{FRAGMENT XIV.}

\section{W I N GERW OR T H.}

\section{EXTRACT FROM 'THE RED BOOK OF WINGERWORTH, IN DERBYSHIRE,}

A SEAT OF SIR WINDSOR HUNLOCK, BART.

CHAPACTER AND SITUATION.

The elevated situation of the House, on one of those broad hills peculiar to the most picturesque county in England, would alone stamp the character of importance on the place, in whatever style the house might have been built; for where we see a large pile of building on the summit of the hill, we are naturally led to compare its relative importance with the scenery to which it belongs. And here we shall be surprised, on approaching the mansion, to find it so much larger, richer, and more dignified, than it appears from a distance: the reason is, that the mansion is one square mass, almost a cube, and every building which partakes of this form, however great its proportions, always appears less than it really is, because the eye is not attracted either by its length, depth, or height, each being nearly equal: and it is only from a subordinate building placed near it, that we form any idea of its real magnitude.

The House at Wingerworth is one of those magnificent piles 
which were copied from the modern palaces of France and Italy, before our more fistidions Arehitects had discovered the remains of ancient Greece, and applied the Peristyle and the Portico of a Grecian 'Temple, without any windows, to a dwelling-house in England, requiring more than a hundred such useful apertures. But the true admirer of pure Grecian Arehitecture is apt to forget the diflerence betwixt the Hypæthral Temple without a roof, and the English Mansion, not habitable without doors and windows and chimneys.

It is with a combined view to utility and magnificence, that we must look at Wingerworth Iall; and however it may be necessary to alter its interior, in compliance with the change in modern habits of life, I should regret any alteration in the stately appearance of its exterior; on the contrary, it will be found, that what I shall suggest will increase, rather than diminish, its imposing character as a Palace.

VIEW FROM THE HOUSE.

If there were any rooms to the north, and if it were desirable to open the view in that direction, by removing the stables, \&c. it would be purchasing a landscape at the expense of all comfort, by opening to the north winds. It is therefore obvious that the stables can no where be better placed; and fortunately there are no rooms to the north to require such a sacrifice.

The view to the east is doubtless the leading object from this house, and to this great attention shonld be given. At present 
it is defective in two particulars; first, the ground falls in an inclined plane, and though the lawn is very deep, yet it is so fore-shortened to the eye, that very little of it is visible, and that part of it near the eye is dirty and unappropriate as a View from such apartments. This will be remedied by the terrace and dressed ground proposed. The distance, consisting of a rich valley, though bounded by the Palaces of Bolsover and Hardwicke in the horizon, wants marked and appropriated features. The smoke and the flame of a foundery attract our notice; but the eye would be more powerfully fixed by the expanse of water, which might be spread over the bottom, and by removing some trees, to do away the traces of those two rows that were at one time thought ornamental. The effect of such widely separated rows of trees was not like that of the ancient arenue, whose dark and solemn grandeur amply compensated for its artificial ranks: but this seems to have been a specimen of the power which Art might exert over Nature, by compel. ling trees to form lines, and take possession of a country far beyond the limits of the park or lawn belonging to the house; and of course such puerile attempts at mock importance are not worthy to be retained.

THE WATER.

It very rarely happens that an object of beauty or taste can also be made an object of profit; but at Wingerworth the same surface, covered by water, may be more profitable than the 
richest pasture, because it may be so managed as to admit of being occasionally drawn down two or three feet to supply canals, and other circumstances of advantage in this populous and commercial part of the kingdom; exclusive of the increased supply of fish, where such food is in constant requisition. For this reason $I$ do not hesitate in recommending the piece of water already mentioned, which forms so striking a feature in the view fiom the house, and of which the effect will not be less striking, when viewed from the ground near its shores.

The sketch will give some idea of this change in the scenery, although its appearance in reality will be far more striking than any representation of it by the pencil.

THE APPROACHES.

There is no part of the Art of Landscape Gardening in which so much absurdity has been displayed by the followers of Brown, as in the line of road, which should lead to the house: and because before his time every road was straight along an avenue to the front, and in the shortest line from the high road, it has been supposed that an approach is now perfect, in proportion to its curvature, and to its length: but good taste, which is only plain common sense, aided by observation, directs us to make the road as easy as possible, consistently with the shape of the grounds; and if one line shews more beauty and interest than another, to prefer it; and if it is not actually the nearest possible, to make it more natural and easy. 
For this reason I marked a line from the south, through the plantation, to shew the most interesting scenery of Wingerworth, when the lake shall be completed; and also to ascend the hill more gradually than by any other line.

\section{ENTRANCE FROM CHESTERFIELD.}

The line of this approach is not only too steep, but it is very naked and uninteresting. It may be made more easy by a little more curvature to ascend the hill, and direct the eye to some grass-land beyond the road, which will appear a continuation of the Park. The following Vignette will shew the eflect of the alteration in the road, and of placing a Lodge across the present line of road.

CONCLUSION.

It would be impossible to enumerate all the points in which new beanties might be elicited from the natural situation and circumstances of Wingerworth; it seems to have been unfortunately treated, in all that regards its pleasure-ground walks, as if it had been a Villa at Clapham, or a flat scene in Lincolnshire; but I will not advise the alteration of what has been so recently finished; I will rather turn my attention to the general eflect of the whole, and the improvement of its great features, leaving the lesser errors to outgrow and correct themselves.

The too hasty removal of hedges and masses of trees, in 



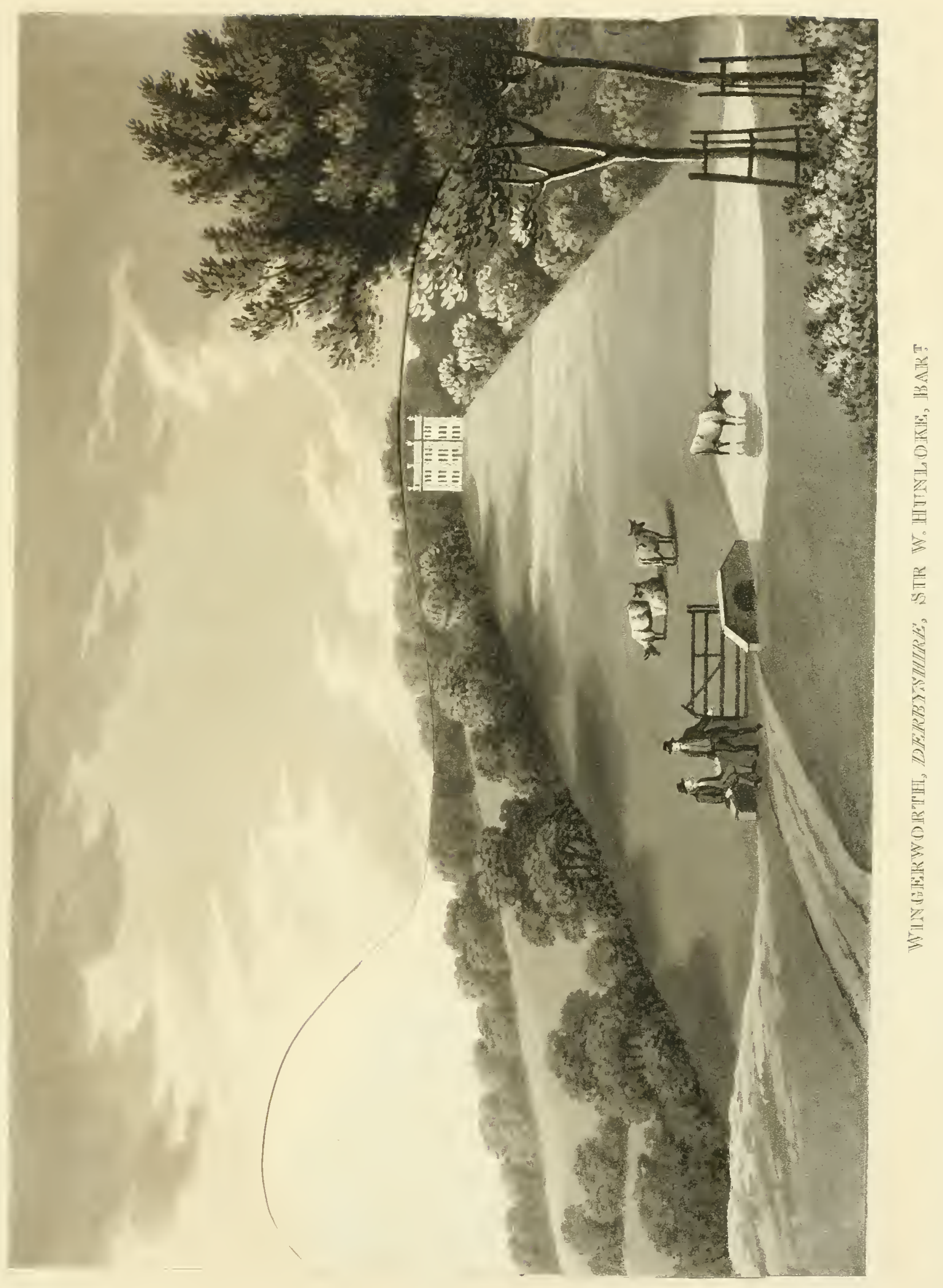





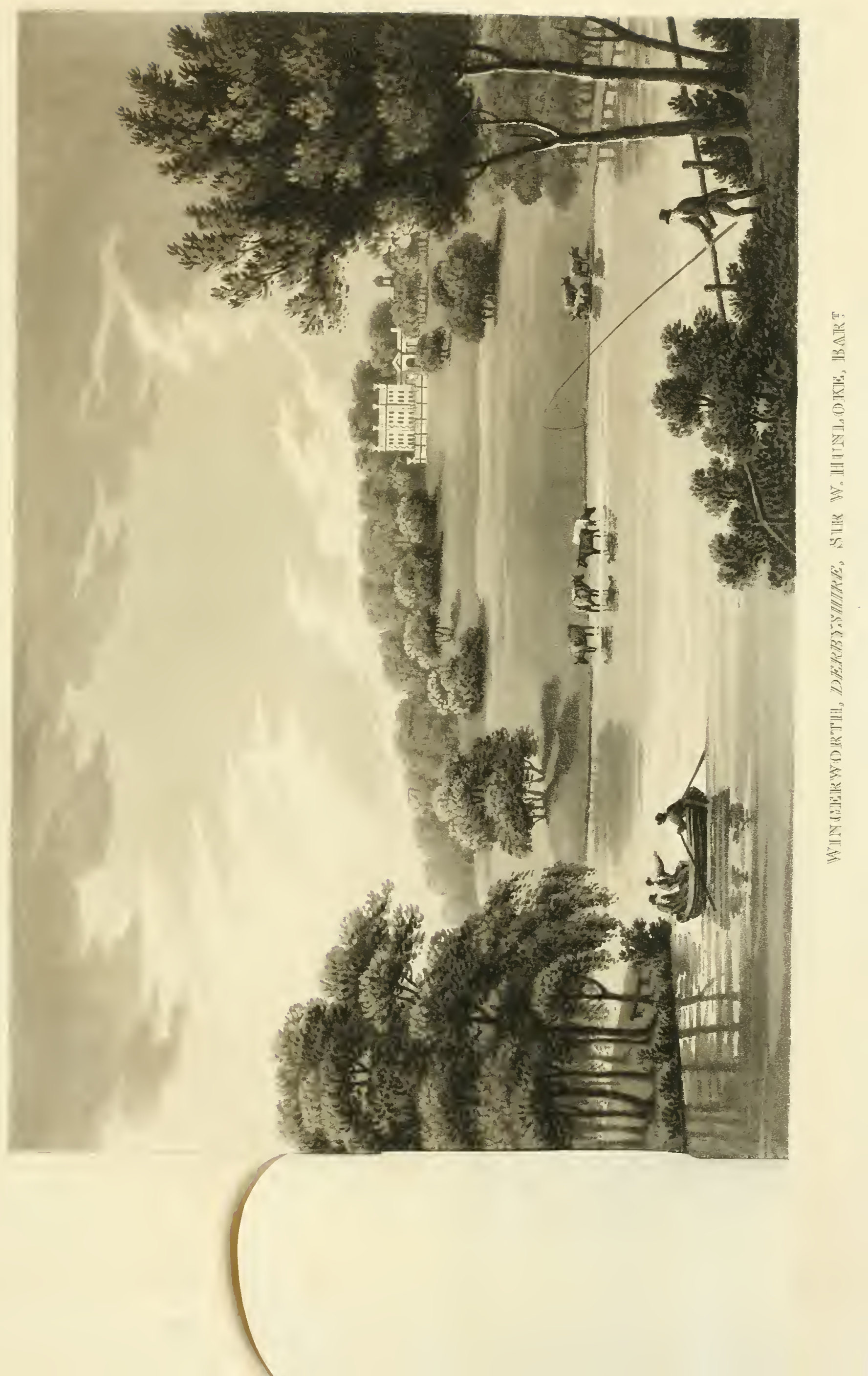





\section{FRAGMENT XV.}

\section{O N \\ PLANTING SINGLE TREES.}

TO TIIE RIGHT HON. LORD ERSKINE, \&c. \&c.

MY LORD,

Is answer to your Lordship's query, I will begin by stating it in your own words, because it is probable you have kept no copy of them, and I have no recollection of having made the remark you record, although I fully confirm it.

Your letter says, "I have followed your advice in the shel" ter given to my Cottage, withont sacrificing my prospect; and "you said very truly, that when a man is annoyed with sun, "wind, or dust, he puts his hand near his face, and does not "depend on distant shelter."

I then recommended you to plant only beech, and now you ask if there may be added a fer cedars of Lebanon, pineaster, and silver firs. This I must answer by the help of a sketch, to explain; what is so obvious when explained; that I consider it only as a proof that the most enlightened minds will sometimes hesitate on subjects which they have not studied with the eyes of a Painter and Landscape Gardener: the former sees things as they are, the latter as they will be. Indeed I have frequently observed that, in planting a tree, few persons consider the future 
growth or shape of different kinds. Thus the beech and the ash will admit of a view under their branches, or will admit of lower branches being cut; while the fir tribe and conic-shaped trees will not.

The annexed Landscape is composed of those materials, which may rather be called tame and beautiful, than romantic or picturesque. It consists of a river quietly winding through a valley; a tower on the summit of a wooded promontory, and a cottage at the foot of the hill; a distant village spire, and more distant hills, mark the course of the valley: to all this is added a foreground, consisting of two large trees to the left, and three small ones to the right.

The former can never be supposed to grow much larger, but the latter may in time fill the whole space now oceupied by the dark elond over them; and in so doing they will neither injure the Landscape, nor hide any of its leading features. Let me now direct the attention to the two small fir trees in the foreground, which appear so out of character with the scene, and so misplaced, that they offend even as they are here represented; but we must remember, that in a few years these trees will grow so high as to out-top the tower on the hill; and also spread out their side branches, till they meet, to the total exclusion of all the valley, and all that we admire in the Landscape.

Thus the hand which should only shade, will then be placed before the eyes; and the Landseape, as well as the sum, wind, and dust, would be better excluded by a Venetian blind at once. 
I have seldom known trees planted singly, or dotted on a lawn, with permanent good effect; because few who have planted such trees hare courage to lake them away after they have begun to grow: for this reason I have always asserted, that it is better to cut down a large tree, which actually impedes the view, than to plant a small one, which will very soon do the same thing.

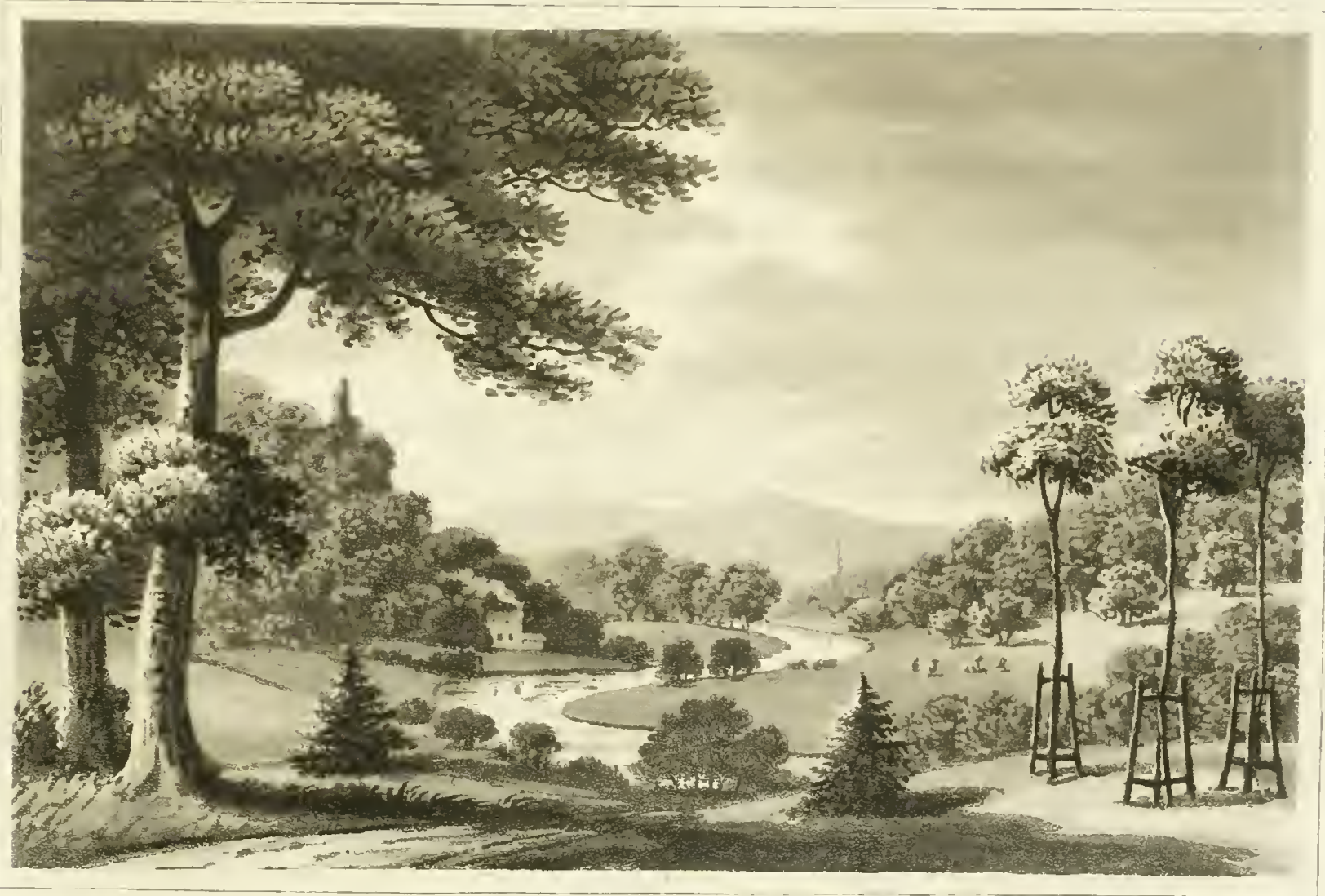

EFFET OF SINGHE TREFS 


\section{FRAGMENT XVI.}

\section{CONCERNING VILLAS.}

Ir has often been hinted to me, when called on for my opinion concerning places of small extent, that I can hardly be expected to give to them the same attention as to those of many hundred acres. My answer has generally been, that, on the contrary, they often require more attention than larger places. They may be compared to the miniature, with respect to the portrait large as life: the former requires to be more highly finished, but the likeness is the chief object; and this likeness in the picture may be compared in Landscape Gardening to that peculiar identity which adapts the place to the wants and wishes of the proprietor, and the character exclusively belonging to each. To pursue the simile one step further: if the nobleman will be painted as a mail coachman, or the plain country gentleman in the dress he wore at a masquerade, we shall look for the likeness in vain : so if the park be plowed and sown with corn, or a field of twenty acres affect to be a park, the art of Landscape Gardening becomes useless : it does not profess to improve the value of land, but its beauty: it does not profess to gratify vanity, by displaying great extent, but to extend comfort, as far as it is feasible; and, if possible, to incul- 
cate the great secret of true happiness- "Not to wish for more." It is not by adding field to field, or by taking away hedges, or by removing roads to a distance, that the character of a Villa is to be improved: it is by availing ourselves of every circumstance of interest or beauty within our reach, and by hiding such objects as cannot be viewed with pleasure: for I have often found, in places of the largest extent, that their principal views are annoyed by some patch of alien property, like Naboth's vineyard; some

"Angulus ille

— Qui nunc denormat agellum."

It seldom falls to the lot of the improver to be called upon for his opinion on places of great extent, and of vast range of unblended and uninterrupted property, like Longleate or Woburn: while in the neighbourhood of every city or manufacturing town, new places as villas are daily springing up, and these, with a few acres, require all the conveniences, comforts, and appendages, of larger and more sumptuous, if not more expensive places. And as these have of late had the greatest claim on my attention, and may perhaps be found more generally useful to those who wish to enjoy the scenery of the country, without removing too far from active life, I shall produce some examples of places of this description, and make such extracts from the Reports as may become interesting to all who make new purchases, and ereate new scenes in the neighbourhood of the metropolis, or of any large town. 


\title{
REPORT CONCERNING A VILLA AT STREATHAM,
}

\author{
BELONGING TO THE EARL OF COVENTRY.
}

MY LORD,

I car nот but rejoice in the honour your Lordship has done me, in requiring my opinion concerning a Villa, which, when compared with Croom or Spring Park, may be deemed inconsiderable by those who value a place by its size or extent, and not by its real importance, as it regards beanty, convenience, and utility. I must therefore request leave to deliver my opinion concerning Streatham at some length, as it will give me an opportunity of explaining my reasons for treating the subject very differently from those followers of Brown, who copied his manner, without attending to his proportions or motives, and adopted the same expedients for two acres, which he thought advisable for two hundred. Mr. Brown's attention had generally been called to places of great extent, in many of which he had introduced that practice distinguished by the name of a belt of plantation, and a drive within that belt. This, when the surface was varied by hill and dale, became a convenient mode of connecting the most striking spots, and the most interesting scenes at a distance from the mansion, and from each other. But when the same expedient is used round a small field, with no inequality of ground, and particularly with a public road bounding the premises, it is impossible to conceive 
a plan more objectionable in its consequences; for as the essential characteristic of a Villa near the metropolis consists in its seclusion and privacy, the walk which is only separated from the highway by a park paling, and a few laurels, is not more private, though far less cheerful, than the path in the highway itself. To this may be added, that such a belt, when viewed from the house, must confine the landscape by the pale to hide the road; then by the shrubs to hide the pale; and lastly, by the fence to protect the shrubs; which all together act as a boundary more decided and offensive than the common hedge betwixt one field and another.

The Art of Landscape Gardening is in no instance more obliged to Mr. Brown, than for his occasionally judicious introduction of the Ha! Ha! or sunk fence, by which he united in appearance two surfaces necessary to be kept separate. But this has been in many places absurdly copied to an extent that gives more actual confinement than any visible fence whatever. At Streatham the view towards the south consists of a small field bounded by the narrow belt, and beyond it is the Common of Streatham, which is in parts adorned by groups of trees, and in others disfigured by a redundance of obtrusive houses. The common in itself is a cheerful object, and from its distance not offensive, even when covered with people who enjoy its verdure. Yet if the whole of the view in front were open to the common, it might render the house and ground near it too public; and for this reason, I suppose, some shrubs have been placed near the windows; but I consider that the defect might 
be more effectually remedied by such a mass of planting as would direct the eye to the richest part of the common only; then, by raising a bank to hide the paling in such opening, the grass of the common and of the lawn would appear united, and form one unconfined range of turf seen point blank from the principal windows; while the oblicque view might be extended to the greatest depth of lawn, and to some fine trees, which are now all hid by an intervening kitchen garden not half large enough for the use of such a house.

This naturally leads me to explain the principle of improvement which I have the honour to suggest. The value of land near the capital is very great; but we are apt to treat it in the same manner as if it were a farm in the country, and estimate its produce by the ACRE, when in fact it ought to be estimated by the root. An acre of land of the same quality, which may be worth $£ \geq$ in Worcestershire, may be worth $£ 5$ at Streatham, for cattle; but if appropriated to the use of man, it may be worth $£ 20$ as a garden. It is therefore no waste of property to recommend such a garden establishment at Streatham as may make it amply worth the attention of the most experienced gardener to supply the daily consumption of a town-house, and save the distant conveyance or extravagant purchase of fruit and choice vegetables: especially as such an arrangement will add to the beauty and interest of the grounds, while it increases their value.

The house at Streatham, though surrounded by forty acres of grass land, is not a farm, but a Villa in a garden; for I never 
have admitted the word Ferme Ornè into my ideas of taste, any more than a butcher's shop, or a pigsty, adorned with peagreen and gilding. A garden is of different value in different seasons, and should be adapted to each. In Summer, when every field in the country is a garden, we seldom enjoy that within our own paling, except in its produce; but near London, where the views from public roads are all injured by the pales and belts of private property, the interior becomes more valuable, and the pleasure of gathering summer fruit should be consulted in the arrangement of the gardens. In W Inter the garden is only preferable to a field by a broad gravelwalk, from which the snow is swept, except we add to its luxury the comfort of such glass as may set the winter at defiance; and the advantage of such forcing-houses for vines and flowers will be doubly felt in the neighbourhood of the capital.

In SPR IN the garden begins to excite interest with the first blossoms of the crocus and snowdrop: and though its delights are seldom enjoyed in the more magnificent country residences of the Nobility, yet the garden of a Villa should be profusely supplied with all the fragrance and the beauty of blossom belonging to "il gioventu del anno."

Lastly, the garden in Autun w to its flowers adds its fruits, these by judicious management may be made a source of great luxury and delight: and we may observe, that it is chiefly in spring and autumn that gravel walks are more essentially 
useful when the heary dews on the lawn render grass walks almost inaceessible.

It happens at Streatham, that a long range of offices, stables, and farm buildings, fronts the south, and seems to eall for the expedient by which it may be best hid, viz. a continued eovered way, extending a rista from the green-house annexed to the drawing-room; houses of every kind for Grapes, Peaches, Strawberries, Vines, \&e. \&e. to any extent, may herie be added, without darkening the windows, which may be lighted under the glass, and a low skreen of flowering shrubs in summer will sufficiently hide this long range of winter eomfort, without intercepting the rays of the sun.

\section{REPOR'T}

CONCRRING

\section{A VILLA NEAR A COMMON,}

IN THE NORTH OF ENGLAND.

'Tue scenery and situations, which I have been called in to improve, are not more diversified than are the characters of those to whom they belong; and were I to relate the difficulties attending my endeavours to meet the wishes of all my friends, this volume might perhaps be deemed a libel. Some who never meant to follow my advice, or even to do any thing to 
their places, would be offended if no notice were taken of them: while others, who have literally realized all I suggested, would be equally offended if their places were named; but in these times, when the landed property of the country is changing with every generation, I shall sometimes venture to allude to subjects where great improvement has been proposed, and in many cases actually carried into effect, without incurring the resentment of my friends from mentioning them by name.

Among the most painful circumstances attending the Professor's life, and the time and contrivance wasted to produce plans although highly approved; yet from vanity, from indecision, or from the fickleness of human nature, not unfrequently thrown aside, and plans more expensive, but less useful or ornamental, adopted in their stead.

About fifteen years after I had given plans for making a house and grounds perfectly comfortable, at an expense estimated at four thousand pounds, I had the mortification to find, that fifteen thonsand had been expended, and the Proprietor told me, that he would gladly add five thousand more, to make it as I had originally proposed.

\footnotetext{
"Video meliora, proboque,

Deteriora sequor."
}

To give the name of the place, or the Proprietor, in such cases, would be only proctaiming the folly or perverseness of individuals; but if all examples were suppressed, from this feeling of delicacy, some of the most interesting specimens would be 


\section{6}

lost; and I should be guilty of injustice to the powers of the Art which I have so long professed to cultivate. For this reason I will refer to a nameless specimen of improvement in the North of England; where a Villa, placed on the edge of a goosecommon, commanded a view of distant country, enriched with woods and gentlemen's seats; but the leading feature of the landscape was a row of mean tenements, with some of those places of worship too apt to disfigure the neighbourhood of all great manufacturing districts. These white-washed scars in modern landscape, form a melancholy contrast to the venerable churches and remnants of edifices of former times, which are now suffered to moulder into ruins.

The annexed sketch represents the advantage taken of an act of Parliament to enclose a common, where the water, which stood in several small pools, was collected into an apparent river; and the road, with all the unsightly objects, is now become a line of plantation, forming a pleasing foreground to the richly wooded distance. 


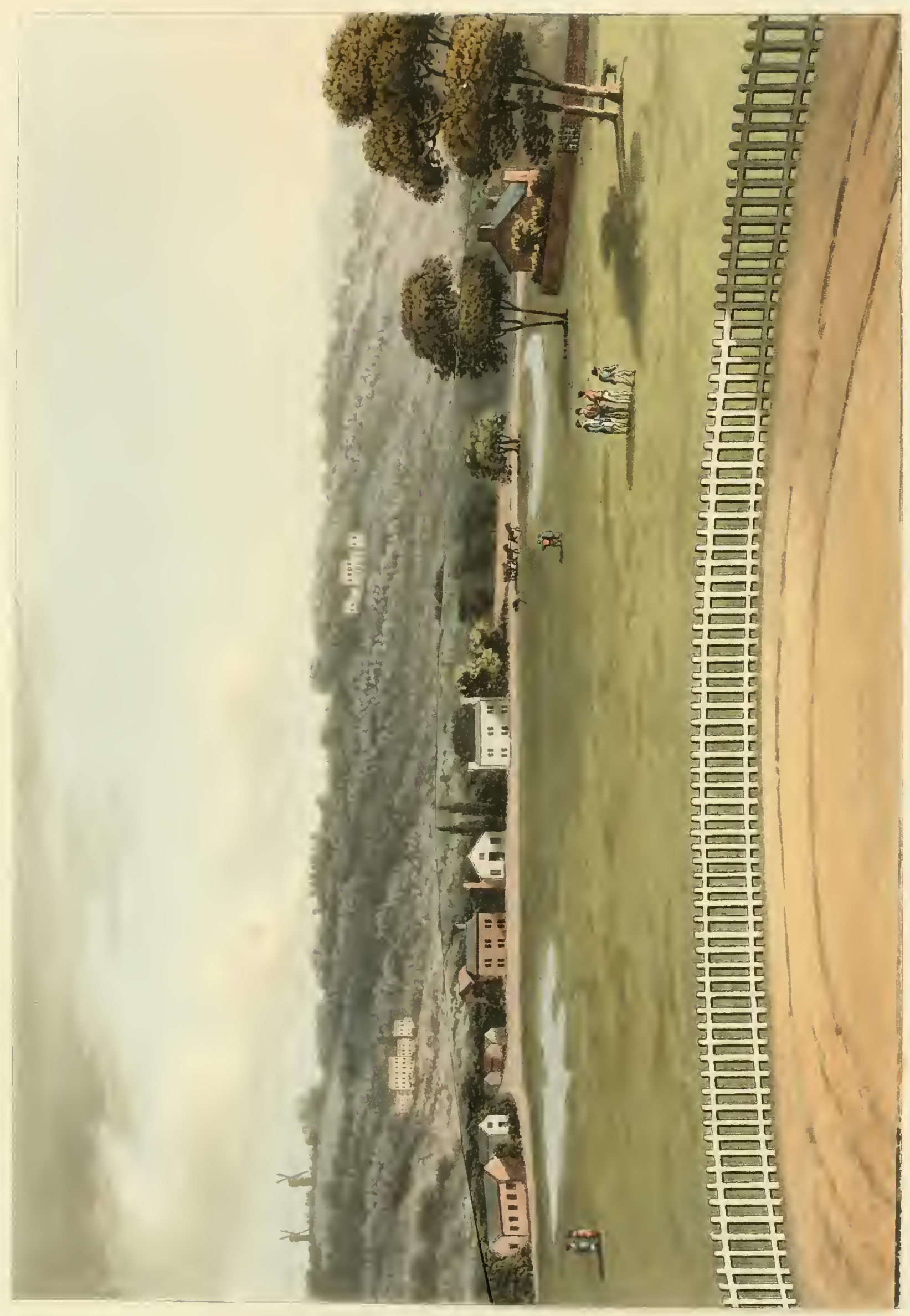






\section{REPORT CONCERNING A VILLA IN ESSEX, VERY SINGULARLY SITUATED,}

Consisting of four or five acres of Garden, in the centre of Epping Forest, abounding in Deer, and immediately surrounded by a Rabbit Warren.

of twenty acres.

Is delivering my opinion concerning the improvement of this place, I must state the peculiar circumstances which render it very different from any other.

The House was much out of repair. It had long been the Rein-Deer tavern, occupied not as an inn by the side of some great road, but as a house in a sequestered part of the forest, with summer access by green lanes, or broad grass glarles; and appropriated to the Sunday visits of those who made holiday, fancying they enjoyed solitude in a forest, amidst the crowd of "felicity hunters" who came here to forget the cares of London. It was not uncommon to see fifty horses in the yards and stables, and twice as many guests filling the large rooms; but these visits were confined to the summer months, and on this account the cool views towards the north were preferred to the sunshine of the south. Now it must have occurred to all who attend to situation in the country, that in this climate the first object of cheerfulness and comfort for a permanent residence is a south or south-east aspect. If a family ever reside here dur- 
ing the winter, they will perhaps discover, that the window on the staircase to the south admits more cheerfulness than any other in the house: and this may perhaps suggest the idea of opening windows to the south in the great room, although they may only look into a conservatory or green-house, which may be also a grapery; but the difference between a public-house and a private one operates in so many ways, that I must proceed farther. The public-house required broad glades and free access in all directions; large stables, stable-yards, and ontbuildings, far more extensive than are necessary to a private house, and consequently all these may be reduced, and the aceess to them simplified. There is yet another consideration which makes this place different from all others: it is not only a spot of four or five acres enclosed from a forest, but it is surrounded by a rabbit-warren, which the late occupier made an object of profit, though with the utmost difliculy could he preserve from these rapacious animals the regetables in the garden, intended for his scarcely less rapacious guests; and thus the whole is subdivided by unsightly palings, and the place altogeher is a scene of slovenliness, with dirly pouds, and numerous puddles, cess-pools, and traps for vermin in every part of the premises; while the surface presents nothing but yawning chasms, or barren mounds of clay withont a blade of grass, which is wholly destroyed by the rabbits. 'The first thing therefore to be done is, to secure the whole by such a fence as shall, at the same time, exchude the deer of the forest, who leap orer any thing that is less than six feet above ground, and the rabbits, who burrow under any 
thing (but a brick wall) two or three feet beneath the ground. Now such a fence, quite round the premises, will be expensive, yet, without an effective fence, there can be no enjoyment of the place: I will therefore suppose, that much of the present fence may be repaired, and where a new fence is necessary it should be constructed according to the annexed section: thus_Suppose the dotted line the present surface of the ground, then begin by digging out the earth at A five or six feet wide, and throw it up at $B$, to raise the walk on a terrace; then face the bottom of the bank about three feet deep with bricks, and put upon it a paling about three feet high; this will make a fence of six feet against the deer, while a person walking withinside will look over the pale, and enjoy the prospect of the forest.

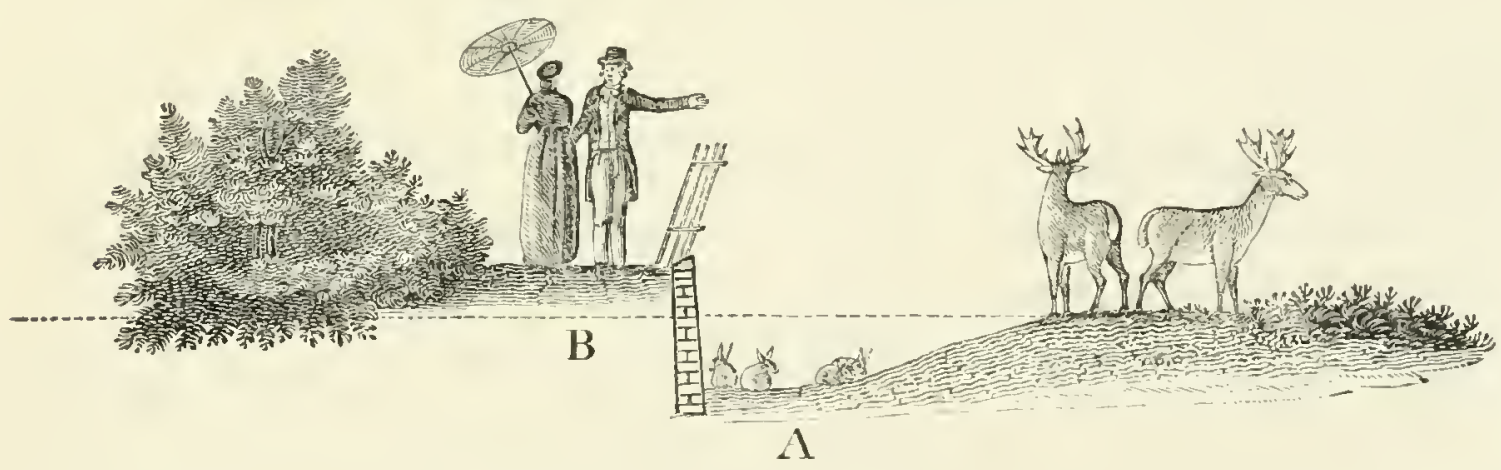

After effectually inclosing and securing the whole area, the next consideration is, how it shall be occupied; this is described by the map. I first allot the garden for fruit and vegetables, which may be locked up, laying it altogether, and making access to the yard by a road to divide the garden from the melon-ground, \&c. This garden may be decorated with neat gravel-walks and beds of flowers and shrubs, with terrace views into the forest; 
and including the house and yards, will be about two acres; there will then remain about two acres and a half to the north, which is too much to be all pleasure-ground, and either the whole may be fed with cattle as a lawn, or the part near the house, including the gravel roads, may be fenced with a wire or trellis fence, which will give neatness and comfort, without waste of land.

All rabbit beds and burrows within the fence should of course be levelled and destroyed.

\section{REPORT CONCERNING EALING PARK.}

THis is one of the few places which still retain the importance of the last century in the blended scenery of Landscape and Gardening: but the trees have outgrown their original intention. Brown (whose work this appears to have been) surrounded the whole place by a narrow belt or skreen of plantation; and in conformity doubtless with the wish of its proprietor, he made a gravel-walk through the whole length of the same; notwithstanding it every where runs parallel to a high road, from which it is only separated by a pale: this was hid while the plantation was young, but now the trees are grown so naked and open at bottom, that the proximity of the boundary is every where felt: and since it would be impossible to remedy this 
defect, without too great a sacrifice of respectable trees in the belt, we must seek for new beauties elsewhere, and have resort to different expedients, to shew the situation to advantage. A circular drive round a place with views only towards the interior, has little to excite our admiration, after the first two or three rounds. It is not sufficient to see the water; and the large group of trees in the lawn; they are still always out of our reach: we long to enjoy more of them; we wish not only to see them, but actually to be on the banks of the water, and under the shade of the trees: and, like Rasselas in the happy vale of Abyssinia, we regret the confinement of this belt, and should rejoice at emancipation from the magic circle by which we are restrained. Yet the exercise and pleasure of such a length of walk is an object not to be hastily relinquished.

There are now but few places where the surrounding belts, planted in Brown's time, have not been cut down for the sake of the timber, or the ground cleared for the sake of the pasture; but where they exist, especially in a flat country, the trees have acquired such height as to exclude all distant view; and consequently an air of confinement is produced, which was not intended in Brown's original belts. Two instances of this kind have occurred to me in the neighbourhood of Ealing and Acton; where a pleasing offskip, with wooded distance, and such features as the Pagoda and Palace of Kew, were totally hid by the lofty trees which formed the belt. In one of them an attempt had been made to break the continuity, but some few tall trees that were left, produced more mischief than all the others before 
they were laken away; because, while the belt remained, we might suppose it concealed some unsightly object; or, that nothing existed beyond it deserving a place in the landscape; but now we perceive features whose beauty is by no means increased by being partially concealed.

The skelch, $\mathrm{N}^{\circ} 1$, represents the opening made in a belt, in which the Pagoda at Kew forms a striking object; but the sketch differs considerably from the original; the spectator in the former is supposed to be stationary, but in the latter, whenever he changes his position, the Pagoda is alternately hid by the four trees, which are supposed to be taken away in the sketch, $\mathrm{N}^{\circ} \mathcal{2}$; and every one must be sensible, that the opening requires to be made thus free from impediment and incumbrance: the distance may then be decidedly separated from the foreground. These two sketches also serve to elucidate another renark: the oflskip, or distant country, must either be seen over or under those objects which constitute the foreground; here advantage is taken of both; in the larger opening it is shewn over an intervening copse, or mass of brushwood, and in the other it appears through the stems of tall trees, and under their branches. Such openings, if not too frequently repeated, or too artificially made, will improve the landscape, without destroying the continuity of wood, and of walk within the same. But in these sketches another effect is hinted, by breaking the line of clipped fence, partly by a few thorns planted before it, and partly by suffering some bushes in the hedge to grow taller; this will render the walk more interesting than in its present 


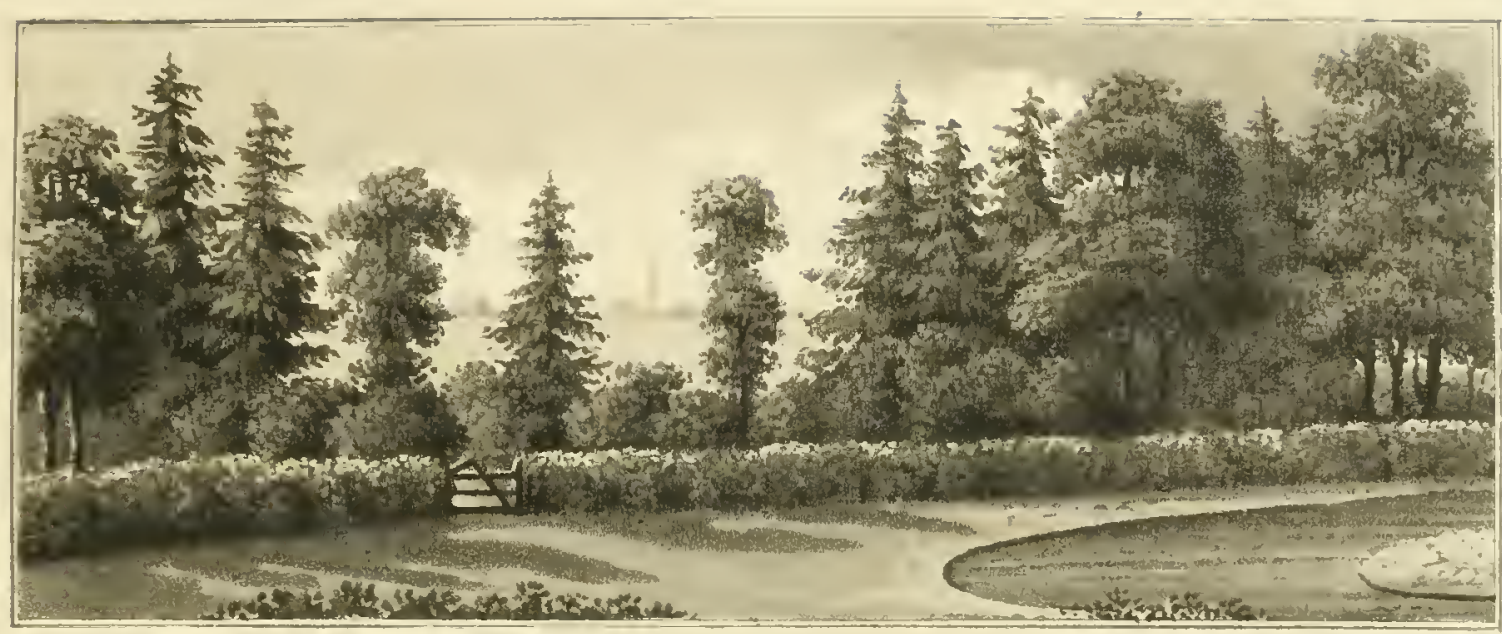

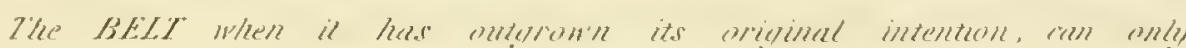

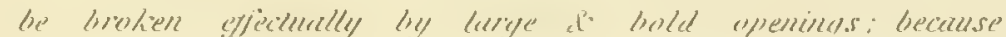

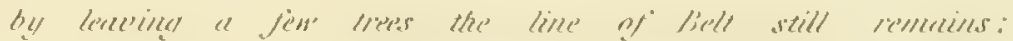

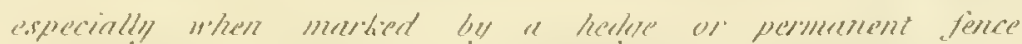

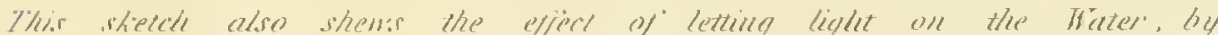

remenume the dert irfection of trees

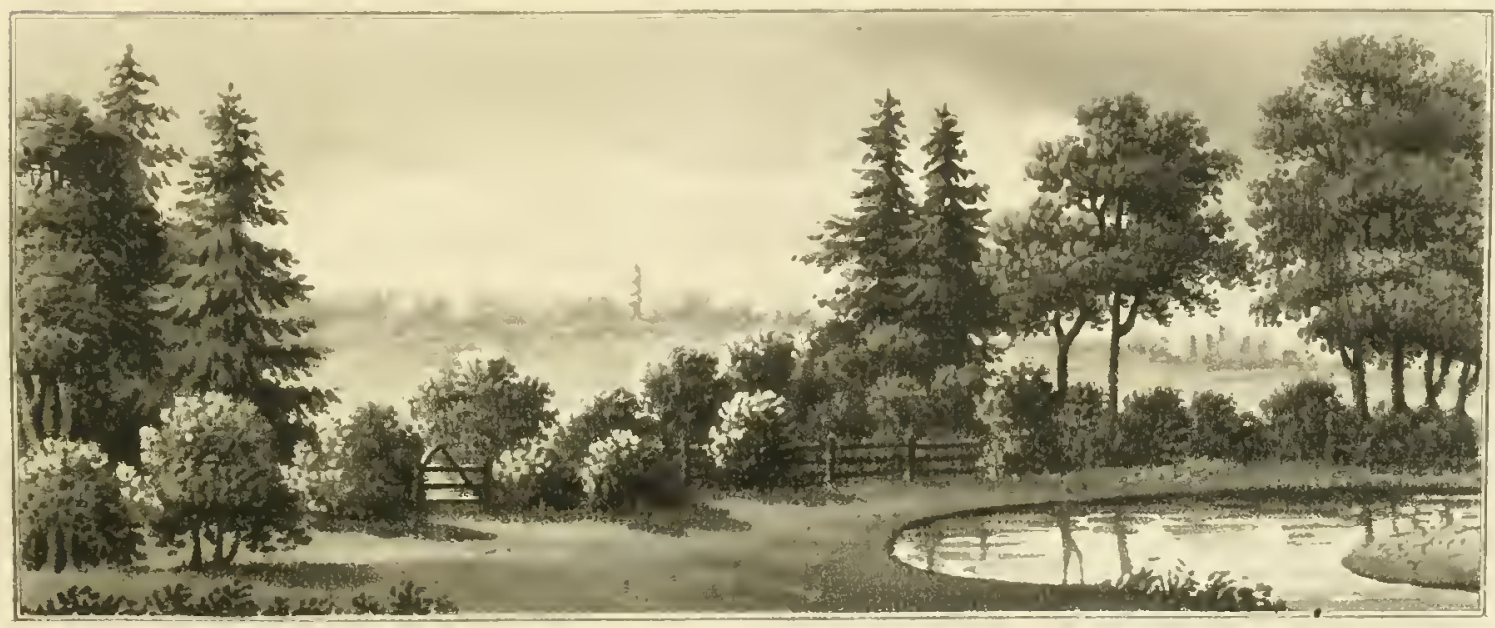



state, where the same view into the same lawn becomes tiresome and monotonous; and where the house and the water is the axis round which we turn, we feel in a manner tethered to a certain point; and it would be a relief to have the attention drawn away to other objects more new, thougl not so beautiful.

Harivg classed under the same head of Small Places or Villas several subjects of very different magnitude and importance, one more may be added, to which not an acre belonged; and therefore it may serve to shew, that the quantity of acres attached does not make a place large or small; and also as yielding a striking example of the difference to be observed betwixt the Scenery of a Park and that of a Garden, blending utility with ornament, and giving privacy to a situation most exposed to the public.

A modern Villa, called White Lodge, is situated nearly in the centre of Richmond Park. This has long been granted by the King as a residence to Lord Viscount Sidmouth. When I first visited the spot in 1805, a small quantity of land had recently been allotled from the Park; without which, indeed, the house was before hardly habitable; for, although it was surrounded on every side with varied landscape, and the scenery of a forest rather than that of a park, being one of the royal domains, the deer and cattle of the forest had access to the 
doors and windows; and were only kept from the corridore by a chain or hurdle put across the arches. It is obvious, under such circumstances, that there could be no walks, no privacy, no enjoyment of garden luxuries, either for pleasure or for use: and neither fruit nor regetables could be raised upon the premises.

There were two modes of treating this subject, according to the modern system of Landscape Gardening. The first was to enclose the whole area granted, by a belt of trees and shrubs: this would have excluded all view into the park, and reduced the situation to that of any villa on Clapham Common. The other mode was that which I found actually begun, viz. to surround the whole with an open or invisible fence, to unite in appearance the Ground of the Park with that of the enclosure, bringing to the same level the surface where it was irregular. This would have completely destroyed every advantage of privacy, of convenience, or of use, in the acquisition from this new grant. I was therefore driven to suggest a third expedient, which in these Fragments has or will be frequently mentioned, viz. to adopt a decided artificial Character for the Garden; boldly reverting to the ancient formal style, which by some will be condemned as departing from the imitation of Nature: and by such treatment is now secured to these premises an ample portion of ground for fruit and regetables of every kind; yet these are so enveloped in skreens of shrubbery and garden flowers, as to be no where visible or offensive. At the same time, by preserving the inequalities in the ground, which were 


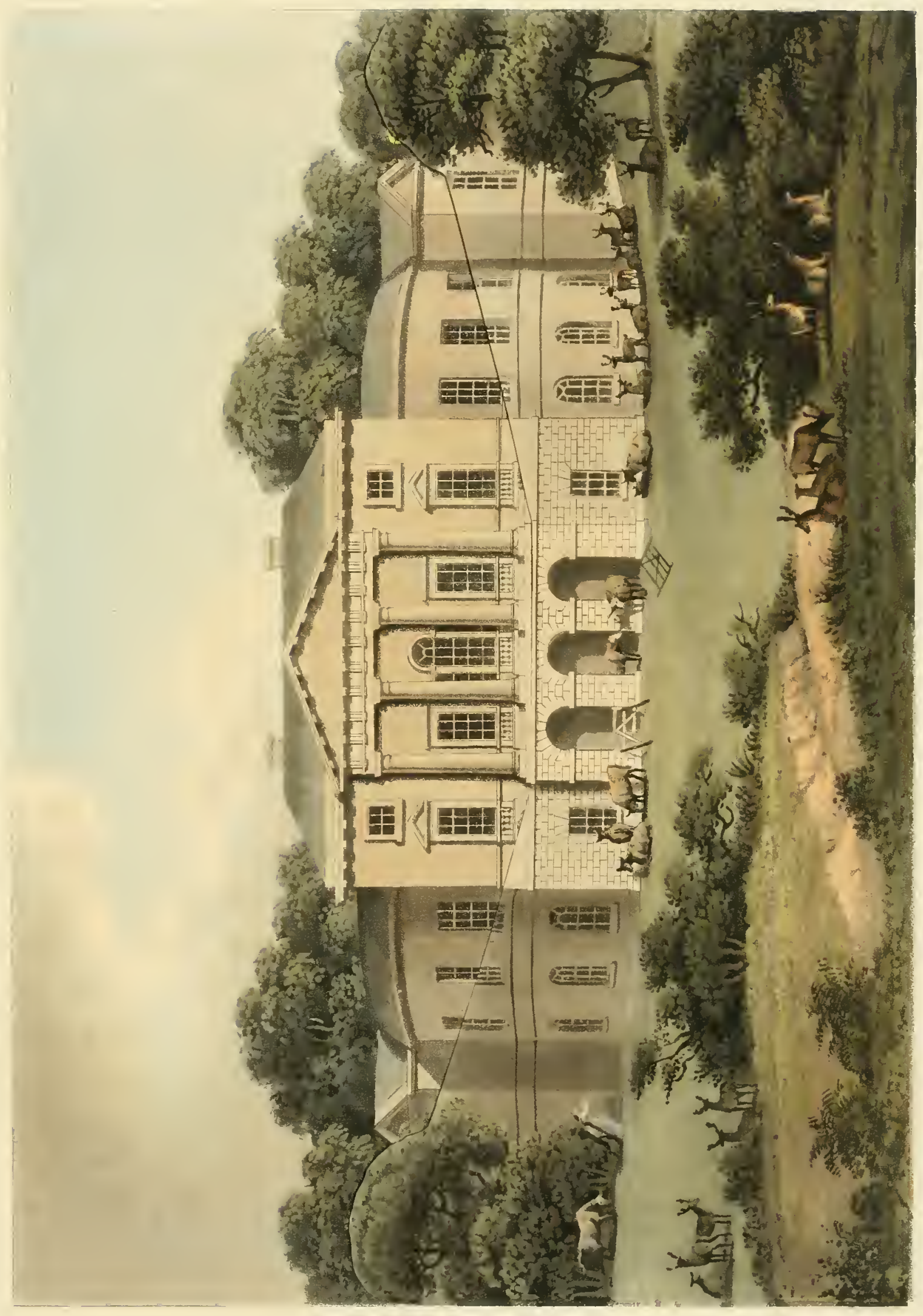



about to be levelled, the walk is made to take advantage of views into the park; and thus neither beauty nor utility is banished by the enclosure.

The Drawing by which this subject is elucidated will perhaps be deemed more picturesque as a Park than as a Garden; but it has frequently been observed, that Garden Scencry seldom presents subjects for a picture. Let us rather consider which of the two is most applicable to the uses of habitationthe neatness and security of a gravel-walk, or the uncleanly, pathless grass of a forest, filled with troublesome animals of every kind, and some occasionally dangerous.

The improvement suggested has been exceuted in every respect by the present noble Inhabitant, with the exception of the. Treillage Ornaments, which may at any time be added.*

* In a beatutiful work lately published in France, entitled, Choix des plus celebres Maisons de Plaisance de Rome, by Cha. Percier and P. F. L. Fontaine, the following just distinction is made betwixt the Italian Gardens and those of France; to which might be added, the modern English Garden also. "Ce n'est jamais, comme on le " voit chez nous, un jardin dans le quelle on a pretendu faire un site, un paysage, " mais au contraire, un site dans le quel on a fiit un jardin c'est l'Art qui a pare la "Nature, et non pas l'Art qui a voulu la creer." 
FRAGMENT XVII.

\section{or \\ A GARDEN NEAR OPORTO.}

TO - HARRIS, ESQ.

S I R,

Whes I first received the honour of your letter, desiring me to furnish a plan for the improvement of Ground belonging to a Villa in Portugal, I doubted whether your correspondent from that place could be in earnest in supposing such an undertaking possible; yet the novelty of the experiment induced me to attend to this request: and notwithstanding all the difficulties of the subject, I have endeavoured to comply with your friend's wishes, "that I should furnish a plan for shewing a specimen of Euglish Gardening in a foreign country."

The difficulties to which I allude are these:

First, My not having ever seen the spot, or any drawing of it.

Sccondly, My never having been in that country, yet from sketches furnished by those who have been there, I had some general ideas of the face of the country near the spot, though not of the spot itself. 
Thirdly, Having only a map of the surface, without any sections of the ground, to describe the various levels: and

Lastly, The rast difference in climate, soil, seasons, and costume, between England and Portugal. All which seem to render the introduction of our English Garden into the grounds near Oporto almost as difficult as it has been to introduce the vegetation of a hot country into the cold regions of the north: yet this has by perseverance been accomplished; and I am happy in an opportunity of attempting to shew in this instance how far difficulties may be surmounted.

Having at various times published my opinion on English or Landscape Gardening, I must beg leave to refer your correspondent to those works, and shall only point out the peculiarities which seem to render our English style almost inapplicable to Portugal, or at least to call for a different mode of treatment in the subject under consideration.

The first of the great requisites in English Gardening is, to banish all appearance of confinement, and to give imaginary extent of freedom, by invisible lines of separation, by a ha! ha! or sunk fences, \&e. If this be difficult in a territory of two or three hundred acres, how much more so must it be in a plot of three or four acres, enclosed by walls, and surrounded by neighbouring buildings: all we can hope to effect is to hide this boundary every where by plantations of such raried outline and depth, as to disguise what we camnot extend or remove.

Secondly, That which peculiarly distinguishes the gardens of England is the beauly of English verdure: the grass of the 
mown lawn, uniting with the grass of the adjoining pastures, and presenting that permanent verdure which is the natural consequence of our soft and humid climate, but unknown to the cold regions of the north, or the parching temperature of the south. This it is impossible to enjoy in Portugal to any great extent; where it would be as practicable to cover the general surface with the snow of Lapland, as with the verdure of England: I mean naturally; yet artificially it may be effected on a small scale by shade and irrigation; some hint, therefore, will be given for producing this effect, if only as a specimen of English verdure.

Thirdly, There is another circumstance belonging to English Gardens, which may possibly be imitated in any climate; and that relates to the prevailing lines of walks, \&c.

In the old Gardens of France and Italy, and I suppose it is the same in Portugal, the walks are always straight, the surface generally flat, and all the shapes, whether of land, of water, of beds, or of parterres and borders, are drawn in circles, or squares, by straight mathematical rules. These are evidently works of Art, and do not pretend to any resemblance to Nature: indeed, when the ground has been formed into level terraces, supported by straight walls, perhaps a straight walk, parallel to the wall, is more rational than the affectation of a serpentine walk, which can only be justified either by irregularity of surface, or by the varicty of views. In a straight walk the view forward is always the same, but in a curving walk it varies with every step we take: thus whether it consist of distant 
prospects, or of the shrubs and plants near the eye, the scene is constantly changing, and this characteristic of an English Garden may be imitated in any combry. The annexed plan will fully explain how this nay be accomplished in the present instance; but there is also an expedient suggested to realize the English style in two other circumstances, viz. the inequality of surface, and its verdure. I an given to understand, that the broad terrace or platform near the honse is about six or eight feet above the second terrace, and that water may be brought thither to supply a basin for gold and silver fish; let us therefore suppose the shape of the ground to be altered according to the annexed plan and sections; * this will make a fall in every direction towards the pool, and if the water by which this pool is to be supplied be led along a natrow channel of stone or lead, from every part of which it may trickle on the grass, it may be spread over the whole surface, in the same manner as water meadows are irrigated, and in the hottest climate the verdure will-be preserved; especially if some trees be planted round the area, to contribute their shade. By this expedient I have no doubs we may produce a specinnen of English verdure in the upper ground; and if it succeeds there,

* In describing this Garden of Portugal, the Plan for the walks and shrubiberics has been omitted; but the Map inserted with the sections of the ground may be considered as of a morc general nature; serving to explain the process of litying out a surfice in such manner, that it may be raised and sunk, aceorling to the stakes by which the ground is divided into squares. This was done under my direction at the gardens at the Pavilion at Brighton, and the whole surface altered accordingly. 
it may also be made to succeed equally in the lowest ground, by the water in the well in the middle of the garden. Not having seen the spot, and not knowing what plants or shrubs there may be now growing, or what will best succeed in this situation, I shall give the following general rules for the planting, after the ground is shaped according to the annexed diagram.

First, If there are any good trees or plants on the spot, too large to be removed, let them not be disturbed, unless very much interfering with the levels of the ground, or line of the walks.

Secondly, The height of the plants must be guided by the objects they are intended to hide, or the views they may obstruct. In those places where good prospects are seen over the walls, they need only be high enough to hide the walls; in others, where houses or other objects require to be concealed, they must be high in proportion.

Thirdly, Let the lowest growing shrubs be nearest to the walks, and some flowers in front; except in those walks which require shade; and there tall plants may be put close to the side of the walks.

N. B. The water to irrigate the grass, and supply the pool, I understand, is to be furnished from a redundance in the adjoining ground belonging to a Convent of Capuchins; and much will depend on the due attention that not a drop shall be lost or wasted. I am happy to add, that this plan was successfully realized, and admired for its effect and novelty in Portugal. 


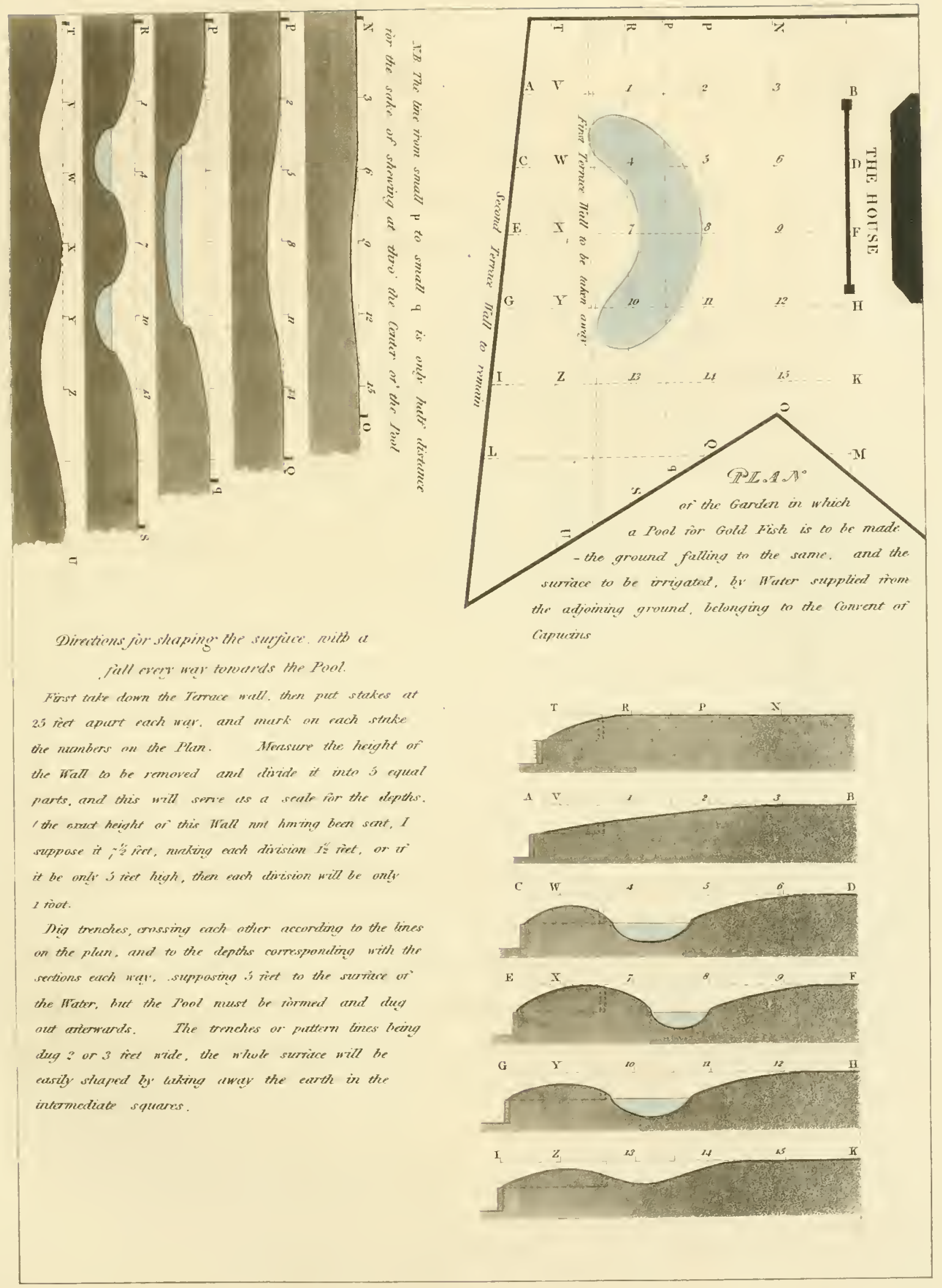

SESTIONS OF A GATLEA NFAR DPORTD 



\section{FRAGMENT XVIII.}

\section{U P P A R K.}

\section{EXTRACT FROM 'THE REPORT OF UPPARK, A SEAT OF SIR HARRY FEATHERSTONE, BART.}

\section{SITUATION AND CHARACTER.}

BEFORF a rational plan for the improvement of any place ean be laid down, it is always necessary to consider its natural situation, and the character which has been given to it by art. The former at Uppark is truly magnificent, being on the summit of the south down range of hills; and when we consider the large masses of wood, the beantiful shapes and verdure of the lawns, with the distant and various views of sea and land, it is difficult to adapt any style of building to such a spot, that may correspond with the great seale of the place. Of this difficulty the Arehitect seems to have been aware, by the degree of irregularity which was originally adopted in the position of the outbuildings: this is evident, both from the map and from an old pieture on the stairease, wherein the stables and other offices appear to have been placed not at right angles, but converging from the entrance front.

His reasons for so doing seem to have been well founded. 


\section{2}

He knew that a correct correspondence of parts in a building tends to diminish its importance; that the Roman style, which was then introduced into England, would not admit of such irregularity; and all that could be done was to spread ont the detached buildings, which produced an appearance of irregularity when seen from a distance, while the effect of symmetry was preserved in the entrance-court, where the lines converging instead of being parallel, increased the apparent length of perspective.*

\section{THE ENTRANCE.}

As the principal object of improvement at Uppark relates to an alteration in the entrance, I shall endeavour to explain the causes which have rendered such alteration necessary.

Before the introduction of Roman Architecture into England, all the Palaces and large Mansions consisted of one or more quadrangles surrounded by buildings, as at Cowdray, Hanpton Court, \&c. But at the time when Uppark was built, the fashion of these quadrangles was about to be changed; although for a long time after, it was continued in the entrance fronts; and at Uppark, where the entrance was to the east, a basse cour, or court, was preserved; and in so lofty and exposed a situation, such an entrance was absolutely necessary to the comfort of the residence; for however the views might be opened

* An example of this may be observed in St. George-Street, as viewed from the end of Hanover-square. 


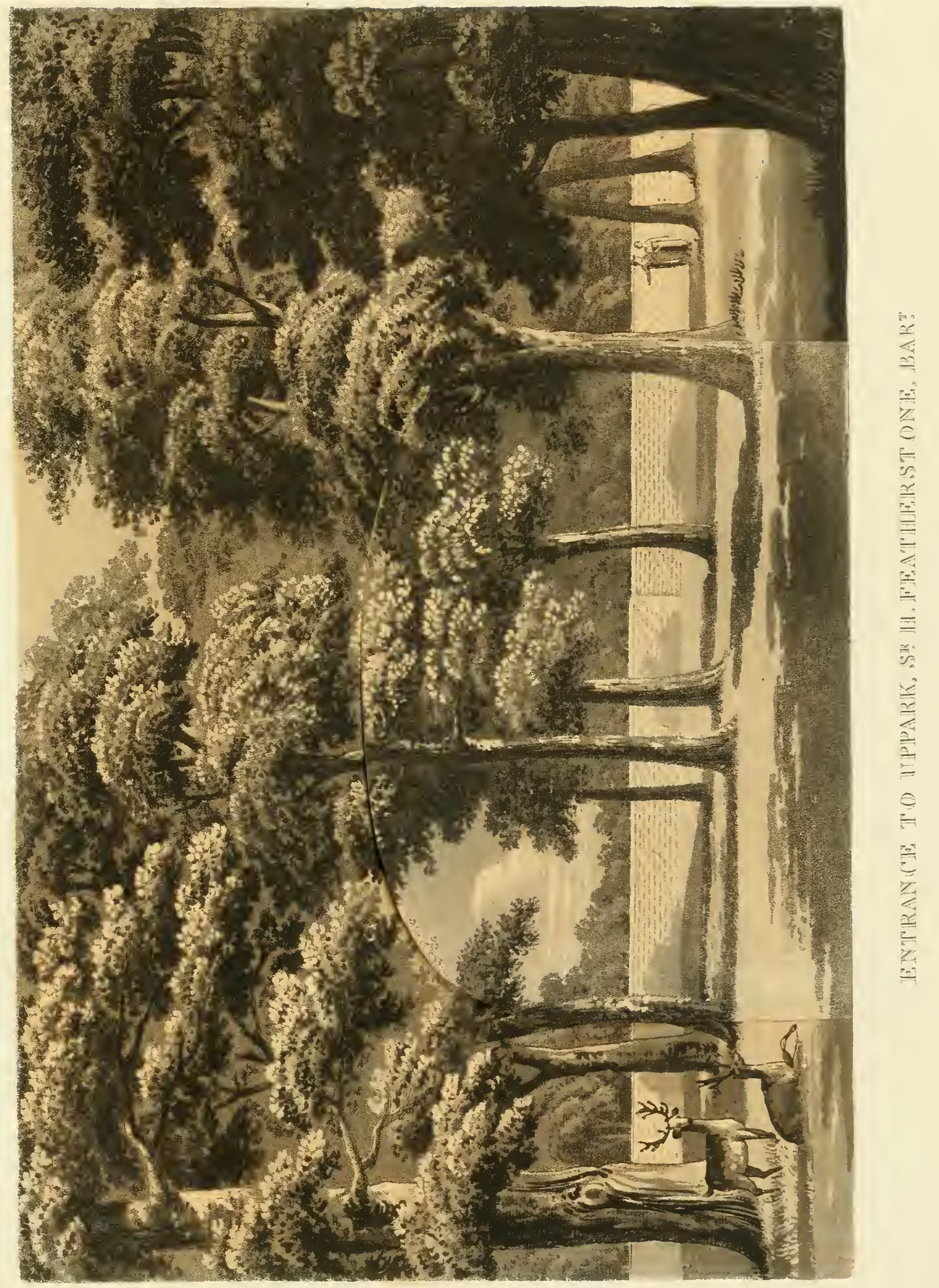





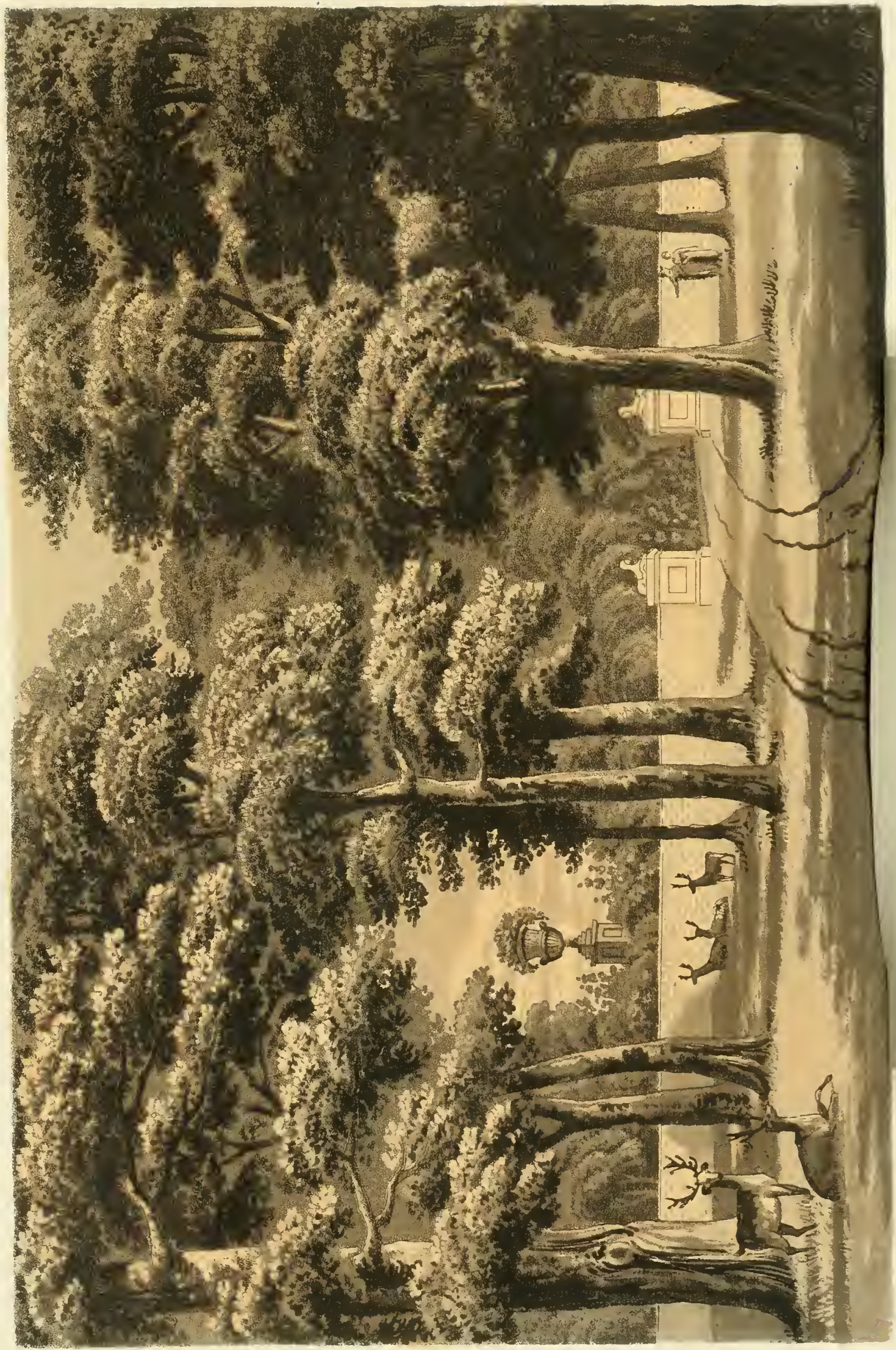



from the other windows of the house, those on the same side with the entrance could command only a view surrounded by walls or buildings.

As the gloomy confined view into a quadrangle, or paved court, forms a great contrast to the cheerful landscape of a park, or more distant prospects, it is no wonder that fashion shonld open the views in every direction; forgetting that one side at least of every house must be appropriated to useful rather than ornamental purposes. In the original plan of Uppark, it is evident, by the little attention given to its appearance, that the Architect intended the north front shonld not be seen; but when the buildings, which formed the due importance of the east or entrance front, were taken down, the entrance still continued as before.

It is difficult to give an adequate idea of the improvement which has been actually executed, without inserting the whole series of sketches and plans by which the report is illustrated, and which consists of nine distinct drawings.

The annexed sketch shews the entrance from the park to the pleasure-ground and flower-garden, which is defended by a wall of flint-work; and after passing through the iron gates, the road continues in the highly-dressed pleasure-ground, till it enters the quadrangle to the north of the house, in which a corridor and portico of Doric columms mark the entrance. 


\section{FRAGMENT XIX.}

\section{CONCERNING COMBINATION.}

I confess myself at some loss for an appropriate title for the subject of this section. Perhaps it will best be explained by comparing a Mansion of the last century with those venerable piles of more ancient date; many of which have been sacrificed to the prim spruceness of that modern fashion which dictates uniformity of style through the whole building, and consequently renders it necessary to hide by planting all such oflices or appendages as cannot be made to assimilate with its character. To this niay be added the prevailing custom of placing a House in the middle of a Park, detached from all objects, whether of convenience or magnificence; and thus making a country residence as solitary and unconnected as the Prison on Dartmoor.

Let us compare such a scene with the ancient Family Mansion of two or three centuries ago, and which may perhaps have undergone repairs or additions in different styles, during a long succession of generations. We shall often observe a combined mass of buildings irregular in their outline, and perhaps even discordant in their style; but the confused mixture in a Mansion, with its offices attached and detached, gives an imposing assemblage, while the church, and even the village, or at least some houses of dependants, add to that quantity and 
variety, without which there can be no real greatness or importance. It is a mistaken idea, that a place is increased in its grandeur by removing all its subordinate parts to a distance, or out of sight: on the contrary, many of our most venerable Palaces are attached, at least on one side, to the neighbouring town; while views into gardens and park scenery are enjoyed from the principal apartments.

Except in the cases of some Royal Domains, the examples of such venerable Edifices are becoming more and more scarce; partly from the prevalence of bad taste, that generally accompanies wealth suddenly acquired, and partly from the propensity which dictates the pulling down and rebuilding, rather than preserving and restoring the ancient specimens of former maguificence. 'This erroneous practice is further increased by the fashion of detaching the Mansion from its natural dependencies, rather than combining it with them. Amongst these, perhaps, there was none deemed more appropriate in old times than the Church or Chapel, or family place of burial and worship. This, so far from casting the gloom, which modern times have annexed to such combinations, was formerly considered as an object of pride and pleasure to the living, by combining the associated remembrance of many generations of the same family.

If there be a pleasing association cxcited by a collection of family pictures in the hall of an ancient mansion; if we look back with a degree of pride and satisfaction on the ancient costume of the stiff portraits of former proprictors, how much 
more forcibly do the busts and statues and recorded deeds of former worthies arouse the mind to a feeling of respect, when we know that all whichican remain is sacredly presered on the spot where they once enjoyed the regard of their cotemporaries! Not having received the permission of the Noble Proprietor to mention the name of his place, I must take the liberty to explain the subject by the help of a sketch, without giving the name.

Near the ancient seat of a Noble Family, the Parish Church (to which is allached the burial place used by the family for more than seven centuries) is so close to the site of the mansion, that some may perhaps think it too near; but a modern house has been restored on the original site, and is now so intimately connected with the church, the church-yard, and oflices belonging to the housc, that it is impossible not to be pleased with the combined cfiect of such a mass of buildings. This I have recommended to be increased, by preserving a piclurespue cottage, formerly the parsonage, and adding a cemetary, to form the boundary of the church-yard.

It is remarkable, that in this neighbourhood a custom prevails of profusely gilding the iombs and grave-stones, which are some of white and some of a black stone; and I suggested the idea of iniermixing shrubs and beds of flowers with the gilded and carved ornaments: the novelty of the scene would tend to remove that degree of disgust which ought not to be excited by the emblems of mortality, while we beliere in the immortalily of man. 


\section{FRAGMENT XX. \\ CONCERNING CONTRASTS.}

THE gandy sketch which accompanies this Fragment was taken at the moment when a dark and heary summer's shower was suddenly succeeded by a bright effulgence of light in a conservatory from which the glass roof had been removed. Although the effect was such as neither this sketch nor any painting can express, it may yet be useful in elucidating the following remarks concerning Contrasts. The first contrast here shewn is that in the shape of the trees, betwixt the straight, stiff, and upright forms to the right, and those drooping forms to the left; and though we may admire the stately and aspiring chiaracter of the hollyhock and larkspur among flowers, with the cedar and cypress among trees, yet if we turn to the opposite side, we shall confess the justice of Mr. Burke's remark, that a certain degree of weakness is not incompatible with beauty; and that in regetables, as in the human form, the apparent need of support increases the interest we feel in what is graceful or beautiful.

The sketch first serves to exemplify the contrast* betwixt

* I have occasionally planted near each other such trees as the Liburnum and the Acacia, with weeping Birch and Willows; adding such flowers and shrubs as gracefully accord, by the pendulous manner of their growtl; this makes a source of pleasing 
aspiring and drooping plants, as well as the contrast of colours. I have also endeavoured to delineate, but found it impossible to do justice to the rainbow, either in its vivid hues or its transparent effect. I should have wished to give an adequate idea of that hamonious contest which I witnessed betwixt the vivid meteor in the sky, and the assemblage of objects seeming to vie with the rainbow in the richness of their colours.

The next contrast I shall mention is that of Light and Dark, not in shadow and shade, but of a variety in colouring observable in Nature, and well worth cultivating in the art of Gardening, although difficult to represent in painting. Of this I shall enumerate several kinds.

First, The difference of a leaf with the light shining full upon it, which renders it an opake object, and the same leaf seen transparent by the light shining through it.*

Secondly, The Contrast produced amidst the more gaudy Colouring by the sort of repose that the eye derives, sometimes from white flowers, as of the jasmine, the passion-flower, and other plants, whose leaves are dark and not glossy: sometimes

variety in our gardens: while in others I have collected together all the different species of some beautiful genus: thus in the Thornery at Woburn are to be found every species of thorns which will bear the climate.

* Haring one day, when at Holwood, pointed this out to Mr. Pitt as a source of the delight we experience in a sumny day, from an open trellis of vines overhead, or the foliage in the roof of a conservatory, he was so forcibly struck with the remark, that he made several experiments with leaves of different shapes and tints, some of which, from the opaker ramification of their fibres, or other circumstances of texture, \&c. became new objects of delight to a mind like his, capable of resorting to the beauties of Nature, as a relief from the severer duties of his arduous situation. 
the same repose is produced by a mass of light foliage, at a little distance appearing without shape or colour, as in a bed of mignionette.

Thirdly, The Contrast in Texture; some plants and flowers appearing as if composed of silk, others of cloth or velvet; some smooth as satin, others harsh, rough, and prickly.

Fourthly, The contrast of Size; some like the aloe, the horse-chesnut, or the tulip-tree, bearing their blossoms above the reach of man; and others, like the diminutive rock plants, and miniatures of Nature, requiring to be raised, or placed on tables, and in flower-pots or baskets. Sometimes plants of the same species assume new dimensions, forming a contrast with their more common measurements; as in the diminutive dwarf Burgundy rose, and the gigantic Viola tricolor; which may be used as an example of contrasts in colour and in relative dimensions.*

* In alluding to the contrast from dimensions, I cannot omit some notice of the power of Art over Nature in this respect.

In China it is a common practice not only to compress the feet of women, but they have a mode of stinting the growth of trees, by which they can reduce Oaks and Elms to the size of shrubs in garden-pots, to decorate the decks and cabins of their ships. A curious specimen of this kind of dwarf plant may be seen growing from the roof of a conduit, near the road side, betwixt Hyde-Park and Knightsbridge; where a perfect Elm in miniature lias existed, to my knowledge, nearly half a century, witlout being now much bigger than a currant bush. In England we are apt to err in an opposite extreme, endcavouring rather to increase the size, than diminish it; thus we destroy the original stock (witness the gigantic but tasteless Goosebcrry of Lancashire); and often injure the flavour, by increasing the size; swelling the Pippin to a Pearmain, and the Nonpareil to a Nonsuch. 
The last contrast I shall mention is that of Cloud and Sunshine. 'There is perhaps nothing more reviving and delightful, than the sudden effect of a summer's shower, after a long continuance of dry weather: then all nature seems revived; the ground and the plants send forth new and grateful odours; the flowers, the birds, the insects, all join to express their pleasure; and even the gold fish in a globe, by their fiolic motion shew that they partake in the general joy; splashing the water, and sometimes leaping out of it to meet the welcome drops. An assemblage of Contrasts, under such circumstances, I vainly fancied I could fix by my pencil's art; but a single drop conrinced me how feeble is Art in her imitation of Nature.

"Si la Nature est grande dans les grandes choses,

" Elle est très grande dans les petites." Rousseau.

Every spray was bespangled by drops hanging like diamonds, and each changing to all the colours of the rainbow, fiom whence they appeared to have newly fallen, to cheer the eye, delight the heart, and lift the mind to the contemplation of that source of light and joy from whence alone such beauties and such wonders can proceed. 


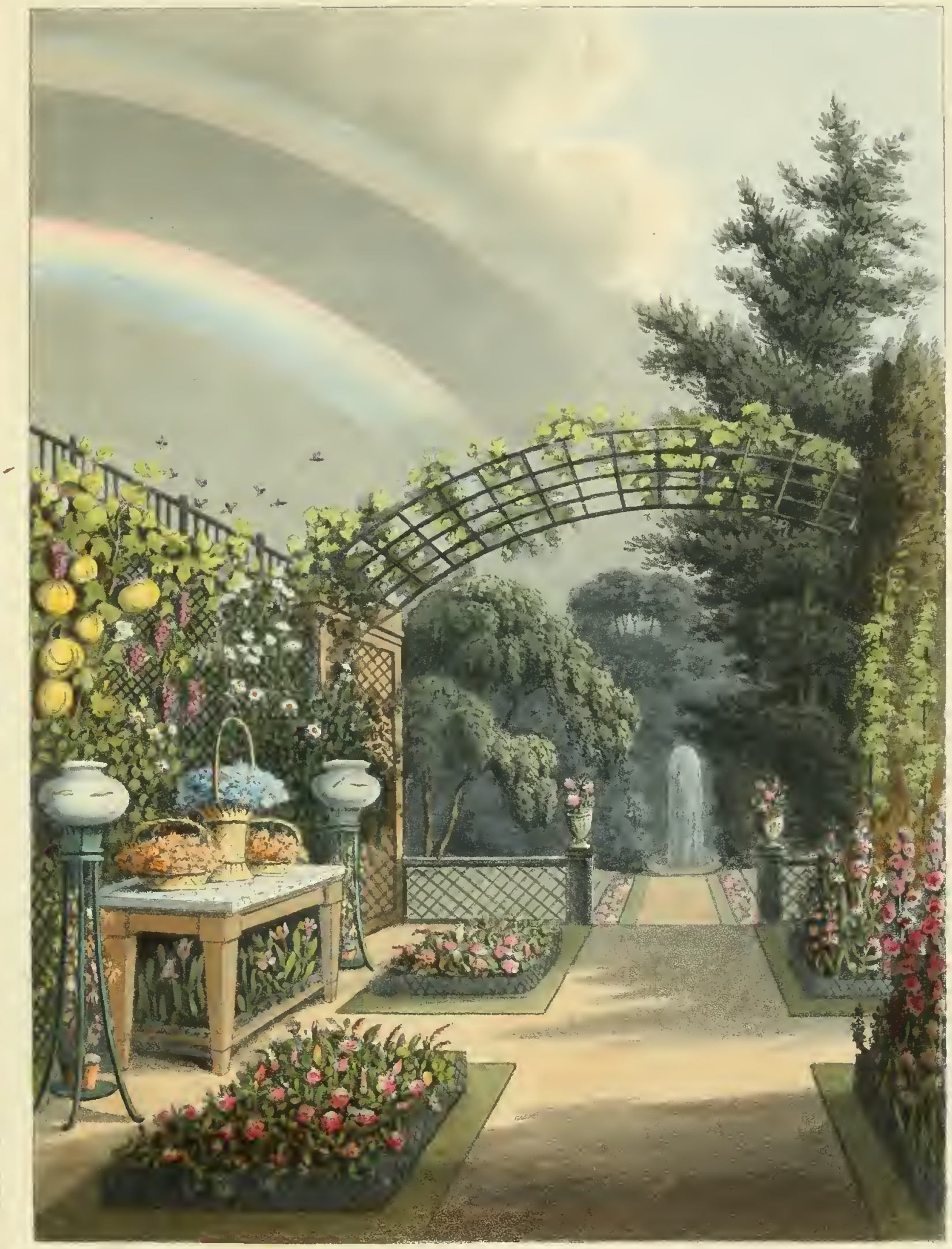

STISSHLNT AFTER RAIX

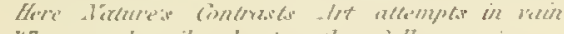

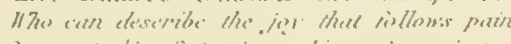

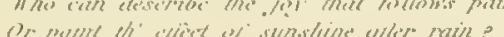





\section{FRAGMENT XXT.}

FROM A REPORT CONCERNING

\section{FROME HOUSE, DORSETSHIRE,}

\section{A SEAT OF NICHOLAS GOULD, ESQ.}

The character of a place will always be influenced by the style of the House; and I have ever considered, that, without absolute necessity, to destroy an ancient mansion, venerable by age, denotes as bad taste, as to erect a modern Castle or Abbey where there are no vestiges or pretensions for a building of that description.

About the date of Frome House, there prevailed in England a certain character of Architecture, holding a middle station betwixt the baronial castle and the yeoman's habitation; it was the Manor House.* In modern times the habits of life are changed; wealth, from the success of industry or adventure, has frequently become possessed of such ancient mansions; and the rage for novelty has often destroyed all vestiges of ancient great-

* A most sumptuous specimen of this kind exists in Norfolk (Wolterton Manor House), and has been recently published by the Society of Antiquaries from Drawings by J. Adey Repton. 
ness of character, to introduce the reigning fashion for greatness of dimension. Hence we often see rooms too large to be warmed, or lighted, or inhabited with comfort; and doors and windows too large to be opened; and sometimes a single house is displayed with a long line of rooms, in which there is not a corner or recess to sit in. Our ancestors, when they made large rooms, contrived bays and breaks in its uniform shape; but the modern saloon of (what is called perfect proportion) thirty-six by twentyfour feet, must be crammed with tables, and sophas, and instruments, to create some intricacy in this barn-like space.

Having too frequently regretted the demolishing of old mansions, it is a peculiar satisfaction to me to be called upon to improve the ancient Mansion of an aucient family: and while I indulge my fonduess for antiquity, I will endeavour to justify the plans I suggest, by answering such objections as may perhaps be offered; at the same time that I assign the reasons for my opinion.

The south-east front of Frome House is a specimen of regular, but not enriched, House-Gothic; and is in such state of repair as makes it unnecessary to take it down, and unpardonable to replace it by any modern style of building. What remains, however, of the old house is neither large enough nor sufliciently convenient for the modern residence of a gentleman's family; being only a single house, without any access to any room, except that which was formerly the hall, but now destroyed as such by an intermediate ceiling. It is therefore proposed to add so much as will double the present building; 
and I trust no one can object to this new part corresponding in style with what is left of the old original mansion, by preserving the character of similar date; although to the proposal of adding at all to the present house the three following objections may possibly be urged.

First, The present site is too low:

Secondly, It is too near the water: and,

Thirdly, It is on the verge of the estate.

To the first I must observe, that our ancestors very judiciously placed their Castles on eminences for defence, and their Abbies and Honses in the vallies for shelter: but in the champaign country of Dorset it would be absurd to place a new house on a more elevated part of the property, exposed to every wind, without a tree to cover it.

Secondly, If the water were a stagnant pool, or one of those sheets of water, as they are called, in imitation of a lake, it might be objectionable to place a mansion so near its misty shores; but where the water is constantly gliding, or in rapid motion, where a hard, pebbly bottom appears through the limpid stream, and where the banks are not swamps or bogs, the current of the stream increases the wholesome current of the air; and its lively motion constitutes its chief interest, it should therefore be bronght close to the windows, in a channel not too deep; as in such streams we do not require the still, sleepy mirror of deep water belonging to a navigable river; which Milton very beantifully contrasts, as distinct objects,

"The shallow Brook, and River wide." 
Thirdly, Where a property is bounded by a natural river, it is surely advisable to take advantage of so interesting a feature; especially where islands or brushwood, on the opposite shore, prevent any nuisance or intrusion from a neighbour; but at present the shores appear more wet and swampy than they really are, from the willows and aquatic plants, which have been suffered to grow, in preference to the alders, which have, not improperly, been called, "the Aquatic Oak." But when new channels are dug, and the ground raised on the island, it will be found capable of bearing all sorts of trees and shrubs, which will do away the present apparent swampiness of the shores.

There is still one other objection, which may perhaps be made by those who consider that a house in the country must not only stand in the middle of its own property, but also that it should be smrounded by park or lawn of great extent. This may be necessary to give the mock importance of space to a modern mansion, but the ancient manor-house generally stood near a public road, and derived its importance from the neighbouring village, or cottages, or pastures, rather than from the destruction of every other dwelling near it, to produce one overgrown grass-field; or by "lawning a hundred good acres of wheat," to produce a bald naked park, dotted with starving trees, or belted and clumped with spruce firs, and larches, and Lombardy poplars.

The sketch subjoined is an accurate portrait of the present view from the south-east front of the house, encumbered by 


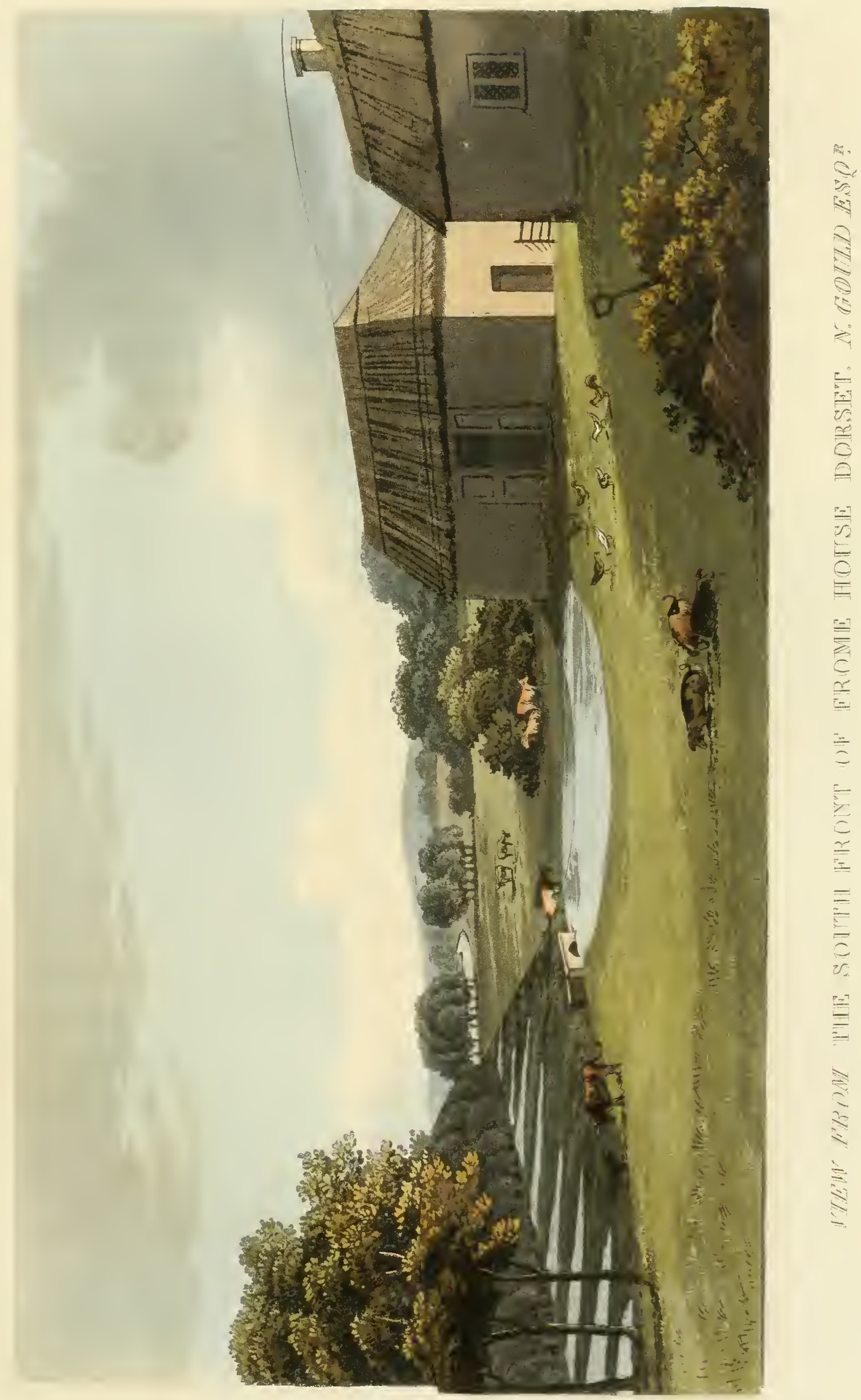





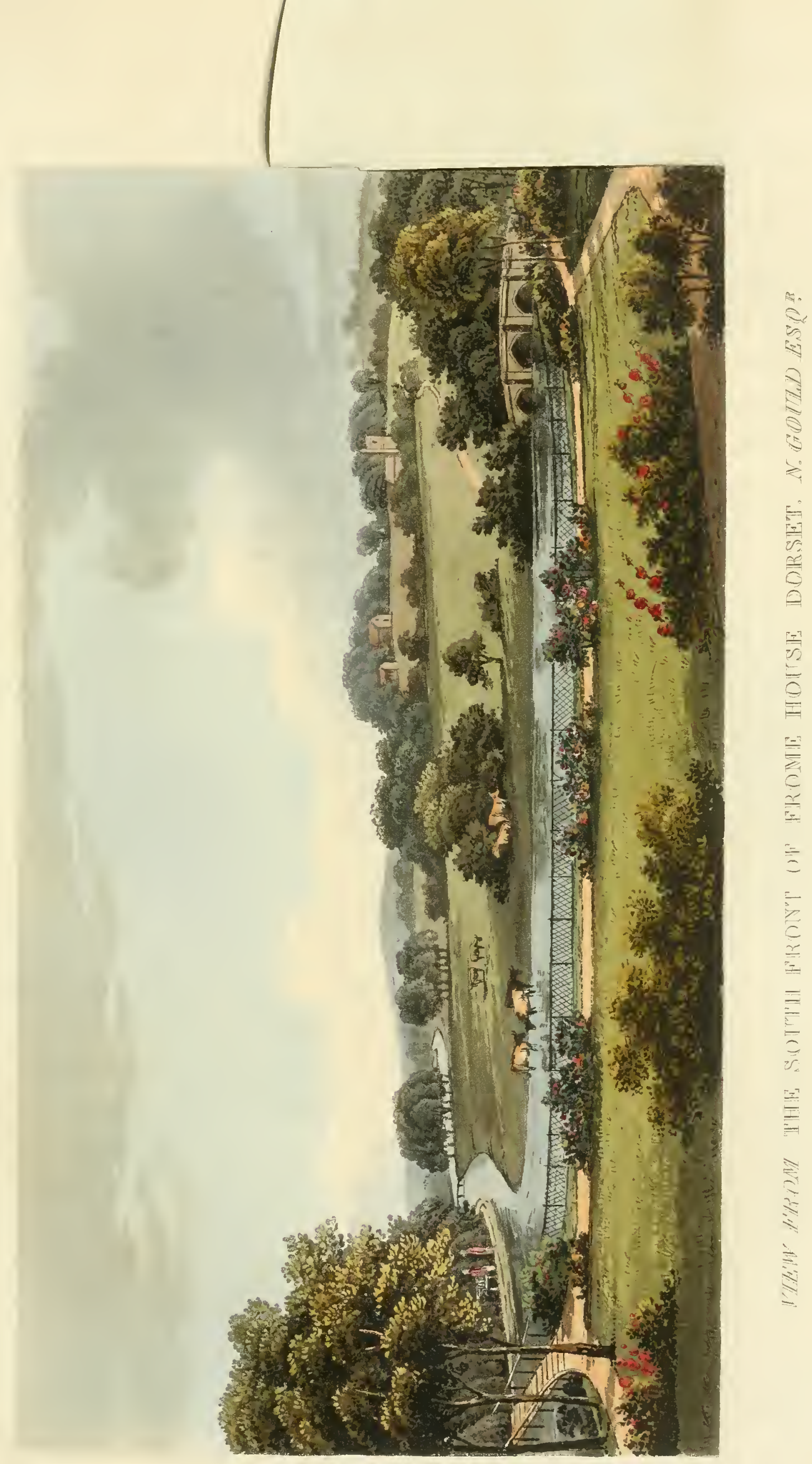



barns, and the water is seen in the furrows along the side of the willow copse. At present the view is neither land nor water; but by digging a channel to connect with the line of the river, the water will become the boundary of the dressed ground near the house; while a pleasing intricacy will be occasioned by the contrasted forms of bridges to connect the several islands; and the landseape, without being bold, or romantic, will become interesting and picturesque.*

* There is a circumstance belonging to the Rivulets in Dorsetshire, which requires peculiar treatment. The water of this and the adjoining counties of Hants and Wilts often consists of small rivers called Bourns, some of which are perfectly dry during the summer, and others are so shallow, as to be nearly invisible, from the quantity of grass and weeds floating on the surfice. Where the water is meant to be ornamental, it will often be advisable to mow and rake the stream, which requires as much attention as a grass or gravel-walk, not to appear slovenly and overgrown with weeds. 


\title{
FRAGMENT XXII.
}

\section{$\mathrm{OP}$ \\ ASPECTS AND PROSPECTS.}

\author{
FroN a REPORT CONCERNING THE SITUATION FOR \\ WALWOOD HOUSE, \\ TO BE ERECTED ON A PROPERTI IN TIE PARISII OF LAYTONSTONE, \\ ESSEX, BELONGING TO WILLIAM COTTON, ESQ.
}

Nothing is more common than for those who intend to build to consult many advisers, and to collect different plans, from which they suppose it possible to make one perfect whole. But they might as well expect to make an epic poem, by selecting detached verses from the works of different poets. Others take a plan, and fancy it may be adapted to any situation; but in reality, the plan must be made not only to fit the spot, it ought actually to be made upon the spot, that every door and window may be adapted to the Aspects and Prospects of the situation.

It was a remark of my venerable friend, Mr. Carr of York, after fourscore years experience as an Architect, that to "build " a house, we had only to provide all that was wanted, and no " more; then to place the best rooms to the best aspects and the 
" best views." Simple as this apothegm may appear, it contains more truth in theory, and more difficulty in practice, than all the rules which have ever been laid down in books by architects, or the remarks of all the admirers of rural scenery, with whom I have conversed. The former never think of Aspects, and the latter think of nothing but Prospects. I will therefore beg leave to enlarge on these two subjects.

I consider the Aspect as of infinitely more consequence to the comfort and enjoyment of the inhabitant, than any Prospect whatever: and every common observer must be convinced, that in this climate a southern aspect is most desirable; but few are aware of the total difierence in the effect of turning the front of the house a few points to the East or to the West of the south; because, although the south-east is the best, yet the south-west is the worst of all possible Aspects; for this reason, viz. all blustering winds and driving rains come from the sonth-west, and consequently the windows are so covered with wet, as to render the landscape hardly visible. My atiention was originally drawn to this subject by travelling so much in post carriages, and often remarking the difference betwixt the window to the south-west and that to the sonth-east, during a shower of rain, or immediately after; when the sun shining on the drops causes an unpleasant glitter, obstructing the prospect, while the riew towards the sonth-east remains perfectly risible.*

* At Organ-Hall, in Hertfordshire, a seat of William Towgood, Esq. the livingroom was towards the south-west, and during a heavy storm of wind and rain we acci- 
If we had only one front, or one aspect to consider, our difliculty would soon vanish; but the prevailing partiality for varicty of Prospect seems to require, that in every direction the views should be retained; and as the opposite walls of the house must be parallel, and the corners at right angles, we must consider the effect on each of the four sides-thus-

First, The Aspect due North is apt to be gloomy, because no sumshine ever cheers a room so placed:

Secondly, The Aspect due East is not much better, because there the sun only shines while we are in bed:

Thirdly, The Aspect due West is intolerable, from the excess of sun dazzling the eye through the greatest part of the day.

From hence we may conclude, that a square house, placed with its fronts duly opposite to the cardinal points, will have one good and three bad aspects.

Let us now consider the effect of turning the principal front towards the south-east, then the opposite front will be to the

dentally went into the butler's-pantry, which looked towards the south-east, where we found the storm abated, and the view from the windows perfectly clear and free from wet; but on returning into the other room, the storm appeared as violent as ever; and the windows were entirely covered with drops, which obstructed all view.

On considering the prevalence of south-west winds, it was determined to reverse the Aspects of the house, by changing the uses of the rooms; making a very comfortable house of one which, from its Aspect only, was before hardly habitable; since no window, nor hardly any brick walls, will keep out the wet, where a from is exposed to the south-west: for this reason, it has been found necessary in many places, as at Brighton, \&c. to cover the walls with slates, or pendent tiles, and to use double sashes to the windows so situated. 
north-west; an Aspect far better than either due north or due west; because some sunshine may be preserved, when its beams are less potent than in the west, and the scene will be illuminated by those catching lights so much studied by painters; especially where, as in the present instance, the landscape consists of large masses of forest trees, and thickets richly hanging down the side of an opposite hill. An Aspect open to the northeast would be objectionable during the cold winds of spring; but in this instance it is effectually sheltered by an impervions skreen of trees, and large holleys, not drawn across the landscape, but perspectively receding into a deep bay, and forming an admirable defence against the north-east winds; while the richness and variety of this amphitheatre of evergreens, will render the Prospect as perfect as the Aspect. This warmly sheltered corner will invite the cattle from every other part of the grounds, to enliven the home view near the windows.

It now remains only to mention the side towards the southwest; and having stated the objection to this Aspect, we may consider it fortunate that the Prospect in this direction is such as requires to be hid rather than displayed; and, conserfuently, the detached oflices and plantations, to connect the gardens with the house, will defend the latler from the driving storms of the south-west, and give that sheltered and shady connexion betwixt the house, offices, and gardens, which constitutes one of the most delightful agrèmens of a country residence.

While speaking of the three different Aspects, I have slightly 
adrerted to their respective views or landscapes; but I will speak further on that towards the south-east, to which all the others may be considered as subordinate, although not sacrificed.

It is very common for admirers of landscape or natural scenery, to orerlook the difference betwixt a tree and a pole, or hetwix a grove of old trees and a plantation of young ones. We fancy that time will reconcile the difference; but, alas! we grow old as fast as the trees; and while we dot and clump a few starving saplings on an open lawn, we indulge hopes of secing trees, when in fact we only live to see the chmsy fences by which for many years they must be protected. Happy therefore is that proprietor of the soil, who becomes possessed of large trees, already growing on the land he purchases; since no price can buy the eflect of years, or create a full grown wood; and without that, we may possess a garden, or a shrubbery, but not a landseape. This consideration alone is sufficient to attach us to the vicinity of that venerable avenue, which it would be a sort of sacrilege to desert, and whose age and beanly will give an immediate degree of importance to the house, which could never be expected in any more open part of the estate.

'The view towards the south-east will consist of a glade into the forest, where the distant woods of Wanstead are seen betwixi the stems of large trees in the foreground, producing a purple tone of colouring, so much studied by painters and admirers of picturesque effect. To this may be added, the 
cheerful moving scene of a public road, not too near to be offensive; for however some may affect to prize the solitude and seclusion of a forest, shut out from all the busy haunts of men, yet within six miles of the capital, few places can boast such privacy as Wallwood House commands within its forly acres surrounded by a forest. Who then would regret to see occasionally, and at a proper distance, the enlivening mixture of man with animal life, and regetation in its most interesting formis!

From its situation within so few miles of the metropolis, this place ought to combine all the pleasures of the country, wilh the conveniences of a lown residence.

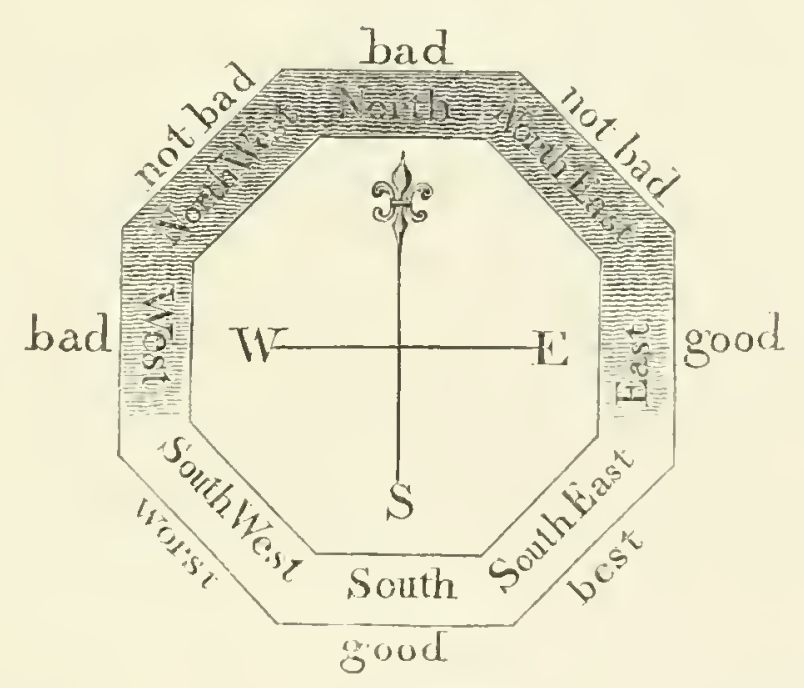




\section{FRAGMENT XXIII.}

\section{OF VARIETY.}

Ix delivering my opinion in a former work, I used an expression respecting the humility of experience, which was ridiculed by some critics, but which I now repeat after a lapse of many years. "I do not presume to establish principles in taste, but to "record my practice, and the motives which led to it. This I do "with all the humility acquired by experience." When I look back on the many hundred places I have visited, and plans I have formed, I can find no two which exactly resembled each other; but where some small similitude might perhaps be traced, there ever existed such variety in the eircumstances, the wishes, or the characters of the possessors, that it was impossible to class them in such a manner as might lead to general use. Indeed, if we consider that of the many thousand houses which have been built, no one has ever been exactly copied in the plans for any future house; but, on the contrary, that every plan is either taken from designs which have never been executed, or from the remains of ancient buildings, of whose uses we are almost ignorant: we may ask, Cui bono? to what good purpose are plans and designs and works of art ever published? The only answer 
that seems plausible, beyond that of amusement to the mind from variety, is, that by examining and comparing different designs, the best parts of each may be selected; but this is contradicted by every day's experience.

There is no instance in which a good plan has ever been the result of much diversity of opinion: and in no instance, since the effort of Beaumont and Fletcher, has combined genius excelled individual unity of talent or experience.

To the remark in the preceding Fragment, which recommends "placing the best rooms towards the best Views and the "best Aspects," I should add, " not placing the entrance on "the same side of the louse with the principal apartments:" and thus, after all, it will be found, that nine times in ten the entrance must be on the north side; and notwithstanding the absurdity of a magnificent portico towards that aspect, where no sunshine can illumine its columns, or require its shade, almost all the finest porticos in England are placed to the north; and I have myself, from necessity, been compelled to do so in many instances, against my better judgment.*

In approaching the close of my active life, it is natural that I should look back on the various objects which have claimed

* The late Sir William Chambers asserts, that the entrance to a House, like a nose on a face, was the principal feature, and ought to be the most prominent. Yet in his oren Villa at Whitton he had five doors in the principal front: that in the centre opened into a shell-work grotto, used as a dairy. Such is the difference betwixt Theory and Practice, even where the Professor may be supposed to have been uncontrolled. 
my attention, and called forth my exertions: some of these I can view with delight, and record with exultation; but, alas! in how many have my time, my labour, and my contrivance been employed, without producing fame or profit: the latter was only a secondary consideration, and yet, when that has been withheld, the other has generally suffered in proportion.

By leaving this memorial of some of my works, I shall endeavour to recover a little fame, although I may derive no other emolument: and I insert the annexed sketch of a House, stables, a school-house, a parsonage, and numerous plans for buildings, which have been made, approved of, and executed, without our ever being permitted to visit the progress of works on so extensive a scale, and for which we furnished the minutest details, without ever receiving the expected remuneration. The name both of the Place and its Proprietor are omitted; but in the annexed drawing

$$
\text { "STAT NOMINIS UMBRA." }
$$




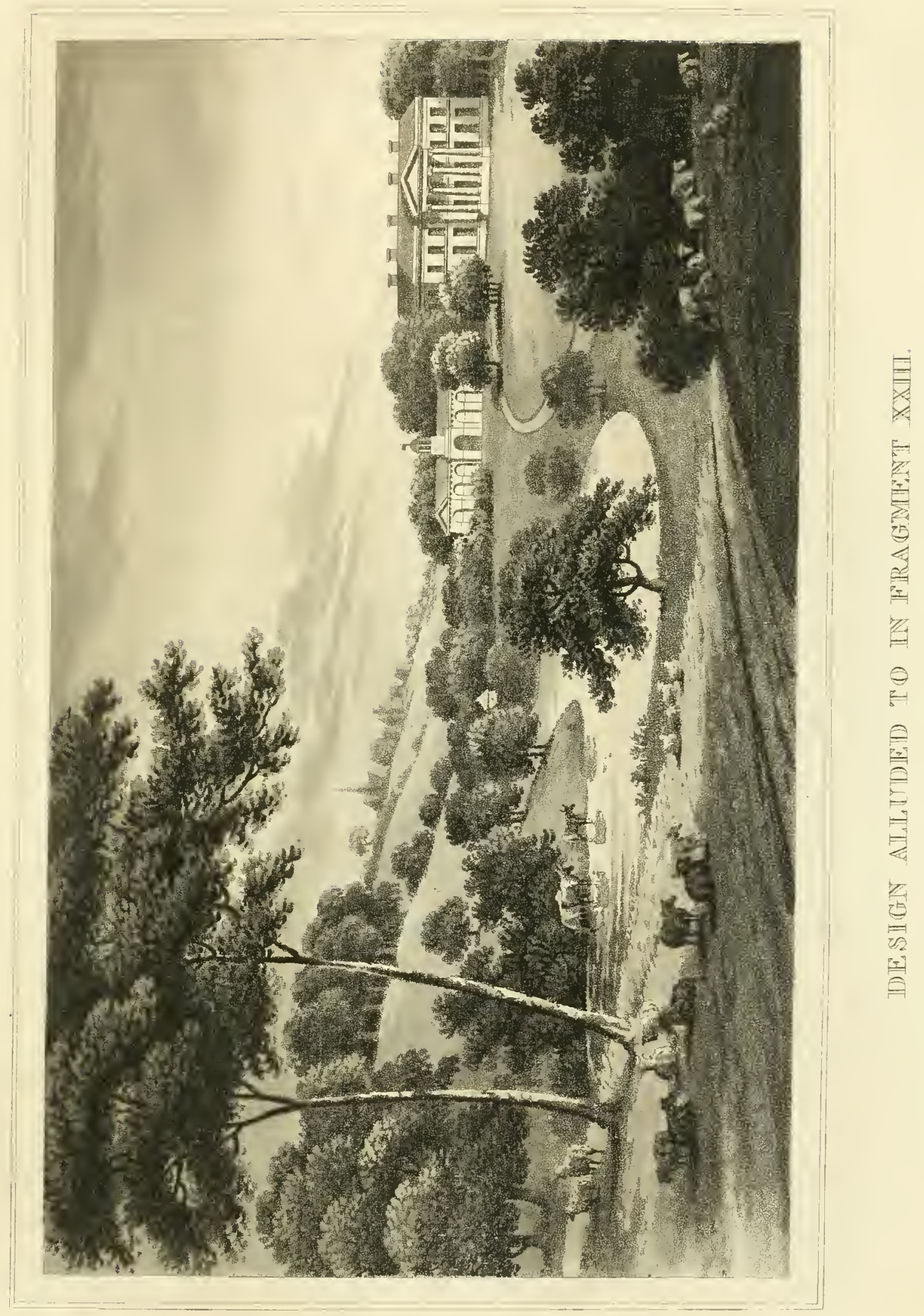





\section{FRAGMENT XXIV.}

\section{LONGLEATE, W I L T S H I RE,}

A SEAT OF THE MARQUIS OF BATH.

\section{EXTRAC'T FROM THE REPORT OF 1803.}

CHARACTER AND SITUATION.

"Whether we consider the natural shape of the ground, forming ample hills and valleys, the great masses of wood with which these hills have been magnificently clothed, the extensive range of park and surrounding domain, the vast command of various distant prospects, or the great style and magnitude of the House itself, we must acknowledge, that the character of Greatness makes a strong impression, and is pecnliarly appropriated to Longleate. But as objects are only great or small by comparison, and it is the duty of the improver to guard against any thing that may tend to weaken this first impression, he must, if possible, increase the apparent vastness of the place in all that belongs to Nature, and preserve the character of Greatness in such parts as depend on the works of Art.

"I must here again remark, that there is no error more common than to substitute greatness of dimensions for greatness of character. Thus in Landiscape we often see lawns of great 
extent, with as little variety or interest as Salisbury Plain; and walks and drives of many miles in length, through shrubberies and plantations, without any change of scenery, or any diversity of fealures; while in Architecture we occasionally see huge masses without shape or proportion, boasting the ground they cover, or the apartments they contain, yet with less appearance of a palace than a cotton-mill, or a manufactory. I am here led to make a marked distinction between the improvements relating to Art and those relating to Nature, from the two leading circumstances to which my attention was first called, viz. the proper situation for the stables, and the proper management of the Water: the latter belongs to Landscape Gardening, as an Art which imilates Nature; the former to Arehitecture, as an Art that arlorns Nature, and indeed forms the strongest auxiliary to the Art of Landscape Gardening.

"This Mansion was built at the period when the Gothic Character was giving place to the introduction of Roman and Grecian Architecture; and although some would call the House Greciun, from its Pilasters and Entablatures, yet its general appearance is Gothic, from the bold square projection of the windows, and the varied outline of the roof, occasioned by the turrets and lofty chimneys, and the open-work enrichments.

"The eight Towers in the roof are so placed, as to occasion some confusion, or rather a certain degree of intricacy in perspective, from whatever point they are viewed; had they been placed at regular distances, the effect of grandeur in this building would have been weakened. To explain this, I must 
observe, that symmetry, or an exact correspondence of parts, assists the eye in viewing and comprehending the whole object at once; but irregularity retards the progress of vision; and from the difficulty of comprehending the whole, its magnitude increases on the imagination. (This subject is further explained in my first printed work, Sketches and Hints on Landscape Gardening.)

"The Hills at Longleate have been boldly planted, and at the same period many fast growing trees were planted in the valleys; these latter were become in many places too tall for their situation. There are some limes and planes, and lofty elms, near the water, in situations where maples and crabs, and thorns and alders, or even oaks and chesnuts, would have been far more appropriate: and there are some few tall shattered trees remaining of the avenue near the house, which tend to depress its importance.*

"It is a mistaken idea, that the planter may not live to see his future woods, unless they consist of firs and larches, or planes and other fast growing trees; but every day's experience evinces, that man outlives his trees, where plantations do not consist of oak; and that often tall mutilated planes, or woods of naked stemmed Scoteh firs, remind him, that groups of oaks and groves of chesnut might have been planted with greater

* Since this Report was delivered, almost all the objectionable trees have been removed by a spring blight, which destroyed so many Planes in every part of England; and the place has been greatly improved in consequence. 
advantage. It is not therefore in compliance with the modern fashion of Gardening that I advise the removal of a few tall trees, but in conformity to taste, founded on reason, and which dictates that the character of Greatness, in a work of Art, should not be obliterated by the more powerful agency of Nature: and without wishing to go back to that taste which prevailed when this vast pile was surrounded by cut shrubs, and avenues of young trees newly planted, I think some of its grandeur might be restored by judicionsly removing some of the encroachments of vegetation.

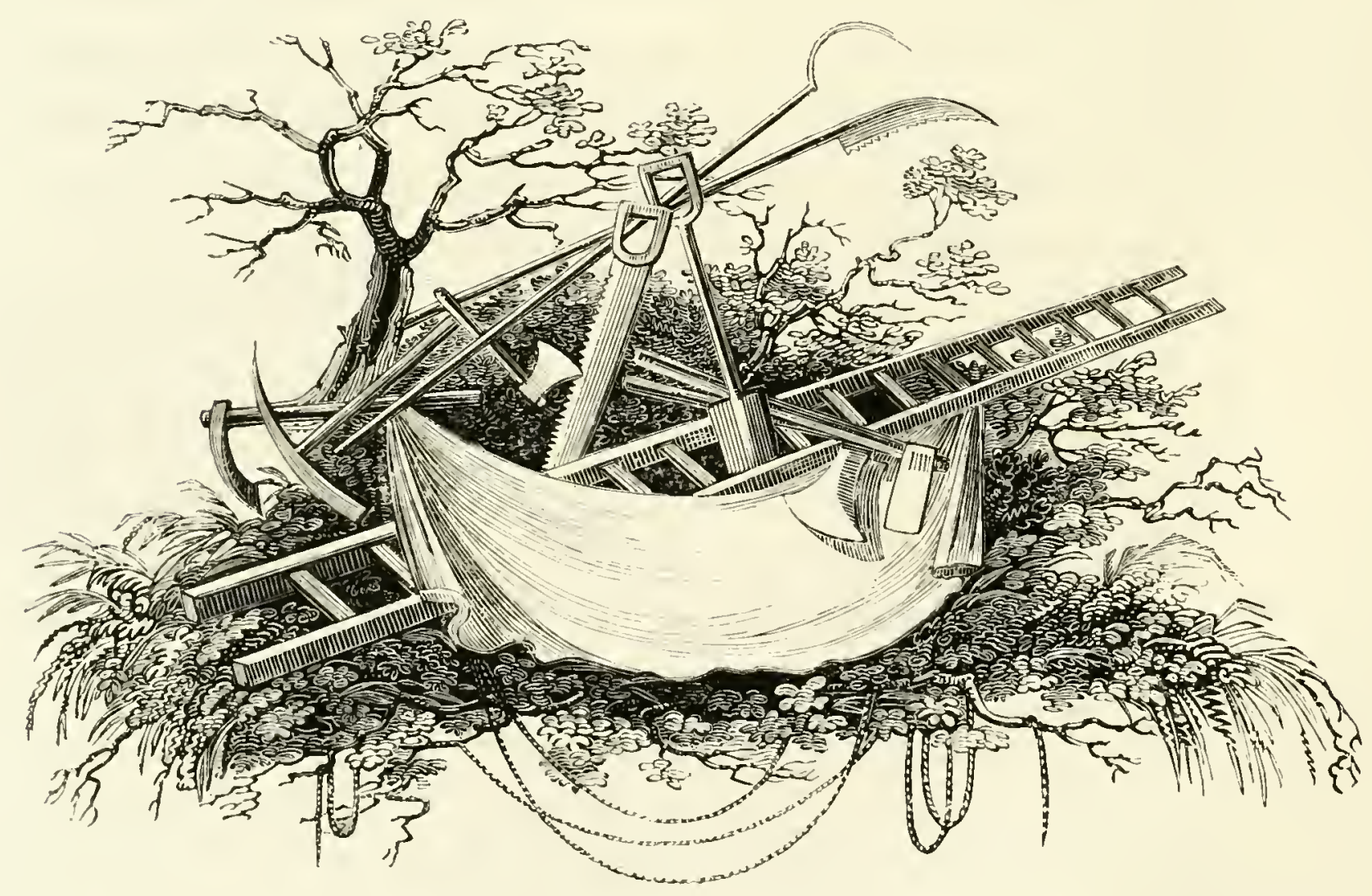


"There having been various opinions concerning the management of the $W$ ater, it may not be improper to state and examine each in the following order.

"The first opinion arises from the natural wish that the water should be in the lowest ground, and therefore it was proposed to float the valley to the north, making one large lake. To this there are many objections: first, it would not be seen from the house; secondly, if seen, it wonld not be desirable, being to the north; and lastly, if it were possible (of which I have some doubts), it could only be accomplished by an enormous dam across the valley: this it would be far more difficult to disguise than the present dam, which only requires to be planted to deceive, and conceal the lower ground; for every piece of water that is made by Art to imitate Nature, must be produced by some degree of deception.

"The second opinion is, that the brook should pass through the valley in a natural channel, instead of being checked by so many different dams, to form so many different pools: the objection to this arises from the supply not being sufficient. Where a rattling turbulent mountain-stream passes through a rocky valley, like the Derwent at Chatsworth, perhaps Mr. Brown was wrong in checking its noisy course, to produce the glassy surface of a slow moving river; but as the quantity of water at. Longleate might pass through a narrow channel, or water- 
course, far beneath the dignity of the place, it ought rather to be carried in a culvert under ground than be shewn at all in the humble shape and scanty quantity that Nature has allotted: yet it was a stream of sufficient magnitude for the purposes of Art, in the ancient style of Gardening, when Art was boldly avowed, and this stream supplied the fountains and cascades and basins, which then constituted the magnificent but artificial scenery near the house. To this may be added, that it supplied the mill, a very important object in old times; and this mill, Leate, gave its name to the place, now called Longleate.

"We next proceed to the third opinion, viz. that the water should form an apparent liver through the whole valley; this, I believe, was originally the intention of Greenway, ${ }^{*}$ who preceded Brown, and whose fondness for serpentine lines gave the water its present shape, at a prodigious expense. Brown continued the same idea, but reduced the scale of the original design; and though he has in some degree produced the effect of a River by various different pools, yet the deceptions are not well disguised, and the part most unfinished is that nearest the house, where the two plans of Greenway and Brown are brought into contact, without being well united or blended together.

"My opinion only goes to the completion of Brown's idea, to imitate Nature in the form of a large river, and disguise

* Or Bridgeman, disciples of Kent, in the first departure from straight lines. 
the Art by which this is effected. I will suppose that a large River has always passed through the valley, and, like many large rivers, that it was not originally navigable, but that by art it has been made so to a certain spot, and that near this spot the house was built; under such circumstances a bridge would naturally be placed where rocks present a foundation, and to this bridge, and no further, we may imagine the water navigable.

"The bed of the river being dug so deep as to bring all the water below the bridge to the same level, the house would stand high above the water, instead of appearing on the same level, as it does at present.* The shape of the water should be made gradually to swell into the broad river; but as there will then be a disproportion between the channel near the bridge and the broadest part of the river, this might be accounted for by a channel dug near the group of elms, and thus the house would seem to stand on a broad promontory, formed by the conflux of two different streams.

"The water above the bridge will not require to be dug any deeper, nor the surface to be much lowered; because the fall at the bridge will fully account for the river being no further navigable, than where a ledge of rocks impedes its course; for the largest rivers in the world are interrupted by reefs, called rapids; and therefore, not only at the bridge, but at the junc-

* This in 1814 was completed; and the effect produced exceeds the promise, or any representation made by the drawings. From the ground near the house there was a fall of only five feet to the surface of the water; that surface has been lowered thirteen feet. 


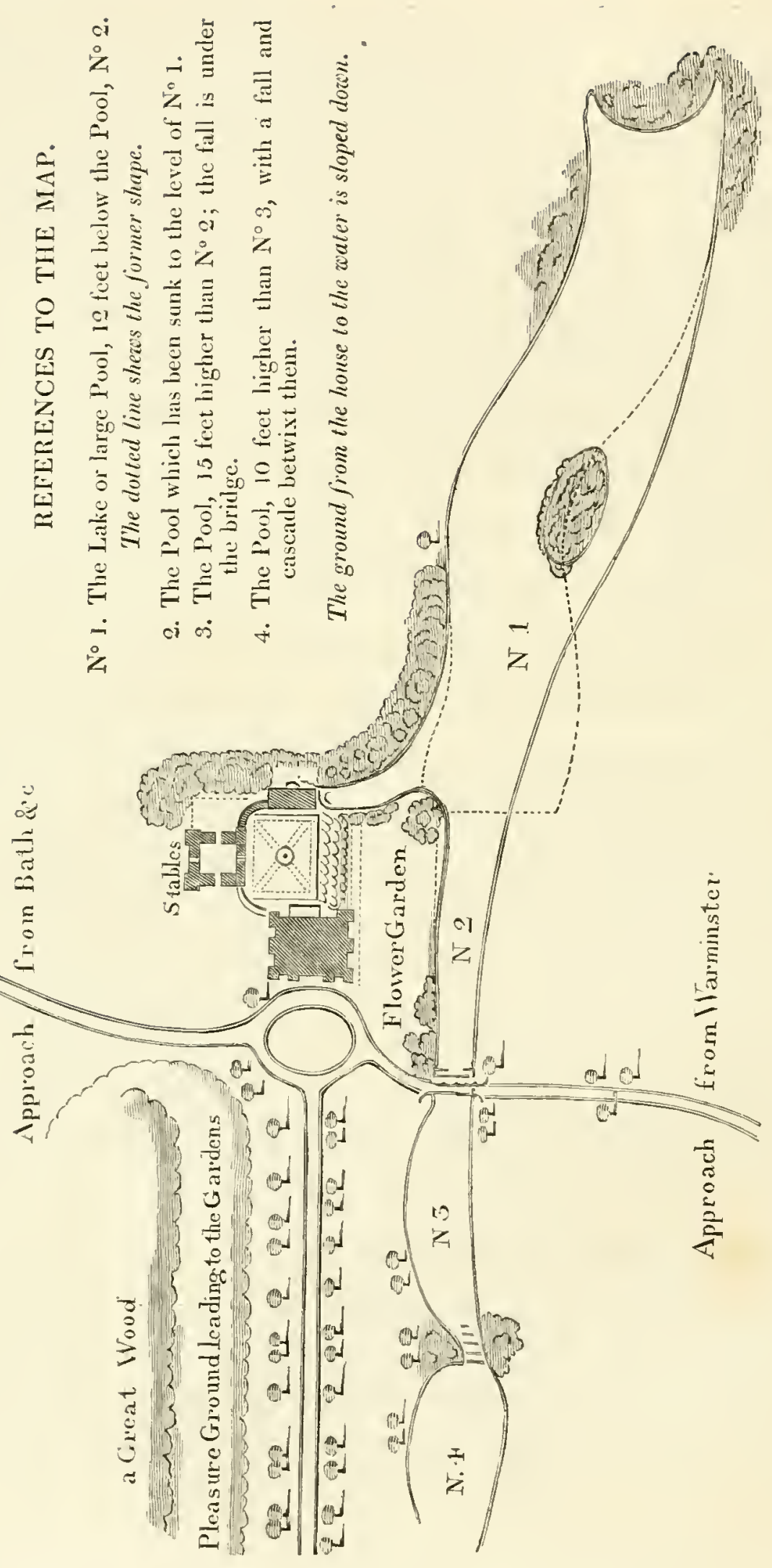





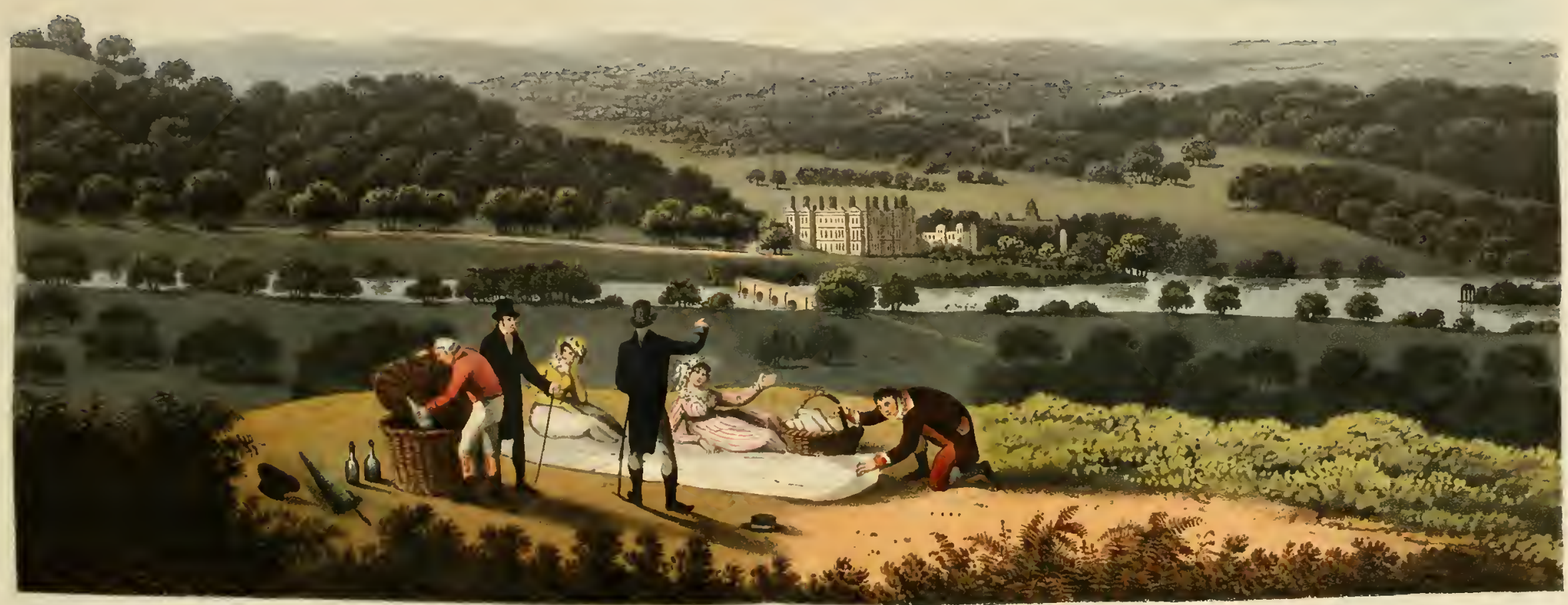


tion between the two next pools, this process of Nature should be imitated.

"The different levels of the several pools were formerly disguised by plantations; but these having outgrown their original intention as brushwood, have become trees, between whose stems the deception of the dams is too much betrayed. These screens should be repaired by Thorns and Alders, so as to produce the general effect of one continued river, as I have represented in all the different views of the water."

With permission of the Marquis of Bath, the preceding extracts have been made from the volume of Reports concerning the improvements of Longleate. The original MS. is elucidated by fourteen different drawings, from which is selected the drawing representing the south and east fronts of the House from Prospect Hill, a spot at no great distance from the Warminster approach. It is difficult to represent the vast range of country which this hill commands, extending over the whole county of Somerset towards the Welsh hills, beyond the Bristol Channel. This magnificent Park, so far from being kept locked up to exclude mankind from parkaking of its seenery, is always open, and parties are permitted to bring their refreshments; which circumstance tends to enliven the scene, to extend a more general knowledge of its beauties to strangers, and to mark the liberality of its Noble Proprietor, in thus deigning to participate with others the good he enjoys. 


\section{FRAGMENT XXV.}

\section{A PLAN EXPLAINED.}

I HAVE frequently observed, that those who perfectly understand a Drawing in Perspective, have sometimes no idea of a Plan or Map, and are not ashamed to confess they do not understand either. I will therefore avail myself of the following letter, addressed to a Lady; and I trust the difficulty will be removed, by referring to the Plate, which gives an example of both the Map of a Garden and the Ground Plan of a House and its appendages.

$$
\text { TO LADY } \text { LA** }^{*}
$$

M A D A M,

As you have confessed to me that you never could understand a Plan, I will endeavour to remove your difficulties, by a reference to the one annexed. We must begin by supposing that the embroidery at the corner is a pattern for a FlowerGarden, the blue patch in the middle is a fountain, the basin of which is about ten feet wide; the orange lines are gravel walks; the little patches of red and green represent roses and other flowers in beds or baskets, standing on the neatest mown grass; 
and the four circles may be berceaux, with hoops to support creepers, or they may be grass plots with vases or statues. I am aware that this will cause some alarm to those who fancy all Nature at variance with Art, and who will exclaim, that it is going back to the old fashioned formal gardening of former days: I answer by reminding them, that I am not now describing a Landscape, but a Garden; and "A GARDen 1s A work “ of Art, using the materials of Nature."

Among the infinite variety of flowers which adorn the Garden, there are some so minute, that they require being lifted from the ground to meet the eye, and some so formed, that they should be raised even above the eye, to shew their beanties (such as the Fuscia, the Meadea, and other pendulous plants): to provide for these, we will suppose four beds of fossils or flints, or rocky fragments, for the reception of that interesting. class of plants, which requires such a soil and situation: these are described on the Plan by purple and yellow. As occasional spray from a fountain might wet the gravel walk, it should be neatly paved with pebbles round the basin.

On that side of the Flower Garden which fronts towards the south, is a house for peaches and strawberries. On the side opposite, and in some degree corresponding, is a row of posts with hoops to train creepers, and an architectural gate communicating with the park, betwixt two projecting lines of shrubbery, which are meant to consist of every kind of thorns, towards the park to the south, and American plants towards the garden to the north. This attention to north and south is very essen- 
tial, since every thing in a flower garden depends on its exposure, and therefore I must refer you to the compass to ascertain the aspects, of which that to the north is cold, sunless, and gloomy; that to the south is hot, genial, and cheerful; that to the cast partakes of both, but requires shelter in spring; and that to the west is exposed to more stormy rains and winds than any other, and therefore we will suppose the flower-passage marked $N^{\circ} 3$ on the Plan to be defended from the west by a flued wall, and on the side next the flower-garden by glass in spring, but removable in summer; the glass-roof may remain constantly. The whole inside of this roof is covered with a wide trellis, to support vines and other climbing plants.

Another sketch represents this flower-passage terminated by a Statue of Flora, which conceals the join in two large lookingglasses placed behind it. In this mirror are repeated all the objects in the passage; nor is the deception discovered, till on a nearer approach we find that we can proceed no further in that direction. The passages to the right and left lead to the fruithouses, or to an aviary at the back of the mirror.

By the help of the Plan, let us go back again to the flowerpassage, $\mathrm{N}^{\circ} 3 . \mathrm{N}^{\circ} 4$ is the Orangery, which is lighted from the roof, and receives only the morning and evening sun, that at noon being impeded by the position of the mansion to the south; but an orangery does not require so much sunshine as a hothouse; and in the summer the orange-trees in tubs are placed in front of the house in the two quarters of a circle described on the Plan. 


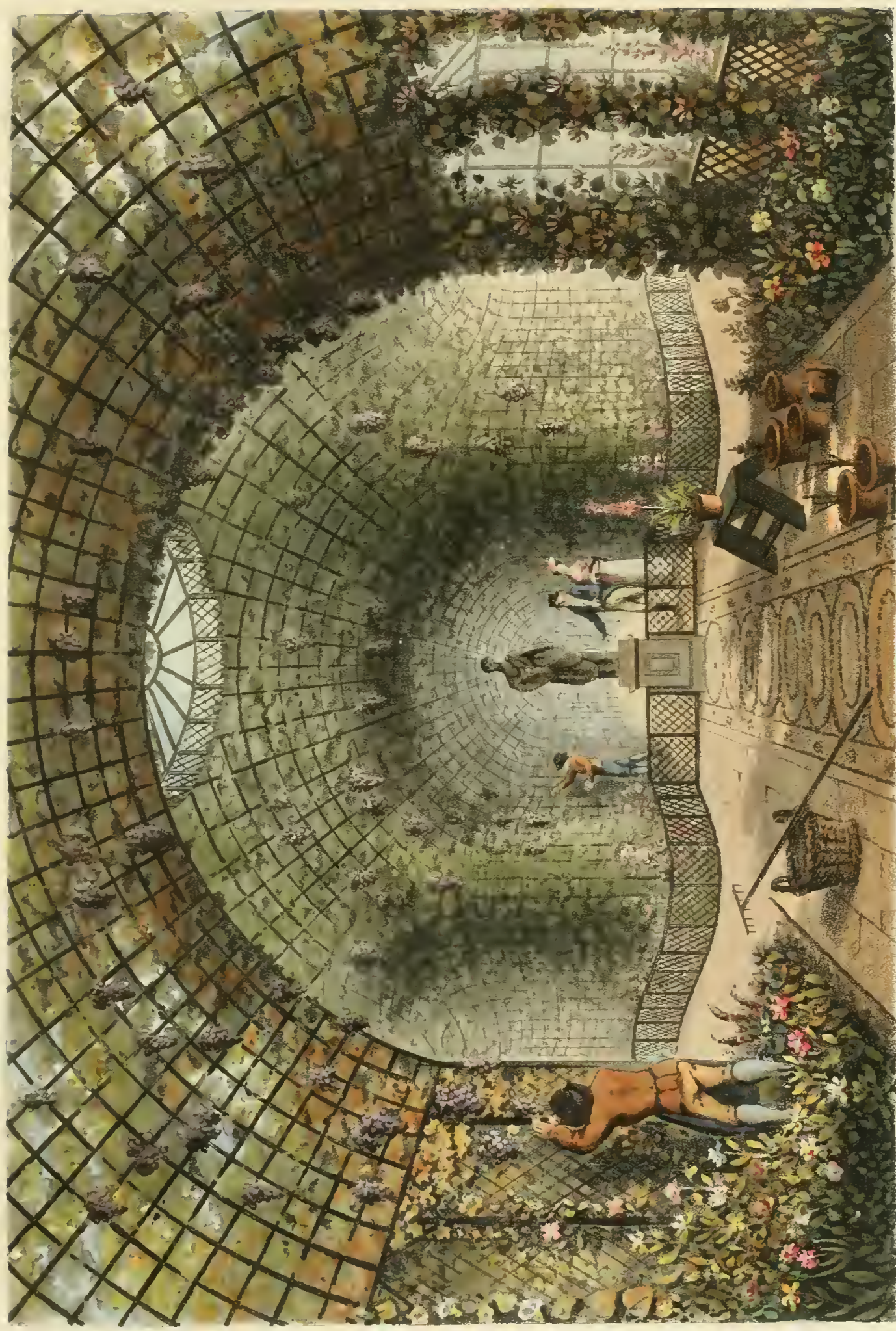



The magnificent Library, or Living-room, consists of three compartments, with a fire-place in each, and a flue near the windows of the bow: the centre is fifty feet by twenty-eight, opening into two recesses, or tribunes, of diflerent shapes, fitted up in very different manners, one being for music-books and instruments, the other for books of prints and portfolios of drawings; and both joined to the large library by a skreen of columns, or at pleasure separated from it by drapery and curtains. All this is repeated by a large mirror over the fire-place, which, aided by three apertures for stained glass above the level of the bookcases, prevents this end from being deficient in light, and gires to the whole an air of united cheerfulness, magnificence, and novelty.

On leaving these new rooms, $\mathrm{N}^{\circ} 6,7$, and 8 , we enter the old suite of apartments, $N^{\circ} 9,10$, and 11 , now opening into each other by large folding doors, and from the spot marked $\mathrm{X}$ we have two enfilades, one of about three hundred feet, but in fact, by the mirror of Flora, rendered indefinite; and the other of about seventy feet along the two green-houses, through the entrance-porch, and terminating either by a statue or fountain, or doubled by another mirror at the end.

On the Plan are distinguished by a light brown wash, the grounds for use and not for ornament, being invisible from the house; and by a green wash those which are visible from the principal rooms, consisting of landscape and park scenery, where the cattle are prevented from breaking the windows by a dwarf terrace-ivall, richly dressed with flowers, which forms 
the foreground or frame of the picture. So magnificent and complicated a Plan may perhaps appear ideal, but it actually exists, although I have never seen it since I made the Plan on the spot.*

* To explain this, I will relate the following fact. The Proprietor called at my door, and took me to the place, to ask my opinion about adding a new room of large dimensions to an old house. I described by a pencil sketch the general idea of this annexed Plan, with which he was so much pleased, that he desired me the day following to explain it to a gentleman, who I afterwards discovered was a clerk of the works to an eminent Architect. The pencil sketch was all that I was ever permitted to deliver, fiom which the whole was immediately carried into execution, without having yielded me either emolument or fame, or any other advantage, except the useful lesson-Not to leare a Pencil Sketch in the hands of a Clerk of the Works.-Under such circumstances, I hope I may be excused for claiming my share in a design which I have often heard commended as the sole production of the late Proprietor's exquisite taste. IIc certainly made it all his own: but there was not a single idea which I had not furnished. 


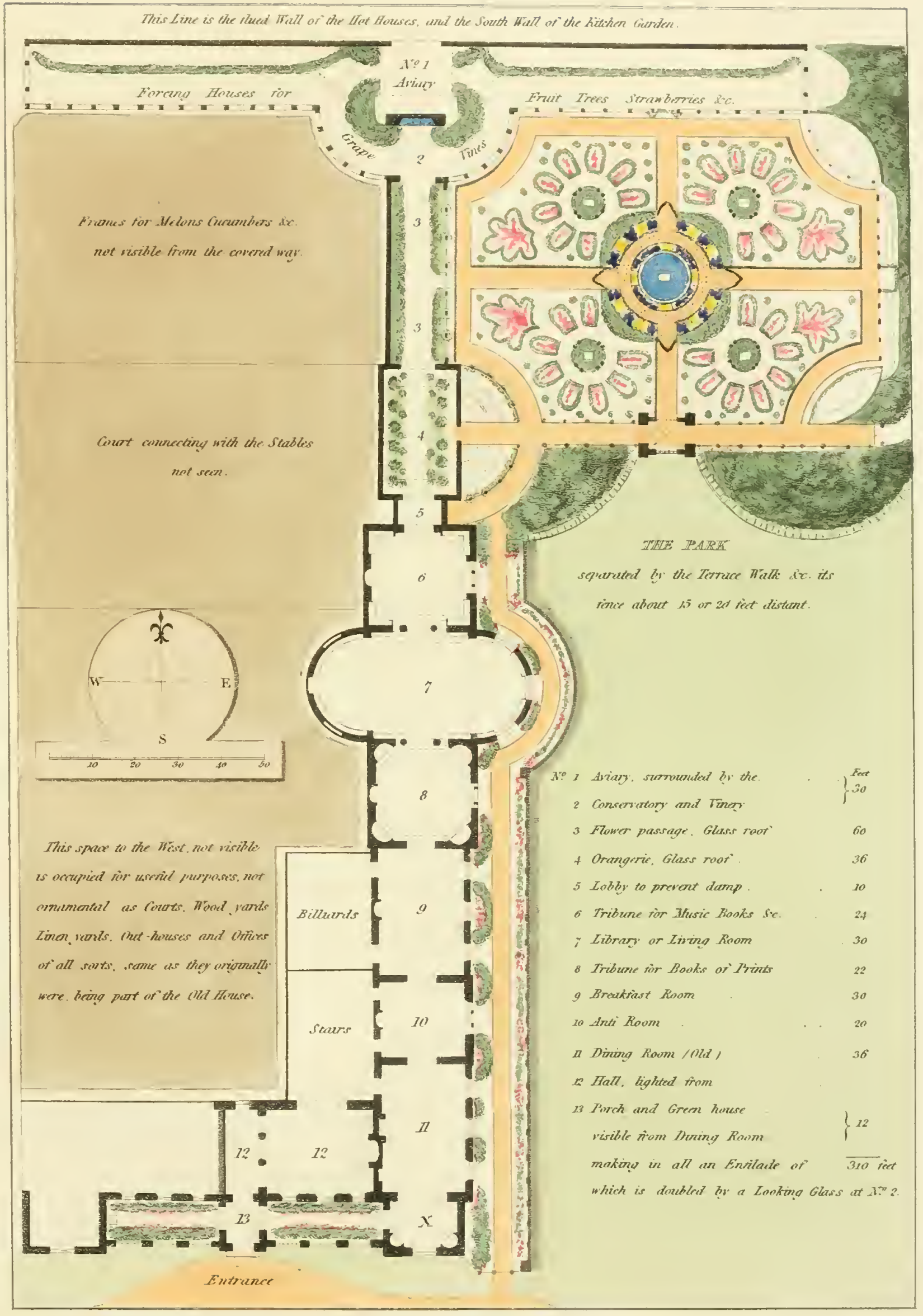





\section{FRAGMENT XXVI.}

\section{A PLACE NEAR THE CAPITAL.}

ONE $_{\mathrm{N}}$ of the most magnificent places in this country, which furnishes examples of the Geometric style of Gardening, has so recently been submitted to my opinion, that little time has yet been given to the development of plans, to which I shall therefore not allude by name; but in a few years, I trust, there will be no reason for regretting that the following Sketch and Extract from the Report have been allowed to form a part of this volume, intended to record some of the most striking and important of those Designs which I have had the honour to deliver.

\section{INTRODUCTION.}

CONCERNING THE STYLE AND CHARACTER OF *********

If the fashion of Gardens could be altered with the same ease as the fashion of dress or furniture, it would be of less consequence how often it was varied, or by what caprice or whim it was dictated; but the original plan of this Place must ever strongly traced in many parts, though a century has elapsed; and it is impossible to be quite obliterated, in conformity with more modern styles. It is therefore an object worthy of consi- 
deration, whether the original, or the more recent style, be adrisable; and how far both may be admitted, without the incongruous mixture of two things so opposite, that they cannot be blended in one rational plan. I shall eall the Ancient Style of Gardens that of Versailles, as introduced into this country by Le Nôtre, in the beginning of the last century; and the Modern Style, that called English, as invented by Brown, and practised in England during the latter half of the last century.

THE ANCIENT STYLE.

'This consisted in straight lines and geometrie figures, and had more reference to Art than to Nature. It was distinguished by Arenues, or even single straight rows of trees, extended to a great distance, and far beyond the actual limits of the place. The surface of the ground was cut into slopes, ealled Amphitheatres, or raised up in conic shapes called Mounts; and even the water was obliged to assume some geometrical outline. So far from consulting or following Nature, the chief object of Art was to display its triumph over Nature. All this had its admirers, and beeame at length so much the fashion, that every garden in the kingdom (whether great or small) was condemned to submit to the same striet rules, till they were brought into ridicule by the admirers of more natural landseape; as by the satirical allusions of Pope, in this couplet so often quoted:

"Grove nods at Grove, each Alley has a brother,

"And half the platform just reflects the other." 
When every Villa had its little symmetrical Garden thus laid out, it is not to be wondered that the universal sameness of the design should create disgust in him who could never see any thing else, and at length that,

"Tir'd of the scene Parterres and Fountains yield,

"We find, at last, he better likes a field."

However imposing and magnificent a straight walk may be, between two lines of lofty trees, yet if every walk about a place be of the same kind, we shall prefer the winding footpath across the forest; and it was therefore very natural that the formal and artificial style should have given place to one more free and natural.

THE MODERN STYLE.

This was in every respect the reverse of the former. Instead of displaying the means by which Art could trimph over Nature, it seems to adopt for its motto-" Artis est celare Artem." The natural Landscape was the chicf object to be studied; and while in the ancient style, every situation, when shut up, became the same: in the modern style, every place open to the country varied with the different surrounding scenery of Nature; and consequently Nature was the model for Art to follow, but not to copy: she was to furnish hints and patterns, but not to be imitated with exact servility. The poet's rule says,

" To build, to plant, whatever you intend,

"To rear the Column, or the Arch to bend,

"To swell the Terrace, or to sink the Grot,

"In all, let Nature never be forgot." 
From hence it is evident, that the Poet no more meant to hanish entirely the Terrace or Grotto of the old style in Gardening, than Columns or Arcades in Architecture: but as manlind always step at once from one extreme to another, so every straight line became curved; and in contrasting Art with Naure, it was asserted, that a serpentine line was the true line of beauty, and that Nature abhorred a straight line; forgetting that in Nature's most sublime works the straight line prevails; as in the apparent horizon of the ocean, and the rays of the sun, which may be broken, but cannot be bent. This favourite meandering and undulating line soon prevailed in every thing, whether it was a line of a road, a walk, a canal, or the surface of the ground, or even the fence of a plantation; till at length it became as monotonous as the straight line, and every place in the kingdom was alike, whether large or small; from a Citizen's Villa with two acres, surrounded by a shrubbery and serpentine walk, to the Nobleman's Park of two thousand acres, surrounded by a belt of plantation and serpentine drive. These, by their uniform sameness, are equally iusipid, and have called forth from a modern poet lines not less severe than those of Pope.

" Prim gravel Walks, through which we winding go,

"In endless Serpentines, that nothing shew,

"Till tir'd, I ask, "Why this eternal romd?"

"And the pert gard'ner says, "'Tis pleasure-ground."

The Landscape, wy R. P. Knigh, Esq.

As applicd to this place, if all straight lines must be abolished, almost every tree wonld be sacrificed: and if all the 
shapes of land or water, which are artificial, must be made natural, the cost would be as much more to undo the work of former times, as the difference between the price of labour and the value of money now, and at the period when these costly works were executed.

My opinion respecting this View will, I have no doubt, be considered as a dereliction of all the modern notions of taste in Landscape Gardening. In this view towards the west we can see nothing natural, except the materials which Nature has furnished, of land, trees, and water; but all these have been so forcibly brought under the control of Art, that they are no longer to be considered as natural objects, any more than the stones and masonry of the house can be considered as natural rocks. The surface of the ground has been shaped to form corresponding and adequate roads of approach, and the trees have been ranged in rows to accompany such roads. The water has been collected into a vast bason by an effort of art, which is avowed in the lofty mound that separates the upper from the lower levels. All these have existed nearly a hundred years; and, whether right or wrong, cannot now be altered; while they afford a magnificent specimen of the ancient style of Gardening. The great character of this place must be considered as it relates to the vicinity of the capital. 'Those who conld treat this splendid Palace like the seat of an English country gentleman, at the 
distance of a hundred miles from the metropolis, would rob it of all its importance, and more than half its interest and beauty. It would be absurd in this place to conform to the modern style, of placing the house in the centre of its domain, from which every thing is banished, but the beasts of the forest. On the contrary, it must be elassed with those royal and princely residences, which form the retreats of the great from the court or city: and we do not expect near a Metropolis any thing like perfect seclusion from mankind, either in the Palaces of Versailles, Potsdam, or Kensington, any more than in the Metropolis, as at Carleton House or St. James's. To each of these the gardens behind the house may be private, but the entrancefront must be exposed to the public; and we must not (as in lesser places) consider the entrance of the park as the boundary of the domain: on the contrary, I have always considered the gate which opened immediately into the fore-court, or bassecour, as the dressed limit of such Palaces. And if it were possible to exclude from Hyde Park or Kensington Gardens the gay assemblage of company which enlivens the scene, we should only produce one dull and cheerless soliude, without a single feature to constitute natural landscape, or to reconcile the mind to artificial rows of trees with their symmetrical formality.

It has been justly observed by a late Author on Taste (Lord (Kaimes), "that Symmetry on a small scale is displeasing; but "where the object is too large to be comprehended at once, "Symmetry assists the eye in developing its parts:" and therefore, to a very large Palace, the richness of a symmetrical par- 
terre is more consonant than a square area of lawn, too small to be fed by flocks and herds, and too large to be considered as a bowling-green. This, I hope, will be a sufficient excuse for my having advised, or, I should rather say, acceded to the disposing of the area or garden in front of this place. But there is also another reason for it: the principal rooms being raised orer a basement story, the interior of this area will be visible from thence; while the clipped fence, with which such a garden ought to be surrounded, will prevent the public from looking into this private garden, and will exclude even those who actually come into the fore-court, and drive up to the portico. The contrast betwixt the works of Art and of Nature will increase the interest of both; and the foreground may be viewed as a rich carpet spread under the eye, in perfect harmony with the vases and obelisks, and other works of art, attached to the architectural grandeur of the entrance-front.

THE IVATER.

The natural surface about this place is so flat and level a plain, that it must depend for all its interest and beauty on the wood and the water, withont which it would be a dreary waste. But these two objects are at present unconnected; and the naked banks of the large ponds give rather the appearance of a land flood, than of natural lakes or pools. It will therefore be advisable to clothe very amply the heads and banks of the reservoir pool in such manner, as may render it unnecessary to 
alter its form; except that it might be greatly improved by giving it a better connection with the lake, all view of which is at present excluded from the lower level by the paling along: the side of the road, and from the principal floor by a wood planted in quincunx rows. This wood was originally intended to have been kept low, but it has now outgrown its intention, and not only hides all view of the water, but also the distant prospect of the forest hanging down to the banks of the lake; and in the horizon, that view of the Metropolis which, at such a distance, is a most impressive feature, and in perfect harmony with the grandeur of the scene.

The annexed sketch may serve to give some idea of the magnificent Landscape which this Villa commands. It is supposed to be taken from the principal front, and shews a part of the alteration proposed in the parterre to the west, and the improvement of the water towards the south-west, which is at present almost totally hid by the intervening quincunx of trees, which have been suffered to outgrow the original intention of Le Nôtre, who meant to form a foreground to the picture, which ought to be seen over it. 


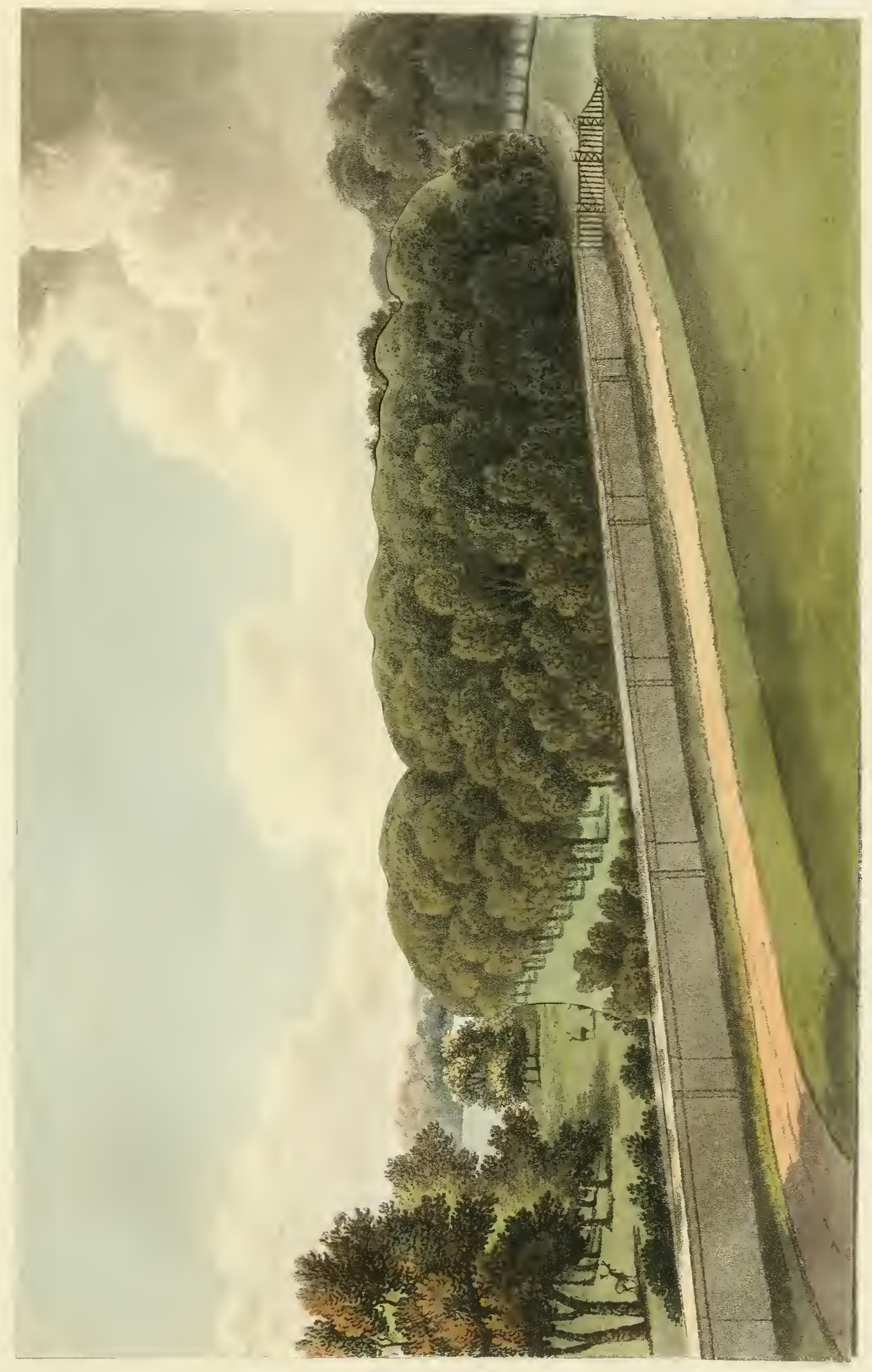





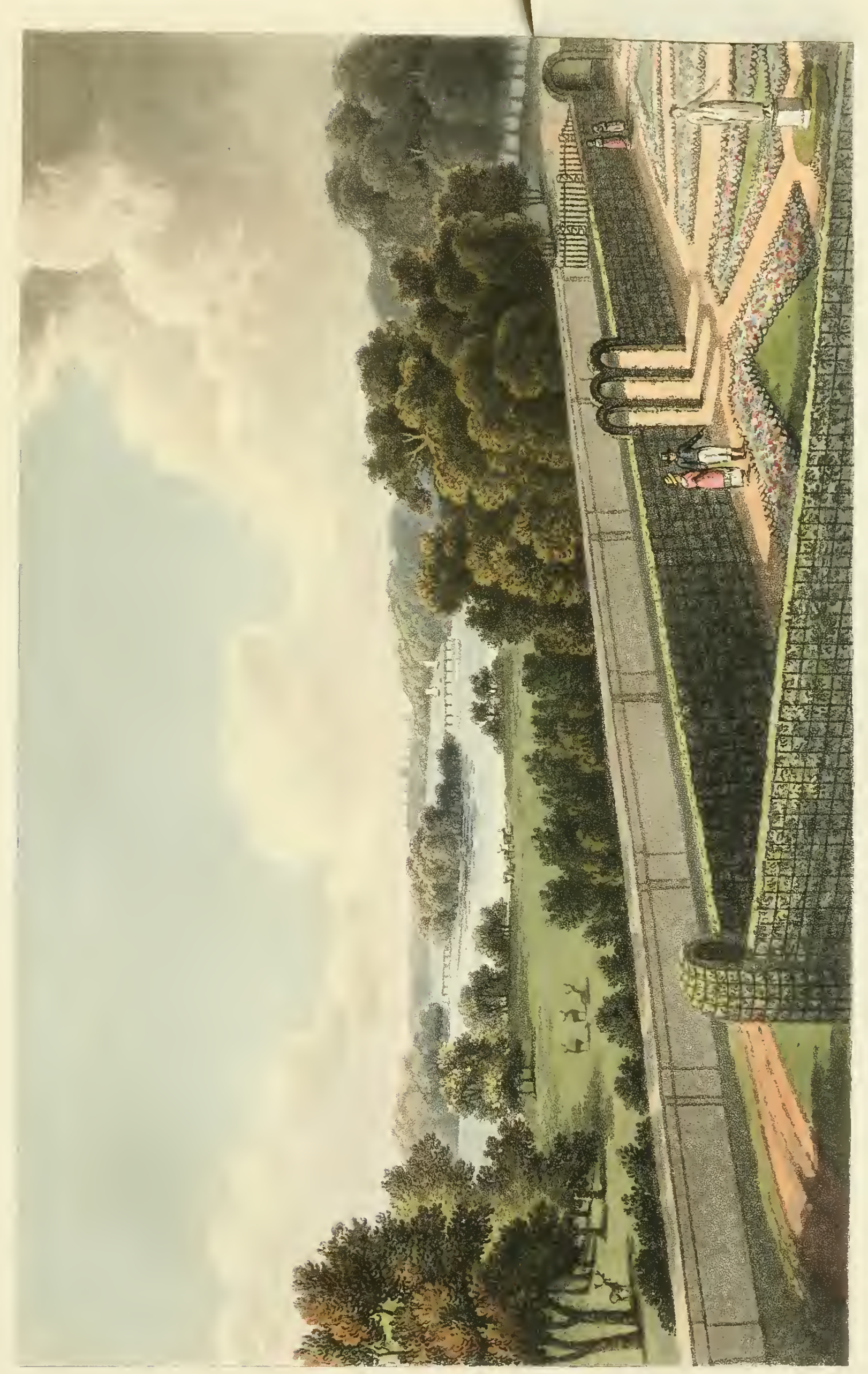





\section{FRAGMENT XXVII.}

\section{GARDENS OF ASHRIDGE.}

OF all the subjects on which I have been consulted, few have excited so much interest in my mind as the Plan for these Gardens. This may partly be attributed to the importance and peculiar circumstances of the place, but perhaps more especially to its being the youngest favourite; the child of my age and declining powers: when no longer able to undertake the more extensive plans of Landscape, I was glad to contract my views within the narrow circle of the Garden, independent of its accompaniment of distant scenery.

The large and magnificent Palace reeently erected in his best style of Gothic Architecture by James Wyatt, presents two fronts of more than six hundred feet, of beautiful stone, by a depth of one hundred and thirty to one hundred and seventy feet from north to south; and from the richness of its ornaments, and the quantity of its mass, it must be considered as one of the most splendid specimens of wealth recently expended under the guidance of taste.

It may perhaps be asked by the fastidious Antiquary, whether the whole Edifice most resembles a Castle, an Abbey, or a Collegiate Pile. To which may be given this simple answer: It 
is a modern House, on a large scale, where the character of the rich Gothic of Henry VII. has been successfully introduced and imitated. And knowing the wish of the noble Proprietor to direct every part of the improvements both in the house and grounds, I could not but feel highly gratified on being desired to give my opinion concerning the mamner of adapting the ground near the house to the magnificence and importance of the place and its possessor.

The situation of the new House, built over the cellars and foundation of the ancient monastery, has not much beauty of locality to boast: though commanding a very extensive view of park to the south, yet the surface is flat, and withont water. Although the Park abounds in fine woods and large trees, yet in the view from the windows the landscape is naked and uninteresting.

Under such circumstances, we had only two modes of treating it; either to bear with the nakedness and flatness of the prospect, and enliven it by bringing the deer and cattle near the eye, or else to exclude the landscape altogether, by bringing plantations near the house; and I recommended both these expedients in the manner explained by the map. The boundary fence of the pleasure-ground having been completed before I visited the spot, I have not had sufficient influence to effect its removal; but I was permitted to suggest the plantation of about eight acres, which hides one half of the naked lawn, forming a rich mass of foliage near the eye. It was next to be considered how best to convert the interior of this mass to the purposes of 
beauty, convenience, and variety, with some degree of novelty in the plan.

Every part of a modern pleasure-ground is alike; and unless varied by views into the adjoining country, we soon tire of the sameness of gravel walks, in serpentine lines, with broad margins of grass and flowers and shrubs, every where promiscuously mixed and repeated; and therefore I ventured boldly to go back to those ancient trim Gardens, which formerly delighted the venerable inhabitants of this curious spot, as appears from the trim box hedges of the monks' garden, and some large yew trees still growing in rows near the site of the monastery.

I delivered my opinion, elucidated by many drawings, some of which have since been realised, and with some I had hoped to enrich this volume, but I am informed the book has been mislaid, and I can therefore only describe the general principles of what I had the honour to suggest, by a reference to the map, and a sketch from memory of the Rosary and the Conduit or Holy Well, for which a Gothic design is given, with a hint of its relative situation, shewing the rosary and entrance to the monks' garden.

No less than fifteen different kinds of Gardens were proposed in the Map, of which $\mathrm{N}^{\circ} 1,2,3,14$, and 15, belong to the modern style of pleasure-ground, but the others are all different, viz. in

$\mathrm{N}^{\text {To }}$, I proposed a Conduit, or Holy Well, in an enclosure of rich masonry, and decorated by flowers in vases, \&c. This is supposed to front the centre of the conservatory. 
$\mathrm{N}^{\circ} 5$, the Winter Garden, with covered walk open to the south, which is a luxury that no place should be without.

$N^{\circ} 6$ is the Monks' Garden restored.

"The close clipt box, th' embroider'd bed

" In rows and formal order laid,

“And shap'd like graves (for mindful still

"Of their last end, the church doth will

" E'en in their joys her sons should be

" Pensive in very gaiety)."

Hon. Mrs E. Erskine.

$\mathrm{N}^{\circ} 7$, disposed in groups, the various kinds of foreign Trees which will bear so sheliered an enclosure.

$\mathrm{N}^{\circ} 8$, availing ourselves of a very large building, the Magnolia and other American plants will here find an appropriate situation.

$\mathrm{N}^{\circ} 9$ and 10, are Gardens with beds raised to meet the eye, and very unlike any other garden. The Grotto is an excavation formed out of an old pool, instead of filling it up, and the whole area of $\mathrm{N}^{\circ} 12$ has been formed into small hills and valleys, and so surrounded by plantation, that its original flatness is totally disguised. In the Rosarium, $\mathrm{N}^{\circ} 13$, is proposed a Fountain, supplied from the holy well, and then led into the grotto, from whence it is finally conducted into the drinking-pool in the park, presenting from one and the same source a redundance of water under different appearances. 


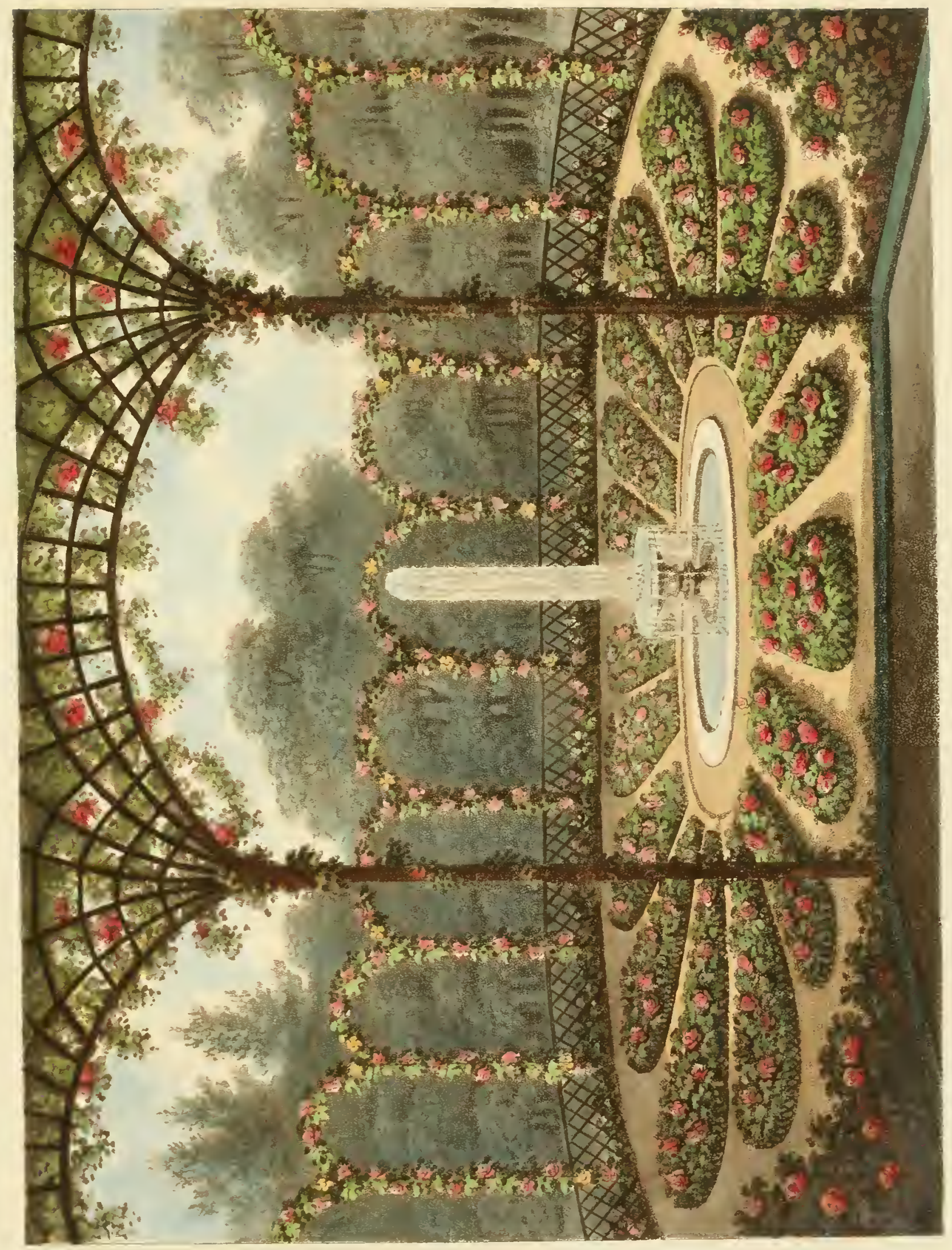





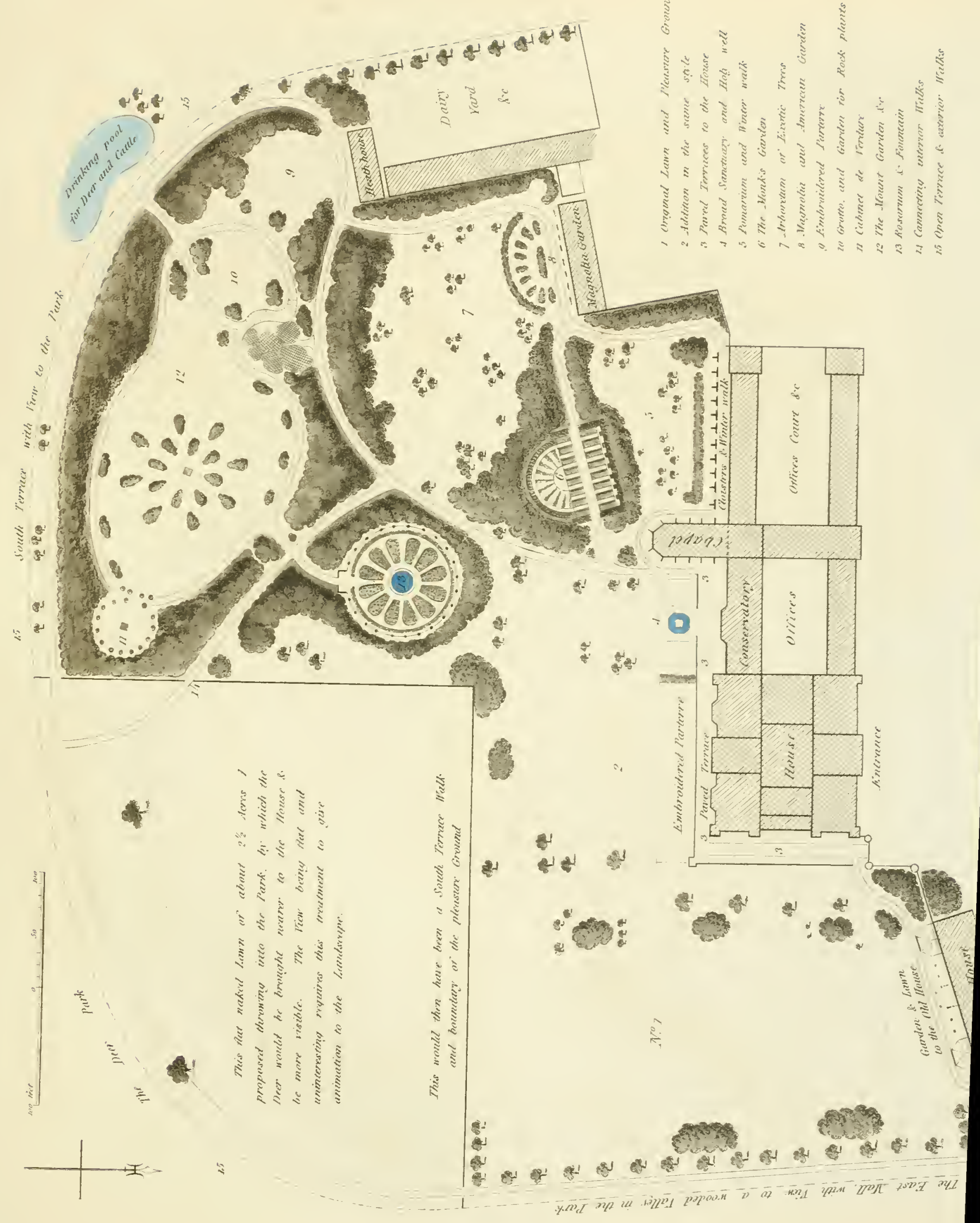





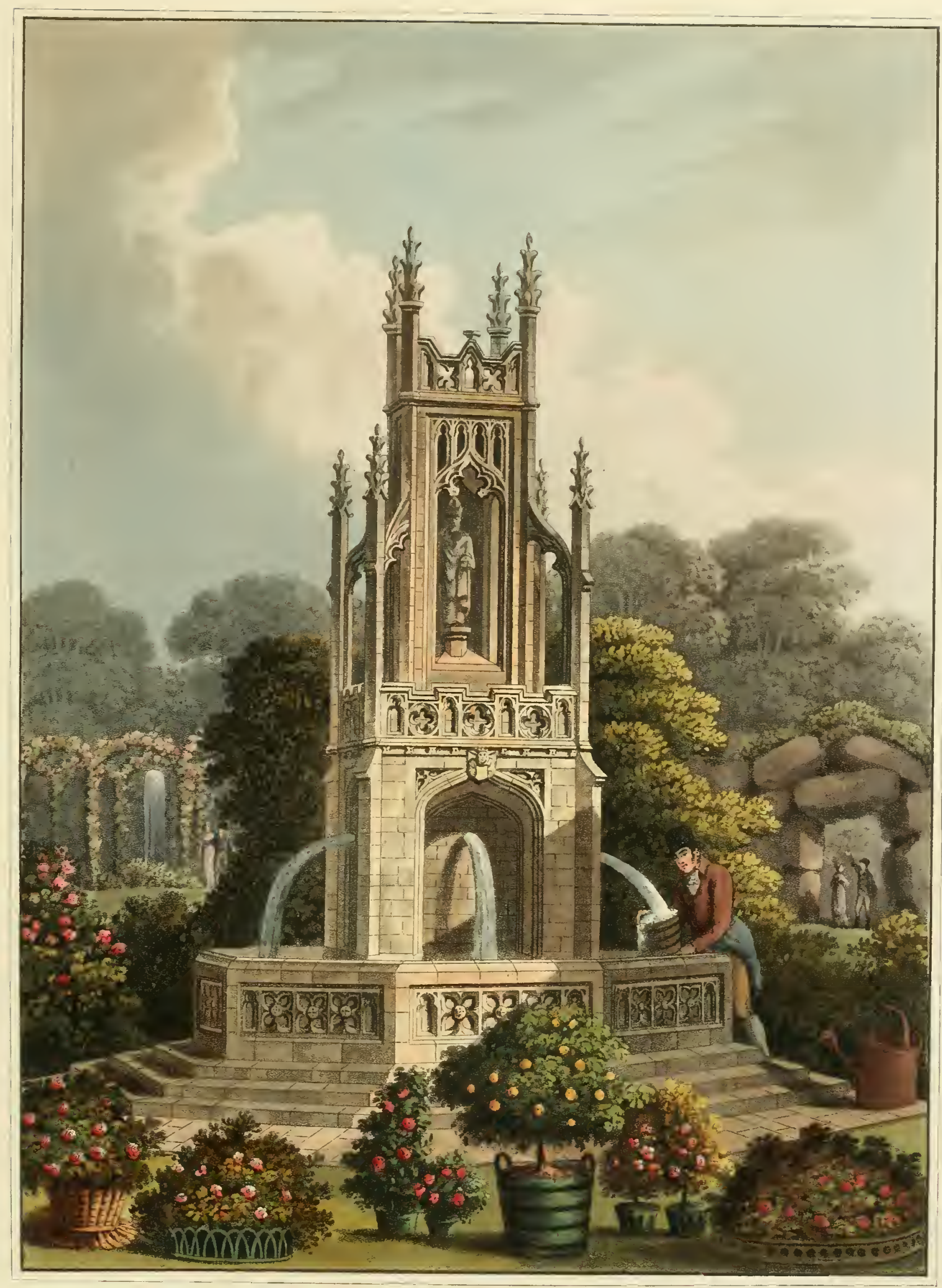

DESIGN FOR A CONDDIM, PRDPOSED AT ASHRID GF. WITH IOISTANT VIEW OF THE ROSARY AND MONKS GARDIEY. 

After almost half a century passed in the Parks and Gardens of England, and during much of that time having been professionally consulted on their improvement, I am fully convinced that Fashion has frequently misled Taste, by confounding the scenery of Art and Nature. And while I have acceded to the combination of two words, Landscape and Gardening, yet they are as distinct objects as the picture and its frame. The Scenery of Nature, called Landscape, and that of a Garden, are as different as their uses; one is to please the eye, the other is for the comfort and occupation of man: one is wild, and may be adapted to animals in the wildest state of nature; while the other is appropriated to man in the highest state of civilization and refinement. We therefore find, that although Painters may despise Gardens as subjects for the pencil, yet Poets, Philosophers, and Statesmen, have always enjoyed and described the pure delights of Garden Scenery.

A Garden, as the appendage to a place of such importance as Ashridge, is no trifling consideration: and it ought well to be weighed, before we sacrifice one of the most splendid and costly works of Art to the reigning rage for Nature, and all that is decmed natural.

It will perhaps be said, that where we work with Nature's materials, the production should imitate Nature: but it might, with equal propriety, be asserted, that a house being built of rocks and stones should imitate a cavern.

Let us then begin by defining what a Garden is, and what it ought to be. It is a picce of ground fenced off from cattle, 
and appropriated to the use and pleasure of man: it is, or ought to be, cultivated and enriched by art with such produets as are not natural to this country, and consequently it must be artificial in its treatment, and may, without impropriety, be so in its appearance; yet there is so much of littleness in Art, when compared with Nature, that they cannot well be blended: it were therefore to be wished, that the exterior of a garden should be made to assimilate with Park Scenery, or the Landscape of Nature; the interior may then be laid out with all the variety, contrast, and even whim, that can produce pleasing objects to the eye, however ill adapted as studies for a picture.

If my pencil has given inadequate representations of scenes not yet existing, I may plead in my excuse that I am not a painter; and if I were, my subjects could not be painted; yet they may serve (better than mere words) to realize and bring before the eyes of others those ideas which have suggested themselves to my own imagination.

Segnius irritant animos demissa per aures

Quam qux sunt oculis subjecta fidelibus.

OF ANCIENT GARDENING.

It fortumately happens at Ashridge, that the area proposed to be dedieated to Garden and Pleasure-Ground is bounded both to the east and to the west by a straight line of lofty trees; these give a character of antiquity and grandeur to the site, and prove it to have existed before serpentine lines were introduced. 
I can hardly expect that the sweeping line of wire-fence should be immediately altered; but as it must very soon perish, it becomes my duty to point out a different line for the future more durable boundary of the Gardens: and this alteration will throw out two or three acres of ground, which must otherwise be kept mown, since no plantations can possibly be made there, without injuring the view of the park. The only use that could be made of these three acres would be an open cricket-ground, which may either be in the park, or excluded from it, yet appear one surface with the intermediate space of lawn, which I have called the Bowling-green. This is an appendage perfectly accordant with the ideal date and character of the building; and would be made still more perfect, by extending the walk from the east terrace, to form the quadrangle complete. These walks may all be considered as part of the original artificial and truly magnificent style of Gardening in former times, when the works of Art were avowed as artificial, their costliness bespeaking their value.

* I cannot here omit mentioning the haring been present when Mrs. Siddons objected to the straight braids represented in her celebrated picture in the character of the Tragic Muse; and requested Sir Joshua Reynolds to let the hair flow in more graceful ringlets; but that great master observed, that without straight lines there might be grace or beauty, but there could be no greatness or sublimity; and this same rulc applies to Gardening as to Painting. It was therefore with peculiar satisfaction that I observed the straight lines of walks near the house, and that mall to the east in a line with the trees, which Mr. James Wyatt hatd advised. 


\section{$14 \dot{x}$}

OF MODERN GARDENING. *

When the straight walks and lofty walls of ancient gardening hat disgusied by their sameness, prevailing in all places alike, whether great or small, it was naturally to be expected that fashion would run into the opposite extreme, by making every lhing curved as the greatest contrast to straight. To the little interest we experience after the first hundred paces, in a meandering walk betwixt two broad verges of grass, at a great distance from the beds of flowers and shrubs, may be added the mistake of mixing together in such a manner every kind of plant, that no one part of the garden differs from another. Yet there are many pleasure-grounds of this kind, with walks of a tedious length, which I have shuddered to encounter: for this reason I have never advised such walls, except as the connecting lines leading to other objects.

\section{WATER.}

The Water at Ashridge is by art brought from a deep well, dug by the monks, immedialely under the ehapel; and this must be pumped up into reservoirs. Now it would be possible to lead pipes from these reservoirs in such a manner, that every drop of water used for the gardens should be made visible in diflerent ways, beginning with a conduit in front of the conser-

* It will perhaps be objected, that this same idea has already appeared in the preceding fragment; but such repetitions must occasionally be unavoidable, in a work like this, collected from various detached subjects. 


\section{5}

vatory, and from thence led to supply a jet d'eau in the rosary. Another branch might form a falling shower or dropping well near the grotto; from which the waste pipes might be led to keep up the water in the park pool, inducing caltle to assemble on its margin; the glitter of this pool might be seen through the stems of trees. But the greatest effect would be obtained from the conduit, or Gothic fountain, near the greenhouse: this could be thrown up from the well, and the surplus would find its way into the tank beneath. Thus with actual scarcity there would be an appearance of great command of water. Perhaps a contrivance might be introduced to filter this water by ascent, and make an artificial bubbling fount of the purest and brightest colour. It is not necessary for me to describe the various expedients by which this could be effected in a place where so much taste and contrivance have already been evinced: all I wish to hint is, the possibility of making much display of a little water, at the same time losing none. In Garden Scenery a fountain is more lively than a pool; and as the nature of the chalk soil will not admit of those imitations of rivers and lakes, which modern Gardening decms essential to Landscape, and as in proportion to the scarcity of any thing it becomes more valuable, it is the duty of the Improver to render visible every drop of water that can be obtained: for, besides the pleasure the eye takes in seeing water, we cannot but consider it of the utmost consequence to a Garden, where, if the labour of pumping cannot be avoided, it ought to be carried on unseen, lest our choice of the site should be condemned in these words of Isaiah, "And ye shall be confounded for the Gardens 
"that ye have chosen, for ye shall be as an oak, whose leaf

"fadeth, and as a garden that liath no water."

FE N CES.

The most important of all things relating to a Garden is that which cannot contribute to its beauty, but without which a Garden cannot exist: the Fence must be effective and durable, or the irruption of a herd of deer in one night may lay waste the cost and labour of many years. Every thing at Ashridge is on a great scale of substantial and permanent grandeur, and the Fence to the Gardens should doubtless be the same. The deep walled ha! ha! invented by Brown was seldom used by him but to give a view through some glade, or to afford security to a terrace-walk; from whence we might see two bulls fighting, without the possibility of danger: this cannot be said of that wire-bird-cage expedient, which has of late years been introduced, to save the expence of a more lasting barrier; and though it may be sufficient to resist sheep, or even cows, for a few years, in the villas near London, yet the mind is not satisfied when a vicious stag approaches it with undaunted eye, and a mien not to be terrified. Add to this, the misery of viewing a landscape through a prison-bar, or misty gauze veil ranging above the eye. Besides iron is a material of which we have had but litle experience, except that it too soon decays. For this reason a line is shewn on the map, which may hereafter be adopted; and I must consider the present wire-fence only as a temporary expedient. 


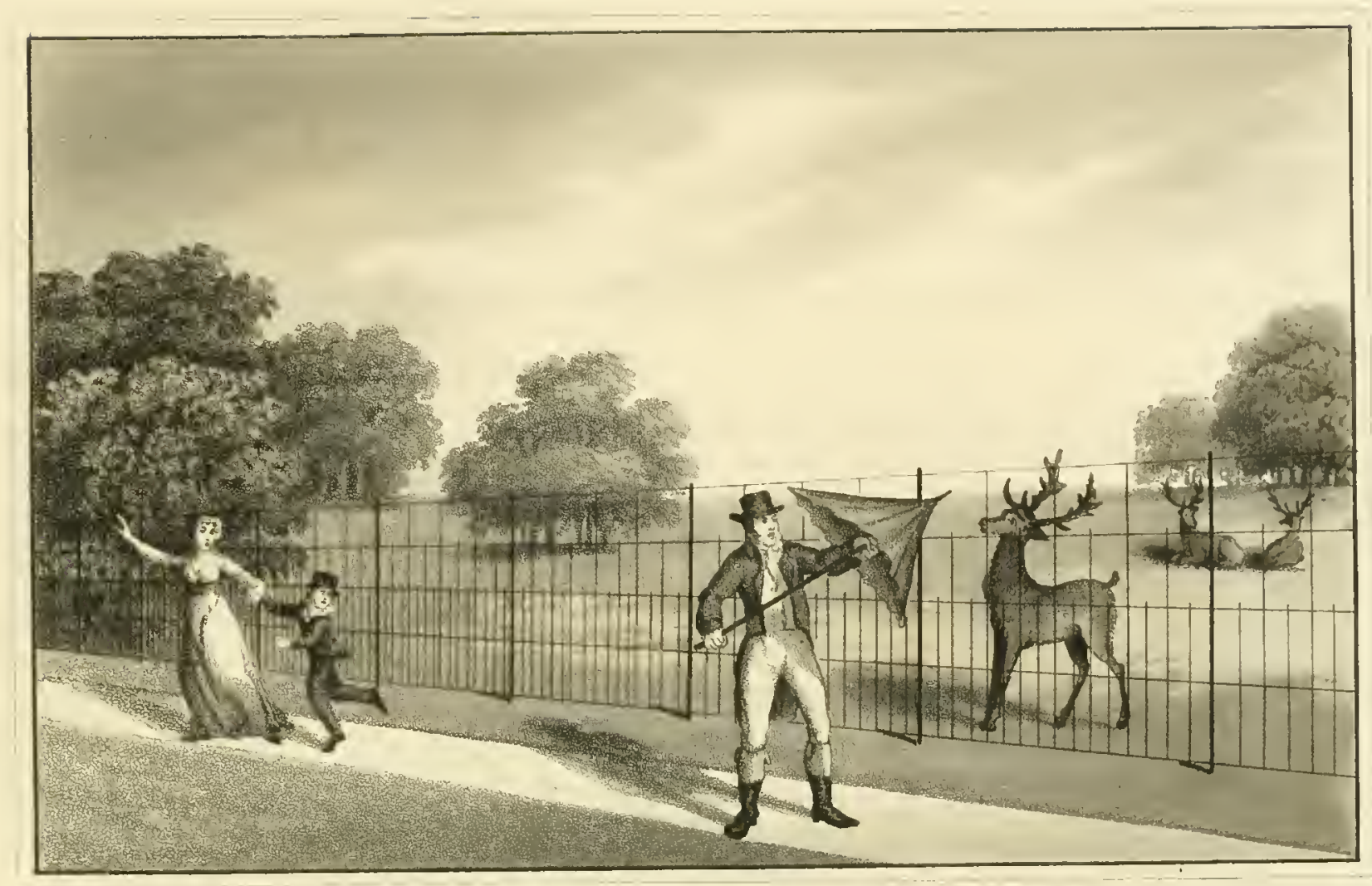

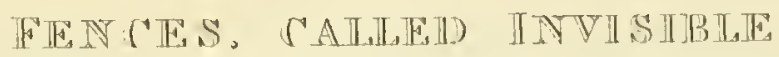

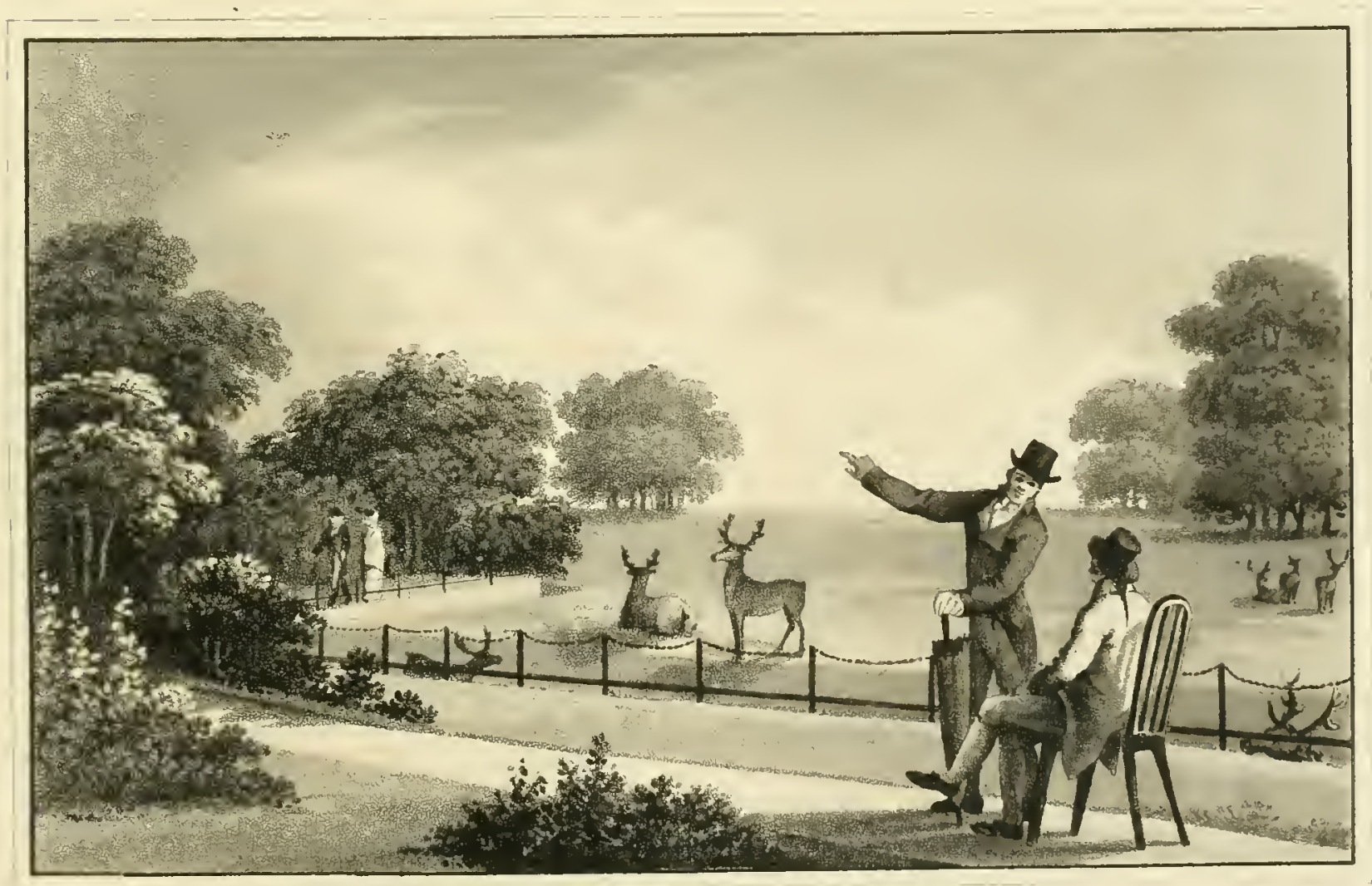



I might also add another argument against invisible Fences in general (except in short glades), viz. that when they divide a park from a garden, they separate two things which the mind knows cannot be united.

In modern Gardening it has been deemed a principle to exclude all view of Fences; but there are a certain class of flowering plants which require support, and these should be amply provided for in all ornamental gardens. The open trellisfence, and the hoops on poles over which creeping and climbing plants are gracefully spread; give a richness to garden scenery that no painting can adecurutely represent.

The novelty of this attempt to collect a number of Gardens, differing from each other, may perhaps excite the critic's censure; but I will hope there is no more absurdity in collecting Gardens of different styles, dates, characters, and dimensions, in the same inclosure, than in placing the works of a Raphael and a Teniers in the same cabinet, or books sacred and profane in the same library. Perhaps, after all, the pleasure derived from a Garden has some relative association with its evanescent nature and produce: we view with more delight a wreath of short-lived roses, than a crown of amaranth or everlasting flowers. However this may be, it is certain, that the Good and Wise of all ages have enjoyed their purest and most innocent pleasures in a Garden, from the beginning of time, when the Father of mankind was created in a Garden, till the fulness of time, when ne, who often delighted in a Garden, was at last buried in one. 


\section{FRAGMENT XXVIII.}

CONTAINING EXTRACTS FROM THE REPORT OF

\section{WOBURN ABBEY.}

The Improvements I have had the honour to suggest have no where been so fully realized as at Woburn Abbey; I am therefore peculiarly obliged to his Grace the Duke of Bedford for permission to avail myself of my original manuscript, by extracting more largely than in any other instance, although such extract can only be considered as a fragment, since the original report consists of ninety pages, elucidated by forty-seven drawings, maps, and diagrams.

TO HIS GRACE THE DUKE OF BEDFORD.

MY LORD DUKE,

I have the honour to lay before your Grace the following remarks concerning the further Improvement of the Grounds about Woburn Abbey. If in composing this volume I have had some difficulties, they have arisen less from the nature of the subject, than from my delicacy, as a professional man, making me unwilling to mention with disapproba- 
tion the works of another. I have however endeavoured to do my duty, in conformity to your Grace's instructions, so strongly and so clearly expressed, that I shall repeat the directions by which I lave been guided in my consideration of the subject, and which, I hope, will justify my freedom in discussing it.

"Much has been done here, but much remains to be done, " and something, I think, to undo. I am not partial to destroy" ing works recently executed; but sometimes cases will oceur "where an alternative is scarcely left. My wish is, that you " should look over every thing about the grounds here atten" tively, and then freely give me your opinion, as to what alte" rations or improvements suggest themselves to your judg" ment, leaving the execution of them to my own discretion or "leisure."

Such instruction will best plead my excuse for the freedom with which I deliver my sentiments; and if in many instances I must condemn what Mr. Holland has done at Woburu, as a Landscape Gardener, yet, as an Architect, the magnificent Library, in which this volume aspires to hold a place, will be a lasting monument of his genius and good taste.

The original situation of Woburn Abbey was judiciously chosen in those times when water, the most essential necessary of life, was suffered to take its natural course along the valleys; and before the ingenuity of man had invented hydraulic engines to raise it from the valleys to the hills. The great object of the monks was to take advantage of two small springs or rivulets, of which the traces are still left in the pools and shapes 
of ground, one near the green-house, the other near the dairy. These two streams united a little above the site of the old Abbey, contributing greatly to its comfort by reservoirs and fish-ponds; so recpuisite to the supply of a numerous ecclesiastical establishment, whose chief food was the fish of fresh water.

It is now too late to inquire why this site was preserved in the present house; or why the residence of a Noble Family retains the name of Abbey, when every vestige of the original pile has been destroyed. If any mistake is committed, it becomes the duty of the improver to suggest expedients that may retrieve errors, or remedy defects. And since it is impossible to raise the house in reality, or to alter its real situation, we must endeavour to do so in appearance; at least we should cautiously avoid every thing which tends to lessen the magnitude, to depress the importance, or to diminish the character which so obviously belongs to Woburn Abbey, as now altered from a monastic to a ducal residence.

\section{CHARACTER AND SITUATION.}

So intimately connected is the Character of a place with the Situation of the House, that it is hardly possible to separate them in idea; yet it is obvious, that at Woburn these two circumstances are at variance with each other.

The Character of Woburn Abbey (whether we consider its command of surrounding property, its extent of domain, the hereditary honours of the family, the magnificence of the Man- 
sion, or the number of its appendages) is that of Greatness. 'To Greatness we always annex ideas of Elevation; and, I believe, in every European language, loftiness of situation, whether literally or figuratively expressed, forms the leading characteristic of Greatness; to which we are always supposed to look up, and not to look down. Every epithet applied to it seems to confirm the general opinion, that what is low cannot be truly great; from the exalted Sorereign to the kneeling slave, or from the lofty mountain to the humble valley.

But as Greatness of Character may be distinct from greatness of dimensions; so loftiness of Character may exist withont loftiness of Situation. The Works of Art, however great or lofty in themselves, can never be truly so when surrounded by the Works of Nature, with which they are liable to be compared: thus the stupendous mass of ruins at Stonehenge is rendered diminutive in appearance by the rast extent of Salisbury Plain.

TIIE SHAPE OF GROUND.

The surface near the house has been so altered by the various works of art at different periods, that it is difficult to asceriain precisely what were the natural levels; but it is not improbable that the Abbey was originally placed across the valley, or near the conflux of the two small rivulets; leaving a space on one side, if not on both, for the water to take its course towards the west. As the buildings became enlarged, the valley was 
lessened, till at length they nearly filled in the whole of the hollow between the two hills.*

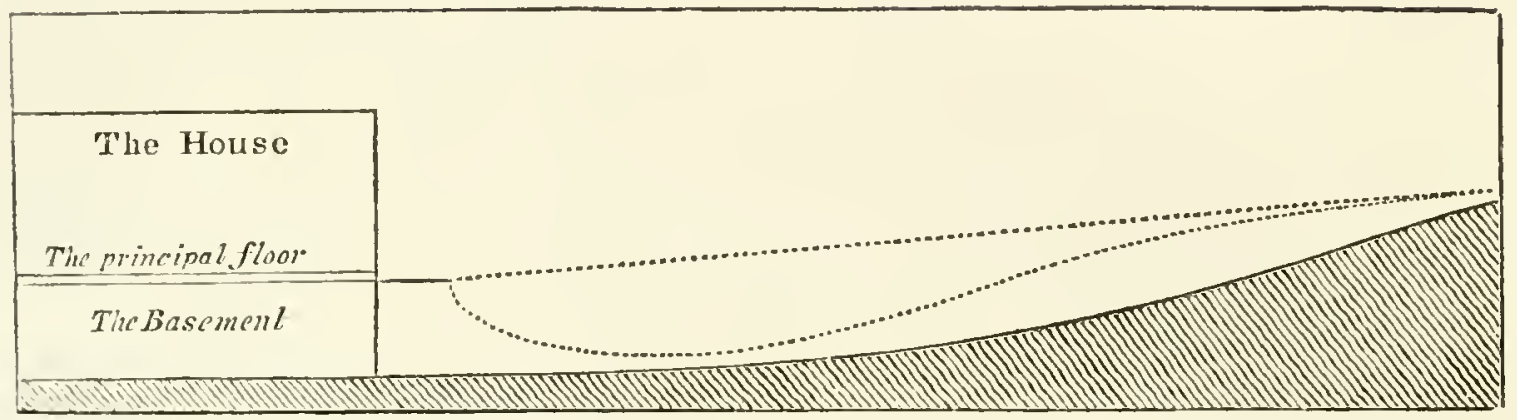

The natural surface of the valley is the lower dotted line, and the earth has been brought and filled in to the upper dotted line, making a plane, or rather an inclined-plane, sloping towards the windows of the south front. If this was done under an idea of giving a natural shape to the ground, the principle was a mistaken one; for had such been the original shape, we must suppose a hole dug in the ground, in which the house had been placed; but the fact is, that near a large house the shape of the ground must be made to accord with the building, since no house, however large or small, can be erected without the interference of art, and without disturbing the natural surface of the ground.

* Very soon after I had buried the lower story of the House at Welbeck (as described in my volume of Sketches and Hints, \&c.) Mr. Holland began to do the same thing at Woburn, but never proceeded further than the south front. 
We must therefore study the convenience of the Mansion, to which the ground about it must be altered, in the way most conducive to its uses and appearance, without fettering the plan by any fancied resemblance of Nature. I an quite sure that the old magnificent taste for straight lines, and artificial shapes of ground adjoining to a Palace, was more consonant to true taste and greatness of character than the sweeping lines and undulating surface of modern Gardening.

Such is the convenience derived in the country from having the principal floor on a level with the ground, that I must highly commend the disposition of the summer apartments at Woburn; where the earth is raised to give a ready communication with the pleasure-ground, without descending a flight of steps. The intention was good, but the mode of execution has proved defective; and had the same idea been continued in the north and west fronts (as once proposed), it would have been fatal to the character of the house, without altering its situation; because it would have reduced it one story in height, a defect for which even the proposed raising of the attics could never have compensated.

TIETVS FROM THE HOLSE.

If the perfection of the Art consists in shewing beauties and hiding defects, it must be previously asked, From what point of view any object is to be seen? This may be answered by 
stating, that the leading features of every place must be considered under the three following heads, or points of view.

First, As they appear from the windows of the house.

Secondly, As they appear in the approaches to the house; and

Thirdly, As they appear in the walks and drives.

Reversing the order in which these are placed, I shall begin by observing, that in the last we are at full liberty to display good features, or avoid bad ones, by altering the course of the drives, \&c.

In the approaches we may do the same, yet under certain restrictions, because the roads must lead to the house; but in the prospect from the windows, we have no choice of removing the point of view; it is fixed, and must be stationary: it is therefore necessary to study this with peculiar attention, and to ascertain what are the objects most desirable to form this permanent scenery, and how other objects may be introduced, to vary and enliven the same landscape, always seen from the same spot.

'IIE WATER.

Although the large circular pond at Woburn was originally made by art, yet it has very much the appearance of a Cheshire Mecr; and I shall therefore consider the mode of treating it the same.

There is something so fascinating in the appearance of water, that my predecessor (Brown) thought it carried its own excuse, 
however unnatural its situation; and therefore in many places under his direction I have found water on the tops of hills, and have been obliged to remove it into lower ground, becanse the deception was not sufficiently complete to satisfy the mind, as well as the eye. Common observers suppose that water is usually found, and therefore is always most natural, in the lowest ground; but a moment's consideration will evince the error of this supposition. Lakes and Pools are generally in the highest situations in their respective conntries; and without such a provision in Nature, the World could not be supplied with Rivers: these have their source in the highest monntains; and, after innumerable checks to retard and expand their waters, they gradually descend towards the sea.

If Nature be the model for Art in the composition of Landscape, we must imitate her process as well as her effects: Water, by its own power of gravitation, secks the lowest ground, and runs along the valleys. ${ }^{*}$ If in its course the water meets with any obstruction, it spreads itself into a lake or meer, proportionate to the magnitude of the obstruction; and thus we often see

* Indeed I have sometimes fincied, that, as action and reaction are alike, and as cause and effect often change their situations, so valleys are increased in clepth by the course of waters perpetually passing along them: thus if the water only displaces one inch of soil in cach year, it will anount to five hundred feet in six thousand years, and this is equal to the deepest valleys. In loose soils the sides of the hills will gradually wash down, and form open valleys; in liard soils, they will become narrow valleys: but ravines I suppose to be the effect of sudden convulsions from fire or steam, and not made by any gradual abrasion of the surface. 
in the most picturesque countries a series of pools connected by channels of the rivers which supply them.

THE BASIN. -

The large pool or basin in front of Woburn Abbey, in its present naked form, is rather an object of splendour than of cheerfulness; yet it is so conspicuous a feature of the place, that it ought not to be given up, without some struggle or endearour to make it appear more natural.

Could an ample river be obtained through the whole course of the valley, it would doubtless be a circumstance worthy of any effort of Art to produce it; but the levels of the valleys forbid the attempt: we must therefore have recourse to other expedients for retaining the advantage of water, with the least apparent interference of art. The present heal or dam forms a complete circle of about half a mile in circumference, round which the eye glances in a moment, meeting with nothing to check its progress; and from the saloon the ground is seen to fall below the surface of the water. If a tongue of land or promontory be formed on the head by the earth to be taken from the south front of the house, two improvements would be carried on at once. This promontory would disguise the dam, and the pool would appear to be the consecfuence of a stratum of rock, or other hard impenetrable soil, through which the water could not force its way.

The island, the bays, and the chamnels described on the 
map and in the drawings, would also contribute to improre the shape of this pool; while the plantations suggested, on the heal, would hide the low ground beyond it: for although water in nature is really on high ground, yet in appearance it fills the lowest place, because we seldon see ground below the water; either the descent is so gradual, or the obstruction so bold, as to conceal the different levels, and deceive the sight.

\section{OF BRIDGES AND VIA-DUCTS.}

There are two obvious uses for a Bridge, the first is to pass over, the second to pass under; the first is always necessary, the other only occasionally so, or where the water under the bridge is navigable; yel self-evident as this fact may appear, we often observe bridges raised so high, as to make the passage over them difficult, when there is no passage under them required; and this is the case with the present lofty bridge at Woburn. The construction of bridges has been so often and so ably discussed, that it is dangerous to attempt any thing new on the subject; yet I think such a form adapted to the purposes of passing orer, as may unite Strength with Grace, and Use with Beauty, is still a desideratum in architecture. The consideration of this subject has led me to insert the following short digression, which will not, I hope, be deemed wholly irrelevant.

Architecture has been classed under two different heads, Grecian, and Gothic; the first depends on perpendicular pres- 
sure, the other on lateral pressure. By the laws of gravitation, all matter at rest keeps its place by its own weight, or tendency to press downwards; and is only to be removed by superior force acting in a different direction. A perpendicular rock, and a solid wall built upright, will preserve their position so long as the substance or the materials of which they are composed retain their power of cohesion; and on this principle all Grecian Arehitecture is founded. Hence have arisen those relative proportions in the different orders, from the heaviest Doric to the most graceful Corinthian, which, after the experience of ages, were deemed fixed beyond the power of improvement; and by these proportions the distances of intercolumniation are regulated according to the strength of the parts supporting and supported.

The Areh was rather of Roman than Grecian invention; and when composed of a semicircle, its construction belongs rather to perpendicular than to lateral pressure; but in every other arch (except the Elliptical and the Catanarean Arch) there is a great lateral pressure, and this constitutes the basis or first principle of Gothic Archiecture; to which pimacles and finials, and other parts were added for the purpose of strength to the abuttals, although frequently mistaken, and ignorantly copied, as if merely ornamental. 
THE ORIGIN OF

GRECIAN ARCHITECTURE.

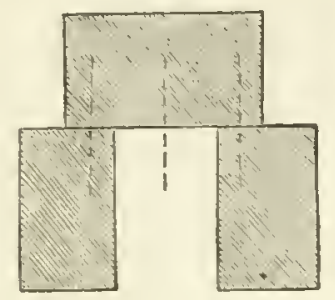

THE ORIGIN OF

GOTIIC ARCHITECTURE.

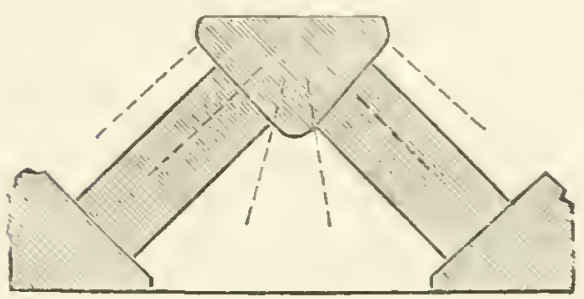

The relative pressure of each is shewn by the dotted lines.

Hence it is evident that Gothic Architecture will admit of larger apertures than Grecian; and althongh externally more massive, yet it is internally more capacious. It is requisite that the resistance of the sides or abutments should be equal to the lateral pressure of the arch, from the most massive bridge to the lightest roof of an abbey.

Since the discovery of those wonderful excavations in India, of which no date remains, but which have been lately made known to us by the drawings of Hodges, Daniell, and other Artists, I have been led to consider, that, besides the Grecian and Gothic styles, there may be a third distinct from both, the origin of which was rery different.

Instead of erecting buildings on the surface of the ground, the people who formed those awful wonders of antiquity began their operations by cutting away the foundation of the rock, to obtain room below, without endangering the superstructure; and thus by degrees the Indian Architccture seems to have grown to the most beautiful forms from the rudest excavations. 
The use which I wish to make of this digression is, to explain the manner of passing the valley by artificial means, where the road does not require a common bridge, but rather a via-duct, to ornament the dam or mound of earth thrown across the valley; and as this must necessarily cause some obstruction to the water, I think it might be made subservient to the other object in view, that of raising the water to a higher level, instead of digging a deeper channel; thus producing a continued surface of water in appearance, though in fact the levels may be very different.

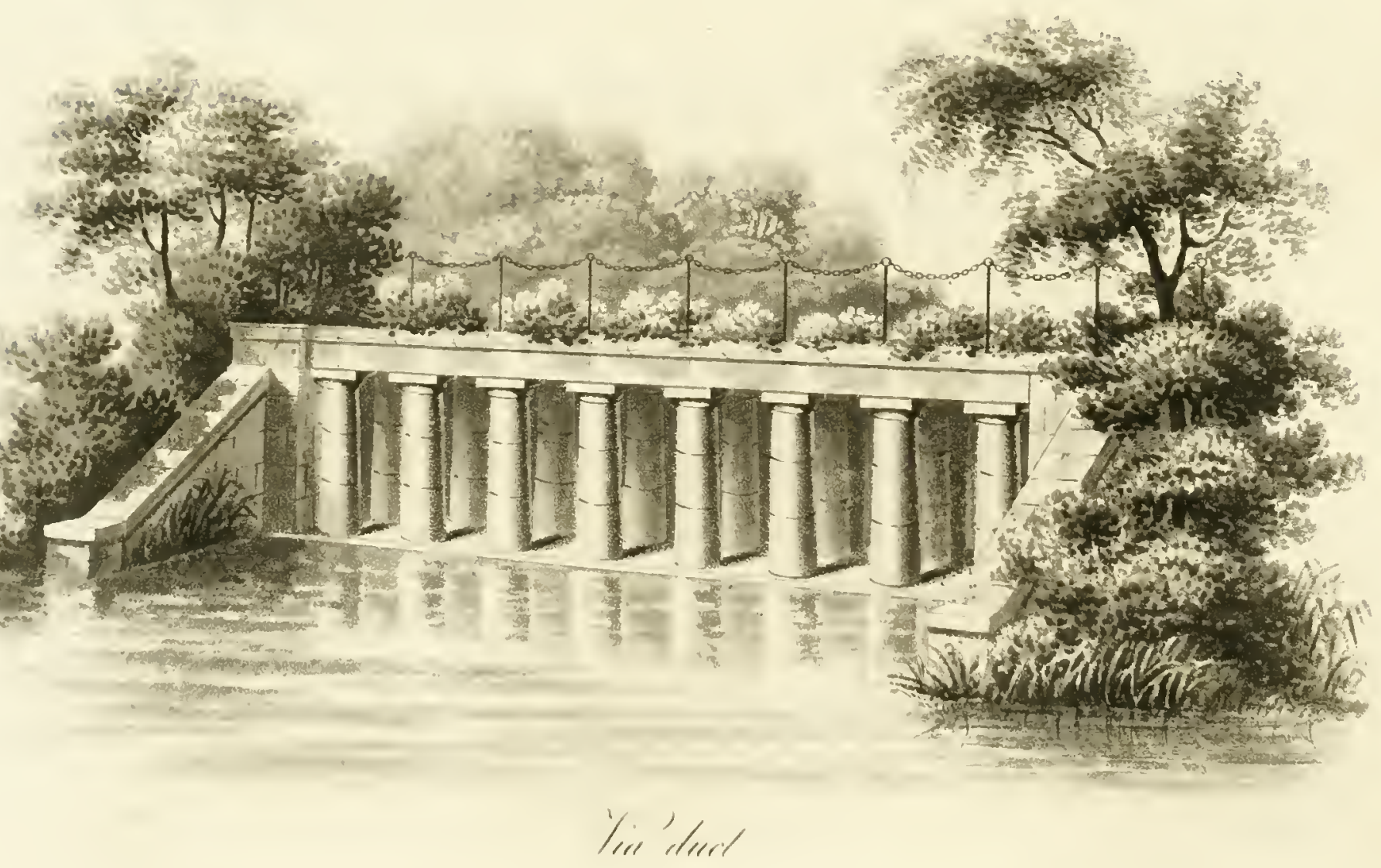


There being at present no architectural form adapted to this purpose, I have ventured to suggest a hint for such a structure as may support the road and raise the level of the water, rather calling it a Via-Duct than a Bridge.

APPROACHES.

As there is no part of the arrangement of the grounds at Woburn where so much alteration seems necessary as in the Approaches, 1 shall take this opportunity of enlarging on the subject, by an inquiry into the canse of the errors so often observable in this most essential part of Landscape Gardening.

I call the Approach the most essential, because it is self-evident, that if there be a house in a park, there must be a road to it through the park: but the course of the line in which that road should be conducted has been the source of much discussion and difference of opinion. Utility suggests that the road should be the shortest possible: it was for this reason (I suppose) that in former times the straight line was adopied, accompanied by rows of trees leading to the front of the liouse, which was probably the origin of avenues. The first grand approach to Woburn was of this kind; but experience haring pointed out the monotony of a long Avenue, where the house is always seen in the same point of view, Le Nôtre boldly conceived an idea, which was realized at Woburn, at Wanstead, and in the front of some other palaces, viz. to obstruct its course by placing a large round basin or pond in the midlle of the 
avenue, which not only obliged the road to pass round it, but by acting as a mirror, shewed the house doubled in its reflection on the surface, and thus increased the importance of its architecure. Such an expedient is beneath the dignity of Art, which should display her works naturally, and without puerile ostentation. The straight line in front of a house might be the shortest from the house to the road at one particular spot; but when it is remembered that approaches are generally necessary from oblique points, it is obvious that they can seldom be brought with propriety to one immediately in front.

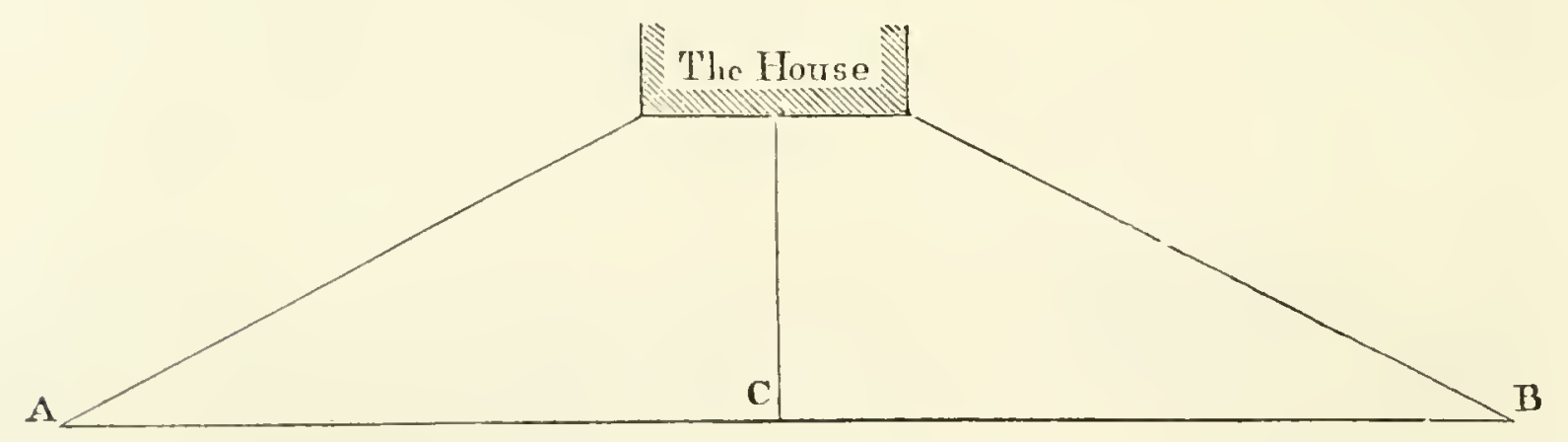

Those who come from $\mathrm{A}$ or $\mathrm{B}$ will not find $\mathrm{C}$ the nearest line to the house: this is sufficient to shew the mistake of some persons, who in all cases contend for the old style of approaches by an arenue in front.

When the oblique line was adopted, and a road brought through the park, instead of taking a straight line, it was discovered that, with very little deviation, some interesting parts of the scenery might be shewn in the approach; and by degrees its first object, that of being the nearest way to the house, was changed into that of being the most beautiful. Hence have 
arisen all the absurdities of circuitons approaches, so aptly ridiculed by a modern poet in describing improvers, who

" lead us many a tedious round

"To shew th' extent of their employer's ground."

APPROACH FROM LONDON.

Having marked on the ground, and also on the map, the general line, it is less necessary to describe it; but as there is little difference in the leugth of the present and proposed lines, it may be proper to assign reasons for the alteration.

The present approach enters through a part of the park, which can be made interesting only by planting all the ground that has been unfortumately cleared of wood; and when the road enters that part of the park, where a few large trees have been left, we perceive that they are too distant from each other, and in an unhealthy state, from the grove having been too hastily thinned. But the most objectionable part of this approach is the unfavourable circumstances under which the house is first shewn. 'The first sketch is a correct portrait of this scene; but from the difficulty of representing a view down hill, the drawing does not shew the house so low ats it appears in reality: it serves, however, to describe the following objections, exclusive of that which gives a bad first impression of the place, from shewing it below the eye.

First, Part only of the sonth front is visible, which gives an idea of its being a small house. 
Secondly, The house is not backed by wood, but opposed to the lawn, which does not form a sufficient contrast to relieve it.

Thirdly, The distant view, though extensive, is not appropriate; it is evidently beyond the boundary of the park, and may be as well seen from many parts of the public road.

Fourthly, The road passes along the side of a sunk fence, and destroys all privacy in the south apartments, which are exposed to every person coming to the house.

Fifthly, and lastly, The immediate and sharp descent near the house increases the first impression made by its apparently low situation.

The first effect of the house in the proposed approach is represented in the second sketch: After passing along the great glade, which is terminated by the island in Drakelow-pond, and which, from its length, and the size of the trees, is very magnificent, the road winds among some large oaks, betwixt whose lofty stems the house first appears, partially exciting the attention, till on our quitting the grove it is at once displayed to us in all the pomp of Greatness, blended with the intricacy of picturespue irregularity. It has no longer the effect of a solitary and inconsiderable edifice, but a Palace of depth, proportioned to its front, and accompanied by all the cupolas and domes, and more elevated parts of those attendant buildings and oflices, which it has become the false taste of modern times to hide by plantations. Add to all this, that the whole seems embosomed in a magnificent wood, and as seen across the valley, it appears 


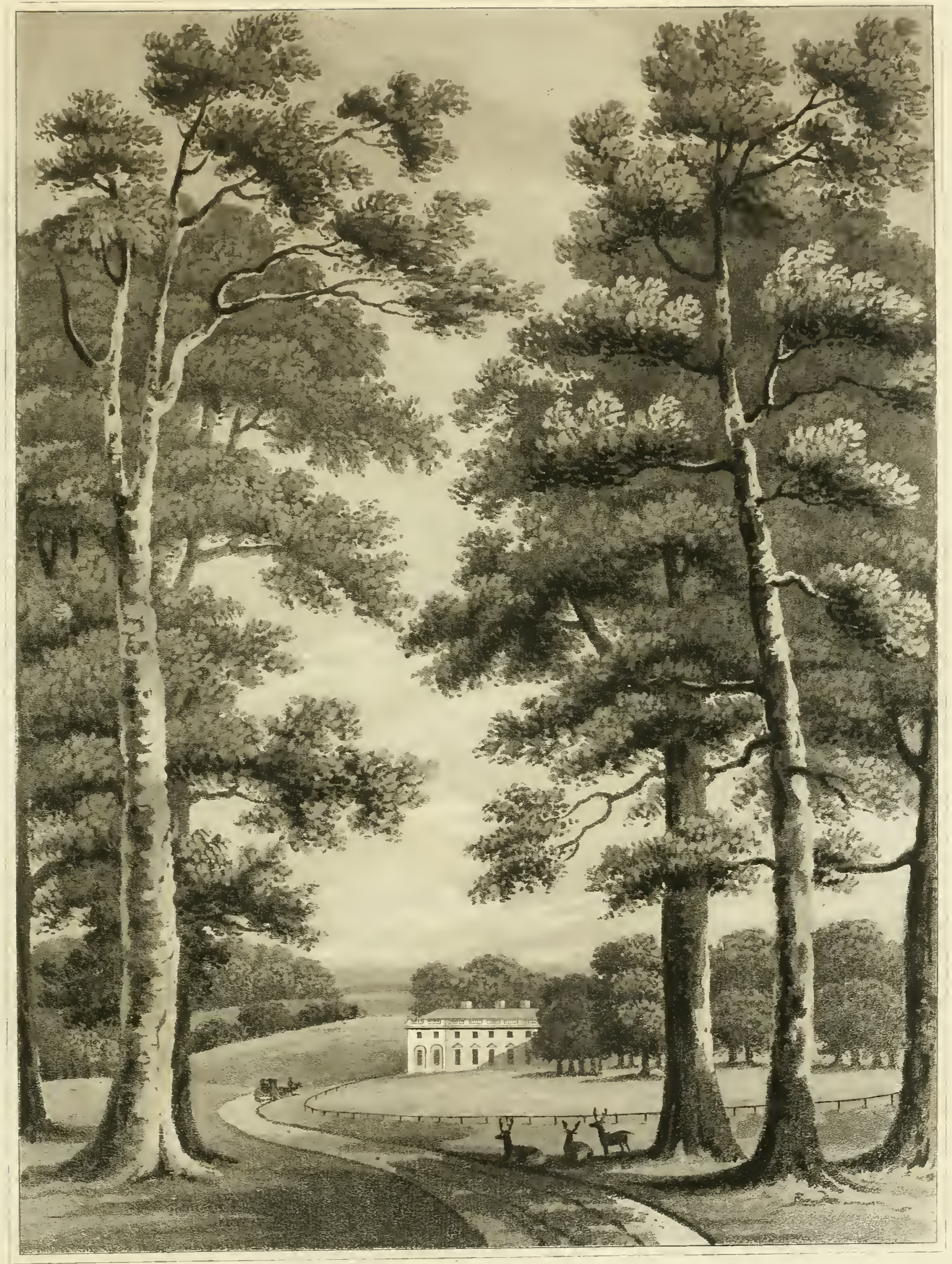

APPRDACH TO WOBTSRN ABBEY, BEFORE IT WAS ALTERED. 



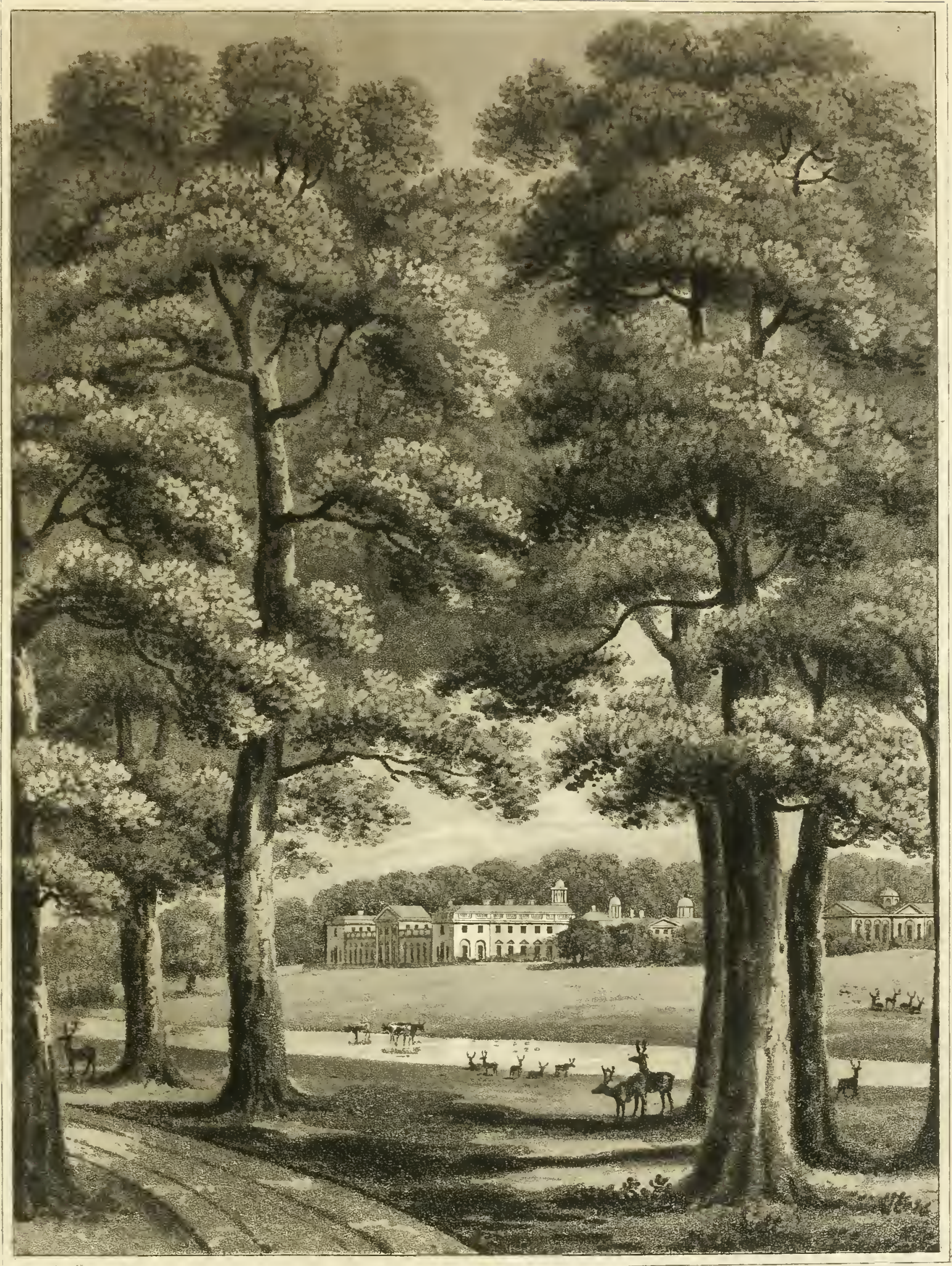

ATPRDACHI TOO WOBTRN ABBEY, AS IT IIAS IBEFN ALTERED 

elevated and not depressed, while its apparent quantity marks its character as a Ducal Palace.

\section{THE PLEASURE GROUND.}

By a strange perversion of terms, what is called modern English Gardening seldom inchudes the useful Garden, and the name of the Ornamental Garden has been changed into Pleasure Ground; but it is not the name only that has been changed; the character of a Garden is now lost in that of the surrounding Park; and it is only on the map that they can be distinguished, while an invisible fence makes the separation between the lawn fed by cattle, and the lawn kept by the roller and the scythe. Although these lawns are actually divided by a barrier as impassable as the ancient garden wall, yet they are apparently united in the same landscape, and

..... wrapt all o'er in everlasting green,

"Make one dull, rapid, smooth, and tranquil seene." R. P. Kxignt.

The gardens or pleasure-grounds near a house may be considered as so many different apartments belonging to its state, is comfort, and its pleasure. The magnilicence of the house depends on the number, as well as the size of its rooms; and the similitude between the house and the garden may be justly extended to the mode of decoration. A large lawn, like a large room, when unfurnished, displeases more than a small one: if only in part or meanly furnished, we shall soon leare it with 
disgust, whether it be a room covered with the finest green baize, or a lawn kept with the most exquisite verdure; we look for carpets in one, and flowers in the other. If in its unfurnished state there chance to be a looking-glass without a frame, it can only reflect the bare walls; and in like manner a pool of water, without surrounding plantations or other features, reflects only the nakedness of the scene.

This similitude might be extended to all the articles of furniture for use or ornament required in an apartment, comparing them with the seats and buildings and sculpture appropriate to a garden.

Thus the Pleasure Ground at Woburn requires to be enriched and furnished like its Palace, where good taste is every where conspicuous.

It is not by the breadth or length of the walk that Greatness of Character in Garden Scenery can ever be supported; it is rather by its diversity, and the suecession of interesting objects. In this part of a great place, we may venture to extract pleasure from Variety, from Contrast, and even from Novelty, without endangering the character of Greatness.

THE GARDEN.

In the middle of the last century almost every mansion in the kingdom had its Garden, surrounded by walls, in the front of the house. To improve the landscape from the windows, 
Brown was obliged to remove those gardens; and not always being able to place them near the house, they were sometimes removed to a distance. This inconvenient part of his system has been most implicitly copied by his followers; although I observe that at Croome and some other places, where he found it practicable, he attached the kitchen garden to the offices and stables, \&e. behind the mansion, surrounding the whole with a shrubbery; and indeed such an arrangement is most natural and commodions. The intimate connexion between the kitchen and the garden for its produce, and between the stables and the garden for its manure, is so obvious, that every one must see the propriety of bringing them as nearly together as possible, consistent with the views from the house: yet we find in many large parks, that the fruit and regetables are brought from the distance of a mile, with all the care and trouble of packing for much longer carriage; while the park is continually cut up by dung carts passing from the stables to the distant gardens. To these considerations may be added, that the kitchen garden, even without hot-houses, is a different climate; there are many days in winter when a warm, dry, but secluded walk, under the shelter of an east or north wall, would be preferred to the most beautiful but exposed landscape; and in the spring, when

" Reviving Nature seems again to breathe,

"As loosen'd from the cold embrace of death,"

on the south border of a walled Garden some early flowers and vegetables may cheer the sight, although every plant is 
elsewhere pinched with the north-east winds, peculiar to our climate, in the months of March and April, when

"Winter, still ling'ring on the verge of spring,

"Retires reluctant, and from time to time

"Looks back, while at his keen and chilling breath

"Fair Flora sickens."

STILLINGFLeET.

N. B. The disposition of the Gardens at Woburn has now been so far completed, that it would be superfluous to describe their details, because the several objects may be viewed on the spot; but I will briefly enumerate the heads under which they have been classed:

The Corridor, or covered-way, by which a sheltered communication is given from the house to the stables, conservatory, flower-lıouses, temnis-court, riding-house, Chinese-dairy, gamelarder, se.

The dressed or architectural Pleasure Ground, separated from the Menagerie by the door represented in the amnexed sketch.

The Forcing Garden has not yet been completed, but as an object of winter comfort, a sketch is subjoined.

The Chinese Buildings were proposed to be decorated by an assemblage of Chinese Plants, such as the Hydrangia, Accuba, and Cameilla Japonica.

An American Garden was also proposed; and, as an object of curiosity, a botanical artangement of all the Grasses forms an interesting circumstance.

The variety of Pheasants and aquatic fowls in the Menagerie creates new features in this collection of different scenery. 


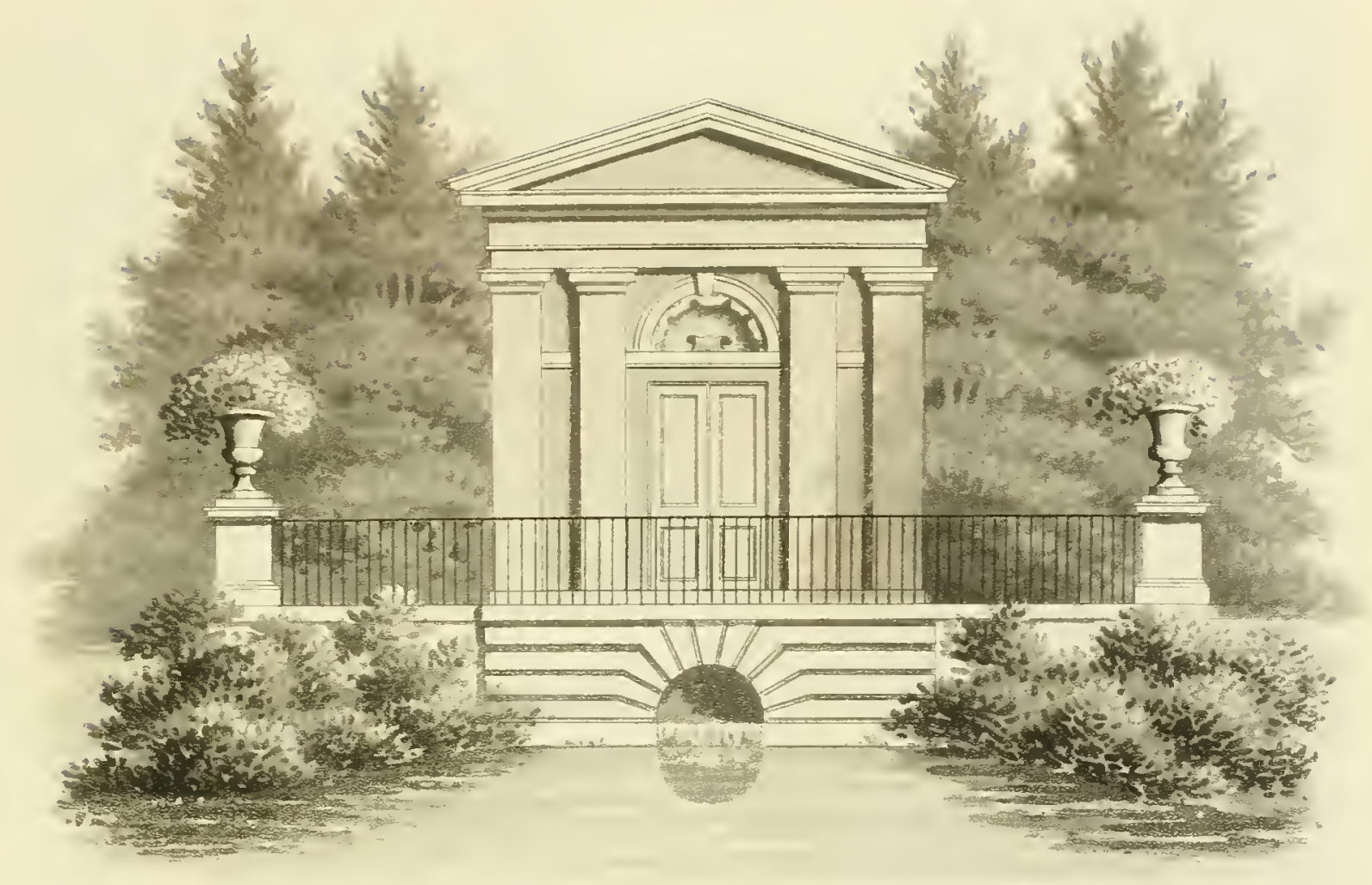

This Architectional Entrance or Deor, forms the Boundary
betwikt the dressed-plecusure Ground at the Henagerie
AT WDBTIRN ABBEY:

At the buck of it, is this Pavillion. constructed with

Branches and cones or Fir tres

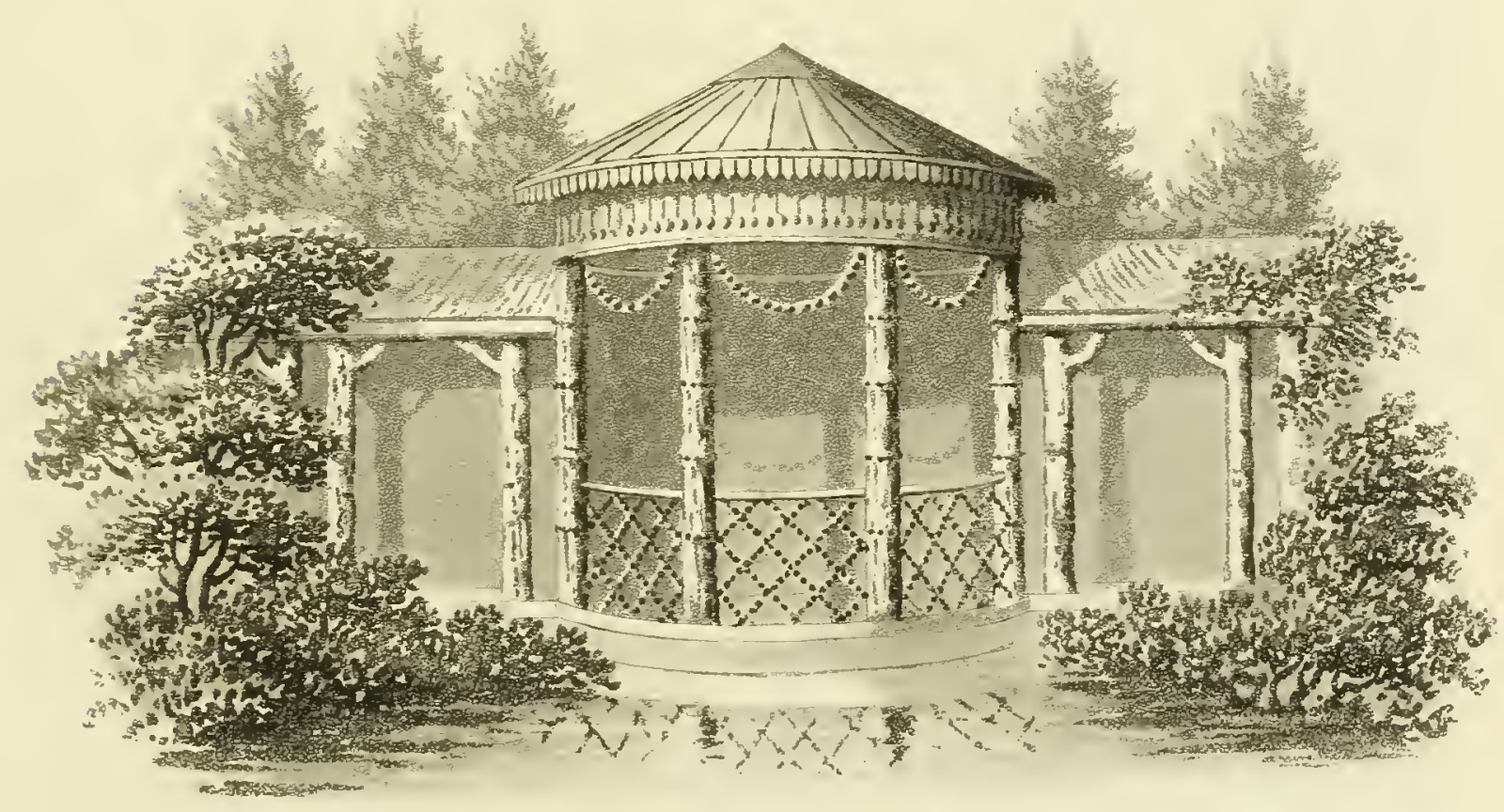





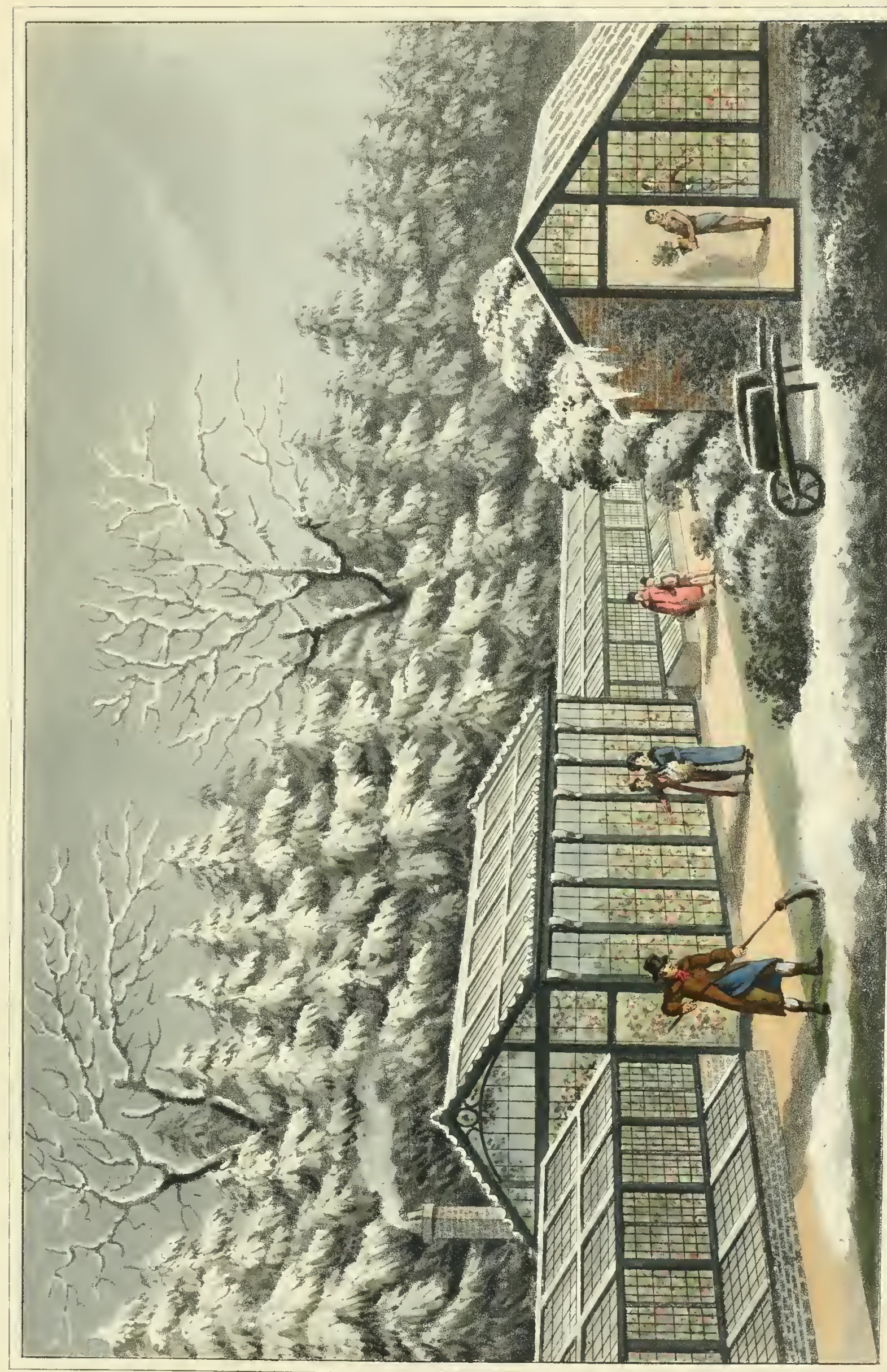



THE FORCING GARDFN.

If the espalier fruit and common vegetables were provided for elsewhere, one acre of walled garden would be equiralent to eight or ten acres in the common mode of disposing kitchen gardens. The walls should be placed at such distance from each other as to admit of a walk near the trees, and of a border for early regetables between the walk and the part shaded by the next wall; on which a hedge of Laurel and Lauristinus, or even Rhododendrons, might be planted.

The upper part of this Garden might be appropriated to every species of forcing: and though it is difficult to ornament the mean slanting roof of a hot-house, yet, when all other vegetation is destroyed by cold, we may occasionally enjoy the sight of plants protected by art, without disgust at the means by which they are protected.

THE PARK.

So natural is the partiality for extent or greatness of dimensions, that I have constantly been asked, How large is such a Park? or, How many miles is it round? And since I visited Woburn, every body talks to me concerning the length of the Park-wall. I can only answer, that I do not estimate places by measurement; and that I never go round the extremity of a place to form an idea of its beauty. With respect to the bound- 
ary, whether it be a wall or a pale, my business is to hide it, and not to lead a Drive so near as to display it.

In this instance, the fashion of Drives las, like all other fashions, passed from one extreme to the other. The ancient Drive was in an arenue, through the middle of a park; the modern Drive avoids the middte, and skirts roind its border; and although two thirds of the places I have visited, and to which I have suggested improvements, are surrounded by a Belt and a Drive, yet I must beg leave to repeat my protest against that sort of modern Belt, by which Mr. Brown's followers have brought disgrace on the genins and good taste of their master.

'THE DRIVES.

Before I speak of the Drives at Woburn, I shall endeavour to trace the progress of fashion in Planting; by which I mean the various systems adopted at different periods for making trees artificial ornaments. The first was doubless that of planting them in a single row at equal distances; and this prevailed in the gardens mentioned by Pliny.

The next step was in doubling these straight rows, to form shady walks; but fashion, not content with the simplicity of such an avenue of trees placed opposite to each other, invented the Quincunx, by which those straight lines were multiplied in three different directions.

As the eagerness of adopting this fashion could not always 
wait the tedious growth of trees, where old woods existed, they were cut through in straight lines and vistas, and in form of stars and Pates d'oie, which prevailed at the beginning of the last century.
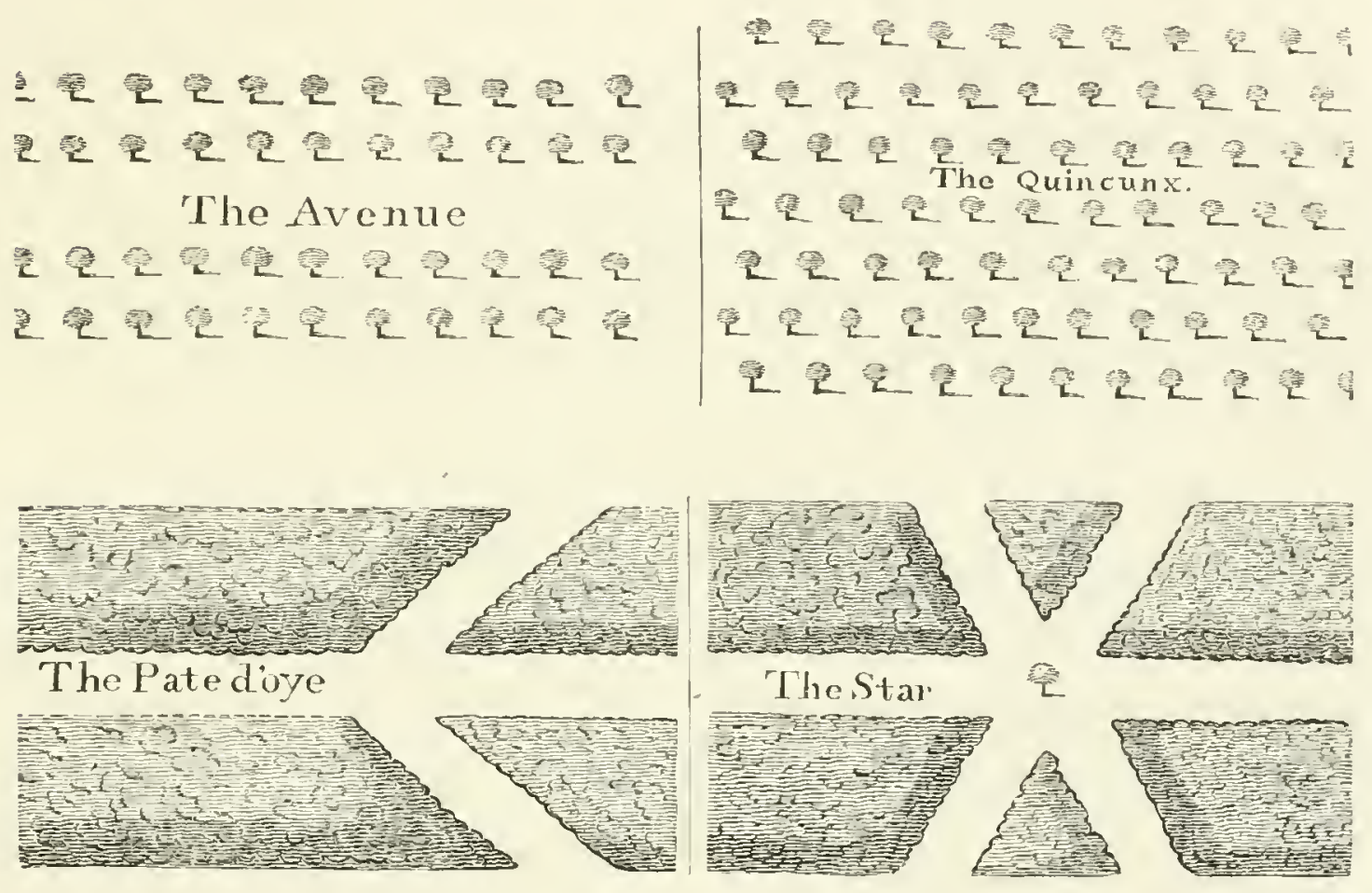

Fashion, tired of the dull uniformity of straight lines, was then driven to adopt something new: yet still acting by geometrical rules, it changed to regular forms of circles and curves, in which the trees were always placed at equal distances. This introduced also the serpentine avenue for a road, of which there is a specimen in the approach from Bedford to Woburn Abbey which is not unpleasing. 

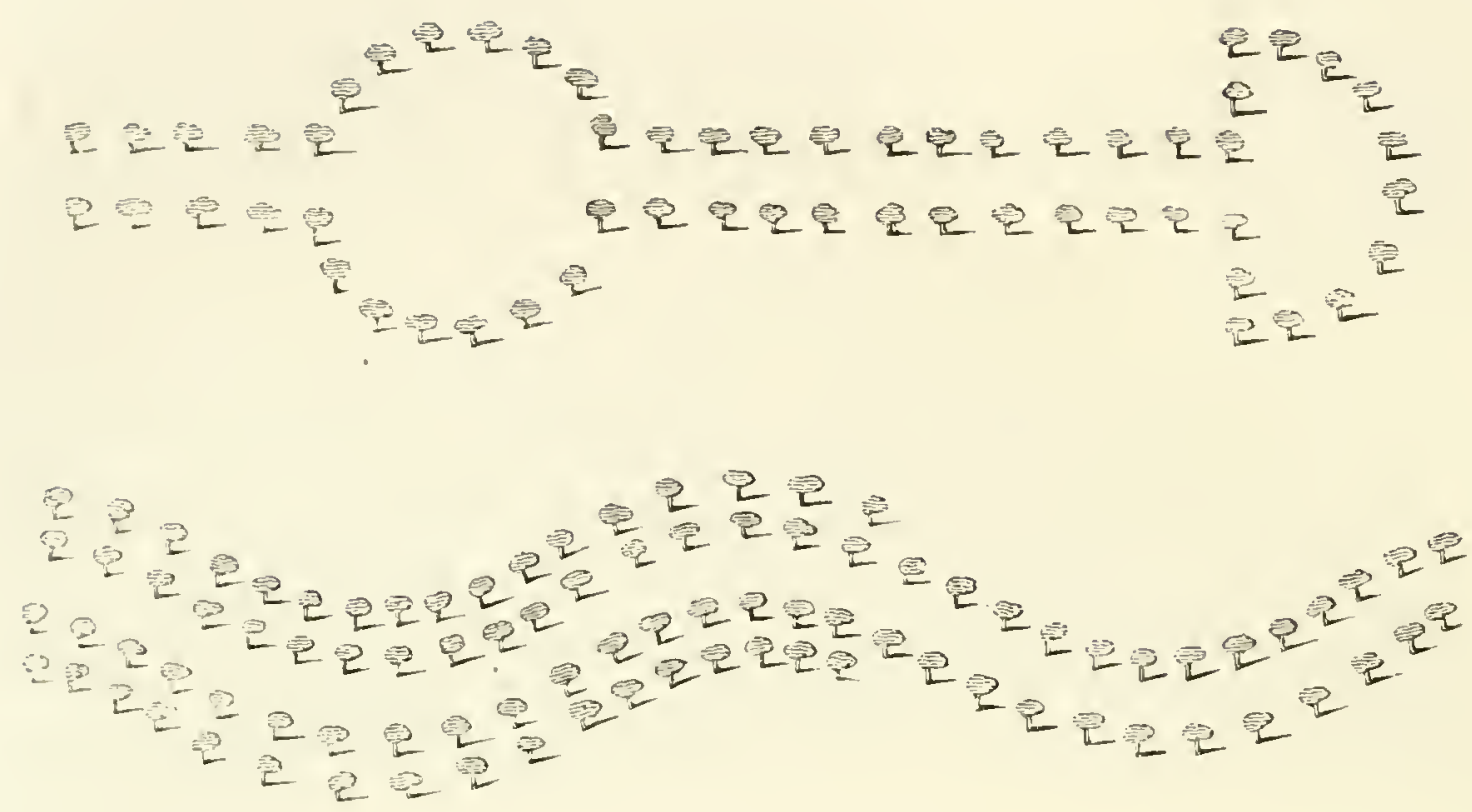

The next bold effort of fashion was that of departing from the equi-distant spaces, and trees were planted in patches of chumps, square or round, alternately shewing and hiding the view on each side of the road; and where no view was required, a skreen or double row of trees entirely shut out one side, while in the other the view was occasionally admitted, but still at regular intervals. This prevails in the Drives at Woburn.

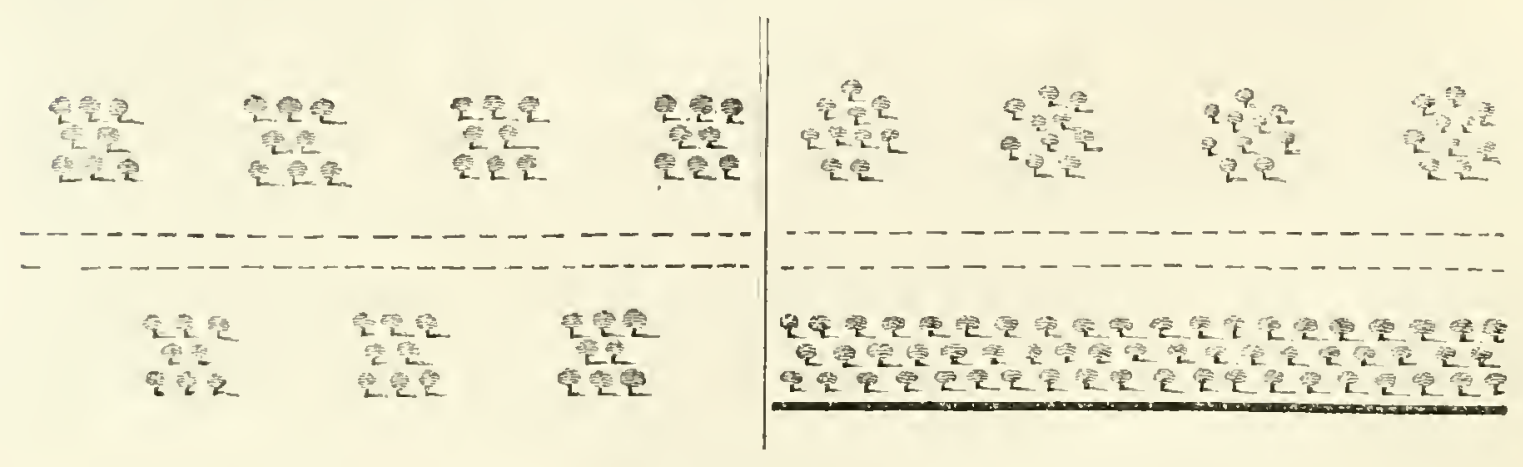


I perfectly remember, when I was about ten years old, that my father (a man of such general observation, that no innovation or novelty escaped him) remarked to me the change which was then taking place in ornamental planting; and then, although little supposing hor much it wonld become the future study of my life, I recollect his observing the discorery made by some ingenious planter (perhaps Kent or Brown), that the straight line might be preserved in appearance from the ends of a vista or avenue, without actually filling "up all the sides; and thus alternate openings of views to the conntry might be obtained, without losing the grandeur of the stringht line, which was then deemed indispensable.* He then observed, that this would lead to the abolishing of avenues; and, I believe, few were planted after that date, viz. the middle of the last century.

About this time a total change in the fashion took place; and under Brown we were taught that Nature was to be om model, and that Nature seldom moved in a straight line. It was not therefore to be wondered at, that his illiterate followers should have copied the means he used, and not the model he proposed. They saw him prefer curved lines, and concluded

* " The late Lord Bathurst told me, that he was the first person who ventured to deviate from straight lines, in a brook which he had widened at Ryskins. 'The Lord Stafford being carried to see the effect of the new improvencut, asked him to own fairly how little more it would have cost to have made the course of the brook in a straight direction."

Danes Barrington. Archaologia, Vol. VII. 


\section{1}

that Nature abhorred a straight one. Hence procecded those meandering, serpentine, and undulating lines in all their works, which were unfortunately conlirmed by Hogarth's recommendation of his imaginary Line of Beauty. 'Thus we see roads sweeping round to avoid the direct line to their object, and fences gracefully and fancifully taking a longer course; and even belts and plantations in useless curves, wilh a drive meandering in parallel lines, which are full as much out of nature as straight ones.

Thus has fashion converted a Belt or screen of plantation, introduced by Brown, into a Drive quite ats monotonous and more tedious than an avenue or vistal, because a curved line is longer than a straight one.

A Belt should consist of wood, througle which a road maty wind to varions points of view; or scenery may be shewn under various circumstances of foreground; but a Drive should only be anong the trees, and moler the shade of their branches; especially where a few large old trees may help to vary the sameness of a plantation uniformly consisting of young saplings.

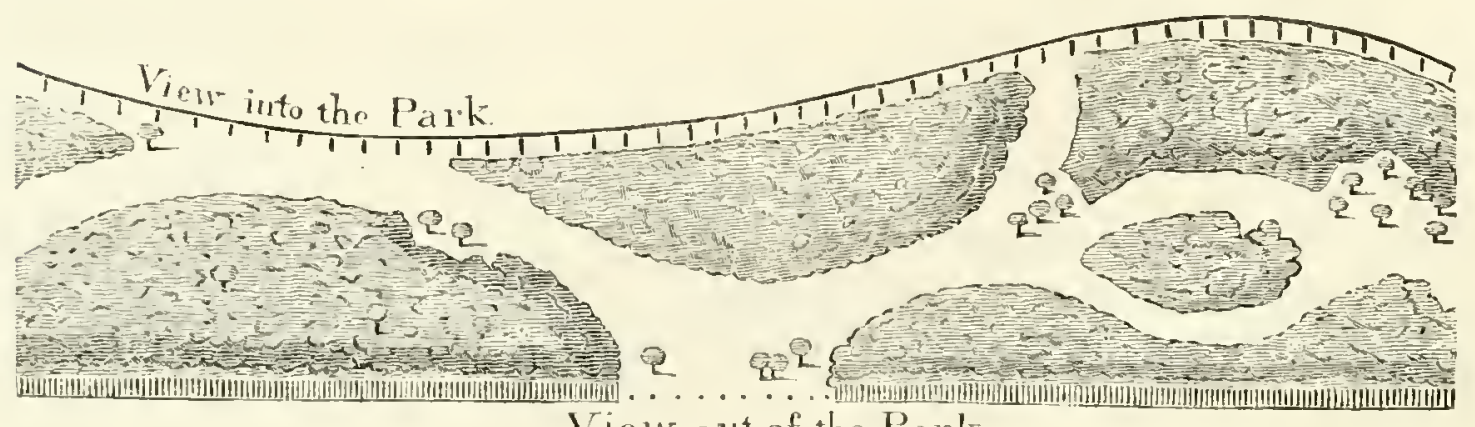

View out of the Park 


\section{5}

Very different from this is the drive too often adopted, which is an open Drive, so wide that it never goes near the trees, and which admits such a current of air, that the front trees are generally the worst in the plantation. Add to this, that two narrow slips of plantation will neither grow so well, nor be such effectual harbours for game, as cleeper masses; especially where the game is liable to be disturbed by a drive betwixt them. The Belt may be useful as a screen; but unless very deep, it should never be used as a drive; at least till after the trees have accuired their growth, when a drive may be cut through the wood to adrantage.

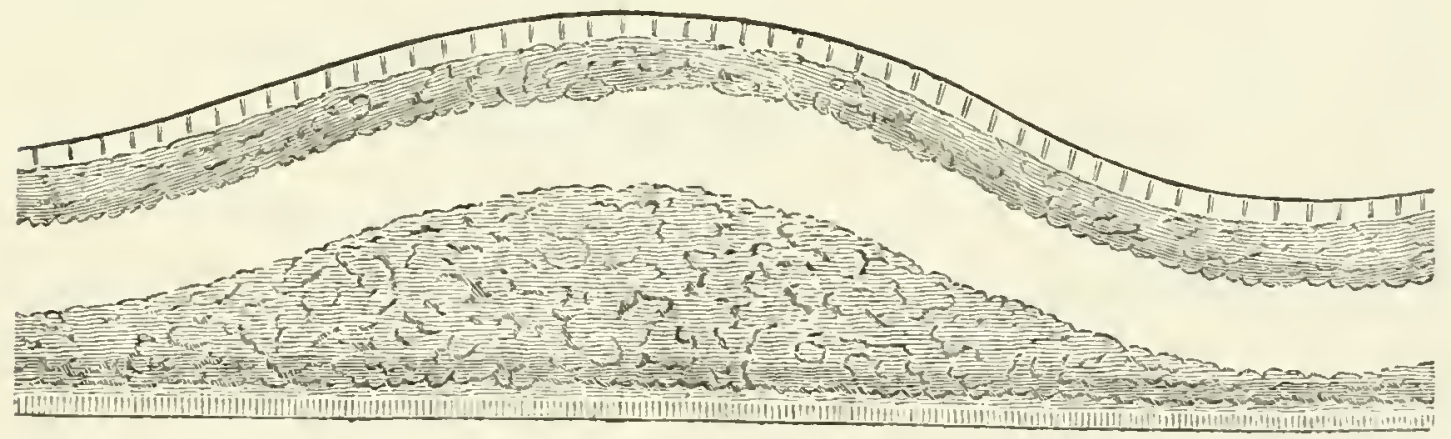

It is not only the line of the modern belt and drive that is ohjectionable, but also the manner in which the plantation is made, by the indiscriminate mixtmre of erery kind of trees, particularly Firs and Larches.

All rariety is lost, and all contrast destroved, by different genera; by the recurrence and monotony of the same mixture of trees of all the different kinds. And here I must not omit my full tribute of applause to that part of the Drive at Woburu, in which erergreens alone prevail: it is a cireunstance of gran- 
deur, of variety, of novelty, and, I may add, of winter comfort, that I never saw adopted in any other place on so magnificent a scale.

The contrast of passing from a wood of deciduous trees to a wood of evergreens must be felt by the most heedless observer; and the same sort of pleasure, though in a weaker degree, would be felt in the course of a Drive, if the trees of different kinds were collected in small groups or masses by themselves, instead of being blended indiscriminately. I do not mean to make separate groves or woods of different trees, although that has its beanty, but in the course of the Drive to let Oaks prevail in sone places, Beech in others, Birch in a third, and in some parts to encourage such masses of Thorns, Hazels and Maple, or other brushwood of low growth, as might best imitate the thickets of a forest.

It is difficult to lay down rules for any system of planting, which may ultimately be useful to this purpose. Time, neglect, and accident, will often produce unexpected beanties. The gardener or nurseryman makes his holes at equal distances, and generally in straight rows; he then fills them with plants, and carefilly avoids putting two of the same sort near each other; nor is it very easy to make him put two trees into the same hole; he considers them as cabbages or turnips, which will rob each other's growth, unless placed at equal distances: yet in forests we most admire those double trees, or thick clusters, whose stems seem to rise from the same root, and these should be our models in ornamental planting. 


\section{FRAGMENT XXIX.}

\section{CONCERNING \\ THE LUXURIES OF A GARDEN.}

The Fruit or Kitchen Garden, as it is generally cultivated, is little better than a ploughed field, where crops are sown in drills; for this reason, it has frequently by Brown, and always by his followers, been banished to a distance, where it might no longer be an unsightly object. I have occasionally found Gardens so placed, at two miles from the house, and consequently the choice fruits are removed with as much care and trouble in the packige and conveyance, as if they came from Brentford to Corent Garden market.* What I have to insert in this fragment is not the result of any single report, but is collected from various hints, thrown out at different places, for the rational improvement of a useful Garden, shewing how it may be rendered ornamental; for though I have elsewhere asserted, that a Ferme Ornè is a solecism in language, yet a Jardin Omè may be made one of the most interesting luxuries of a country residence: and this may be effected in varions ways; the most

- I have noticed this error in the extract from the Report of Woburn Abbey. 
simple, and that which I have successfully adopted in several Villas near London, has been to surround with a border of shrubs and flowers three or four areas of different dimensions, from an eighth to three-quarters of an acre of Garden ground, to raise crops of fruit and vegelables, perfectly hid from the lawn and walks by the surrounding skreen of flowering shrubs and evergreens; which in some cases will even hide dwarf walls, and pits and frames for forcing early fruits. By this means the lawn of pleasure-ground may be varied in its shapes, and the quantity of mowing curtailed: and if we choose to view the interior of the masses, which serve to diversify the landscape, we find new objects to amuse the eye or gratify the taste, at the time those fruits are ripe which are most delicious when gathered by our own hands.

The interior fence of these patches may be of holley, roses, gooseberries, or barberries; serving to increase the mass of skreen, and to protect the produce of the Garden. 'This may be perfectly applicable to places on a small scale; but in large establishments, where one Garden of several acres may be preferred, that Garden should, if possible, be contiguous to the mansion, and a wood or skreen of shrubs should envelope the whole, as it is described on the Map of Cobham Hall.

If a Kitchen Garden consists of such unsightly crops as we see in a common gardener's ground, there will be little inducement to make it one of the visible appendages of a place; but it may be so arranged as to be highly ornamental; and from its sheltering walls it may always be considered as a Winter 
Garden, when an occasional gleam of sunshine will invite even the invalid to brave the rigours of the season.

This naturally leads me to observe how many joys and comforts and luxuries may be preserved, beyond that period of life, when youth and health require no special indulgencies. Having so long dedicated the active part of my professional career to increasing the enjoyment of Rural scenery for others, my own infirmities have lately taught me how the solace of Garden scenery and Garden delights may be extended a little further, when the power of walking fails, and when it is no longer possible for decrepid age to reach the ground, to gather fruits, or to pluck and smell and admire those humble flowers which grow near the earth.

The loss of locomotion may be supplied by the Bath chair with wheels; but if these are to grind along a gravel-walk, the shaking and rattling soon become intolerable to an invalid, and therefore glades of fine mown turf, or broad verges of grass, should be provided, as means of avoiding the gravel; and such grass communications may be so made, as to increase the interest of the scenery, by varying its features; for although a gravel-walk must have its two sides parallel, or nearly so, yet a grass-walk should never be of any uniform breadth; it should rather vary in its outline, sometimes flowing among shrubs, sometimes under trees, as in the ehequered shade of an open grove; and sometimes in one ample green mall or terrace, commanding a distant prospect, a pleasing landscape, or even the curious though confined combination of rare exolic trees, within 
the sheltered boundary of the pleasure-ground. All these may be enjoyed by the cripple, with as much and perhaps more satisfaction from his wheeled chair, or from a garden-seat, than by those who can encounter the fields of the farm, or the haunts of the forest; caring very little for the Luxuries of a Garden, as felt under the painful pressure of infirmity. These remarks are equally applicable to the fruit garden, the flower garden, or the pleasure-ground: they should all be accessible to a garden-chair on wheels, and all should be provided with ample grass-walks, to avoid the oflensive noise of gravel.

Let us now consider the Garden for Use, rather than for Beauty, and we shall find that these two objects are by no means incompatible. The walks of a Kitchen Garden are apt to be uncomfortably exposed to the sun's heat during the summer and autumn: this may be corrected by training the fruit trees of espaliers on hoops over the walks, to make shaded alleys; or covered berceaux, from whence the apples, pears, and plums, are seen hanging within our reach; and grapes so trained, will sometimes ripen without artificial heat. These trellis arcades may be straight or curved, and the walks may be of gravel or grass, surrounding and enclosing those quarters for garden crops, which, if well managed, will be scarcely visible from the walks; and a skreen of gooseberries, eurrants, raspberries, and asparagus beds, surrounding these, will make a cheerful blind during great part of the summer months.

If the Garden happens to be situated on ground hanging to the south, it should be formed into terraces one above the other; 
and this is particularly applicable to strawberrics, which may then be gathered without stooping: indeed the same expedient may be used artificially, where the ground is naturally flat, as represented in the Vignette to this Fragment. Strawberrybeds may be thus made: confine the earth at bottom by at brick wall about two feet high, then slope the mould to the height of three or four feet, and cover the whole with bricks or tiles, leaving spaces betwixt for the roots of the strawberry plants. On the summit, a channel or trough is left open in the bricks to receive water, either from showers or from the watering-pot: the moisture is conveyed to the roots of the plants without injuring the fruit, which is by this means kept dry and clean, and a little forwarded by the reflection of the heated bricks: these should be occasionally secured by mortar, to keep them in their places. Such a raised bed, when covered with strawberries, either in blossom or in fruit, is one of the most delightful of Garden Luxuries; and even when the leaves begin to decay, it has been observed, in Sir W. Temple's works, that a most grateful fragrance is produced.

This same sort of raised bed may be used for various purposes, and particularly in a Flower Garden, where its form may be irregular, oval, triangular, octagon, or any other shape, to raise such diminutive flowers as eannot be seen without being brought nearer to the eye. The ledges or shelves may be receptacles for ornamental vases, or Maltese flower-pots; and the lower wall may be covered with jessamine, periwinkle, or such plants as require a little support; while the upper parts 
may contain fossils, with rock plants growing amongst the stones, and falling in festoons over them. The Vignette only describes a bed for strawberries. Near the end of the bed a hint is given for training gooseberries, currants, \&c. to a certain height, to bear their fruit out of the reach of children, and at a more convenient height for full grown persons. In the gardens of Holland, where such fruits are raised in great perfection, every bush, as well as every espalier, is trained by hoops, so as to assume the form of cups or basins, to admit the sun and air into the interior, and ripen the fruit. Such attention gives great neatness to a Garden, which ought always to appear trim and artificial.

The mass of mankind may be so indifferent to the productions of a Garden, that they hardly deserve to enjoy its choicest luxuries. There are many who would not know the difference betwixt a peach gathered and one that had fallen from the tree; or betwixt the strawberries plucked from the bed, or those brought from a fruit shop, and perhaps gathered with unwashed hands the day before.

Of all the places which I have ever scen, where perfect attention was given to the fruit, I was most struck with Woollaton, in the time of the late Lord Middleton: the grapes were always gathered with a portion of the stalk and leaves; and the bloom of the plums and other fruit was preserved from the touch of fingers, by being cut from the trees, and dropped into the baskets in which they were brought to table. The gooseberries and currauts, as well as the grapes, were so trained, as to 
admit branches, loaded with fruit and leaves, to be cut off, and fastened to stands, with iron or wooden hoops, or led in graceful festoons round the dessert, and intermixed with bouquets of sweet smelling flowers. This may truly be called enjoying the Luxury of a Garden.

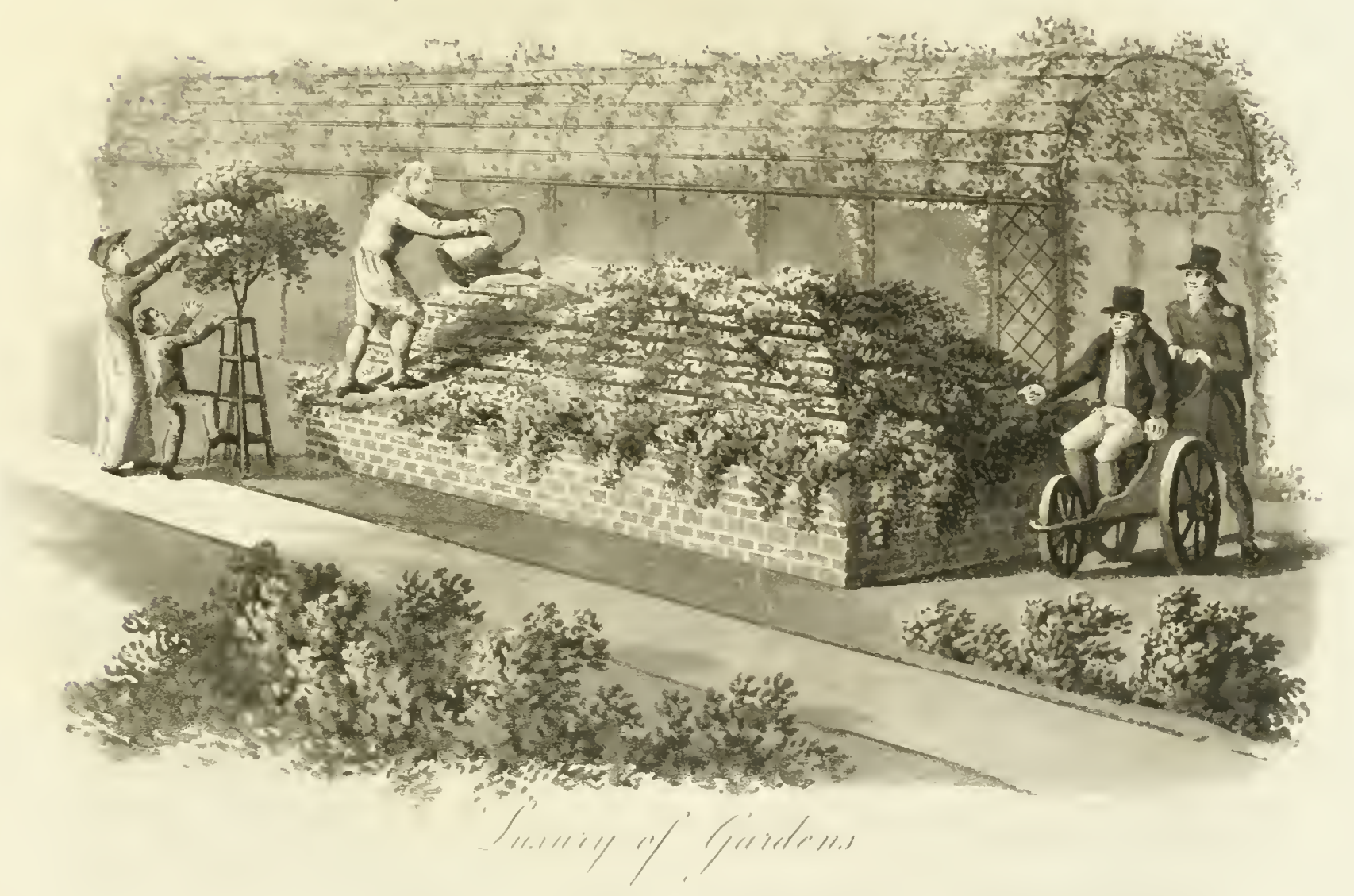




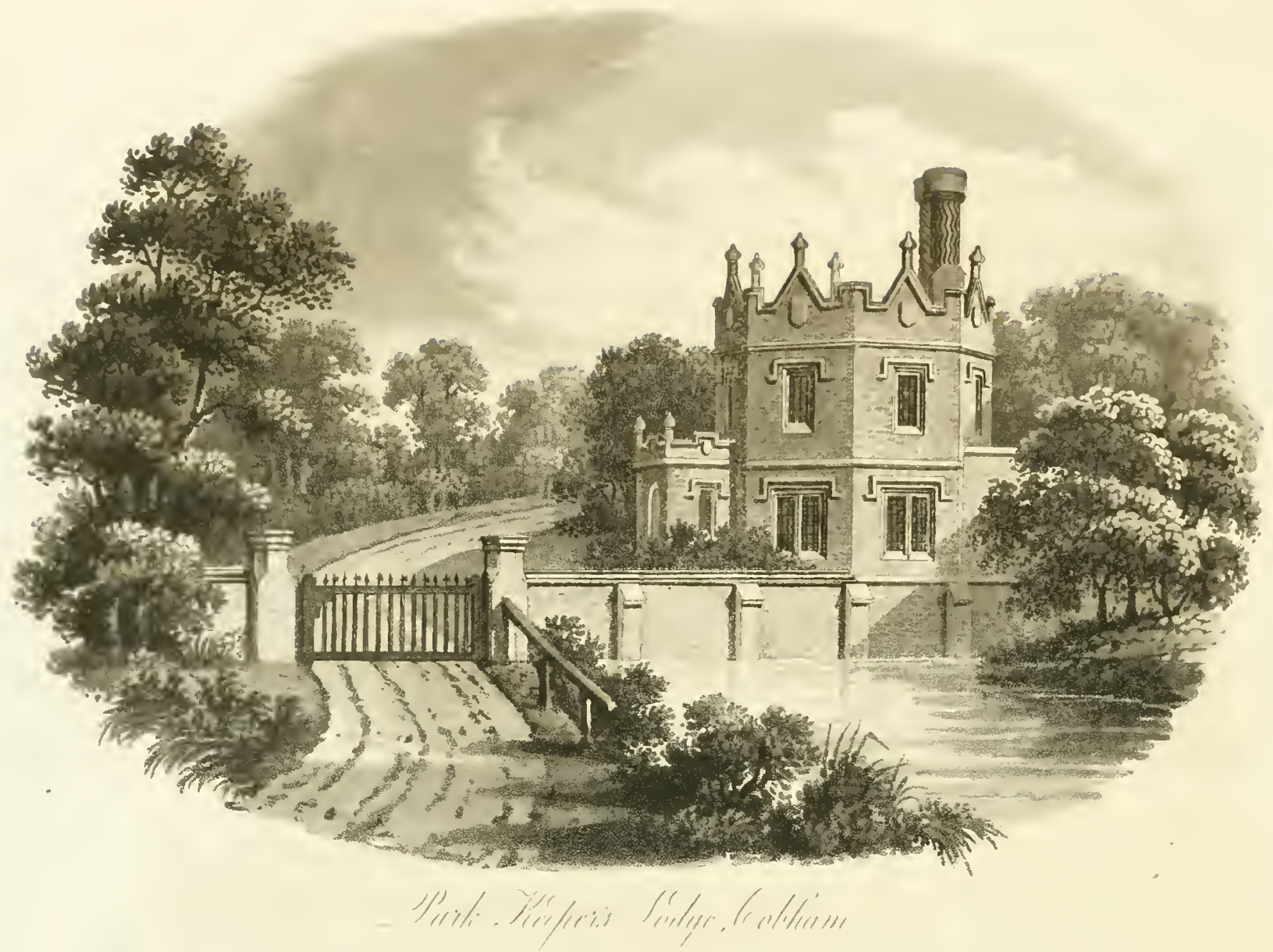

FRAGMENT XXX.

CONCERNING

\section{ENTRANCE LODGES AND COTTAGES.}

VARIOUs expedients have been suggested to mark the entrance to a place with importance. A Villa with a few acres, or a Park with an extensive domain, must now be at some distance from the high road, in compliance with the modern custom of placing the house in the centre of the grounds. In such situations the utility of an Entrance Lodge or Cottage is too evident to require discussing, but its character may be worth some consideration. 
The entrance to a place is generally best marked at any branching off from a public road; and where the boundary of a park is at some distance from the road, and the entrance a kind of private cross-road, a mere Cottage may perhaps be sufficient, of any style of architecture, without reference to the style of the house, and a proper gate will distinguish it as an entrance to a place. But where the gate immediately opens into a park, strongly marked, and bounded by a wall or parkpaling, a Lodge seems more appropriate than a Cottage: that it should partake of the style and character of the mansion seems also to be required by the laws of unity of design, which good taste adopts in every art. If the architecture of the house be Grecian, the style of the Lodge should be the same; as in the design for a Lodge at Wingerworth House, page 64, and the annexed sketch for the Entrance to Longnor, where the house is Gothic. It may be objected, that the Gothic Cottage bears no reference to Woburn Abbey; but that is not an Entrance Lodge, it is a Cottage near a gate into a wood, at the distance of some miles from the House.

To mark the Entrance to Cobham Hall, the seat of the Earl of Darnley, built in the reign of Queen Elizabeth, the style and character of the honse proposed to be adopted in the Lodge is not the modern Gothic style, with sharp-pointed windows, and a flat slate roof just rising over the battlements, but that which is distinguished by massive square-headed windows, with pinnacles, mouldings, gables, escuteheons, and the lofty enriched chimneys of former days, as shewn at the head of this Fragment. 
To a modern Cottage or Lodge of Grecian architecture the Gate may either be a light wooden one between two posts, or iron folding gates with brick or stone piers, and it may be of any fanciful design. But if the Entrance to a place be marked by a respectable Gothic Lodge, or a correct Gothic Cottage, the Gate itself, and even the gate-posts, should also be of the same correct style of architecture. I do not mean the flimsy light deal Gothic gate, frittered with little pointed arches like a showbox, but the heavy strong oak Gate with massive hinges, and occasionally ornamented with fleur de lys, and iron spikes: it should appear to have been constructed at the same period in which the Lodge itself is supposed to have been built.

Among the various designs for the Entrance into a Park, that of an Archway is stipposed to be copied from those ancient specimens which may still be found near colleges and manorhouses, and in the remains of monastic buildings: but it should be remembered, that such lofty arches are only found when joined on each side by high walls, or attached to buildings surrounding a court-yard. When a lofty Archway is seen rising up in the air, being placed at the boundary of a park, and having only a low paling on each side, it is out of character, and in fact bears the appearance of a mere eye-trap, and may be compared to a high gate or stile by the side of a gap in the hedge.

The same observation respecting the Archway may also serve for the Gatehouse; that is, a covered way with a room over it (which room in monastic buildings was called the Scrip- 
torium). These Gatehouses are more appropriate to the courtyards of the mansions, as at Knowle, Penshurst, HamptonCourt, \&c. than as Entrances to a park. In general they had large massive close folding-doors, and sometimes a small don' or postern inserted in one of the folds for foot passengers; and sometimes a single door-way separated from the carriageway, as in the gates of cathedrals, monasteries, colleges, \&c. But with these the modern spruce Iron Gates will be deemed out of character by all those who have made the antiquities of the country their study, or who consider unity and congiruity of design amongst the first principles of good taste.

\section{By J.A.li.}

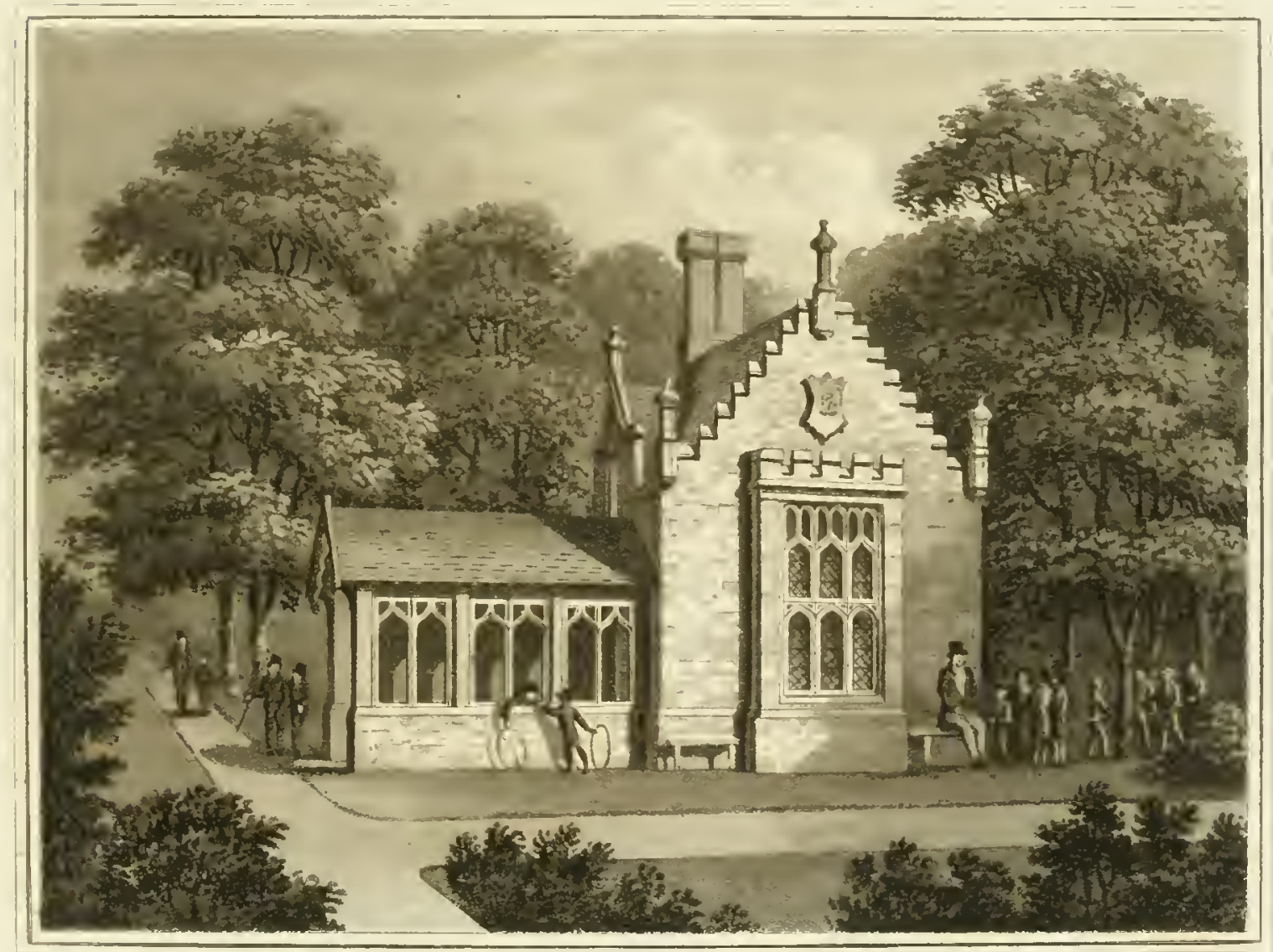

THE SI"HODL HOTSE AT J,OXGYOR, SHRDPSHIRF, 


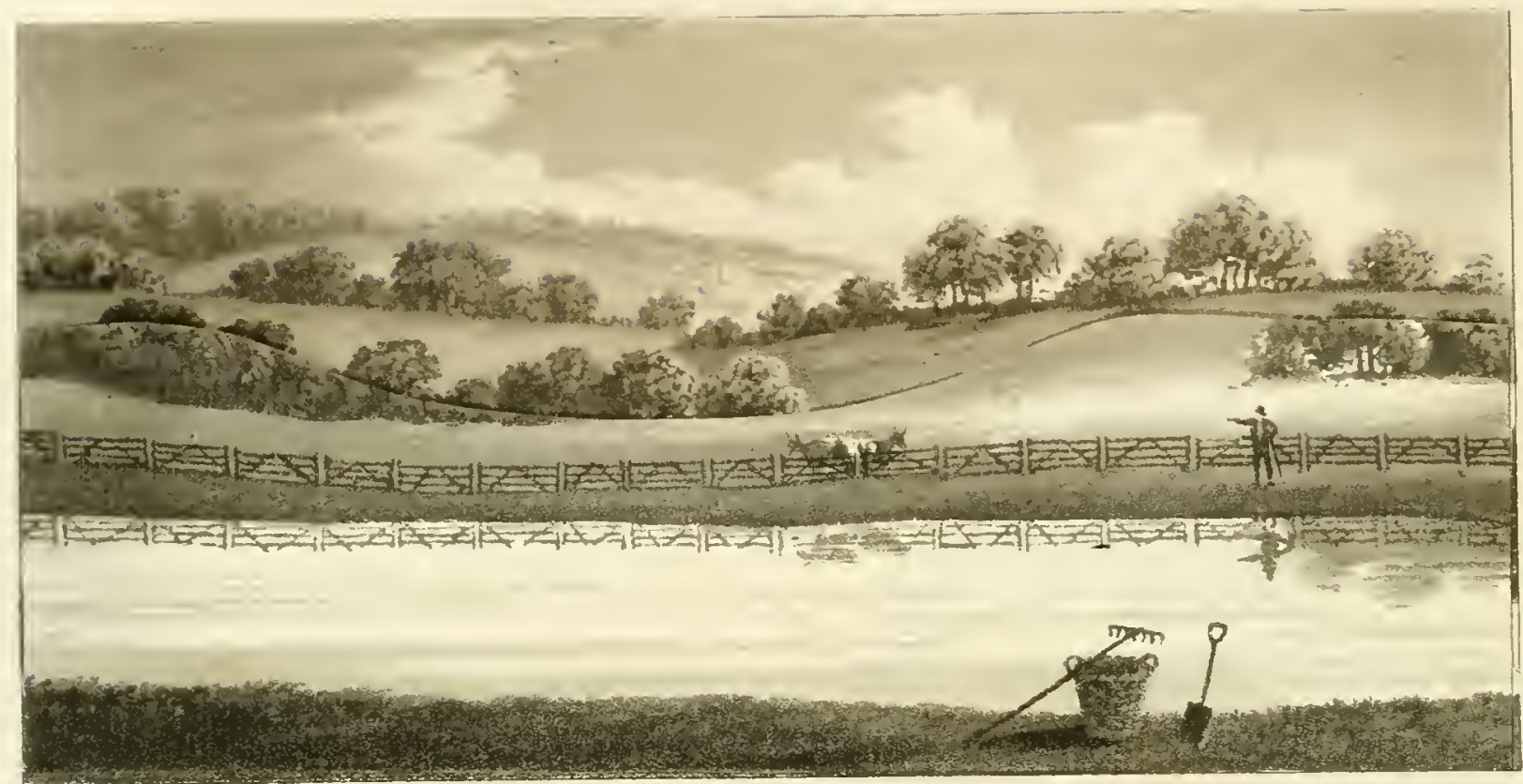

\section{FRAGMENT XXXI.}

\section{OF WATER FENCES.}

IT often happens that a piece of Water, whether natural or artificial, forms the boundary of the pleasure-ground near a house, and makes an obvious line of separation betwixt the dressed or mown lawn and the park or ground fed by cattle. But Water is not a sufficient fence on all occasions, for unless very deep, cattle will wade through it, and however deep, deer will swim across. In some cases, as at Woburn and Longleate, a wall has been built of sufficient depth below the watersurface, to prevent animals from making good their landing; 
but in the winter this is no fence; and while the ice remains they must either be kept out by a temporary line of hurdles, or driven away into a different part of the park; otherwise in one fatal night a herd of deer, or a drove of bullocks, will destroy the produce of years in a shrubbery, pleasure-ground, or flowergarden.

The following expedient occurred to me very recently, on considering the view from the windows at Dagenham in Essex, a seat of Sir Thomas Neave, Bart. The Landscape consists of a Park wooded sufficiently, and the distance presents a pleasing offskip; but the most conspicuous feature is a large cireular pond or pool, with naked banks, from which the eattle are excluded by a hurdle, to prevent their poaching the clay shores. The sight of this hurdle is very offensive; but it is rendered doubly so, by being reflected in the water, where it becomes still more conspicuous by its opposition to the sky. It has long been matter of doubt and difference of opinion, whether it would not be advisable to drain off the water, and make a dry valley or dell of this unsightly pool, which from its situation reflects nothing but the sky. Yet there is something so cheerful in the glitter of Water, that we must always give it up with reluctance, however ill placed or badly shaped: it was therefore decided to preserve this pool, and io make it an ornamental part of the dressed ground near the house.

In the stiff elay soil of Essex there is great objection to admitting cattle to tread down or poach the margin of a piece of water so near and immediately opposite to the windows; yet 
to exclude them entirely from the pool would be to rob the water of the most interesting features of which such a pool is (apable, viz. the reflection of moving objects on its banks, and the glitter of its surface when put in motion. Add to this, if cattle can be kept from browsing the bonghs which overhang the water, there is nothing more interesting than the contrast made by dark foliage reflected and opposed to those parts of the margin which reflect only the sky. An attempt is made in the annexed plate to represent this effect, which also shews the present appearance of the Pool, where no objects are reflected except the sky and the line of hurdles. To realize this landscape, it is proposed to fence the opposite bank of the pool by such a line of paling as may sweep round the thickets of thorns and alders and brushwood, by which they will be concealed, and then a post and chain should sweep into the pool just below the surface of the water, admitting cattle to stand on a bank, which should be gravelled or paved, to prevent their sinking into the soil, and discolouring the water. 


\section{FRAGMENT XXXII.}

\section{CONCERNING IMPROVEMENTS.}

I IAvE frequently been asked, whether the Improvement of the Country in beauty has not kept pace with the increase of its wealth; and perhaps have feared to deliver my opinion to some who have put the question. I now may speak the truth, without fear of offending, since time has brought about those changes which I long ago expected. The taste of the country has bowed to the shrine which all worship; and the riches of individuals have changed the face of the country.

There are too many who have no idea of improvement, except by increasing the quantity, the quality, or the value of an estate. The beanty of its scenery seldom enters into their thought: and, what will it cost? or what will it yield? not, how will it look? seems the general object of inquiry in all improvements. Formerly I can recollect the Art being complimented as likely to extend its influence, till all England would become one Landscape Garden: and it was then the pride of a Country Gentleman to shew the beauties of his place to the public, as at Audley End, Shardeloes, and many other celebrated Parks, through which public roads were purposely made to pass, and 
the views displayed by means of sunk fences. Now, on the contrary, as soon as a purchase of land is unade, the first thing is to secure and shut up the whole by a lofty close pale, to cut down every tree that will sell, and plough every inch of land that will pay for so doing. The annexed two Sketches serve to shew the effect of such improvement; they both represent the same spot: formerly the venerable trees marked the property of their ancient proprietor, and the adjoining forest, waste, or common, might perhaps produce nothing but beauty; now the trees are gone, the pale is set at the very verge of the statute width of road, the common is enclosed, and the proprietor boasts not that it produces corn for man, or grass for cattle, but that it produces him rent: thus money supersedes every other consideration.

This eager pursuit of gain has of late extended from the new proprietor, whose habits have been connected with trade, to the ancient hereditary gentleman, who condescending to become his own tenant, grazier, and butcher, can have little occasion for the Landscape Gardener: he gives up beauty for gain, and prospect for the produce of his acres. This is the only improvement to which the thirst for riches aspires; and while I witness too often the alienation of ancient family estates from waste and extravagance, I frequently see the same effect produced by cupidity and mistaken notions of sordid improvement, rather than enjoyment of property. But to whatever cause it may be attributed, the change of property into new hands was never before so frequent; and it is a painful circumstance to the 
professional Improver, to see his favourite plans nipped in the bud, which he fondly hoped would ripen to perfection, and extend their benefits to those friends by whom he is consulted.

In passing through a distant county, I had observed a part of the road where the scenery was particularly interesting. It consisted of large spreading trees intermixed with thorns: on one side a view into Lord ****'s park was admitted, by the pale being sunk; and a ladder-stile placed near an aged beech tempted me to explore its beauties. On the opposite side, a bench and an umbrageous part of an adjoining forest invited me to pause, and make a sketch of the spot. After a lapse of ten years, I was surprised to see the change which had been made. I no longer knew or recollected the same place, till an old labourer explained, that on the death of the late Lord the estate had been sold to a very rich man, who had improved it; for by cutting down the timber, and getting an act to enclose the common, he had doubled all the rents. The old mossy and ivy-covered pale was replaced by a new and lofty close paling; not to confine the deer, but to exclude mankind, and to protect a miserable narrow belt of firs and Lombardy poplars: the bench was gone, the ladder-stile was changed to a caution against man-traps and spring-guns, and a notice that the foot-path was stopped by order of the commissioners. As I read the board, the old man said, "It is very true, and I am forced to walk a mile further round every night, after a hard day's work." This 


\section{4}

is the common consequence of all enclosures: and we may ask to whom are they a benefit?

"Adding to Riches an increased Store,

"And making poorer those already poor." 

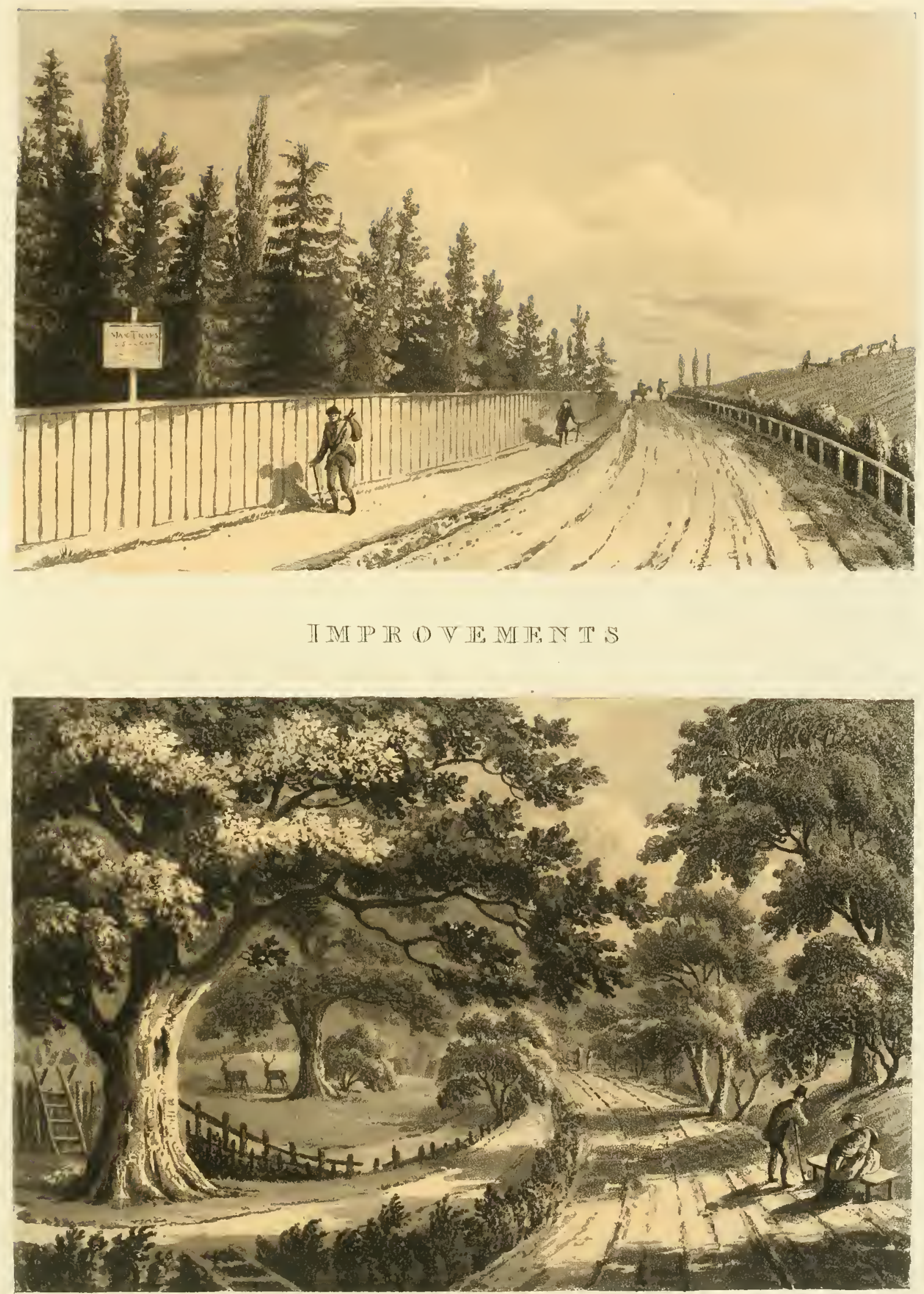



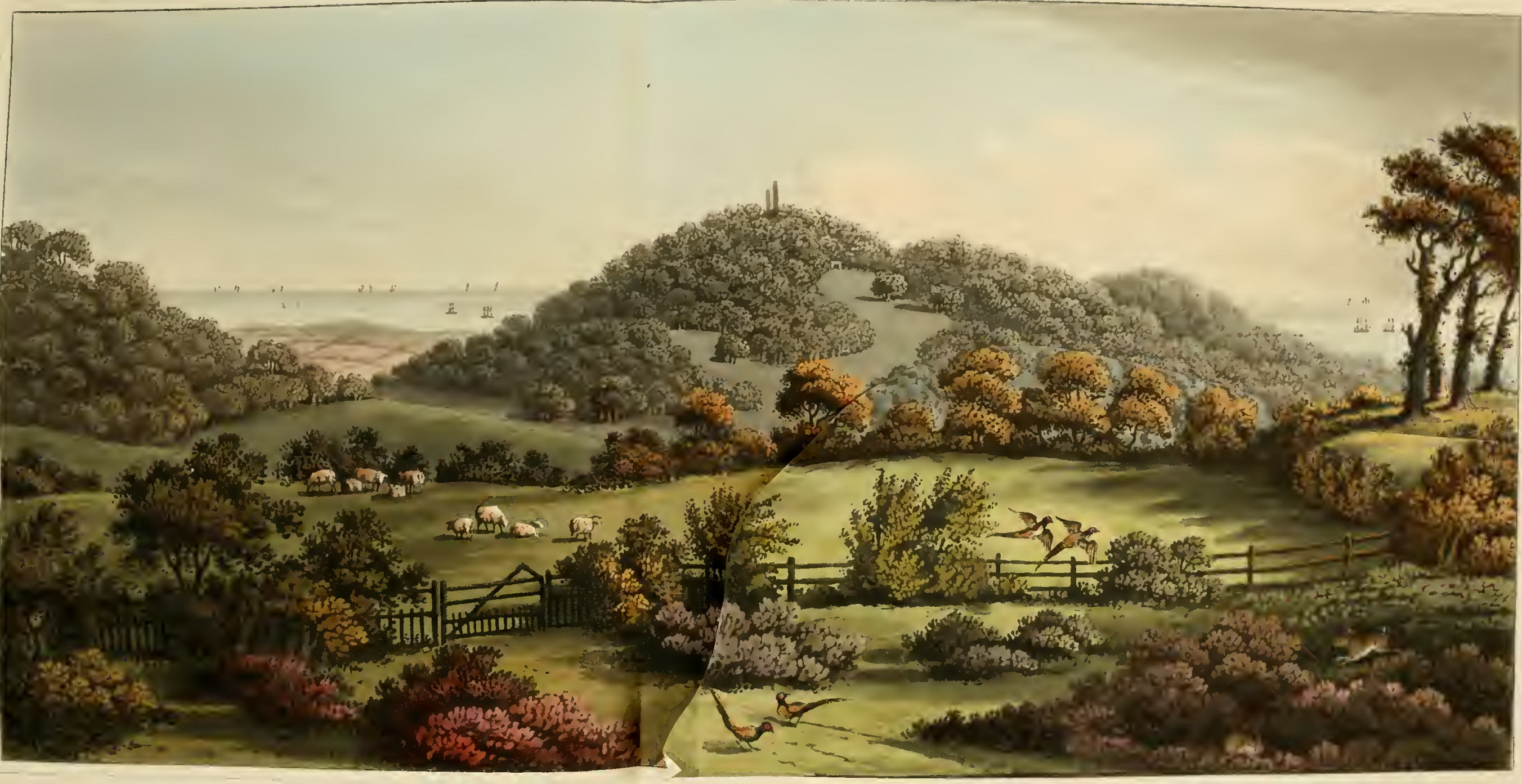




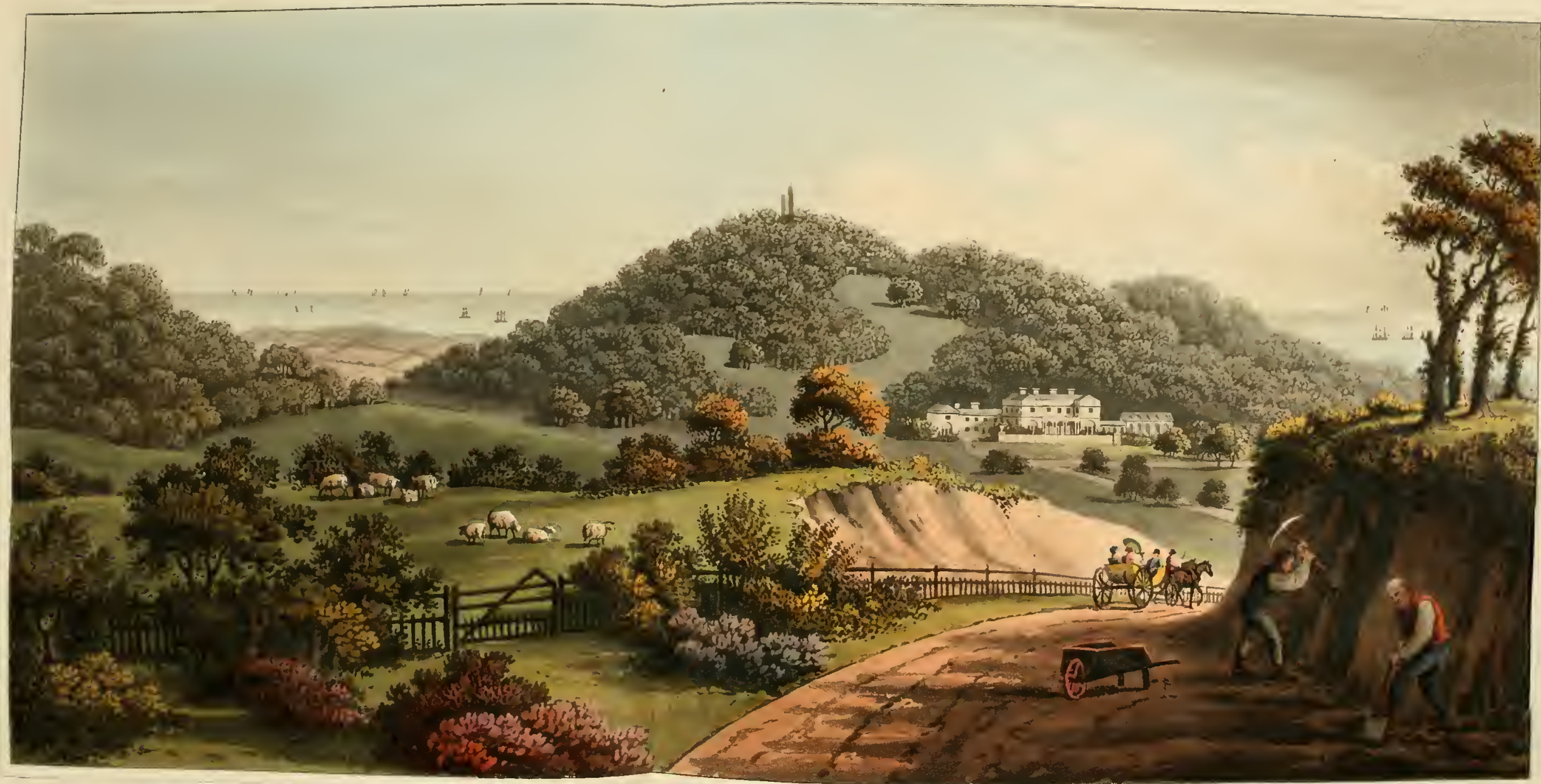




\section{FRAGMENT XXXIII.}

\section{EXTRACTED FROM THE REPORT \\ ON SHERRINGHAM BOWER, IN NORFOLK,}

A SEAT OF ABBOT UPCHER, ESQ.

SITUATION.

IT may appear a bold assertion to pronounce, that Sherringham possesses more natural beanty and local advantages, and is more capable of being rendered an appropriate gentlemanlike residence, than any place I have ever seen. I must here premise, that I do not estimate places by their Measure or Value, each of which may be applied separately to the diamond and the mill-stone; and in comparing it with other places, I must confine myself to those which command views of the Sea, that being always the leading feature of the Scenery of Great Britain as an Island. The most celebrated places of this description which I have seen, are Mulgrave Castle in the North, Tregothnan and Mount Edgecombe in the West, and various places in Sussex, and the Isle of Wight in the South; yet much of the celebrity of these places may be derived from the permission liberally given to have them seen by the public; and, 
indeed the boasted beanty of the Isle of Wight is associated with the moving from one spot to the other, and the cheerful animation of its visitors and tourists; for, if we take any one place in that Tour, and can suppose it solitary and divested of this enlivening circumstance, it cannot be compared with the scenery of Sherringham, where the combination of Hill and Valley, Wood and Sea views, continually remind us of being in that beantiful little Island, without the occasional difficulty of having the water to cross in our return. Much of the interest in the scenery of the Isle of Wight is indebted to the circumstance of its being visited only in Summer, when the gay decorations of the gardens, whether belonging to a Palace or a Cottage, present an assemblage of elegance and comfort, in which Sherringham is at present woefully deficient; but which it is the object of these pages to provide. I recollect when I first visited the Isle of Wight, a continued series of fine weather, amidst the profusion of roses and other fragrant shrubs, operated on my senses like a charm, till on opening a door in one of the most delightful retreats, the sight of Cloaks and Umbrellas, made me exclaim, "Can it ever rain in Paradise?" In considering Sherringham as a permanent Residence and not as a mere Summer Villa, we must recollect how it may appear in Winter. 
The View of the Sea at Sherringham is not like that of the Bay of Naples, or even the Southern Coasts of England; the Sea is to the North, and however delightful the summer visitors of the Norfolk Coast may deem such a View, those who have experienced the cold North winds of winter, and even those who contemplate their effect on some of the Oaks opposed to their violence, will be fully aware that a view of the Sea from the House ought not to be the first consideration; and will pity the bad taste of any one who should recommend a Site for a Mansion looking towards the Sea-

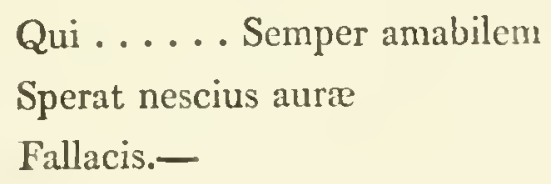

THE WOODS.

The effect of these Woods I consider as accidental, rather than designed, since it is obvious that the only rule observed, was to plant such land as would not bear corn, and consequently all the hills have been clothed boldly; and, fortunately for their beauty, the value of the timber was not so much considered as that of the land; since it may be observed, that the trees in the Valleys have grown much taller than those on the Hills; and the walks and drives have been made through these woods, yet their comparative interest is hitherto unknown, 
since few can distinguish betwixt what they do see, and what they might see. Some trifling changes in the course of these walks would prove how easy it is, by the proper line of a path, to make it not only beautiful in itself, but a beautiful display of other beauties; or, as De Lille expresses it,

" Les Sentiers de nos pas guides ingenieux,

"Doivent embellir en nous montrant ces lieux."

For this reason we may assert, that the treasures of Sherringham are yet in the Mine, and from the present site of the House almost useless.

PLANTATIONS.

Some have asserted, that it is more pleasant to make improvement by the axe than by the spade; but I consider it a fortunate circumstance that some further planting is necessary, since I may venture to affirm, that after a few years the Proprietor will derive more real satisfaction from the trees planted by himself, than from those which have long existed. All Planters delight in Woods reared by themselves, as parents are most fond of their own progeny.

In making new Planlations some useful hints may be taken from that great variety which at present exists, either from accident, by being planted at diflerent times and of different sorts of trees, or perhaps from the influence the sea may have had in destroying some and checking others; for, although in some places the Sea has proved an enemy, yet it points out what trees are best adapted to the situation and exposure. 
This is an object most important in Landscape Gardening, yet there is none so often mistaken or misunderstood, because mankind are apt to judge by the eye rather than by the understanding, and oftener select objects for their beanty rather than for their use or intrinsic worth. The experience of the inconveniences to which most beautiful situations are liable, has induced me to view the subject in all its bearings, and well to weigh against each other all the advantages and disadvantages which ought to influence our choice: these I have generally classed in the following order:-the Aspect, the Levels, Objects of Convenience, and lastly the Views from the House.

First, the Aspect. There can be no doubt that a southern aspect is the most desirable for rooms which are to be occupied throughout the year, because the sun in winter is always acceptable, and in summer it is so much more elevated, that it is rarely objectionable and easily shaded. This is not the case with the eastern or western aspect, where the rays being more oblique, are not to be shaded but by obliterating the prospect, and as the prevailing winds with rain generally come from the southwest, a little turn towards the south-east is to be preferred. This I propose at Sherringham, and for two other reasons, it makes the view towards the opposite woods more central ; and it gives more room for the offices and appendages proposed towards the 
west. A northern aspect is seldom advisable, except in mansions on a very great scale, or in Cornwall or on the southern coast, where it is generally preferred to the sea exposure; it will, therefore, I trust, be acknowledged that the site is perfect as far as it relates to aspect.*

2dly, The Levels. This is an object of much more importance than is generally supposed. We frequently see houses placed, for the sake of the prospect, so high that they are annoyed by every wind; and others, for the sake of shelter, so low that they are flooded by every heavy fall of rain, or by the sudden melting of the snow. The Site here proposed is on a sufficient eminence to enjoy prospect, and yet to be sheltered from the sea winds : the ground by Nature falls gently from it in every direction except towards the north; and in that direction it will easily be made to do so by Art: this is necessary to prevent any damps from the hill, and to provide a sufficient drainage for the House and Offices, all of which will require very little cost or labour. Thus, I trust, I may pronounce that the Site is perfect with respect to its Levels.

$3 \mathrm{dly}$, Objects of Convenience, of which the first is the Supply of Water. This is an object of great importance, yet I have frequently seen large houses placed where no water can be had, but by aqueducts or distant land carriage; and as

- The reasons for a South-East Aspect were before given in Fragment No. 24, although here repeated to preserve this Fragment entire. 
it is not only for the constant use of the family, that water is essential, but as a security in case of fire, some great Reservoir or Tank ought always to be provided near the House. From the situation of the two ponds near the Site, we have reason to expect water will not fail.

Qdly, Sufficient space to contain all the numerous appendages of comfort and convenience, as Offices and Office Courts, Stables and Yards for Wood, Coals, Linen, \&c. all which should be near; and others at no great distance, such as Kitchen Garden, Melon-ground, Poultry Yard, Timber Y Yard, Ice House, \&c. These if possible should be on the contrary side of the House to the Flower Garden, Conservatory, and Pheasantry, which are naturally connected with Pleasure ground.

3dly, Relative Objects, or such as though not immediately belonging, must be considered as relating to the place, and therefore must be properly connected with it, viz. the Post Towns, the Church and Village, and the Sea; to all which there must be roads, and these may be made highly ornamental, useful, and convenient, or the contrary. It fortunately happens that the three roads from Aylsham, Holt, and Cromer, all meet at the summit of the hill, from whence the public roads descend steeply towards the two towns of Upper and Lower Sherringham, and at this spot, I propose to enter the premises, and proceed to the House along a line of approach, the most easy, natural, varied, and beautiful; and as it is nearer than the public road, it places the new Site exactly 
at the same measured distance with the old one from the three Post Towns, while the apparent distance will be shortened by a mile, because we are apt to consider ourselves arrived at a place as soon as we have passed the gate of the Grounds or Woods or Park belonging to it.

4thly. View from the House. Although with many, the Viers from a House form the first consideration, yet I an not so infatuated with Landscape as to prefer it to any of the objects ahready enumerated. Perhaps a natural habit of cheerfulness operates too powerfully on my mind; but I have ever considered the View of trees and lawns only, as creating a certain degree of gloom; which I am convinced is oftener felt than acknowledged by the possessors of places admired for their solitary grandeur. We are apt to lament the desertion of such family mansions for the residence of London in winter, and watering places in summer; but we should consider the difference betwixt the country gentleman's Seat, when only separated from his neighbours and dependants by Court Yards or Garden Walls, and the modern fashion of placing the House in the middle of a Park, at a distance from all mankind,

"Where only grass and foliage we obtain

" To mark the flat insipid waving plain,

"Which wrapt all o'er in everlasting green

"Make one dull vapid, smooth, though tranquil scene."

KNIGHT'S LANDSCAPE. 
To this might be added, that,

" Now not one moving object must appear

“ Except the owner's Bullocks, Sheep, or Deer,

"As if his Landscape were all made to eat,

" And yet he shudders at a Crop of Wheat."

For in the present taste for Park Scenery a Corn-field is not admissible, because every fence must be removed except those which are most offensive, such as separate woods and lawns. In the principal View to the South, this modern taste may be indulged to the greatest excess by "Lawning a hundred good acres of wheat," but I should not advise the extending the verdant surface too far, as I consider the mixture of Cornlands with Woods at a distance more cheerful than grass, because at certain seasons, at seed time and at harvest, it may be enlivened by men as well as beasts. I hope I may be here allowed to indulge my favourite propensity for humanizing as well as animating beautiful Scenery, by a hint respecting the future occupation of Sherringham. It has already been observed, that the places most celebrated for their beauty are most known to the Public, for " many a gem of purest ray serene" is locked up in the casket, lest man should breathe upon it; let me hope to unlock this treasure occasionally to strangers. I do not mean to destroy the comfort and privacy of Sherringham by admitting near the House all the Tourists and Felicity Hunters of Cromer and the Coast, but at such a distance as the Temple. One day in the week might be 
granted them to share in the beauties of this spot. This occasional glitter of distant moving objects, with the sight of carriages coming to the House, would furnish lively features to contrast with the quiet, yet appropriate View from the House towards the South.

THE VILLAGE.

Notwithstanding the modern fashion of placing a House in the Centre of a Park, at a distance from the haunts of men, or even the habitation of its own dependants and Labourers, yet there are numerons objects belonging to a Village with which the Mansion must be connected, such as the Church, the Inn, the Shop, the Carpenter, Blacksmith, and other Tradesmen, to which may here be added the farming premises and the Steward's house.

'The vicinity of a Village is very differently marked in different parks. In some, I see lame and blind beggars moving sorrowfully towards the Hall-house, where I know, and they fear, no relief will be given: in others, I see women and children with cheerful faces bearing their jugs and milk and provisions at stated periods, and I know, before I enter the House, which are the happiest families. In some places I hear complaints that the neighbours are all idle thieves and poachers: in others, that all the inhabitants of the neighbouring Villages would rise at night to serve their liberal Patron; and I have 
been often led to consider the source of this difference. Formerly the poor labourers on an Estate looked for assistance in age or sickness to the hand that paid for their work when they could work; now they are turned over to the Parish Officer, and prisons are erected under the name of Workhouses for those who are past all work. A common Farmer, who works as hard as his labourers, with them, is considered as one of themselves; but when a very opulent Gentleman Farmer told me that by rising at four o'clock every day, and watching his men all day, he could get more work done, I thought he paid dearly for it; and whether the poor slave is urged on by the lash of the Negro-driver or the dread of confinement in a Workhouse, he must feel that man is not equal, though he may be taught to read that he is so.

I consider the proximity of the Town of Sherringham as a mine of wealth, a source of infinite interest, more valuable than the interest upon interest of the Usurer. The Workhouse, instead of an object of terror to the poor and of disgust to the rich, may be made to look more like an Hospital, or an Asylum, and less like a Prison : the Street may be improved, and a cheerful Village Green, with benches and a Maypole, may be laid open to this House of Industry: this will remind us that happiness may be extended to all ranks of mankind. The Labourers' Cottages belonging to the Estate, may be marked by neatness, and decorated by those ornamental shrubs and creepers, which make the whole Isle of Wight a Garden so enchanting to strangers. 
Instead of forbidding all access to the poor, in some places, I have observed it is customary"one day in the month, or oftener if necessary, particularly after any storm of wind, to admit into the woods, but under the eye of the keeper, all persons belonging to the Parish, to pick up dead wood for firing; and in these places no wood is stolen, and no trees are lopped and disfigured. With respect to the Game, which is every where, and particularly in Norfolk, the perpetual source of suspicion and temptation, I foresee that at Sherringham it will be one source of conferring happiness; for, there is a great difference betwixt shooting and coursing; one is a selfish, the other a social enjoyment. The villagers will occasionally partake in the sport like those where the games of cricket or prison-bars are celebrated; thus promoting a mutual endearment betwixt the Landlord, the Tenant, and the Labourer, which is kept up with little expense, securing the reciprocity of assistance of each to the other, by a happy medium betwixt licentious equality and oppressive tyranny.

Although the local advantages of Sherringham may not be decmed of general interest, yet their consideration has had great influence with me in the preference I have given it over every other in which I have been consulted.

1st. It is situated within half a mile of the sea, without being exposed to it.

2dly. It is within a morning ride of the capital of the county, and within an hours drive of the several ports and 
market towns of Holt, Aylsham, North-Walsham and Cromer; at each of which are Balls and Book Clubs, besides the monthly meetings of magistrates, and annual Fairs and Festivals, where society and amusement may occasionally be had to vary the monotony of rural life.

$3 \mathrm{dll}_{\mathrm{y}}$. The Soil is delightful for habitation, being neither so light and sandy as to be barren, nor so rich and wet as to make the roads impassable.

4thly. It is within five or six miles of the sea-port of Blakeney to the West, and of Cromer to the East, where those who do not object to the mixed company of a Watering-place, may partake of its variety.

5 thly. There is no manufactory near; this, for the comfort of habitation, is of more importance than is generally supposed: manufacturers are a different class of mankind to husbandmen, fishermen, or even miners: not to speak of the difference in their religious and moral characters: the latter from being constantly occupied in employments which require bodily exertion, and their relaxations being shared with their families and friends, become cheerful and contented; but the former lead a sedentary life, always working at home, and seeking relaxation at their clubs, the birth-place and cradle of equality, discontent, and dissatisfaction.

6 thly. There are some who consider that no place can be perfect without water, while others do not consider the Sea as water belonging to a place, but as its boundary; in answer to 
both these fastidious hypercritics it may be observed, that here two lively brooks flow through the Estate; and, that in a distant recess in the woods, a small pool exists, which might be increased to any size.

I cannot help considering Sherringham as deriving a degree of advantage from what some will think the reverse, because they not only look to increasing the value, but the quantity of an estate. This is bounded by property to the West, that is not to be purchased; and, therefore, like the boundary of the sea to the North, it so far fixes a boundary to our wishes. Men are apt to indulge the vain hope of making all they see their own, like children who cry for the moon; or like dogs who bark at it.

WALKS, DRIVES, AND STATIONS.

'The natural shape of the surface is so infinitely varied, that it is impossible from a map to form any idea of the scenery; and drawings can but feebly represent a few of those landscapes which change at every step. The peculiar character of Sherringham is beauty, without any of that sublimity which is derived from horror, as on the brinks of rocky precipices in mountainous regions: yet there is a sublimity attached to the sea, which is here softened into the character of beauty, and forms the leading feature of Sherringham. For this reason I do not advise that degree of softuess and artificial smoothing, 
described by Mr. R. P. Knight, in his attack on Brown's followers,

"To improve, adorn, and polish they profess;

"But shave the goddess whom they came to dress."

There are some few trees which have felt the terrific effects of winter winds; these cannot be removed without endangering others to which they have long been the advanced guard; and so far from wishing them trimmed, or otherwise reduced to a softer character, I consider them like a dry rugged channel of a Winter's cataract, leaving in Summer sublime memorials of the power of Nature's mighty agents: they form a contrast to the generally prevailing forms of beauty; and for this reason I have recommended, near the same spot where the ridge of the hill is to be cut down a little to ease the descent of the road, that its banks should be left steep and abrupt, and not smoothed and turfed over; since a road is an artificial object, and may be avowed in such cases as a work of art. As this chasm, dividing the land from the sea views, will be one of the most striking stations at Sherringham, I have called it the Scalp, from a noted scar of this kind in Ireland. The annexed View is supposed to be taken from this spot.

INTERIOR ARRANGEMENT.

It is remarkable, that of the many thousand plans which have been made in different ages and countries, no one has $2 \mathrm{E}$ 
ever been deemed so far perfect as to become the model for any future design. In digesting the arrangement for the House at Sherringham, we have proposed a plan in many respects differing from other houses, for which we plead the following reasons:

First, The wishes of the Proprietor.

Secondly, the adaptation of the house to the situation, character, and circumstances of the spot.

Thirdly, The style in which it is supposed to be inhabited.

Most modern houses, as well as those of former times, are too large to be occupied with economy. It is not a large house, but a large room, that is most comfortable to live in ; yet, many such large rooms tend to increase the expenses, if constantly lived in, and the miseries of life if only used occasionally. Let us then consider what are the rooms required for a house on the scale here proposed.

These may be thus enumerated,

1st. One large living room, to contain books, instruments, tables, and every thing requisite to modern comfort and costume.

2d. An ample eating room, to be used in the morning for breakfast, and not to have a fire lighted five minutes only before dinner.

3d. An entrance, with such vestibule and passage as may impress a certain degree of importance, without useless waste of space or expense, the ancient Hall not being necessary.

4th. A room on the ground floor, which I call a parlour; it may serve various purposes, besides that of the proprietor's 
own study; it should have a bed, in case of age or infirmity, or it may be occupied by an eldest son; but its chief use is to give the proper number of bed-rooms on the floor above, which would otherwise be defective, in a house in the country.

5 th. The gentleman's own room, connected with the offices, to give access to persons on business, without admitting them into the body of the house. This may be Gun-room, Justice-room, \&c.

6th. The lady's own room, or boudoir up stairs, and connected with the wardrobe and bed-room on the same floor, having a degagement or private stairs, although the approach for strangers is by the principal stair-case.

7th. The bed-rooms to have dressing-rooms, in which sophabeds may occasionally be used.

8 th. The rooms over the offices, to be used as nurseries, should have large folding-doors to admit air, and may be connected on the same level with the hill at the back of the house, for exercise to the children.

The Eating Room is of that proportion, about two by three, which is now considered the standard of perfection : indeed, in many modern houses, every room partakes of the same shape and dimensions; such a room requires Tables and Sophas to fill up its area and create that sort of intricacy which is so admirably conspicuous in the old houses of the date of Queen Elizabeth, where large bow windows and deep recesses give a degree of comfort worth copying in a Modern Room. With this idea, the windows for Sherringham are proposed to take a new character, as applied to Grecian Architecture, which in fact has 
no more to do with a Modern Sash than with a large Gothic Window.

In the centre of this Room, and opposite to the fire-place, is a deep recess, which will be one of the most interesting and striking novelties, admitting a small company to live in the Room or out of the Room at pleasure, and commanding a delightful View of the Flower Garden, with just so much of the Sea as will be sufficient to announce its proximity, withont exposing the Room to its baneful effects. The View to the East from this Window in the Recess, will be so peculiar that it may perhaps be advisable to exclude all View from the Windows on the sides, only leaving the upper part for Transparent Blinds, or Stained Glass. 

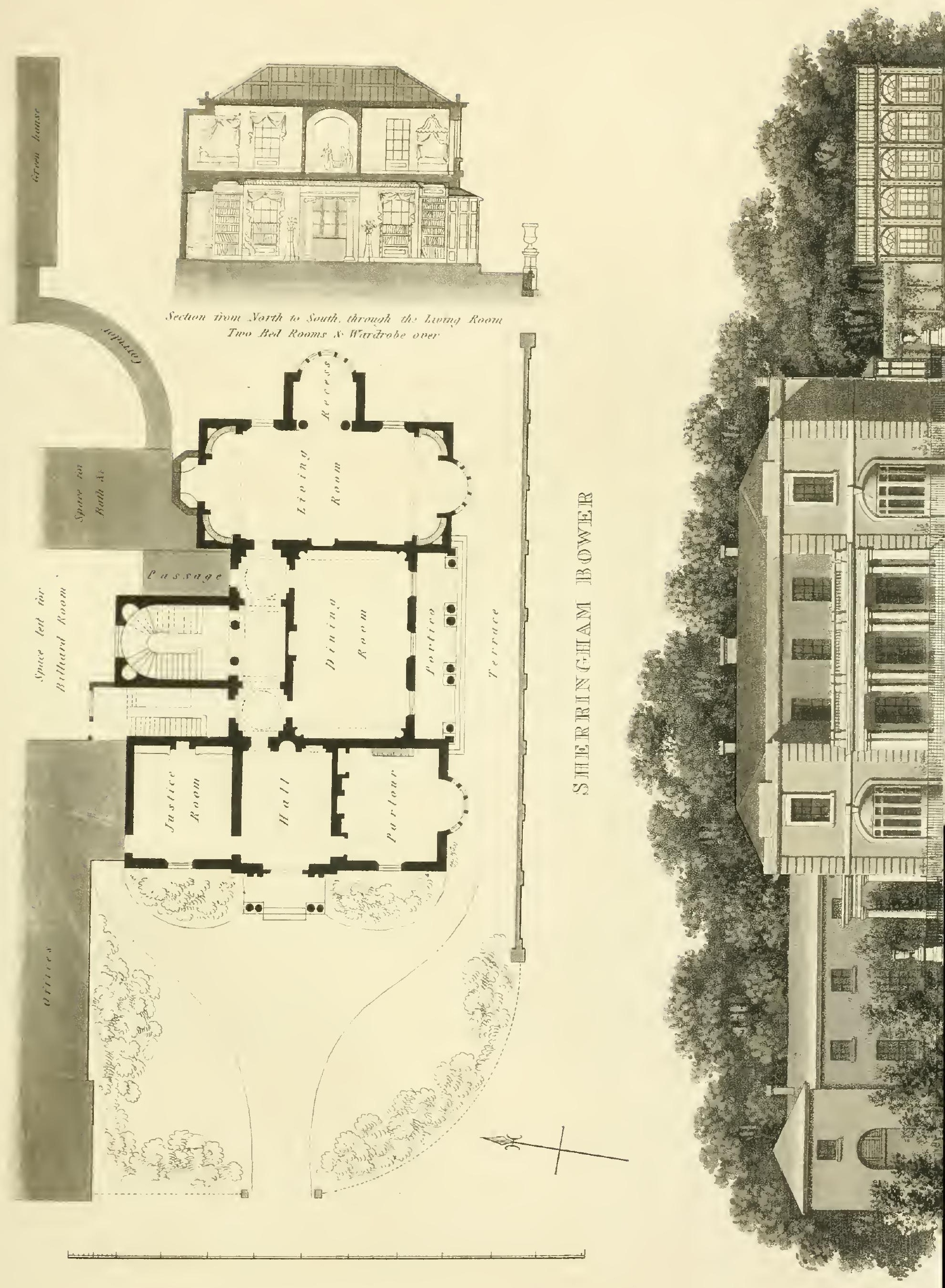



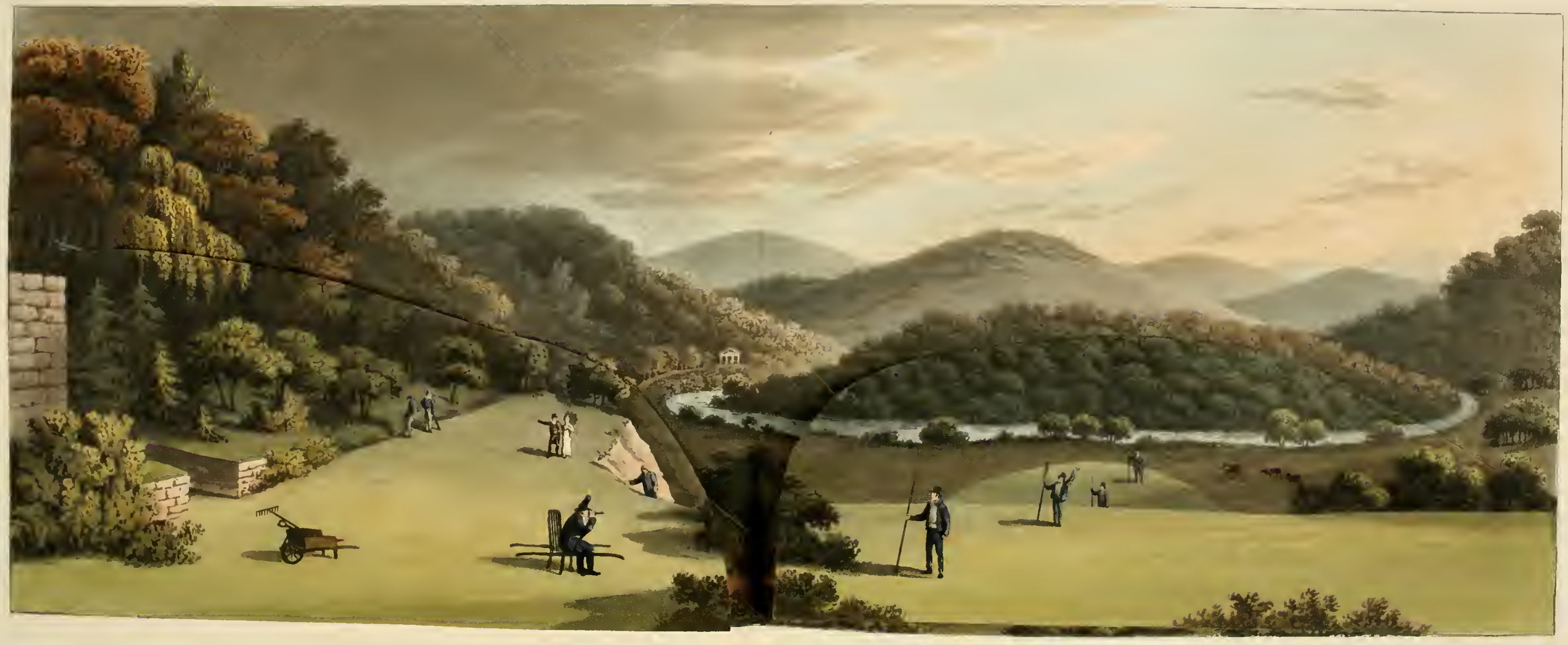

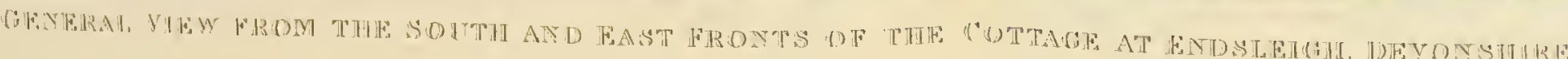




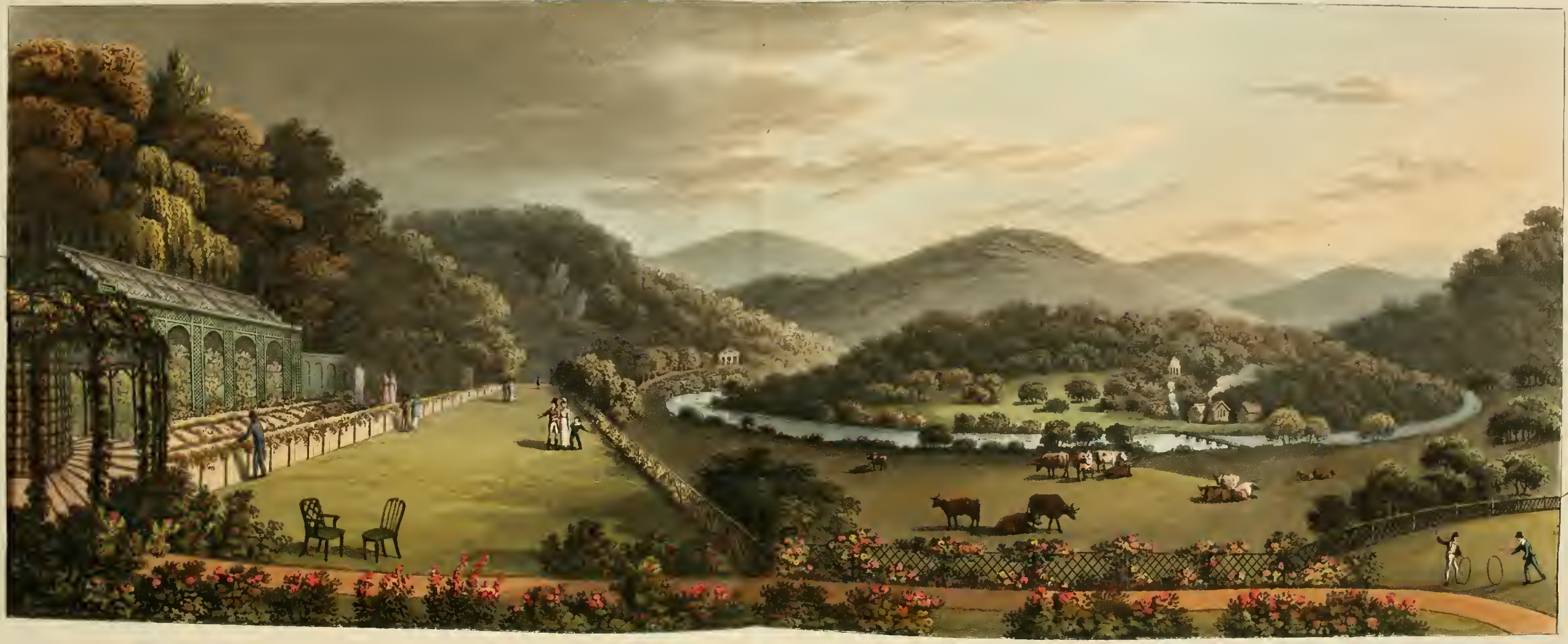




\section{FRAGMENT XXXIV.}

\section{EXTRACTED FROM 'THE REPOR'I' OF ENDSLEIGH,}

A CO'TAGE ON THE BANKS OF THE TAMAR IN DEVONSIIIRE.

BY PERMISSION OF HIS GRACE THE DUKE OF BEDFORD.

SITUATION ANI) CHARACTER.

THose who have sailed on this beautiful Rivernear Plymouth and Saltash, will figure to their minds one of those calm sequestered retreats, reflected on the smooth surface of a broad expanse of waters, very different from the River Scenery of Endsleigh: to explain this difference it will be necessary to describe the Tamar.

There are hardly two things in nature nore contrasted, than a River near its source in a mountainous country, and the same River when it becomes navigable, and spreads itself into an estuary, like the Tamar at Plymouth. Nothing can be more delightful to those who have braved the storms of the Ocean, than to sail between the romantic Banks of the Tamar, whose echoing rocks often repeat the music, which from pleasure boats enlivens its peaceful surface, and a Cottage on the Banks of the Tamar will naturally suggest such tranquil Scenery. Very different is that of Endsleigh. Here, Solitude, embosomed in all the sublimity of umbrageous majesty, looks down on the infant River struggling through its rocky channel, and hurrying onwards with all the impetuosity of ungoverned youth, till it 
becomes useful to mankind. This idea often occurred to me, while contemplating the River on the spot. The Tamar, like all mountain streams, however it may amuse the eye with its frolic motion, by not being navigable or passable, becomes a barrier, and seems to serve no other purpose than that of dividing the two Counties of Devonshire and Cornwall; but even in this apparently useless state it is busy in collecting the " little streams which run among the mountains;" and on tracing its progress we find that it soon becomes more and more useful to man, till at length it is acknowledged as the great source of the Harbour of Plymouth, to which England owes much of its Glory and its Commeree.

In speaking of the course of the Tamar, I should wish to make a distinction betwixt the Chamnel and the Bed of the River, if I may be allowed so to use these two words. By the Channel I mean the whole flat surface, over which a river spreads its waters during the floods of winter, extending to the foot of the hills which form the valley. By the Bed, I mean the narrow channel to which the water is confined during that "Belle Saison," when all Nature presents her beauties to advantage; when all Rivers sleep in their beds, and even the most turbulent are restrained within their narrowed limits. Let us now consider the process of Nature in forming this Bed. Light never moves but in straight lines. Water always takes some degree of curvature. The rays of light may be broken by reflection or refraction, but can never be bent. Water, on the contrary, may easily be bent, but cannot be broken without 
changing its fluid character to froth. The course of a River is never straight, and seldom along the middle, or lowest part of the flat, but it shoots across from side to side, increasing its utility by thus retarding its progress; this observation applies to all rivers, though I was first led to examine the subject by the tortuous course of the River Manyfold in Derbyshire.

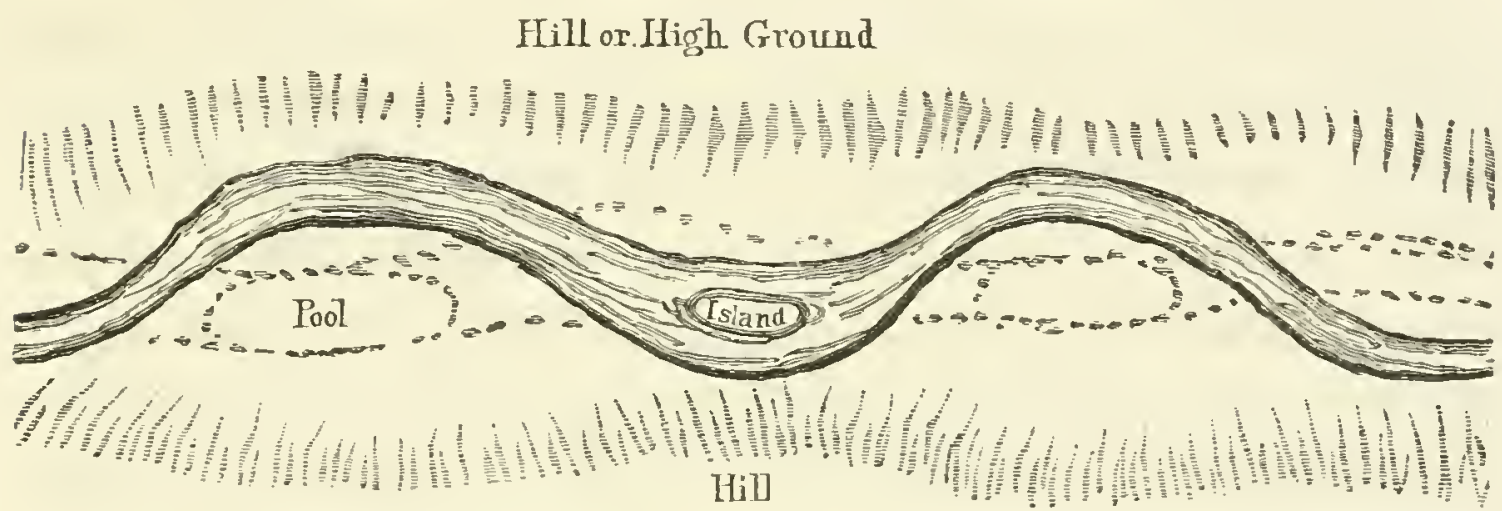

In the above Sketch, which I have supposed to represent the course of any river, a dotted line shows a second track, which the water seems to mark out during floods, and which leaves occasionally swamps or pools of water in summer after the River has subsided. This sort of channel may be observed at Endsleigh, in the shape of the ground on the left bank of the River.

Sometimes a River forsakes its bed entirely, and takes one of these new channels; and I have frequently had occasion to assist, or retard this operation of Nature, by an interference of Art; but in the present case I shall only revert to the difference, which I have endeavoured to establish betwixt the 
Channel and the Bed of the River Tamar, so far as it relates to the best means of crossing it without the sort of bridge aptly described by Cowper,

"That with its wearisome but needful length

"Bestrides the wintry flood."

If a substantial bridge were necessary or expedient, no person would be so competent to construct it, as my scientific and experienced friend Mr. Rennie, who has been consulted on the subject; but I shall beg leave to make some observations, first, on the uses of a bridge, and next consider its effect on the scenery. The Wood opposite being now annexed to Endsleigh, access is required to it; but, if there were no other expedient, I should doubt the accommodation being equivalent to the difficulty and expense of such a bridge as might be passable at all seasons, requiring at each end an embankment, and arches on dry ground above the level of the highest Winter floods. This would be necessary, if it were a public road; but, on the contrary, it would be a private bridge seldom used, and might be dispensed with during floods; therefore such a bridge is not absolutely necessary. With respect to its effect on the scenery, it would present an object totally at variance with that calm sequestered retreat, which forms the striking characteristic of Endsleigh: since a great bridge announces a great road, and a great road destroys all solitude, both real and imaginary; there is also another objection to a conspicuous bridge in the situation proposed. 
The part of the Tamar forming the chief view from the house, is so nearly in a straight line, that it would more resemble an artificial Canal than a natural River, if the extremity, now forming a graceful curvature, were to be terminated by a bridge, and especially one so large as to rob the River of allits importance. In addition to these objections, it may be added, that if a crossing can be effected more immediately near and opposite to the house, it would doubtless be a better situation for a bridge, in point of convenience; and, as an object of beauty, it might assume a picturesque character more in harmony with that of the place.

\section{OF THE PICTURESQUE.}

This word has of late excited considerable interest and controversy; but the word, like many others in common use, is more easy to be understood than defined: if it means all subjects capalole of being represented in a picture, it will include the Pig-sties of Moreland, as well as the filthy Hostels of 'Teniers and Ostade: but the absurdity of representing all that is visible, without selecting what is most beautiful, cannot be better exemplified than by the following fact. One of our most eminent Landscape painters was desired to make a portrait of a Gentleman's Seat: he saw the place during a land-flood, and when the whole valley was covered by vapour he made a beautiful picture of a fog, after the manner of Vernet; and thus he painted an atmospheric effect, when he should have 
painted a Landscape. In like manner a beautiful woman represented during a fainting fit, may display great ingenuity in the artist; but surely this is sickly picturesqueness. The Subjects represented by Salvator Rosa, and our English Mortimer, are deemed picturesque; but are they fit objects to copy for the residence of man in a polished and civilized state? Certainly not. This naturally leads to the inquiry, how far we may avail ourselves of picturesque circumstances in real Landscape. These circumstances may be classed under three heads: Steepness of ground-abrupt rocks-and, Water in rapid motion; for, we may consider wood, and lawn, and smooth water, as common to all landscapes, whether in Cornwall or in Lincolnshire.

In the Drives through Leigh Wood, some advantage has been taken of the steepness; but it should be shewn as an object of beanty from the precipitous side of the road, and not as an object of terror, by making the roads too steep.

There are many places in which romantic rocks are now totally hid by brushwood; these doubtless require to be brought into view. But of all picturesque objects, there is none so interesting as Water in rapid motion; and it is the duty of art to avail ilsclf of every opportunity to force it into notice; in a mountainous country there hardly exists a dell or dingle, in which some stream, that might be drawn forth to form a conspicuous part in the Picturesque Landscape, does not steal its way unseen amongst the long grass or foliage of brushwood, and is therefore entirely lost. 
In all mountainous conntries, it is common to place troughs to receive the water wbich flows from the neighbouring hills. 'These by the road side, as drinking places for Cattle, form interesting circumstances in the Landscape peculiar to romantic scenery, while the interest is considerably heightened, by reflecting, that the supply is not the scanty produce of human labour and mechanism, but flows from that source whence the most mighty rivers derive their existence: perhaps there is hardly a more striking example of the inexhaustible bounty of Providence, than may be drawn from the never-ceasing overflow of "L'abreuvoir des Montagnes."

THE WEIR.

Instead of a magnificent and costly bridge at a distance from the house, I should propose crossing the water immediately opposite, by means of a Weir. 'The surface of this Weir may be levelled and paved with flat stones, to the width of fifteen or twenty fect, at about eighteen inches or two feet below the common summer height of the river, making a safe ford for carriages; and, by inserting large blocks of stone, a bridge of timber or cast-iron may be thrown over for horses and foot passengers, above the common Summer's flood, but so strongly secured as to bear the Winter torrents to flow over the whole.

A stream from the river may be brought sufficient to turn the under-shot wheel of a corn-mill, or it may be worked by 
an over-shot wheel; to supply which, a channel or feeder may be brought through the wood, from so high a level up the river as to produce the sort of water-fall which I have hinted in the Sketch, where such a stream is supposed to pass over the face of certain rocks now hid by brushwood. It is hardly necessary to remark how much the View from the House would be enlivened by the smoke of a Cottage on the opposite side of the water; and if this Cottage were to be a Mill, the occasional traffic and busy motion of persons crossing the Tamar, would add to the picturesque effect of a Landscape, which at present wants a little more animation.

Perhaps it might be possible to give much additional interest to the Tamar at Endsleigh, if this Weir could be converted into a Salmon-leap of any height, that would not require much embankment to preserve the meadow from being overflowed by common floods.

\section{THE COTTAGE.}

Having considered the Situation and natural Character of the Country, I must now consider the artificial character by which Endsleigh is made habitable; for, without the aid of art, the most romantic or picturesque scenery in nature is a desert, and only fitted to the babitation of wild beasts. The first question that obviously occurred was, What style of house will best accord with this Landscape? Here the good taste of the noble proprietor of Endsleigh was directed by what he 
saw. An irregular farm-house, little better than a cottage, backed by a hill and beautiful group of trees, presented an object so picturesque, that it was impossible to wish it removed and replaced by any other style of building that architecture has hitherto invented, viz. a Castle, or an Abbey, or a Palace, not one of which could have been so convenient and so applicable to the scenery as this cottage, or rather group of rural buildings. With respect to the manner in which the design has been executed, I shall only say, it is such as will do credit to the name of Wyatt, when time shall have harmonized the raw tints of new materials. The design and outline are so truly picturesque that I must regret my inability to do them justice.

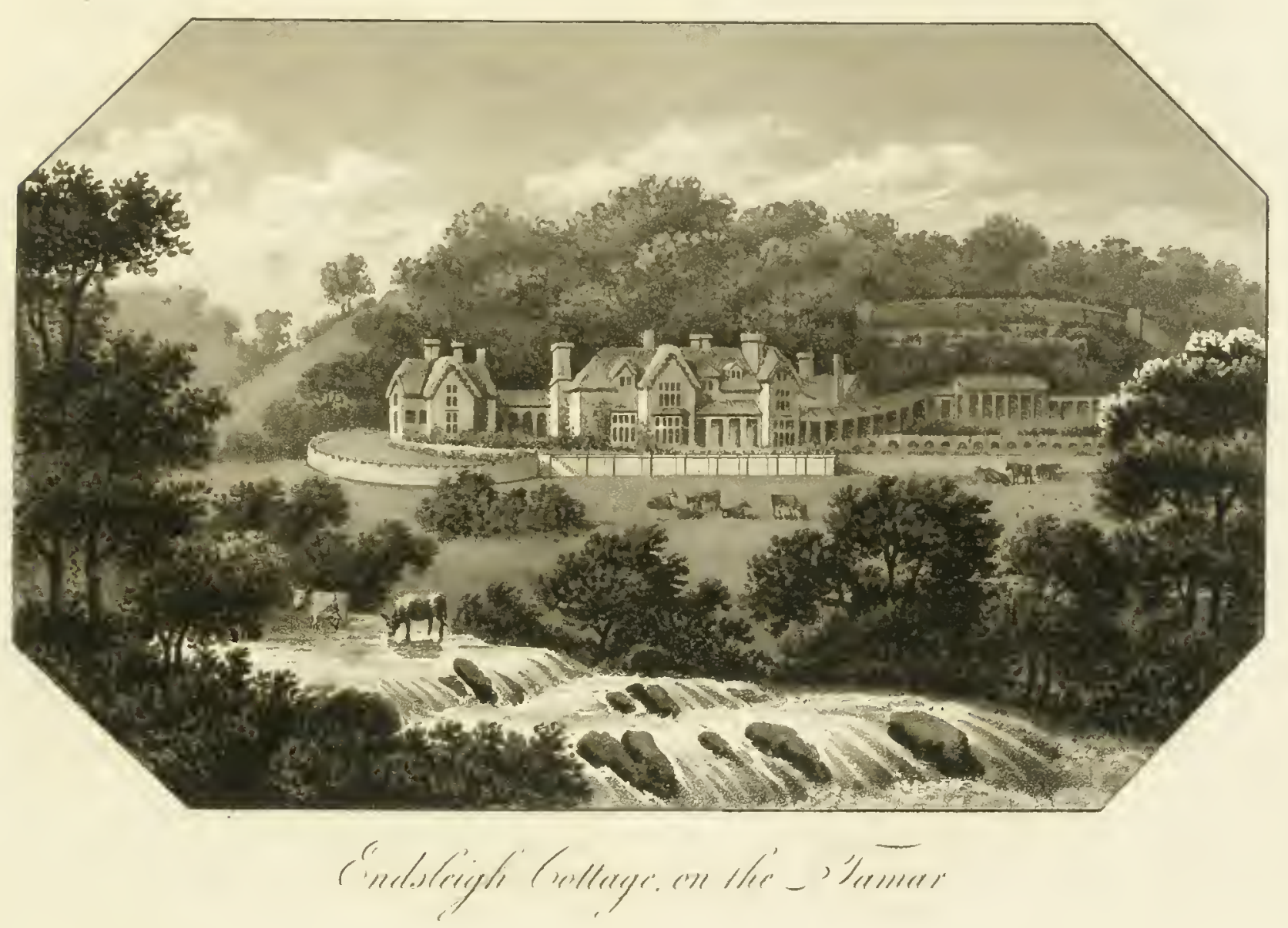


One of the subjects to which I was instructed to direct parlicular attention, was the fence and line of demarkation betwixt the Lawn to be fed and that to be mown and dressed as pleasure-ground. The general fall of the ground from the House to the Valley is an inclined plane, with the exception of a small rise in the centre, which had been artificially converted into a kind of bastion; this left a considerable space to be covered with Flowers and Shrubs; but when I began to mark the situations of clumps and patehes, I placed persons at different stations, and found that in every part of the surface of this Lawn beyond the distance of 25 feet from the House, any shrub of six feet high would hide not only the meadow below, but also that line of River which, by an uninterrupted continuity of glitter, constitutes the leading feature of the place. This is very different from the stagnant sheets of water (as they are ealled) which require masses of planting to hide the mechanism of their arlificial deeption. One obvious advantage of removing the fence so much nearer the House, will be that of introducing the appearance of Catile to animate the Landseape, and by their perspective effects to shew the distance of Lawn betwixt the House and the Tamar; and perhaps a certain portion of the opposite bank might be thrown into pasture with the same view, when access can be had to it by means of the Weir proposed. 
If Houses were built only to be looked at, or looked from, the best Landscape-painter might be the best Landscape-gardener; but to render a place in all seasons comfortable, requires other considerations besides those of pieturesque effeet.

It is during the winter and in the shooting season that a residence at Endsleigh will be most desirable; but the Climate and South Western Aspect of a monntainous district will expose it to the rains, winds, and fogs which are the natural concomitants of all lofty and pieturesque stations. In spring it has become a fashion to desert the country, and in summer every field is a garden; but in antumn and winter we experience the truth of a maxim which I have endeavoured to inculcate, and must again beg leave to repeat, that a Gurden is a work of ART, making proper use of the Materials of $\mathrm{N}_{\mathrm{ATU}} \mathrm{E}$. A well cultivated Fruit-garden requires shelter to secure its produce in autumn, and this same shelter may be extended to the comfort of its inhabitants during that season when a walk along a south wall, while the sun shines, though "ten times repeated," will please more than the richest Landseape in the most romantic country, when stripped of foliage and exposed to driving winds, and covered with its wintry garment of suow. For this reason a Garden becomes the chief Appendage of Comfort, and should never be at a distance; and though it may be offen- 
sive, when enclosed in the usual way by lofty scarlet walls, yet if the walls were to be disposed in terraces, and rendered ornamental by piers or arches for each tree recessed, the Garden at Endsleigh might be made no unsightly feature; but, from the relative situation of the Cottage, the proposed Conservatory and the Plantations, it would be very little seen. 'The same intervening objects which tend to hide the walls from the View in the Valley, will also tend to intercept the current of air during the sweeping gusts of wind and fog from the Sonth Western Mountains, at the same time that, from their declivity, the Sun's rays will act with uninterrupted force.

We read of the hanging Gardens of Babylon, and I have heard described by (an eye-witness) something similar in the Gardens still existing near Damascus.* Of all the comforts belonging to a Garden, there is none more delightful than the Covered Way, or rustic Corridor of Woburn: such a line of communication naturally suggests itself here from the Cottage to the Conservatory, and from thence to the Foreinghouses, Terrace Garden, \&c.

* From these hints I will confess that in two other situations I have recommended a similar disposal of Garden in Terraces : but with this difference, at Beau Desert (Marquis of Anglesea's) the shape of the ground requires the walls to be straight; at Sherringham Bower, (Mr. Upcher's,) the walls were proposed conrex, and the gromnd behind the Cottage at Endsleigh requires the walls to be concave: thus the same expedient may be varied to suit varions situations, but all contributing to the comfort of habitation. 
The long sketch is supposed to be taken from the windows of the Dining-room; the terraces, grass, and gravel, seem to justify the boldest interference of Art in the accompaniments of this Garden Scene. The style of Conservatory, the Alcove in the Children's Garden, and the Fountain and artificial trimness of the Parterre, must all be considered with reference to the Noble Occupiers rather than to the humble character of a Cottage. Since contrast and variety are not less sources of pleasure than uniformity, the trim character of this Garden of Art will act like the frame to a natural Landscape. At the end of the gravel terrace is a quarry which might be converted into a grotto-like receptacle for specimens of the fossils and ores abounding in the neighbouring mountains.

CON CLUSION.

So interesting and so picturesque a subject, makes me regret the inadequate efforts of my pencil in representing, as well as the difficulty of my progress in viewing it. I will, howerer, indulge the hope that the preceding pages may not only be useful in improving the Scenery of Endsleigh, but in furnishing employment and amusement to its Noble Possessors for many years to come; and having in a manner provided against the rigours of Winter, I will not be unmindful of that Winter of Life which must alike assail the Cottage and the Palace. With this in view I will venture to advise, that all $2 \mathrm{G}$ 
the walks be made sufficiently wide to admit a carriage; and having myself lost the power of gathering a flower or picking up a fossil from the ground, I have found great comfort in banks raised to the height of three or four feet on a face of ornamental pebbles, to bring nearer to the eye those lesser rock plants or delicate blossoms which are too minute to be seen from the ground. At this enchanting Retreat the most pleasing attention has been paid to the Comforts of Infancy and Youth, of which the Children's Cottage is one of the most perfect examples. Let the same attention be extended to solace the infirmities of Age.

It is with peculiar satisfaction that I have been called upon to exercise my utmost skill on this subject, since every thing that can contribute to the enjoyment of its scenery, I know must also contribute to the improvement of the neighbouring Country in its Agriculture, its Mineralogy, its Civilization, and the general happiness of all who dwell within the influence of this Cottage on the Banks of the Tamar. 



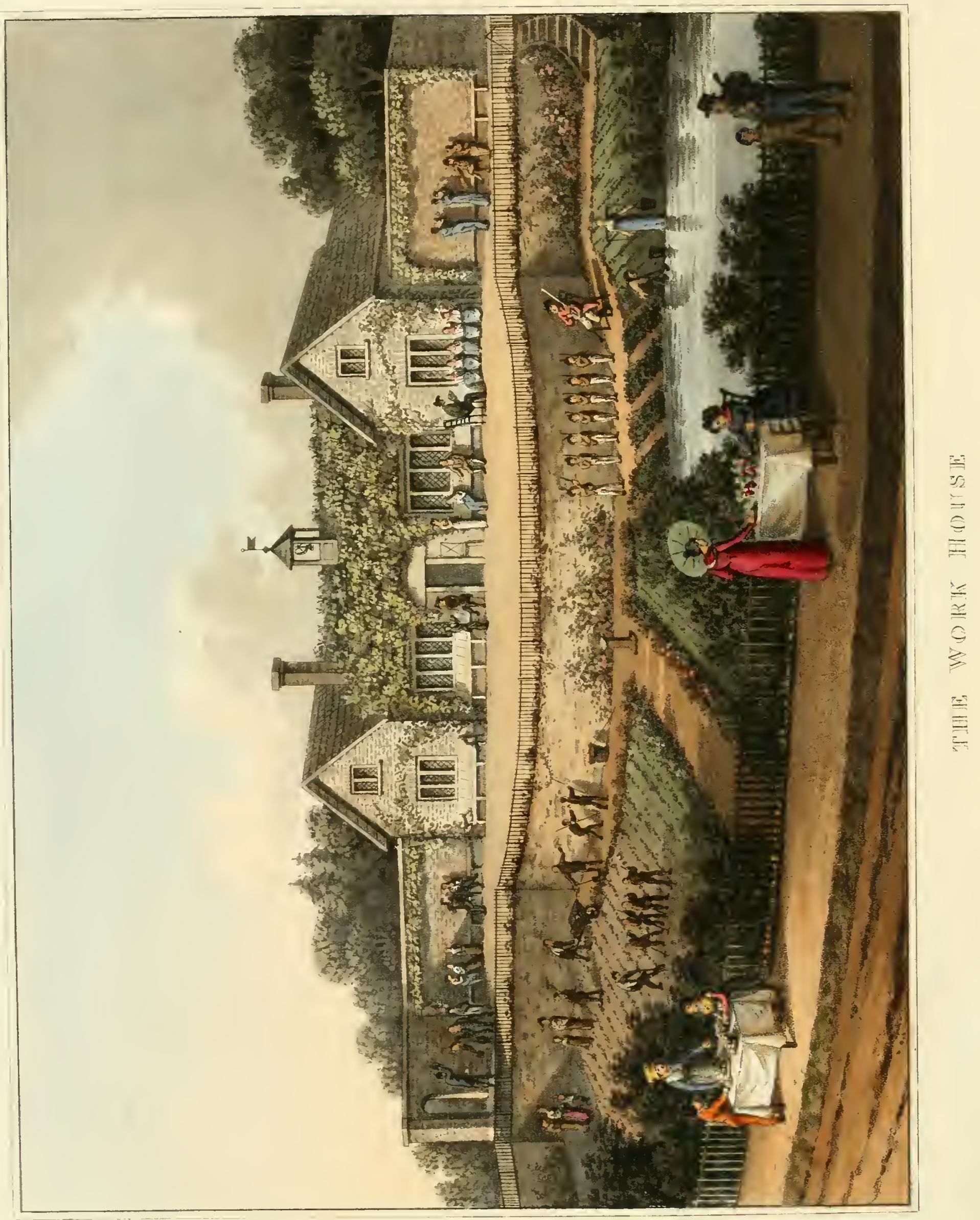




\section{FRAGMENT XXXV.}

\section{CONCRRNING \\ HOUSES OF INDUSTRY.}

VERY soon after the Sherringham Report had been written, in which some hints respecting the treatment of the Poor were introduced, my attention was again called to the subject by an application from the Parish of ** in Kent, to give a design for a new Workhouse, when the following Report was addressed to my Son, at that time the ofliciating Minister there :

To the Rev. Edward Repton, at * * in Rent.

MY DEAR EDWARD,

Your letter communicating the wishes of your Parishioners that I should give my opinion respecting a plan and situation for a New Workhouse, or House of Industry, with all proper attention to the Comforts of the Poor, has excited my heartfelt satisfaction; and as this may be amongst the last efforts of my professional duties, I feel the subject peculiarly interesting to me. 
The present wretched building is so unhealthily placed in the low and wet marshes, that the first consideration seems to be the choice of a wholesome spot, on a dry soil. This may be found on the edge of the Heath about to be enclosed, and near the side of the high road from London to Dover, where a large gravel pit presents a bold terrace full facing the south, and so formed by the excavations already made, that very little more digging would be necessary to make a secure fence to enclose the premises.

My idea of the design or plan and certain regulations for the future comforts of its inhabitants, will, I hope, be understood by a reference to the annexed Sketch. The building, as before mentioned, is supposed to front the South, and to have an ample Platform or Terrace betwixt it and a steep bank of the gravel pit. The centre consists of one long and lofty room for the Paupers to live in and to take their meals; this is flanked by two buildings which contain the Governor's and Matron's dwelling, Kitchen, Store-rooms, and other useful apartments. At the back of the Premises towards the North, is a square Yard, on each side of which is a Work-shop, with Bedrooms for the Paupers over them.

The difference betwixt the cold darksome gloom of the North Quadrangle, and the warm cheerful appearance of the Site towards the South, may easily be imagined; and suggests the idea of taking great advantages of the contrast. 
Let the back-yard be considered as a sort of punishment for misbehaviour and refractory conduct, where, shut up between four buildings, nothing can be seen to enliven the prospect: while, on the contrary, from the South Terrace, cheered by the Sun, the View of the Country will be delightful; since the immediate fore-ground consists of a Garden, and the perpetually varying and moving scene which is presented by the great road to Canterbury, and the Coast.

In addition to the usual employments of the Paupers in the Work-rooms, it were to be wished that more wholesome and useful labour might be taught to the Children than spinning, and other manufactures. This might be considered as the reward of good conduct: the Children, supplied with spades, and hoes, and tools, proportioned to their strength, should be taught and exercised in the cultivation of the Garden, and perhaps drilled to become the future defenders of their Country.

The Sketch will in some degree explain the effect of this scene as viewed from the high road. We may suppose the warm benches along the front of the building occupied by the aged and infirm, who may there enjoy their few remaining days of sunshine, without being totally shut out and lost to the world. On the warm tiles of the central building some vines may be trained, and the produce of these, and every part of the Garden, such as fruit and flowers, may be exposed to sale on the public road, and the profits of these commodities might be the reward of extraordinary industry or good behaviour. 
In this plan there is no pretension to ornament in any respect that may incur umecessary expense, except perhaps in the small Cupola for the Bell; and this appendage, trifling as it is, gives to the whole that characteristic feature which distinguishes it as a public building.

To you, my dear Edward, it is unnecessary to remark one circumstance which you may perhaps find an opportunity of inculeating to your Parishioners; that in providing for the future comforts of the Poor, they may possibly be anticipating the future happiness of themselves or their descendants; since we too often see the hard-hearted opulent oppressor, in the vicissitudes of life, reduced to look for support to those public institutions to which he has reluctantly contributed.*

It may perhaps be objected to the design, that something more ornamental might have been proposed, perhaps adopting the Gothic style, but the answer is obvious; the first consideration in a Poor-house is economy.

The prevailing Taste for fragments of Gothic Architeeture is apt to display itself in the doors and windows of a Dairy, for which there can be no plausible reason assigned; but if the Gothie character be introduced in any small building, there is

* This Plan was at first highly approved by the leading persons in the Parish, till it was discovered that the Situation proposed was so desirable, that the Site occupied in private houses would produce more profit, and therefore the Poor for the present continue in their former unwholesome abode; but, as a late Orator observed of Negro Slares, compared with Eels flayed alive-" they are used to it." 
none more appropriate than the Schools, either public or private, which of late have been erected, sometimes by the parishes and sometimes by individuals, as ornamental appendages to their Parks; under the latter circumstances, a more costly design may be recommended. Having made several for this purpose, one of them is annexed, (see Vignette, p. 187) which has been proposed for a School endowed and patronized by Mrs. Burton, at Longnor, near Shrewsbury. 


\section{FRAGMENT XXXVI.}

\section{H A R E S T R E E T.}

OF RUANTITY AND APPROPRIATION.

Althoun, during a long and active life, my efforts have contributed to the happiness of some hundred individuals, and the employment of some thousands; I trust, that not a single instance can be adduced in which useless expenditure was advised, for unreasonable gratification of vanity; but wealth is never so well employed, as in improvements that display the genius of art, and call into active employment the labourer and artificer. To demonstrate the little consequence of Quantity or Value, when speaking of the Beauty of scenery, many places have been mentioned, which may perhaps appear too inconsiderable in a work that treats of Dukedoms and Royal Domains: but I wish to evince, that in many eases great effect may be produced by a very contracted quantity of land, and not unfrequently that almost every thing depends on the foreground. Thus, in the Villas on the margin of the Lake of Geneva (like that of Gibbon) nothing more is necessary than a terrace, or a few shrubs and flowers to form a frame to the picture: thus also it fre- 


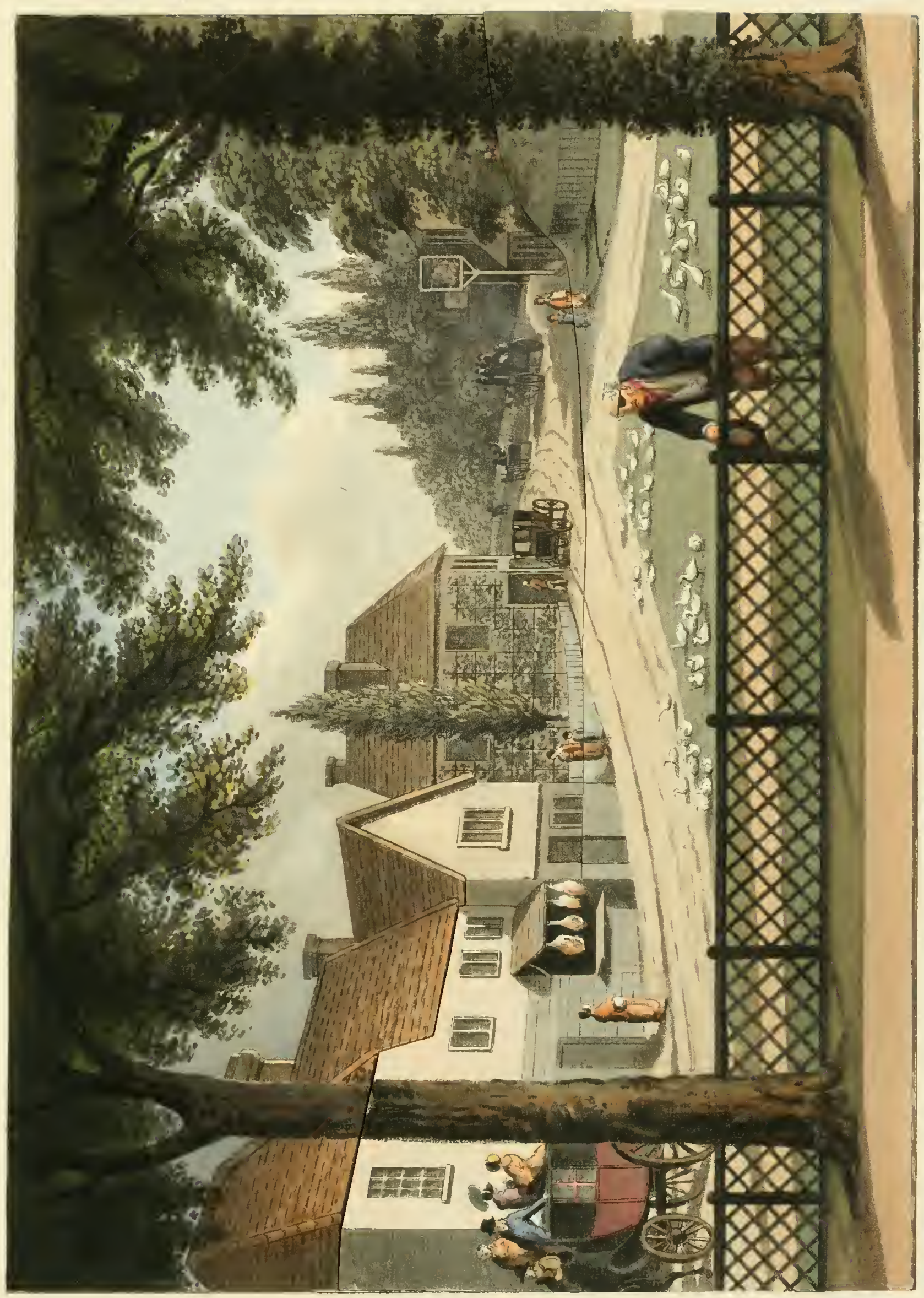





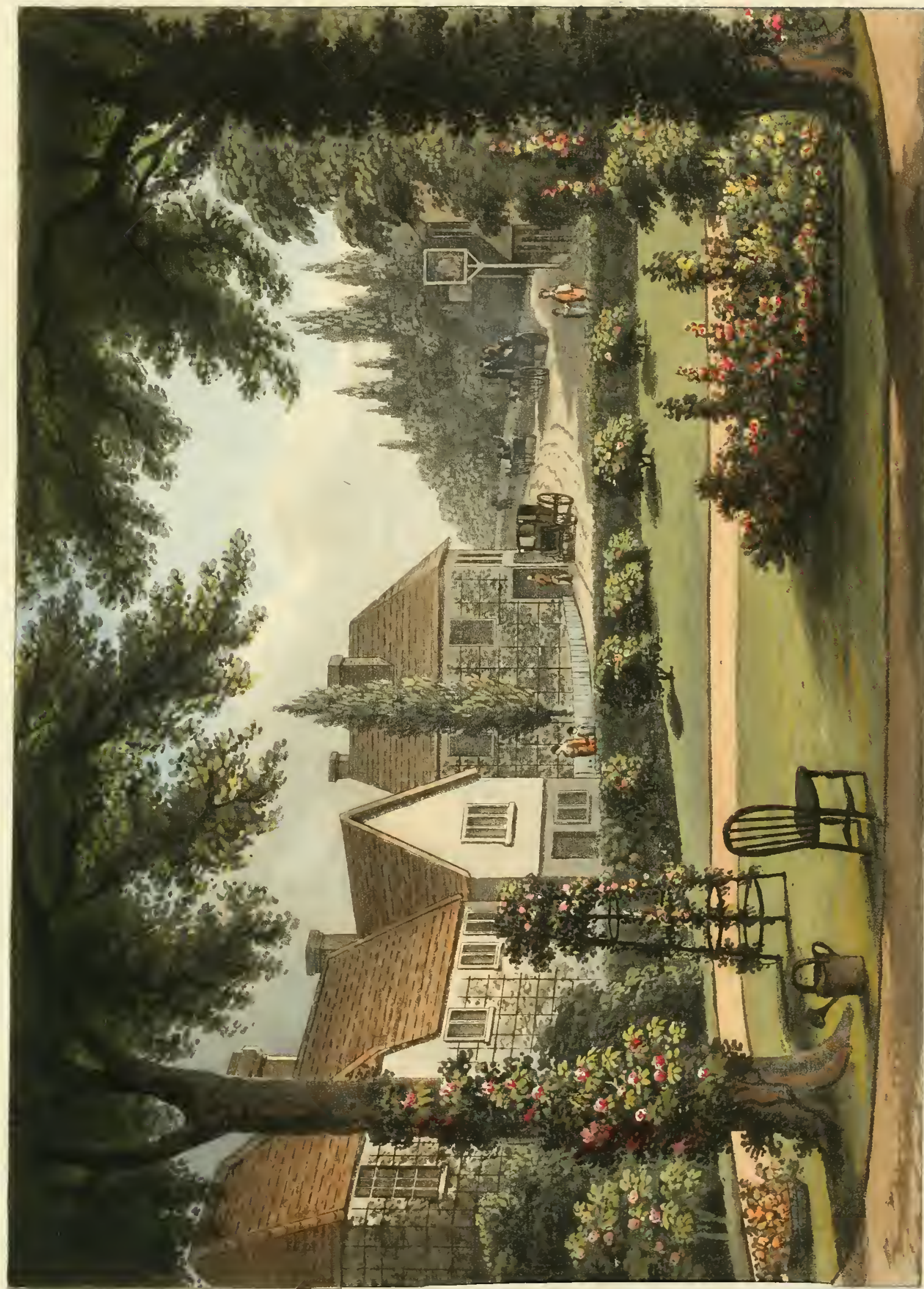



quently happens, that by the enclosure of a common, or the grant of a small piece of land from a forest, the most essential benefit may be derived, although the quantity of land acquired be very trifling; and I have often observed, that the cupidity natural on such occasions, generally leads to the obtaining more land than can be rendered useful; since it is either too small to be fed, or too large to be kept under the scythe and roller.

In my former volume I used the word appropriation, to describe that sort of command orer the Landscape, visible from the windows, which denotes it to be private property belonging to the place.

A riew into a square, or into the parks, may be cheerful and beautiful, but it wants appropriation, it wants that charm which only belongs to ownership; the exclusive right of enjoyment, with the porver of refusing that others should share our pleasure: and however painful the reflection, this propensity is part of human nature. I have too frequently witnessed a greater satisfaction in turning a public road, in stopping a foot-path, or in hiding a view by a pale and a skreen, than in the most beauliful improvements to the scenery; and sometimes have contended in vain against the Firs and Poplars, which on the verge of a forest presented more agreeable objects to the proprietor than the scenery of the forest itself; one acknowledged that he would rather look at a young sapling of his own, than the most venerable oaks belonging to the Cromn. 


\section{4}

This propensity for appropriation and exclusive enjoyment is so prevalent, that in my various intercourse with proprietors of land, I have rarely met with those who agreed with me in preferring the sight of mankind to that of herds of cattle, or the moving objects in a public road to the dull monotony of lawns and woods. Of these few, I cannot resist mentioning one venerable Nobleman, who enjoyed health, cheerfulness, and benevolent feelings, more than eighty years, retaining to the last his predilection for the scenery of a garden, rather than that of a Park; and who used at his Villa on Ham Common, to enjoy the sight of the public passengers from his garden-seat surrounded by roses. To this rare instance of benevolence in the noble Viscount Torrington, may be added that of his friend and cotemporary, the late Duke of Portland, who gave leave to all persons to pass through the Park at Bulstrode, and even encouraged the neighbouring inhabitants to play at cricket on the lawn. How different is this from the too common orders given at the gates and lodges of new places, recently purchased by strangers, and only visible to themselves and their own inmates. For the honour of the Country, let the Parks and Pleasure-grounds of Englind be ever open, to cheer the hearts and delight the eyes of all, who have taste to enjoy the beauties of Nature. It was formerly one of the pleasures of life to make tours of picturesque inquiry; and to visit the improvements in different parts of the kingdom: this is now changed to the residence at a watering- 
place, where the dissipation of a Town life is cultivated in a continual round of idle, heartless society; without that home which formerly endeared the life of a family in the country. And after all, the most romantic spot, the most picturesque situations, and the most delightful assemblage of Nature's choicest materials, will not long engage our interest, without some appropriation; something we can call our orvn; and if not our own property, at least it may be endeared to us by calling it our own Home.

I will conclude these Fragments with the most interesting subject I have ever known; it is the View from the humble Cottage to which for more than thirty years I have anxiously retreated from the pomp of palaces, the elegancies of fashion, or the allurements of dissipation: it stood originally within five yards of a broad part of the high road: this area was often covered with droves of cattle, of pigs, or geese. I obtained leave to remove the paling twenty yards farther from the windows; and by this Appropriation of twenty-five yards of Garden, I have obtained a frame to my Landscape; the frame is composed of flowering shrubs and evergreens; beyond which are seen the cheerful village, the high road, and that constant moving scene, which I would not exchange for any of the lonely parks, that I have improved for others; some of their Proprietors on viewing the scene I lave described, have questioned my taste; but my answer has always been, that in improving places for others I must consult their inclinations; 
at Harestreet I follow my own. Others prefer still life, I delight in movement; they prefer Lawns fed by their own Cattle; I love to see mankind; they derive pleasure from seeing the sheep and oxen fatten, and calculate on the produce of their beef and mutton: perhaps they might not object to the butcher's shop which I have taken some pains to hide, giving the preference to a basket of roses. This specimen may serve to shew how much may be effected by the foreground; how a very small object, aptly placed near the eye, may hide an offensive object ten times as large; whilst a hedge of roses and sweet-briars may hide the dirt of a road, without concealing the moving objects which animate the Landscape. Such is the lesson of quantity and appropriation. And as I have now approached near the end of my labours, and am still permitted, though with difficulty, to collect my thoughts on a subject most interesting to my feelings, I will add a lesson of far greater moment. When I first appeared before the public in 1794, in a work which has long been out of print, the introduction began with these words :-

"My opinions on the general principles of Landscape Gar"dening have been diffused in separate MS. Volumes, as "opportunities occurred in the course of my practice; and I " have often indulged the hope of collecting and arranging " these scattered opinions, at some fulure period of my life, " when I should retire from the more active employment of my "profession; but that which is long delayed, is not therefore 
" better executed; and the task deferred to declining years, is "frequently deferred for ever; or at best performed with "languor and indifference."

Twenty years have now passed away, and it is possible that life may be extended twenty years longer, but from my feelings more probable that it will not reach as many weeks; and therefore I may now perhaps be writing the last Fragment of my Labours. I have lived to see many of my plans beautifully realized, but many more, cruelly marred; sometimes by false œconomy; sometimes by injudicions extravagance. I have also lived to reach that period, when the improvement of Houses and Gardens is more delightful to me, than that of Parks or Forests, Landscapes, or distant prospects.

I can now expect to produce little that is new, I have therefore endeavoured to collect and arrange the observations of my past life : this has formed the amusement of the last two winters, betwixt intervals of spasm, from a disease incurable, during which time I have called up (by my pencil) the places and scenes of which I was most proud, and marshalled them before me; happy in many pleasing remembrances, which revive the sunshine of my days, though sometimes clouded by the recollection of friends removed, of scenes destroyed, and of promised happiness changed to sadness.

The most valuable lesson now left me to communicate is this : I am convinced that the delight I have always taken in Landscapes and Gardens, without any reference to their Quantity or Appropriation, or without caring whether they were Forests 
or Rosaries, or whether they were Palaces, Villas, or Cottages, while I had leave to admire their beauties, and even to direct their improvement, has been the chief source of that large portion of happiness which I have enjoyed through life, and of that resignation to inevitable evils, with which I now look forward to the end of my pains and labours.

While I was actually writing this last page of my work, I received a letter from one of the ablest Statesmen now left to the Country, in which are these words, "The best comment upon " what has been the leading pursuit and employment of your "life, is to be found in the relief and solace which at this time " you derive from it. 'Quid purè tranquillet?' has long been a " philosophical question, Religion answers it. But I have always " thought that the sort of Taste which you have eminently con" tributed to form and diffuse, has a peculiar tendency to sooth, " refine, and improve the mind; and consequently to promote " most essentially the true and rational enjoyment of life."

Feeling the full force of this just remark from one of the most pious and benevolent of men, I will finish with the remark of one, who possessed more wit than real worth, who, after enumerating various experiments to obtain happiness, concludes with these words,

"Allons mes amis, il faut cultiver nos jardins." 


\section{I T O F P L A T E S.}

\begin{tabular}{|c|c|c|c|c|c|c|c|c|c|c|}
\hline & & & & & Page & & & & & Page \\
\hline Emblematic Vignette ( & (wood & & - & - & -1 & View from Frome House & - & - & & -104 \\
\hline Characters' of Houses & - & - & - & 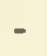 & -2 & Variety - - - - & $-\quad-$ & - & & -114 \\
\hline Grecian and Gothic & - - & - - & - & 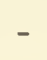 & -4 & Longlcate - - - - & $-\quad-$ & - & - & -122 \\
\hline ce near the House & - & - - & - - & - & -6 & The Vinery - - - - & - & - & - & -126 \\
\hline Cobhan Hall, Plan of & f Gar & rden. & $s(w o c$ & & -12 & A Plan explained - - & - - & - & - - & -128 \\
\hline - - - North I & Entra & & - & - & - ib. & Geometric Garden & - & - & - & -136 \\
\hline Timber Cottage - - & - & - & - - & - & -14 & Rosary at Ashridge - & $-\quad-$ & - & - & -140 \\
\hline Gothic Fragment, Vigt & rnette & - & - - & - & -18 & Ashridge Garden, Map o & of - & - & - & $-i b$. \\
\hline Castle - - . & -- & - & $-\quad-$ & - & -20 & - - Conduit - - & $\cdot-$ & - & & - ib. \\
\hline Harlestone Park & - & - & - - & - & -92 & Fences called invisible & $-\quad-$ & - - & - & -146 \\
\hline Blenden Hall - - & -- & - & $-\quad-$ & - & -28 & Via Duct, Vignette - & - & - & & -160 \\
\hline Barningham Hall - & - & - & - & - & -30 & Woburu Old Approach & $-\quad-$ & - & - & -164 \\
\hline - - - Plan and & Sectic & & - & - & -32 & - - New Approach & - & $-\quad-$ & . & $-\quad i b$. \\
\hline - - - Window & - - & - & - - & - & - ib. & - - A Garden Door & - & - & 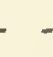 & -168 \\
\hline othic Outline and $\mathrm{Pl}$ & lan - & - & $-\quad-$ & - & -36 & - - - Winter Garden & - & - . & - & ib. \\
\hline Beaudesert - - - & - & - & - & - & -48 & Of Garden Luxuries, Vig & gnette & - & - & -183 \\
\hline Colours - - - - & - & - & - & - & -50 & Park Lodge, Vignette & - - & - - & & -184 \\
\hline Interiors - - - & - & - & $-\quad-$ & - & -58 & School-house Longnor, I & Vignet & tte - & & -187 \\
\hline Wingerworth - - & - & - & - - & - & -64 & Water Fences, Vignette & $-\quad-$ & - & - & -188 \\
\hline - - - Lodge, V & ignet & & - & - & - ib. & Improvements - - - & $-\quad-$ & - & - & -194 \\
\hline Single Trees, Vignette & - & - & $-\quad-$ & - & -67 & Sherringham Bower - & $-\quad-$ & - & - & -195 \\
\hline View on a Common & - & - & -- & - & -76 & - - - Plans ands & Sectio & & - & -212 \\
\hline Belt at Ealing Park & - & - & - & - & -82 & Endsleigh, View from it & $-\quad-$ & - & - & -213 \\
\hline Richmond Park - & - & - & - & - & -84 & - - - The Cottage, & , Vign & ette & & -221 \\
\hline Garden near Oporto & - & - & $-\quad-$ & - & -90 & House of Industry - & - & - & - & -227 \\
\hline Uppark Entrance - & - & - & - & - & -92 & Hare-street - - - & $-\quad-$ & - & - & $-\$ 32$ \\
\hline
\end{tabular}

\section{$\mathrm{E} R \mathrm{R} \Lambda \mathrm{T} A$.}

Page 75, line 10, for and read is the time.

129 , line 3 from bottom, read lie strongly traced.

135, line 5, for Place read Palace.

136 , line 2 from bottom, meant it to form.

143, line 1 of the note, read some one objected.

152, Under the 1)iagram, instead of lines 3 and 4, read thus-

The Natural Surface is the shaded line (that Natural Surface is now altered to the lower dolted line) The carth had been brought, sic.

206, liue last, for ports read post-towns. 



\section{$\Lambda$ \\ Catalogue}

or

\section{MODERN BOOKS}

ON

\section{$\mathbb{A} \mathbb{R} \mathbb{H} \mathbb{I} \mathbb{E} \mathbb{C} \mathbb{R} \mathbb{E}$ \\ THEORETTCAL, PRACTTCAL, AND ORNAMENTAL; \\ CONSISTING OF}

BOOKS OF PLANS AND ELEVATIONS FOR COTTAGES, FARM-HOUSES, MANSIONS, TEMPLES, BRIDGES, \&c.

OF ORNAMENTS FOR INTERNAL DECORATIONS, FOLI

ON PERSPECTIVE; ALSO

PRACTICAL BOOKS FOI CARPENTERS, BRICKLAYERS, AND WORKMEN IN GENERAL,

WHICH, WITH THE BEST ANCIENT AUTHORS, ARE CONSTANTLY ON SALE AT

\section{J. T $A \mathbb{L} O \mathrm{R} ; \mathrm{S}$}

ARCHITECTURAL IIBRARY, No. 59, HIGH HOLBORN, LONDON.

WIERE MAY BE HAD

THE WORKS OF THE MOST CELEBRATED FRENCH ARCHITECTS AND ENGINEFRS.

THE Antiquitics of Atbens; measured and delineated, by Fames 1 Stuart, F. R. S. and F. S. A. and Nicholas Revett, Painters and Architects, in elnee large Volumes Folio, Price 171.175 . in boards. The third Volume may be had separate to complete Sets, Price 6l. I 3 s. in boards-This Work contains 28 , Plates, engraved by the best Artists, of Viezes, Architecture, Plans, Ec. with Letter-press, Historical and Descriptive, illustrating by a Research of many Years' Labour and great Expentse, the pusest Examples of Grecian Architecture, manj of robich so longer exist, and the Traces of them can be found only in this Work.

\section{Contents of the Wark.}

Dorit Portico at Athens, Ionic Temple on the llissus, Octaron Toriver of Aindronicus Cyrrestes, Lantborn of Densosthenes, Stoc, or Pcrtico at Athens: And a large l'iew of the Acropolis. Tentile of Minerva, Temple of Erectbcus, Theatre of Racchus, Choragic Momunent of Thrasyllus, Ete. Propylia: And a large Vieas, and a Plan of the Acropclis. Temple of Theseus, Temple of Cuniter, drcb of Thescus, Aqueduct of Hadrian, Monument of Pbilopappis, Temple of Corinth, Bridge of the llissus, Odeum of Regilla, Ruins at Solonica, Antiquities ont the lislant of Dilos, Eoc.-Also a las ge Mas of Grecee-ivap of Altica-Plas of Atbens, Go.

The Fourth Vol. which is just Published, contains all the remaining Sculpture of the Temple of Minerva at Alhens, with sundry Fragments found in the Greek Islands: aiso the entire Detals of the Antiquities at Pola. in Isiria, from the Drawings left by $M$ : Stuort. Engraved 10:3 Plates, imperial folio, $71.7 \mathrm{~s}$. Boards.

An Essay on the Doric Order of Arcbitciture, containing an historical View of its Rise and Progress among the Ancients, with a Critical Investization of is Principles of Compo ittion and Adaptation to Modern Use, illustrated by Figures from the principal Antique Examples, drawn to ono scale, on 7 Plates, by $E$. Aikin, Architect, large Folio, $1 \% .55$. boards.
The Ancient Buildings of Rome, accurately measured and delineated, by Antony Desgodetz, with Explanations in Ficnch and English; the Tost cuansiated, and the Plates engraved, by the late Mr. George Marshall, Archicect, 2 vols. imperial folio, with 137 Plates, Price 5l. 1 5s. 6d. sewed; or 6l. $16 \mathrm{~s} .6 \mathrm{~d}$. half bound.

Plans, Elevations, Sections and Views of the Church of Batalba, in the Province of Estremadura, in Portugal, with an History and Description, by Father Luis de Suusa, with Remarks, to which is prefixed an Introductory Discourse upon the Principles of Gothic Arclitecture, by Fames Murpby, Archifect. Illustrated with 27 elegant Plates, printed on Impcrial Folio, and hot-pressed, Price 4l. 14s. 6d. half-bound.

Specimens of Gotbic Arcbitecture, consisting of Doors, Windows, Buttresses, Pinnacles, \&ic. with the Neasurements ; selected fron Ancient Buildings at Oxford, \&c. Drawn and etched by F. Mac-

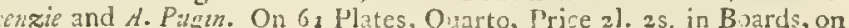
Demy; and on Imperial Paper 3 l. $3 \mathrm{~s}$. Boards; to range with Britton's Architectural Antiquities an I Cathedrals.

Specimens of Gotbic Arebitecture, selected from the Parish Church of Lavenliam, in Suffulk, on 4 o Plates quarto. Price sỏs. Loarc's, on large Paper, 11. 5 s.

Dickinson's Architectural Antiquitic s of Soushwell, Ec. Two Parts, Quarto, with 23 elegant Plates, 11. 1s. Boards.

Views of the Collegiate Chapel of St Georec, at vindsor, on 9 very large Plates, in Aquatintit, by $F$. Nash, Price 4l. 4.

Gotbic Ornamerts of the Cuthedral Clurch of York, $b_{j} \approx$. Hnlfperinj, 305 Plates, large Quarto, 61. 6s.

Fragmenta l'clusta, or the Ancient Buildings of York, by $\mathcal{Y}$. Lalffenny, 34 Plates, large Quarto, $31.3=$ 
The Rudinecrts of Ancient Archilecture, containing an Historical Accoumt of the Five Orders, from Antiques: Also, Extracts from Vitruvius, Pliny, \&c. relative to the Buildings of the Antients. Calculated for tise Use of those who wish to attain a summary Knowledge of the Science of Architecture ; ilt a Dictionary of Terms : illustrated with i I Plates. The Fourth Edition, Boards, $8 \mathrm{~s}$.

Essays on Gothic Mrchitcture, by the Rev. T. WVarton, Rev. J. Bentliam, Cant. Giose, and Rev. J. Miluer. Illustrated with I 2 Plates of Ormaments, \&c. sclected from Ancient Buildings; calculated to exhibit the varions styles of different Periods. The third Enition, with a List of the Cathedrals of England and their Dimensions. Octavo. 105. 6 d. Boards.

An Historical Survey of the Ecclesiastical Antiquities of France, with a View to illustraie the IR ise and Progress of Gothic Architecture in Europe. by the late Rev. G. D. Whithington, of Cambridge. Elegantly printed in Royal 8 ro. With a Frontispiece of the Façade of the Cathedral Cluurch at Rheimes. izs, Boards.

A Treatise on the Ecclesiastical Arcbitecture of England, during the midule Ages, with 10 illustrative Copper Plates, by the Rev. I. Miner, D. D. F. S. A. Royal Octavo. I 5 s. Boards.

Observations on English Arebitecture, Military, Ecclessastıcal, and Civil, compared with similar Euildings on the Continent; including a critical Itinerary of $O x$ ford and Canbridge: also Historical Notices of Stained Glass, Ornamental Gardening, \&ic. with Cluronologir, ] Tables, and Dimensions of Cathedrals and Conventual Churches, by the Rev. Fantes Dallaruay, M. B. F. S. A. Royal Octavo. 12s. Boards.

An History of the Origin and Establishment of Gotbic Architecture; comprehending also an Account from his own Writings of Casar Casarianus, the first professed Commentator on Vitıuvius, and of his Translation of that Author; an Investigation of the Principles and Proportion of that Style of Aichitecture called the Gothic; and an Inquiry ints tise Mnde of Paincing upon and Staining Glass, as practised in the Ecclesistical Structures of the middle Ages By Jutra Silincy Hawkins, F. A.S. Royal Octavo, illustrated wit Eleven Plates, Price 18 s. in Buards.

An Essay on the Origin, 1 listory and Principles of Gothic Arclitecture, by Sir Fomes H.ll, Bart. large Quarto, handsomely printed, with 6o Plates eleganily engraved, of select Examples, 5l. js. in Eoards.

The Builder's Price Book; conaning a corrct List of the Prices allowed by the most cminent Surveyors in London to the several sipififers concened in Eulling: including the Fournermen's Prices. A new Etition, corrected; by an Experienced Surveyor. Sewed, 3s. 6d.

The New Vitrurius Britonicus, consisting of Plans and Elevations of modern Buildings, public and private, erccted in Great Britain by the most celeiraied Auchitects, engraved on 142 Plates, from orioinal Drawings. By G. Rickardson, Architect. Two Vols. Imperial Folio, Jialf buund, 11. 11s.

Sketches for Cotrages, Iillas, \&c. with their Plans and appropriate Scenery, by Fohn Soane; to which is added six Designs for improving cnit embellishing Grouids, with Explanations, by an Inateur, on 54 Plates, elegantly engraved in Aquatinta. Folio. 21. 12s. 6d. half bound.

I'lans, Elevations, and Sections of Bilidings, executed in the Counties of Norfolk, Suffolk, Torkstire, Wilsslire, Wrarwicksbire, Staffordsbire, Somersetsbire, \&c. by Fobn Soane, Arclitect, on 47 Folio Plates, 21. $12 s .6 \mathrm{~d}$.

Plans, Elevations, and Sections, of Noblemen's and Gentlemen's Houses, Stabling, Brilges public and private, Temples, and other Garden Building, executed in tlie Counties of Derby, Durlıam, Middlesex, Nolthumberland, Notingham, York, Essex, Wilts, Hertford, Sulfolk, Salop, and Surrey; by James Paine, Architect. Two Vols. With $1 ; 6$ very large Folio Plates, 81, 8s. balf bound.

\section{]}

The Designs of Inigo fones, consisting of Plans and Filevations for Public and Private Buildings; including the Detail of the intended Palacc at Whitehall; published by $W$. Kent, with some additional Designs. 2 Vols. Imperial Folio, 4l. 4s. in Sheets; or half bound, $41.145 .6 \mathrm{~d}$.

Plans, Elevations, and Sections of Hot-Houses, Green Houses, a Aquarium, Conscrvatories, \&cc. recently built in different Parts of England for various Noblenen and Gentiemen, by G. Tod, Survejor and Hot-House Euilder; including a Hot-House and a Green-House in her Majesty's. Gardens at Frogmore, on 27 Plates, elegantly colousred, with proper Descriptions. Folio, 21.12s. 6d. in Boards.

Designs for lillas and other Rural Buildings, by Edmund Aikin, Architect; witt Pians and Explanations. Iogether with an Introductory Essay, containing Remarks on the prevailing D feets of Modern Architeßture, and an Investigation of the Styie hest adapted to the Dwellings of the present Times; engraved on 3 I Pates large Quarto, Price il is. 6d. in Boards.

Scries of Disigns for Villas and Country Houses. Adanted wit Economy to the Comforts and to the Elegancies of Mudern Life with Plans and Explanations to each. To which is prefixed, an Fssay on Modern Architectural Taste. By C. A. Eusby, Arcbitect. Engraved in Aqua-tinta, on 24 Plates, large Quarto, in Boards, 1). $5 \mathrm{~s}$.

Architectural Designs, for Rustic Cotlages, Pieluresoue Drvellings, Villas, Sic. with appropriate Scenery, Plans and Descriptions; to which are prefixed some crisical Oisservations on their Style and Character; and also of Castles, Abbies, and ancient English Houses.Concluding with Practical Remarks on Buidsing, and the Causes of the Dry Rot. By W. F. Pocock, Architect. Ele antly engraved on 33 Plates, Royal Quarto, Price 1i. 11s. 6d. in Boards.

Designs for Lodges, and Entranees to Parks, l'addocks, and Pleasure Grounds, in the Gothic, Cottage, and Fancy Styles, with characteristic Scenery aad Desci iptions in Letter-press, by T.D.W. Dearn, elegantly engraved on 20 Plates, large Quarto, 11. 11 s. 6d. Buards.

setches in Architccture, consisting of original Designs for Cottages and Rural Dwellings, suitable to Persons of molerate Fortune, and for convenient Retirement; with Plus and appropriate Scenery to each; also some general Observations. By $T$. D.W. Deary, Architect to his Royal Highness the Duke of Clarence. Flegantly engraved on 20 Plates, large Quarto, Price 11.75. in Boards.

Plans and Fiereys of Buildings executed in Eingland ant Scot?and in the Castellated and other Styles. By R. Lugar, sirctitect, on 33 Plates Royal Quarto with descriptive Letter-piess, Price 21, 2s. in boards.

Arcbitectural Skitches for Cotnges, Rural Dwellinss, and Villas: viith Plans, suitable to Persons of genteel Life and moderate Fortune. proper for Picturesque Builfings, by $R$. Lugar, Architect and Land Surveyor; elegantly engraved in Aquatinia, on 38 Plates, Boards, 11. is $6 \mathrm{~d}$.

The Country Gentleran's Archilect, containing a Variety of Designs for Farn Houses and Farn Yards of Diferent Magnitudes, artanged on the most approred Principles for Arable, Grazing, Feeding and Pairy Farns, with Plans and Sections, shewing at large the Construction of Cottares, Barns, Stables, Feeding Houses, Dairies, Brewhouse, \&c. with Plans for 'Stables and Dog-kennels, and some Designs for Labourers' Cottages and small Villas. The whole adapted to the Use of Country Gentlemen about to build or to alter. Engraved on 21 Plates, witli some General Observations, and full Explanations to cacli. By R. Lugar. Quarto, 11. 5 s. in Boards.

Designs for Small Picturesque Cottages, Hunting Boxes, Park Entrances, \&c. b. E. Gyfford, Architect. Part I. Engraved in Aquatinta, on 20 Plates, Quirto, 11. is. Boards.

Designs 
Designs for Elegant Cottages, and simall Villas, calculated for the Comfort and Convenience of Persons of moderate and of ample Furtune, carefully studied and thrown into Perspective, with General istimates, by $E$. Gy, ord, Architect. Part 11. Engraved in Aquatinta on 26 Plates, Quarto 1l. 11s. 6d. boards.

Hints for Dwellings, consisting of Original Designs for Cottages, Farm-loouses, Villas, Ecc. plain and ornamental; with Plan to each, in which strict Attention is paid to unite Convenience and Elegance with Economy. Including some Designs for Townhouses. By D. Laing, Architect, and Surveyor. Elegantly en. graved on 34 Piates in Aquitinta, with appropriate Scenery. Quarto, 11. 5 s. in boards.

Sketches for Country Hou'es, Villas, and Rural Drvellings; calculated for Persons of moderate Income, and for comforrable Retirement. Also some Designs for Cottages, which may be constructed of the simplest Materials; with Plans and general Estimates. By Fohn Plaw. Elegantly engraved in Aquatinta on 42 Plates, Quarto, Il. 1 s. $6 \mathrm{~d}$. in Boards.

Frrme Ornée, or Rural Improvements, a Series of Domestic and Orna. mental Designs, suited to Parks, Plantations, Rides, Walks, Rivers, Farms, \&c. consisting of Fences, Paddock House, a Bath, Dogkennels, Pavilions, Farm-yards, 'Fishing-houses, Spolting-Boxes, Shooting-lodyes, Single and Double Cottages, \&c. calculated for Landscape and Picturesque Efiects. By Yobn Plaw, Architect. Engraved in Aqualinta on 38 Plates, with appropriate Scenery. Plans, and Explinations. Quasto. In Boards, 11. 11s. 6d.

Rural Arcbitecture, or Designs from the Simple Cottage to the decorated Villa, including some which have been executed. By Jobn Plaw, On. 62 Plates, with Scenery, in Aquatinta. Halt Bound, 2l. 2s.

An Essay on British Cottage Architecture, exemplified by fourteen Designs, with their Plans, St. on 23 Plates, clesigned and exe. cuted by $\tilde{J}$ anes Malton. The Second Edition, with two additional Plates, large Quarto, Boards, Il. irs.6d.

A Collection of Architestural Designs. for Villas. Cacinns, Mancinme, Lodges, and Cottages, trom Raniall. Arclitect, engraved in Aquatinta, on 34 Plates, large Folio, 31. I 3 s. od.

The Wrcbitct and Builder's Miscellony, or Pocket Library; containing original Picturesque Designs in Arclitecture, for Cottages, Farm, Country, and Town Houses, Public Buildings, Temples, Green. Houses, Rridges, Lodges and Gates for Entrances to Parks and Pleasure Grounds, Stables, Monumental Tombs, Garden Seats, \&c. By Charles Middleton, Architect. On 60 Plates, coloured. Octavo. By Charles $M$ i.t.
I. is. bound.

Crunden's Convenient and Ornamental Aribitcture; consisting of Originat Designs for Plans, Elevations and Sections, beginning with the Farm-house, and regularly ascending to the most grand and magnificent Villa; calculated both for Town and Country, with Explanation in Letter-press, and exact Scales. Engraved on 70 Copper-plates, I6s. Boards.

A Series of Plans, for Cottages or Habitations for the Labourer, either in Husbandry or the Mechanic Arts, adapted as well to Towns as to the Country. To which is added, an Introduction, containing many useful Observations on this Class of building, tending to the Comfort of the Poor, and Advantage of the Builder; with Calculations of Expenses. By the late Mr. F. Wood, of Batll, Architect. A new Edition, corrected to the present Time, with 30 Plates, large 4to. Il. Is.

The Country Centlemau's Archicect, in a great Variety of New Designs for Cotrages, Farm houses, Country-houses, Vilias, Lodges tor Park or Garden Entrances, and ornmental wooden Gates, with Plans of the Offices belonging to each Design; distributed with a strict Attention to Convenience, Elegance and Economy. On 32 Quarto Plates. By 7. Miller, Architect. Sewed, 10s, 6d.
Essays of the London Arcbitectural Society. Octavo, 4 Plates. 7s. Boards. Also the Second Part, 4 Piates, 8s. 6d.

Aikin's Essay on the Doric Order, 7 Plates, Jarge Folio. 11. 5s. Boards.

Vasi's View of Rome, on 12 Sheets, 3l. I $35.6 \mathrm{~d}$.

Vitruvius Britannicus, 5 Vols.

Chambers's (Sir William) Treatise on Civil Arclutecture.

Chambers's Buildings and Views of Kew Gardens. Half bound, 2l. ros.

Chambers's Designs for Chinese Buildings, \&c. Il. I ss.6d.

Chambers's Dissertation on Oriental Gartening, 4to. 9s.

Inigo Fones's Designs, by Kent, 2 vols. folio.

Givili on Arclies, 8vo. 4 Plates. 63.

Ware on Arches, and their abutment Piers, octavo, 19 Plates, $18 \mathrm{s.}$ Ware's Remarks on Theatres, octavo, 3 Plates. 75.

Atwood on Arches, quarto, Two Parts. Plates. I8s.

Malion (Fames) Perspective, Quarto, 11. Is.

Wozd's Lectures on Perspective, with an Apparatus. 11. I6s.

Paine's Plans, Elevations, \&c. of Noblemen's Seats, Sc. folio, 2 vols. Half bound, $81.8 \mathrm{~s}$.

The Architectural Antiquities of Altens, by Stuart, 4 vols. of Rome, Balbec, Palmyra, Pæestum, Ionia, de la Grece, par Le Roy, \&c. \&c.

Wilkins Antiquities of Magna Cracia, cc. Folio, 10l. Ios.

Wilkins' Translation of Vitruvius, Quarto.

Newton's Translation of Vitruvius, 2 vols. folio.

Murphy's Arabian Antiquities of Spain, roo Plates, large folio, 42l. Nicholson's Principles of Arcbitccture, 3 vols. 8 vo. 3 l. 3 s. boards.

A Treatise on Theatres, including some Exferiments on Sound, by $G$. Saunders, Architect, with Plates, 4to. hoards, $16 \mathrm{~s}$

Sneaton's Description of the Edystone I,ightliouse, Plates, folio. 61. 6s.

Reports, by F. Smeaton, Civil Engineer, 3 vols. 4to. 7l. 7s. Boards.

Smeaton's Miscellaneous Papers, 4to. 11. r rs. 6d. Boards.

Gray's Experienced Millwright. Folio, 44 Plates. 21.2s.

Imison's Elements of Science and Art. 2 Vols. 1l. 5 s.

Bucbanan's Practical Essays on Mill-Work. 2 Voi. Igs, boards.

Gregory"s Treatise on Mechanics, 3 Vols. $21.2 s$.

Hutton's Course of Mathematics. 3 Vols. 11. is 6 d.

Papworth on the Dry Rot, 3 s.

Randall on the Dry Rot, 3 s.

Perronet sur les Ponts, 2 Ton.

Belidor Scicnce des Jngcneurs, 4to. New Edition, with new Plates, Sc. 


\section{[ $\quad 4 \quad]$}

Eelidor, l"Arcbitectuge Hydravlique, 4 Tom. Quarto.

Nouvelle Arch. Hydraulique, par Prony', = Tom.

Piranesi's Works, complete, 23 Vols. large Folio.

Rafael's Ornanents of the Vatican, 3 Parts. Fulio.

Dictionnaire d'Arcbitectire, Civile, Militaire et Navale, far Roland, 3 Tom. Quarto, with 100 Plates.

Plans, Coupes, et Elevations des plus belles Maisons et des Hotels, à Paris, et dans les Environs, arec des Ornemens. Folio, 120 Plates.

Durand Leçons d"Arebitecture, 2 Tom. 4to.

Durand Recueil et Parallele des Edifices Anciens et Modernes. 92 rery large folio Plates.

Plans, Coupes et Elevations de diverses Productions de l'Art de la Cbarfente, par Krafft. 201 Plates, large Folio.

Ornamenti di Alberioli, 3 Parts, Folio.

Museo Pio Clementino, 7 Tom.

Museo Cbiaramonti.

Wiebeking on Bridges, Draining, $\mathcal{E}^{\circ}$. In German. 3 Vols. 4to. and a large Atlas.

Wiebeking des Ponts à Arcbes de Charfente, sto. with a large Atlas of 20 plates.

Ornemens de le Pautre. 3 Vols. Folio.

Bourse de Paris, par Brougizard.

Euvres de Weyrotter.

Vojage de la Grece, par Ctoiseuil Gouffere. 2 Vols.

Antiguité de Poestum, far Delagardette. Folio.

Orremens de Cauvet. Folio.

Foyage Pittoresque de l'istria, far Casas. Folio.

Poyage Pittoresquze de la Suisse. 4 Vols. Folio.

Vojage Pittoresque de Naple et Sicile. 5 Vols. Folio.

Foyage Pituresque des lsles de Sicile, de Malte at de Lipari, par Houel. 4 Tols. Folio.

Suite de Paysage, de Bourgin. Folio.

Cabizet de Cboiseuil.

Cabinet de Poulain. Proofs.

Cosege de Pierre, par Garielle.

Canaux Narigables, de Lalande, Folio.

Cana! du Midi, par Antreossi. = Vols, 4 to.

Encyelopetie de l'Ingenieur, par Delaitre. 3 Vols. 8vo. and Atlas of Plates.

Pousse des Terris, par Maignes, 4 to.

Traite de l'Art de Batir, far Rosdelet. 5 Vols, sto. Plates.
Programne du Course de Construction, par Sgarzin, fto.

Decorations par Percier et Fontains, Folio.

Palais et Maisons de Rome, par Percier, Folio.

Italia avant il Dominio di Romani, par Micali. 4 Vols. 8vo. and Atlas.

Manuel du Tourneur. 2 Vols. 4to. Plates.

Dictionnaire des Graveurs. = Vols. 8vo. Plates.

Cabinet des Pierres-gravées, de Duc d'Orlians. 2 Vols.

Menoire de l'Arcbitecture, par Patte, 4 to.

Coupe de Pierres, de Freziere, 3 Vols. 4 to.

Description du Pont à Moulins, par Régcmorte, Folio.

Boulet Macbines de Theatre.

Scrittori dell acqua. 8 Vols. 4 to.

Paris et ses Monumens, par Ealtard. Folio.

Musèe des Monumens Francais, par Lenoir. 6 Vol. 8 vo.

Annales du Musée, par Landon.

Bossut Traité d"Hydrodynamique. 2 Vols. 8ro.

Bossut et Viallet sur la Construction des Digues.

Bremontier sur le Mouvement des Ondes.

Decessart Travaux Hydrauliques. $2 \mathrm{Vo}$ !s. 4 to.

Ducrest D'Hydrauferie.

Io. Inntrines de Paris. far Duval.

Gautbey de la Construction des Ponts. 2 Vols. 4 to.

Lesage divers Menoires des Ponts et Chaussées. = Vuls. 4ุto.

Navier, Projet d'une Gare ì Clioisy.

Sakolniki Hydrodjnamique.

Berard Statique des Voútes.

Brunet, dimension des Fers qui doivent former la coupole de la IfC.'́ auts Grains.

Pyre, Restauratios du Pantbeon.

Clochar Plans de Maisons, Ec. D'Italie. Folio.

Costume Hollandoise. Plates, coloured.

Voyage en Holland. 3 Vols. 8vo. Plates.

Statistigue d"Ansterdam.

Guide du Voyageur en Hollande.

New Principles of Lincar Perspective, or the Art of Designing ou a Plane, the representation of all Sorts of Objects in a more general and simple Method than has beeu hitherto done. Illustrated by 13 Quarto Plates. By Dr. Brook Taylor, LL.D. and R.SS. The Fourth Edition, 8vo. 14s. in boards.

Dr. Erook Taylor's Netholl of Perspective made easy both in Thecry and Practice; in two Books: being an Attempt to make the Art of Perspective easy and familiar, to adapt it entirely to the Arts of 
Design, and to make it an entertaining Study to any Gentleman who shall choose so Polite an Amusement. By Fosbua Krby. Fllus trated with 35 Copper-plates. The Third Edition, with several Additions and Improvements. Elegantly printed on Imperial Paper. Halt Bound, $21.12 s .6 \mathrm{~d}$.

The Perspective of Arcbitecture, a Work entirely new ; deduced from the Principles of Dr. Brook Taylor, and performed by two Rules of universal Application. Illustrated with 73 Platcs. Begun b; Command of his present Majesty when Prince of Wales. By Foslun Kirby. Elegantly ptinted on Imperial Paper. ${ }_{2}$ l. 3 s. lialf bound.

The Descrifion and Use of a new Instrument called the Arcbitectonic Sec. tor, by which any Part of Architecture may be drawn with Facility and Exactness. By Fosbua Kirby. Illustrated with 25 Plates; elegantly printed on inperial Paper. Half bound, 11. $16 \mathrm{~s}$.

The two Frontispieces, by Hogarth, to Kirby"s Perspective, may be had separate, each 5 s.

Moicm Finisbings for Rooms, a Series of Designs for Vestibules, Halls Stair Cases, Dressing Rooms, Boudoirs, Libraries, and Driwing Rooms, witls their Doors, Chimney Pieces, and other finishings to a large Scale, and the several Mouldings and Cornices at full Size, showing their Construction and relative Proportions: to which are added some Designs for Villas and Porticos, with the Rules for drawing the Columns, \& c. at large. The whole adapted for the Use and Direction of every Person engaged in the practical Parts of Building, hy W.F. Pocock, Architect, on 86 Plates, quarto, 21. $2 \mathrm{~s}$. bound.

The Student's Instructor in drawing and working the Five Orders of Arclitecture; fully explaining the best Methods of striking regula and quirked Nouldings, for diminishing and glueing of Columns and Capitals, for finding the true Diameter of an Order to any given Height, for striking the Ionic Volute circular and elliptical, wit. finished Examples, on a large Scale, of the Orders, their Planceers, Sc. and some Designs for Door Cases, by Peter Nicholson, engraved on 41 Plates octavo. 105. 6d. bound, A new Edition corrected and inuch enlarged.

The Carpenter's New Guide, being a complete Bools of Lines for Carpentry and Joinery, treating fully on Practical Geometry, Soffits, Brick and l'laster Groins, Niches of every Description, Sky-lights, Lines for Roofs and Domes, with a great Variety of Designs for Roofs, Trussed Girders, Floors, Domes, Bridges, \&c. Stair-cases and Hand-rails of various Constructions. Angle-Bars for Shop Fronts, and Raking Mouldings, with many othe! Things entirely new : the Whole founded on true Geometrical Principles, the Theory and Practice well explained and fully exemplified on 84 CopperPlates; including some Observations and Calculations on the Strengtls of Timber, by $P$. Nicholsorr, 4to. 1l. Is. the Sixth Edition corrected and enlarged.

The Carpenter and Joiner's Assistent, containing Practical Rules for making all Kinds of Joints, and various Methots of Hingeing them together; for hanging of Doors on straight or circular Plans; for fitting up Windows and Sbutters to answer various Purposes, with Rules for luanging them :for the Construction of Floors, Partitions, Sofits, Groins, Arches tor Masonry : for constructing Roofs in the best Manner from a given Quantity of Timber; for placing of Bond-Timbers; with various Methods for adjusting Raking Pediments, enlarging and diminishing of Mouldings, taking Dimensions for Joinery, and for setting out Shop Fronts; with a new Scheme for constructing Stairs and Hand-rails, and for Stairs having a conical Well-hole, \&c. \&c. To which are added, Examples of Various Roofs executed, with the Scantlings from aciual Mieasurements, with Rules for Mortices and Tenons, and for fixing Iron Straps, \&.c. with Rules for Mortices and Tenons, and for fixing lron Straps, \&c. on the Strength of Timber, with practical Obseivations. Illustrated with 79 Plates, and crpious Explanations. By Peter Nicholson. Quarto Il. Is. bound. Tlie third Edition, revised and corrected.
]

The Practical Housc Carpenter, or loub's lastructor : containing a great Variety of useful Designs in Carpentry and Arcluitecture; as Cen. tering for Groins, Niclies, Rc. Examples for Roofs, Slay-lights, \&c. The Five Orders laid down by a Now Scale. Mouldings, \&c. at large, with their Enrichments. Plans, Elevations, and Sections of Houses for Town and Country, Lodges, Hot-liouses, Greenhouses, Stables, \&c. Design for a Churc'n, with Flan, Elevation, and two Sections; an Aitar-piece, and Pulpit. Designs for Chimneypieces, Shop Fronts, Door Cases. Section of a Dining-room and Library. Variety of Stair Cases, with many other important Articles and useful Embellishments. To which is added, a List of Prices for Materials and Labour, Labcur only, and Day Prices. The whole illustrated and made perfecily easy by I 48 quarto Copper-plates, with Explanations to each. By Willian Pain. The sixth Edition, with latge Additions. 18s. bound.

$N$. B. This is PAIN's last Work.

The Carfenter's Pockt Directory: containing the best Methods of framing Timbers of all Figures and Dimensions, with their several Parts; as Floors, Roofs in Ledgements, their Length and Backings; Trussed Roofs, Snires, and Domes, Trussing Girders, Pastitions, and Bridges, with Abutments; Centering for Arches, Vaults, \&rc. cutting Stone Ceilings, Groins, Scc. with their Moulds: Centres for drawing Gothic Arches, Ellipses, \&cc. WWith the Plan and Sections of a Barn. Engraved on 24 Plates, with Explanations. By $W$. Pein, Architect and Carpenter. Bound, 5s.

The Builder's Complete Assistont; or, a Librory of Ants and Sciences, absolutely necessary to be understood by Builders and Workmen in general, viz. I. Aritlmetic, vulgar and decimal, in whole Numbers and Fractions. 2. Geometry, Lineal, Superficial, and Solid. 3. Architecture, universal. 4. Mensumation. 5. Plain Trigonometry. 6. Surveying of Land, \&c. 7. Mechanic Powers. 8. Hydrostatics. Illustrated by abore Thirteen Hundred Exanples of Lines, \&c. aiso Methods for raising lieavy Bodies, by th:e Force of Levers, Pulleys, Axes in Peretroclio, Skrews, and IVedges; as also Water, by the common Pump, Crane, \&x. wherein the Properties and Pressure of the Air on Water, \&c. are explained.

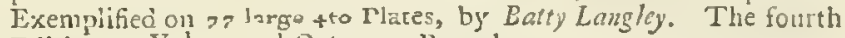
Edicion, a Vols. royal Octaro. Bound, Iss.

Decorations for Parks and Gardins; Designs for Gates, Girlden Seats, Alcoves, Temples, Baths, Entrance Gates, Lodges, Facades, Prospect Towers, Cattle Sheds, Ruins, Bridges, Green-houscs, Sc. Sec. Also a Hot-house, and Hot-wall, with Plans and Scales; neatly engraved on 55 Plates, octavo. 10s. 6d. sewerl.

Desirns in Arclitccture, consisting of Plans, Elevations, and Sections for Temples, Baths, Cassinos, Pavilion, Garden Seats, Obelisks, and other Buildings; for deconating Pieasure-grounds, Parks, Forests, \&c. Ecc. by Jobn Socne. Engraved on 38 Cupper-plates, 8vo. Sewed, 6s.

Grotesque Architecture, or Rural Amusement; consisting of Plans, and Elevatiuns, for Fluts, Hermitares, Clinese, Gotivic and Nis tural Grottos, Noresque Pavilions, \&c. many of which may be executed with Flinis, irregular Stones, rude Branches and Roots of Trees; containing $2 S$ Desizns. By W. Wight. Octavo. Scwed, 4 s. $6 \mathrm{~d}$.

deas for Rustic Furniture, p:oper for Garden Chirs, Summer ITouses, Hermitages, Cottagte, \&:c. engraved on 25 Plates. Octavo. Pricc is.

Designs for Gates and Rails, suitable to Parles, Pleasure-Grounds, Balconies, Sic. Also some Designs for Tiellis Work. On 27 Plates. By C. Milltheton. Octavo, 63.

The Carpenter's Treaszre: a Collection of Desions for Temples, witl thcir Plans; Gates, Doors, Rails, and Bridges, in the Gothic 'Taste, with Centres at large for striking Gothic Curves and Mouldings, and some Specimens of Rails in the Clninese Taste, forming a complete System for Rural Decorations. By N. W'allis, Architect, I6 Plates. Ochavo, Sewed, 25.6d. 


\section{$\left[\begin{array}{ll}6 & ]\end{array}\right.$}

Gotbic Architecture improved, by Rules and Propoltions in many grand Designs of Columns, Doors, Windows, Chimney-Pieces, Arcades, Colonnades, Porticos, Umbrellas, Temples, Puvilions, Ec. with Plans, Elevations, and Profiles, geometrically exemplified. By $B . D^{3} T$. Langley. To which is added, an Historical Discourse on Gothic Architecture. On 64 Plates Quarto. Bound, 15 s.

Thirty Capitals of Columns, with six Frises, from the Antique. Engraved in Aquatinta by G. Ricbardson, on 88 Plates. 4to. $15^{3}$.

Designs for Monuments, including Grave-stones, Compartments, ITallfieces, and Tombs. Elegantly engraved on 40 quarto Plates. Half bound, 16s.

Designs for Chimmey-Pieces, with Mouldings and Bases at large on 27 quarto Plates, 1os. $6 \mathrm{~d}$.

Designs for Shop Fronts and Door Cases, on 27 Plates. 4to. 1os. 6d.

Outlines of Designs for Sbop. Fronts and Dom Cascs, with the Mouldings at large, and Enrichments to each Design. Engraved on 24 Plates. Quirto, 5 s.

Langley's Euilder's Ferwel. Bound, ss.

Haziney's Complete Measurer, a new Edition, much improved, $4 \mathrm{~s} .6 \mathrm{~d}$.

Hofpus's Timber Measurer. Tables ready cast. 4 s.

Plate Glass Book. 4s.

The Foiner and Cabinet-maker"s Darling; containing sixty difierent Designs for all Sorts of Frets, Friezes, Ac. Sewed, 3s.

The Carpenter's Companion; containing 33 Designt for all Sorts of Chinese Railing and Gates. Octavo. Sewed, 2 s.

The Carpenter's Complete Guide to the whole System of Gothic Railing; containing 32 Designs, with Scales to each. Octavo. Sewed, 2 s.

A Geometrical Vieze of the Five Orders of Columns in Architecture adjusted by aliquot Parts; whereby the mennest Capacity, by Inspection, may delineate and work an entire Order, or any Part, of any Magnitude required. On a large Sheet, is.

Elevation of the Neru Eridge at Black Friars, with the Plan of the Foundation and Supersiructure. by R. Baldwin; 12 Inches by 48 Inches, 5 s.

Plans, Elevations, and Sections of the Machines and Centering used in erecting Black Friars" Bridge; drawn and engraved by $R$. Boldzin, Clerk of the Work; on 7 large Plates, with Explanations. 10s. 6d.

Elevation of the Stone Eridge built over the Severn at Shrewsbury, with the Plan of the Foundation and Superstructure, elegantly engraved by Rooker. is. $6 \mathrm{~d}$.

A Treatise on Euilding in Water. By G. Semple. Quarto, with 63 Plates. Serred, I 6 s.

Plans, Elcration and Sections of the curious Wooden Bidge at Schafhausen in Switzerland, built in 1760 by Uiric Grubenman, and lately destroyed by the Frencli. 19 Inches by 29 . Price $12 s$. colourtd, with a descriftive Account in Letter-Pıess.

Perspective View of the proposed Iron Bridge at London, of 600 Feet Span; hy Telford. Size 4 Feet by 2 Feet, Coloured 21.25.

London an.J Westminster Improved. Illustrated by Plans. By Fokn Guynn, Architect. Boards.
Observations on Erick Eont, as practised at various periods; containing an Investigation of the best Disposition of Bricks in a Wall, for procuriug the greatest possible Strength; with Figures representing the different Modes of Construction. Octavo, is.

The Bricklayer's Guide to the Mensuration of all Sorts of Brick Work, according to the Lonton Practice: With Observations on the Catses and Cure of S noaky Chimnies, the Formation of Diains, and tine best Construction of Ovens, to be heated with Coals. Also, a Variety of Practical and Useful Information on this important Brancl of the Building Art. Illustrated by various Figures and Nine Copper Plates. By $T$. W. Dearm, Architect. Octaro, 7s. Boards.

Tabls for the Purcbasing of Estates, Freehold, Copylioid, or Leasehold, Annuities, \&c. and for the renewing of Leases held under Cathedral Chutches, Colleges, or other Corporate Bodies, for Terass or Years certain, and for Lives. Together with severa! useful and interesting Tables, connected with the subject. Als? the Five Tables of compound Interest. By $\mathbb{W}$. Inwood, Architect and Surveyor. In small Octavo for a l'ocket Book, 7s, in Boards.

\section{BOOKS OF ORNAMENTS, \&.c.}

A Collecting of Antique Vases, Altars, Pateras, Tripods, Candelabra, Sarcophagi, Sc. trom various Museums and Collections, engraved in Outline on 170 Plates, by $H$. Moses, with Historical Essays. 31. 3s. Half Bound small Quarto, and on large fine Paper, 5l. 5 s. in extra Boards.

Ornamental Designs after the Manner of the Antique. Composed for the Use of Architects, Ornamental Painters, Statuaries, Carvers, Carpet, Silk, and printed Calico Manufactures, and every Trade dependent on the Fine Arts, by $G$. Smith, with Descriptions. Quarto. Neatly engraved in Outline. Royal 4to. on 43 Plates, Price $21.2 s$. in Boards.

A Collezion of Designs for Modern Fmbellishments suitable to Parlours, Dining and Drawing Rooms, Folding Doors, Chimney Pieces, Varandas, Frizes, \&c. By C. A. Busby, Archited?; neatly engraved on 24 Plates, 14 of which are elegantly coloured; large Quarto. Price $11.115 .6 \mathrm{~d}$

Designs for the Decoration of Rooms in the various Styles of modern Embellishment. With Pilasters and Firizes at large. On 20 folio Plates, Drawn and Etched by $G$. Cooper, Draftsman an. Decorator. 1l. is.

Ornaments Distayed, on a full Size for working, proper for all Car vers, Painters, Sc, containing a Variety of accurate Examples of Foliage and Frizes, elegantly engraved in the Manner of Chaiks, on 33 large Folio Plates. Sewed, iss.

Pergolesi's Ornaments in the Etruscan and Grotesque Styles, large Folio, 5i. 5s. Boards.

A Neru Bosk of Omaments; containing a Variety of elegant Designs for modern Panneis, connonly execured in Stucco, Wood, o Painting, and used in Decorating principal Rooms. Drawn and etched by $P$. Columbani. Quarto. Sewed, 75. 6d.

A Yariety of Capitals, Frizes, and Cornices; how to increase or decrease them, still retaining the same Proportion as the Original. Likewise 12 Designs for Chimney-pieces. On 12 Plates, drawn and etcled by $P$. Columbani. Folso, Sewed, 6 s.

The Principles of Drawing Orizancmis made easy', by proper Examples of Leaves for Mutaldings, Capitals, Scrolls, Husks, Fuliage, \&c Engraved in Imitation of Drawings, on 16 Plates, with Instruc- 


\section{$\left[\begin{array}{ll}7 & \end{array}\right]$}

tions for learning without a Master. Particularly useful to Carvers, Cabinet makers, Stucco-workers, Painters, Smiths, and every on concerned in Ormamental Decorations. By an Artist. Quarto. Sewed, 4s. 6d.

Ornamental Iron Work, or Designs in the present Taste, for Fanlights, Gtair.Case Railing, Winlow Guard Irons, Lamp-Irons, Pulisadoes, and Gates. With a Scheme for adjusting Designs with Facility and Accuracy to any Slope. Engraved on 21 Plates. Quarto. Sewed, 6s.

A new Book of Ornancnts, by $S$. Alken, on 6 Plates, sewed, 2s. $6 \mathrm{~d}$. l.arv's new book of Ornaments. Sewed, as.

A Book of Vases, by T. Law. Sewed, is.

A Book of Vases, by P. Columbani. Sewed, 2s.

A new Book of Eighteen Yases, Mrdern and Antique, =s.

A Book of Vases from the Antique, on 12 Plates, 2 s.

An interior view of Durbam Catbedral, and a View of the elegant Gotbic Shrine in the same. Elegantly engraved on two large Sheets. Size 19 by 22 . The Pair $12 \mathrm{~s}$.

An exterior and interior View of St. Giles's Church in the Fields, engraved by Walker. Size 18 Inclues by 15. The Pair 5 s.

A North-west View of Greenwich Churcli, zs.

An elegant engraved View of Shoreditch Church, 38 Inches by $20,3 s$.

An elegant engraved View of the Monument at London, with the Parts geometrically; Size 21 by 33 Inches, from an Original, by $\operatorname{Sir}$ C. Wren, 7 s. $6 \mathrm{~d}$

Sir Clsistopher Wren's Plan for rebuilding the City of London after the great Fire, 1006 . is.

West Elevation of York Minster, elegantly engraved from a Drawing by Fames Malton, Price iss.

The Buiding Act of the $14 t \mathrm{~h} \mathrm{Geo.} \mathrm{III.} \mathrm{with} \mathrm{Plates} \mathrm{shewing} \mathrm{the} \mathrm{proper}$ Thickness of Party IValls, External Walls, and Chimneys. A complete Index, List of Surveyors and their-Residcince, \&c. In a small Pocket Size. Sewed, 3 s.

N. B. The Notice and Certificate required by the above A\&t, may be had printed with blank Spaces for filling up, Price $2 d$. each, or $1 ;$ for $2 \mathrm{~s}$.

Experiments and Observations made with a View of improving the Art of composing and applying Calcareous Cements, and of preparing Quick Lime; with the Theory of these Arts. By B. Higgins, M. D.

A General History of Inland Navigation, Forcign and Domestic; conzaining a Complete dccount of the Canals already executed in Englant; with Considerations on tbose projacted : to which are added, Practical Observations. A nerv Edit. Octavo, 1os. Gd. Boards.

A Map of England, shewing the Lines of the Canals executed, those proposed, and the navigable Rivers, coloured. On a large Sheet, 5 s.

A Treatise on the Improvement of Canal Navigation, exhibiting the numerous Advantages to be derived from Small Canals and Boats of two to five Feet wide, containing from two to five Tons of two to five Feet wide, containing from two to five Tons Conveyance by Warer, through the most mountainous Countries, independent of Locks and Aqueducts; including Observations on the great Importance of Water Communications;" with Thoughts on, and Designs for, Aqueducts and Bridges of Iron and Wood. By R. Fulion, Engineer. With 17 Plates. Quasto, Boards, $18 \mathrm{~s}$.

Ohservations on the various Systents of Canal Navigation, with In

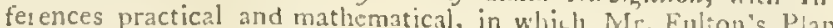
of Wheel Boats, and the Utility of subterancous and small Canals are particulariy investigated; including an $A$ ccount of the Canals and inclined Planes of China, with 4 Plates. By $W$. Chatman, Canals and inclined Planes of China, with 4 Plates. By $W$. Chafman,
Civil Engineer. Quarta. Gs. sewed.

Remarkatile Ruins and Romantic Prospects of North Britain, with ancient Manuments and sincular Suljects of Natulal History, by the Rev. C. Cordiner, of Banfi, with 100 Plates, elegantly en graved by Mazell. 2 Vols. Quaito. 5l. 5s. Boards.

A new Collection of 100 Views in Rome and its Vicinity, neatly engraved by Pronti, Quarto, Price Il. is.

A Treatise on Painting, by Leonarto da Yinci. Faitlfully translated from the original Italian, and now first digested under proper Ileads, By F.F. Rigaus, Esq. R. A. Illustrated with 23 Copper Plates and other Figures. 'Yo which is prefixed, a new Life of the Author, drawn up trom authentic Materials sild now inaccessible, by F. S. Hazukins, Esg. F. A.S. Octavo; gs. 6d. Boards; on Royal Paper, 13s. 6d. Boards.

An Enquiry into the Changes of Taste in Landscape Gardening to which are added, some Observations on its Theory and Practice, including a Defence of the Art. By H. Repton, Esq. Octavo, 5s.

Hints for Picturesque Improvements in Ornamented Cottages and their Scenery; including some Observations on the Labourer and his Cottage. Lllustrated by Sketches, by E. Bartell, Jun. large Octavo, Boards, 10s. $6 \mathrm{~d}$

Cromer considered as a Watering Place, with Observations on the Picturesque Scenary is its Neighbourhood, by E. Bartell, Fun. with two Views and a Map. OStavo, 8s. Boards.

Specimens of Ancient Carpentry, consisting of Framed Roofs selected from various Ancient Buildings, Public and Private. Also some Specimens of Mouldings for Cornices, Doors, and Windows, by the late Mr. Fames Smilh, engraved on 36 Plates, Quarto, Price 125. sewed.

The Arcbitectural Antiquitics of Grcat Britain, represented and illustrated in a Series of Views, Elevations, Plans, Sections and Details, of Various Ancient English Edlifices, with Historical and Descriptive Accounts of each. By Fobn Britton, F. S. A. 4 Vols. Quarto, tive Accounts of each. By Fobn Britton, F. S. A. 4 Vols. Quarto,
with 278 elegant engraved Plates, 21 . in Boards, and on large Paper 321 .

N. $B$. The parts may be had separate to complete Sets at ros. 6d. each, large Paper 16s.

An Historical and Arcbitectural Essay, relating to Redcliffe Church, Bristol, illustrated with $\mathbf{2}$ engravings of Plans, Views and Details, with an Account of the Monuments, and Anecdotes of eminent Persons connected with the Church. Royal Octavo, $16 \mathrm{s.} \mathrm{Medium}$ Quarto, i]. 4s. and Imperial Quarto, I1. I s. 6d.

N. B. The Quarto sizes will range with the Architectural Antiques.

The Catbedial Antiguities of Englant, or an Historical, Architectural and Graphical 1llustration of the English Cathedral Claurches. By Fobn Britton, F. S. A. Of this work, one Part, containing 6 or 7 plates, will be published every three Montlus, Price I2s. Me. dium Quarto, and on Imperial Quarto Il.

N. B. Salisbury Cathedral is completed in 5 Parts.-Norwich Catbedral is now publishing. 


\section{[ 8 ]}

The Fine Arts of the English Scbnol, illustrated by a Series of Engravings from Paintings, Sculpture, and Architecture, by eminent pess, edited by F. Erition, F.S. A. This Volume contins 24 lifoly finished Eugravings, Elephant Q17arto, price 51. 53. extra Boards; on Atlas Quarto, with first Impressions, price 81. 8s. extra Boards.

Plans, Elevation, Scction, Exc. Ecc. of the Cathedral Church of St. Paul's, London, witl an Historical and Descriptive Account. By E. Aikin, Architect. On Elepluant Quarto, Price 21. as. and on Atlas Quarto, l'rice 31.35 . in Boards.

A COLLECTION of DESIGNS for Household Furniture and interior Decoration, in the most approved and elegant Taste, viz. Curtains, Draperies, Beds, Cornices, Chairs and Sofas for Parlors, Libraries, Drawing Rooms, \&c. Library Fauteuils, Seats, Ottomans, Chaise Longue, Tables for Libraries, Writing, Work, Dressing, \&c. Sideboards, Celerets, Book-cases, Screens, Candelabri, Chiftoniers, Commodes, Pier Tables, Wardrobes, Pedestals, Glasses, Mirrors, Lamps, Jardiniers, Sc. with warious Designs for Roons, Geometrical and in Perspective, shewing the Decorations, Adjustment of the Furnuture, and also some general Observations, and a Description of each Plate. By George SMITH, Uploolder Extraordinary to his Royal Highness the Prince of Wales. Elegantly engraved on 158 Plates, with Descriptions, Royal Quarto, Price 4l. 14s. 6d. in Boards, and elegantly coloured 7l. 37s. 6d.

The Parts may be had Separate, each containing 50 Plates, price 11. Iss. 6d. each, or elegantly coloured 21. izs. 6d.

Designs for Housebold Furniture, exhibiting a Variety of Elegant and Useful l'atterns, in the Cabinet, Chair, and Upholstery Branches. By the late T. Sberatoz. Engraved on 84 Folio Plates, Price 31. 13 s. 6d. in Boands.

Mechanical Exercises; or, the Elements and Practice of Carpentry, Joinery, Bricklaying, Masonry, Slating, Plastering, Painting, Snithing, and Turning. Containing a full Description of the Tools belonging to each Branch of Busincss, and snpious Directions for their Use: with an Explanation of the Terms used in each $A_{1} t$, and an Introduction to Practical Geometry. Illustrated by 39 Plates. By Peter Nictolson. Octavo, 18s. Boards, 21s. Bound.

An Essay on the Shafts of Mills; containing their Description and Use, with the Kinds of Stress to which they are subject, and an Inquiry into their Stifiness, Strength, Durability, and Proportion. With a Variety of useful Tables. Also an introductory Account of the Progress and Improvement of MiLL-WORK. By Robertson Bucbanan. Illistrated witl Three Plates, Price 7 s. Boards.
Essays on the Construction and Durability of the Longitudinal Connexions of Shafts denominated Couplings.-On Methods of Disengaging and Re-engaging Machinery, while in Motion.On Mechanism for Equalizing the Motion of Mills, denominated Lift-Tenters, Engine Governors, and Water-Wheel Governors. On the Velocity of WVater-Wheels.-On Changing the Velocity of Machinery while in Motion.-On the Framing of Mill-Work By Robertson Buchanan. Illustrated with 15 Plates, Price $\mathrm{z} z$ s. in Boards.

Curr's Coal Viewer and Engine Builder's Practical Companion. Quarto, 21. 12s. 6d.

Smeaton's Experiments on Under-shot and Over-shot Water Wheels, \&c. Octavo, with five Plates, 10s. 6d. Boards.

Experimental Enquiries concerning the Principle of tlic lateral Communication of Motion in Fluids ; applied to the Explanation of various Hydraulic Phenomena, By F.P. Ventury. Translated from the French by $W$. Nicbolsun, with Plates, 4 s.

A Treatise on the Teeth of Wheels, Pinions, \&r. demonstrating the best Form which can be given them for the various Pulposes of $\mathrm{Ma}$ clinery; such as Mill-work, Clock-work, \&c. and the Art of finding their Numbers, translated from the Frencls of M. Cansis, with Additions, illustrated by $15 \mathrm{Plates,} \mathrm{Octavo,} \mathrm{105.6 \textrm {d } . ~}$

Observations on the Design for the Theatre Royal, Drury Lane, as executed in the Year 812 accompanied by Plans, Elevations, and Sections of the same, engraved on Eighteen l'lates. By Benjamin Wyatt, F.S. A. Architect. Royal Quarto, 21. I2s. 6d. Boards.

\section{PREPARING FOR PUBLICATION.}

Fragments on Landscape Gardening and Arcbitecture, as connected with Rural Scenery. By H. Replon, Esq. Imrerial Quarto, Price 61. 6s. in Boards.

Plans, Elevations, and Sections of Buildings, Public and Private, including Plans and Details of the Nerv Custom House, London, with Descriptions. By David Laing, Architect. Imperial Folio, Price 41.4 s. in Boards.

IINIS. 



